\title{
Correlating tephras and cryptotephras using glass compositional analyses and numerical and statistical methods: review and evaluation
}

\author{
David J. Lowe ${ }^{a *}$, Nicholas J.G. Pearce ${ }^{\mathrm{b}}$, Murray A. Jorgensen ${ }^{\mathrm{c}, \mathrm{d}}$, Stephen C. Kuehn ${ }^{\mathrm{e}}$, \\ Christian A. Tryon ${ }^{\mathrm{f}}$, and Chris L. Hayward ${ }^{\mathrm{g}}$ \\ ${ }^{a}$ School of Science, Faculty of Science and Engineering, University of Waikato, \\ Hamilton 3240, New Zealand \\ ${ }^{b}$ Department of Geography and Earth Sciences, Aberystwyth University, \\ Aberystwyth SY23 3DB, Wales, UK \\ ${ }^{c}$ Department of Statistics, Faculty of Computing and Mathematical Sciences, \\ University of Waikato, Hamilton 3240, New Zealand \\ ${ }^{d}$ Current address: Department of Mathematical Sciences, Auckland University of \\ Technology, Private Bag 92006, Auckland 1142, New Zealand \\ ${ }^{e}$ Department of Physical Science, Concord University, Athens, WV 24712, USA \\ ${ }^{f}$ Department of Anthropology, Harvard University, Peabody Museum of Archaeology \\ and Ethnology, 11 Divinity Avenue, Cambridge, MA 02138, USA \\ ${ }^{g}$ School of GeoSciences, Grant Institute of Earth Science, University of Edinburgh, \\ Edinburgh EH9 3JW, UK
}

\section{Invited review published in Quaternary Science Reviews \\ https://doi.org/10.1016/j.quascirev.2017.08.003 \\ Final manuscript 2 August 2017}

*Corresponding author. Tel.: +64 7838 4438; fax: +64 78384352.

E-mail address: david.lowe@waikato.ac.nz (D.J. Lowe).

Citation:

Lowe, D.J., Pearce, N.J.G., Jorgensen, M.A., Kuehn, S.C., Tryon, C.A., Hayward, C.L. 2017. Correlating tephras and cryptotephras using glass compositional analyses and numerical and statistical methods: review and evaluation. Quaternary Science Reviews 175, 1-44 (https://doi.org/10.1016/j.quascirev.2017.08.003) 


\begin{abstract}
We define tephras and cryptotephras and their components (mainly ash-sized particles of glass \pm crystals in distal deposits) and summarize the basis of tephrochronology as a chronostratigraphic correlational and dating tool for palaeoenvironmental, geological, and archaeological research. We then document and appraise recent advances in analytical methods used to determine the major, minor, and trace elements of individual glass shards from tephra or cryptotephra deposits to aid their correlation and application. Protocols developed recently for the electron probe microanalysis of major elements in individual glass shards help to improve data quality and standardize reporting procedures. A narrow electron beam (diameter $\sim 3-5 \mu \mathrm{m}$ ) can now be used to analyze smaller glass shards than previously attainable. Reliable analyses of 'microshards' (defined here as glass shards $<32 \mu \mathrm{m}$ in diameter) using narrow beams are useful for fine-grained samples from distal or ultra-distal geographic locations, and for vesicular or microlite-rich glass shards or small melt inclusions. Caveats apply, however, in the microprobe analysis of very small microshards $(\leq \sim 5 \mu \mathrm{m}$ in diameter), where particle geometry becomes important, and of microlite-rich glass shards where the potential problem of secondary fluorescence across phase boundaries needs to be recognised. Trace element analyses of individual glass shards using laser ablation inductively coupled plasma-mass spectrometry (LA-ICP-MS), with crater diameters of $20 \mu \mathrm{m}$ and $10 \mu \mathrm{m}$, are now effectively routine, giving detection limits well
\end{abstract}


below $1 \mathrm{ppm}$. Smaller ablation craters $(<10 \mu \mathrm{m})$ can be subject to significant element fractionation during analysis, but the systematic relationship of such fractionation with glass composition suggests that analyses for some elements at these resolutions may be quantifiable. In undertaking analyses, either by microprobe or LA-ICP-MS, reference material data acquired using the same procedure, and preferably from the same analytical session, should be presented alongside new analytical data.

In part 2 of the review, we describe, critically assess, and recommend ways in which tephras or cryptotephras can be correlated (in conjunction with other information) using numerical or statistical analyses of compositional data. Statistical methods provide a less subjective means of dealing with analytical data pertaining to tephra components (usually glass or crystals/phenocrysts) than heuristic alternatives. They enable a better understanding of relationships among the data from multiple viewpoints to be developed and help quantify the degree of uncertainty in establishing correlations. In common with other scientific hypothesis testing, it is easier to infer using such analysis that two or more tephras are different rather than the same. Adding stratigraphic, chronological, spatial, or palaeoenvironmental data (i.e. multiple criteria) is usually necessary and allows for more robust correlations to be made. A two-stage approach is useful, the first focussed on differences in the mean composition of samples, or their range, which can be visualised graphically via scatterplot matrices or bivariate plots coupled with the use of statistical tools such as distance measures, 
similarity coefficients, hierarchical cluster analysis (informed by distance measures or similarity or cophenetic coefficients), and principal components analysis (PCA). Some statistical methods (cluster analysis, discriminant analysis) are referred to as 'machine learning' in the computing literature. The second stage examines sample variance and the degree of compositional similarity so that sample equivalence or otherwise can be established on a statistical basis. This stage may involve discriminant function analysis (DFA), support vector machines (SVMs), canonical variates analysis (CVA), and ANOVA or MANOVA (or its two-sample special case, the Hotelling two-sample $T^{2}$ test). Randomization tests can be used where distributional assumptions such as multivariate normality underlying parametric tests are doubtful.

Compositional data may be transformed and scaled before being subjected to multivariate statistical procedures including calculation of distance matrices, hierarchical cluster analysis, and PCA. Such transformations may make the assumption of multivariate normality more appropriate. A sequential procedure using Mahalanobis distance and the Hotelling two-sample $T^{2}$ test is illustrated using glass major element data from trachytic to phonolitic Kenyan tephras. All these methods require a broad range of high-quality compositional data which can be used to compare 'unknowns' with reference (training) sets that are sufficiently complete to account for all possible correlatives, including tephras with heterogeneous glasses that contain multiple compositional groups. Currently, incomplete databases are tending to limit correlation 
efficacy. The development of an open, online global database to facilitate progress towards integrated, high-quality tephrostratigraphic frameworks for different regions is encouraged.

\title{
Keywords
}

Tephra, cryptotephra, tephrochronology, tephrostratigraphy, glass-shard analysis, microshard, volcanic glass, crystal, phenocryst, microlite, melt inclusion, electron probe, laser ablation, LA-ICP-MS, EPMA, multivariate statistics, similarity coefficients, machine learning, cluster analysis, statistical distance, bivariate plots

\author{
Abbreviations \\ ANOVA, analysis of variance; AVF, Auckland Volcanic Field; BSE, back-scattered \\ electron (image); CV, coefficient of variation; CVA, canonical variates analysis; DFA, \\ discriminant function analysis; EPMA, electron probe microanalysis; FMAZ, Faroe \\ Marine Ash Zone; HFSE, high field strength elements; INTAV, International Focus \\ Group [IFG] on Tephrochronology and Volcanism; IS, internal standard; LA-ICP-MS, \\ laser ablation inductively coupled plasma-mass spectrometry; LLQ, lower limit of \\ quantitation; MANOVA, multivariate analysis of variance; $\mu$-XRF, micro-X-ray \\ fluorescence; MTT, Middle Toba Tuff; OTT, Oldest Toba Tuff; PAM, partitioning
}


around medoids; PC, principal component; PCA, principal components analysis; REEs, rare earth elements; SC, similarity coefficient; SEM, scanning electron microscope; SNICP-MS, solution nebulisation inductively coupled plasma-mass spectrometry; SVM, support vector machines; YTT, Youngest Toba Tuff; XRF, X-ray fluorescence

\section{Highlights}

- Advances in the microanalysis of major, minor, and trace elements of glass shards are reviewed

- We evaluate numerical and statistical methods for tephra correlation via glass/crystal analyses

- We focus on (1) differences in mean composition of samples or their range; and

- (2) sample variance and degree of compositional similarity to establish equivalence or not

- We illustrate various statistical methods and data transformations using case studies 


\section{Introduction}

\subsection{Tephra and cryptotephra deposits and their componentry}

Tephras are the unconsolidated, pyroclastic or fragmental products of explosive volcanic eruptions (Greek tephra, 'ash' or 'ashes') (Thorarinsson, 1981; Lowe, 2011). Erupting pyroclasts propelled through the air, together with volcanic gases, typically comprise three main components: $(i)$ volcanic glass (including glass shards, pumice, and scoriae); (ii) crystalline mineral phases (hereafter crystals); and (iii) lithics or rock fragments. Volcanic glass, a non-crystalline phase, occurs in multiple morphologies including individual bubble-wall (cuspate) or platy glass shards, pumiceous or 'inflated' shards, and pumice or scoria clasts, which all originate from the rapid quenching of molten magma during eruption (Fig. 1). The degree of ordering and linkage of $\mathrm{SiO}_{4}{ }^{4-}$ tetrahedra (so-called 'polymerisation') within these glasses is dependent on composition, and reflects the structure of the magma from which the glass formed. Basaltic magmas are less polymerised than rhyolitic magmas, and are thus less viscous and erupt more effusively. The space between the partly-linked $\mathrm{SiO}_{4}{ }^{4-}$ tetrahedra in the melt is occupied by cations such as $\mathrm{Na}, \mathrm{K}, \mathrm{Mg}, \mathrm{Ca}$, and $\mathrm{Fe}$, which act to depolymerise the melt. Glass may also occur as coatings or rims on crystals (selvedges). Pumice and scoria clasts consist mainly of glass with vesicles (voids) formed by expanding gases 
during eruption and various quantities of crystals or crystal fragments (loose or as phenocrysts) and occasionally lithic fragments. Pumice is most commonly silicic and pale-coloured (although dark-coloured basaltic pumice also occurs) and has a low density, whereas scoriae (or 'cinders') are mafic and dark-coloured, typically basaltic to andesitic, and have a greater density (Fisher and Schminke, 1984). Crystals and crystal fragments are mainly formed in the magma prior to eruption (Jerram and Martin, 2008). Lithic fragments are pieces of pre-existing rock that became incorporated into the tephra during eruption, transport, or deposition (Fisher and Schminke, 1984; Sarna-Wojcicki, 2000). Volcanic glass, pumice/scoria, and most crystals (including tiny crystals, i.e. microcrysts/microlites or microphenocrysts) within glass are juvenile or co-magmatic constituents of the tephra (i.e. formed from magma involved in the eruption), and provide the materials for tephra characterization using physical properties and compositional analyses. Lithic fragments (xenoliths) may be related (cognate xenoliths, or autoliths) or unrelated to contemporaneous magmatic activity. Similarly, crystalline material may be physically removed from older rocks surrounding the magma chamber or vent (becoming xenocrysts), it may be 'reincorporated' from earlier cumulates in the current magmatic cycle (antecrysts, e.g. zircon, sensu Jerram and Martin, 2008), or it may be a restite phase from assimilation of unrelated, older country rock. In some cases material, termed 'detrital' (Sarna-Wojcicki, 2000), may be entrained from clastic sources during transport and emplacement of the tephra deposit. 

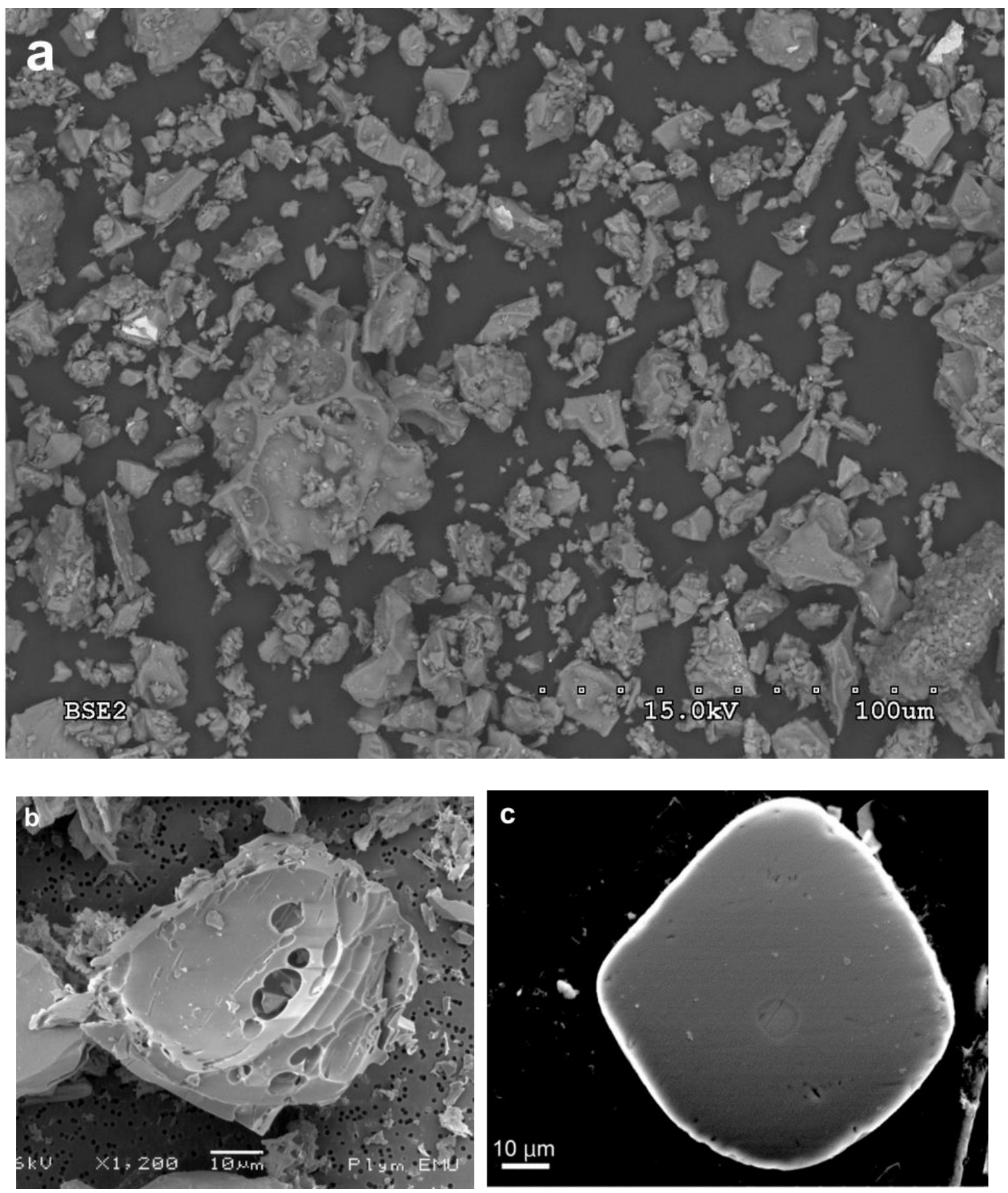
Fig. 1. (a) BSE image of unpolished glass shards, ranging in size from $\sim 1$ to $\sim 75 \mu \mathrm{m}$ in diameter, from tephra erupted in 1997 from the Soufrière Hills volcano, Montserrat (collected at the Montserrat Volcanic Observatory South, 28 September, 1997) (image provided by Stuart Kearns; see also Kearns and Buse, 2012, p. 2). (b) SEM image of a thick-walled cuspate (bubble-wall) glass shard, 50-60 $\mu \mathrm{m}$ in size, from a mid-Holocene rhyolitic tephra deposit preserved in peat, northern New Zealand. Such shards need polishing flat before reliable geochemical analysis can be undertaken on them. Image provided by Maria Gehrels. (c) SEM image of a melt (glass) inclusion within a quartz grain from a cryptotephra deposit in Japan (identified as Kikai-Tozurahara tephra, K$\mathrm{Tz}$ ). The indistinct round melt inclusion, near the middle of the grain, is $7 \mu \mathrm{m}$ in diameter (from Matsu'ura et al., 2011a, p. 51).

The proportions of these various components (glass, pumice/scoria, crystals, lithics) differ widely according to eruption composition and style, proximity to vent, atmospheric conditions, and other factors (Fisher and Schminke, 1984; Alloway et al., 2013; Edmonds and Wallace, 2017). Large-magnitude, very explosive, and voluminous silicic eruptions with dacitic to rhyolitic bulk compositions and dacitic ( 63-69 wt \% $\mathrm{SiO}_{2}$ ) to rhyolitic (>69 wt $\left.\% \mathrm{SiO}_{2}\right)$ glass tend to generate extensively dispersed tephras that persist as relatively thick layers of ash over large distances (e.g. Froggatt et al., 1986; Machida, 2010). Basaltic tephras, much less siliceous ( $\left.<52 \mathrm{wt} \% \mathrm{SiO}_{2}\right)$, derive from typically lesser-magnitude eruptions and lower eruption columns (but with notable exceptions, e.g. Laki and Grimsvötn eruptions 1783-1785: Thordarson and Self, 1993; Tarawera eruption 1886: Walker et al., 1984). The bulk of associated basaltic tephras are mainly locally dispersed but many finer particles of ash are now known to be distributed very widely under favourable wind conditions (e.g. Davies et al., 2010a; 
Watson et al., 2016). However, unlike rhyolitic tephras, dispersed basaltic fallout deposits typically are very thin, commonly forming cryptotephras. Andesitic (and basaltic andesitic) tephras are intermediary in composition $\left(\sim 52-63 \mathrm{wt} \% \mathrm{SiO}_{2}\right)$ and may be locally or quite widely dispersed as either thin tephra layers or cryptotephra deposits.

The pyroclasts making up a tephra deposit potentially encompass grain sizes ranging from volcanic ash $(<2 \mathrm{~mm}$ in diameter), to lapilli $(2-64 \mathrm{~mm})$, to large blocks (dense, angular) or bombs (vesicular, rounded) (>64 mm) (Schmid, 1981). Fine-grained tephras, usually ash-size, can be deposited and preserved hundreds to thousands of kilometres away from their source (e.g. Lane et al., 2013a; Jensen et al., 2014; Ponomareva et al., 2015a; Pyne-O’Donnell et al., 2016; van der Bilt et al., 2017). At such distal locations, deposits may consist solely of bubble-wall or platy glass shards (Izett, 1981; Sarna-Wojcicki, 2000; Pyne-O’Donnell et al., 2012). Diminutive, nonvisible tephra deposits, typically in distal to ultra-distal locations, are referred to as cryptotephras (Greek kryptein, 'to hide') (Lowe, 2011; Davies, 2015). These are defined as tephra-derived glass shard or crystal concentrations, or both, preserved and 'hidden' in peats, lacustrine, aeolian, or marine sediments, in frozen sediments or ice, or in buried paleosols or modern (surface) soils. Cryptotephras are essentially not visible in the field as a layer to the naked eye, and hence in cases where shards or crystals are sparse or dispersed they are best referred to as deposits rather than layers. They are 
usually fine-grained, often comprising particles $<125 \mu \mathrm{m}$ in diameter (i.e. very fine ash or smaller using the detailed classification of White and Houghton, 2006), and grains 40-60 $\mu \mathrm{m}$, or even finer, are not uncommon depending on location and source (e.g. Abbott and Davies, 2012; Stevenson et al., 2012, 2015; Watson et al., 2016; van der Bilt et al., 2017). New approaches have been developed to enable glass shard (or crystal) concentrations from cryptotephras, or from very thin visible tephra layers, to be first detected and then isolated from enclosing sediments (e.g. Kylander et al., 2012; Lane et al., 2014; McCanta et al., 2015; Chan et al., 2016). Geochemical approaches to the quantification of dispersed glass shards in marine sediments were reported by Scudder et al. (2016). Analytical methods including magnetic susceptibility, colour spectrometry, X-radiography, X-ray fluorescence (XRF)-based core scanning, and image analyses were utilized by Cassidy et al. (2014) to detect cryptotephras in marine cores and to separate primary from reworked deposits. Novel 2D and 3D visualisation methods have also been applied to marine deposits (Griggs et al., 2014, 2015). Hopkins et al. (2015) and Zawalna-Geer et al. (2016) have developed new methods for differentiating between primary cryptotephra deposits and reworked ones in lake sediments. The subsequent chemical analysis of such small and often sparse grains of glass has been challenging, and new techniques and protocols have been required to attain high-quality, reproducible data. The key recent developments are described in Sections 2-4 below. 


\subsection{Tephrochronology}

Tephrochronology is the use of primary tephra layers or cryptotephra deposits as isochronous (time-parallel) marker beds to link and synchronize depositional sequences, or soils/paleosols, and to transfer relative or numerical ages or dates to the sequences using lithostratigraphic and compositional data pertaining to the tephras or cryptotephras (Sarna-Wojcicki, 2000; Alloway et al., 2013; Lowe and Alloway, 2015). Tephrochronology has become an important (even essential) tool in a very wide range of fields (e.g. Lowe, 2011; Davies, 2015; Lane et al., 2017), including 'classical' applications such as aligning and dating palaeoenvironmental reconstructions, landscape evolution, and archaeology, and more recent 'modern' applications - growing numbers of which are based entirely on cryptotephra deposits - such as medical and pandemic research (D'Costa et al., 2011; Streeter et al., 2012), evaluating aviation hazards (Scaini et al., 2014; Bourne et al., 2016; Watson et al., 2017a), and hominin/human evolution and adaptation (Tryon et al., 2009; Lowe et al., 2012; Durkee and Brown, 2014; Blegen et al., 2015; McHenry et al., 2016; Alloway et al., 2017).

Although tephrochronology is underpinned by lithostratigraphy and the law of superposition, the method typically relies as much, or more, on characterizing or 'fingerprinting' inherent tephra-derived, pyrogenic components characteristic of the 
magma composition prior to and during its eruption, namely the volcanic glass, pumice fragments, and crystals or crystal fragments (minerals) as described above (Section 1.1). Thus laboratory-based analyses are usually needed to complement field-based evidence such as stratigraphy, especially in more distal regions where tephras become thinner and finer-grained and where exposures tend to contain layers from other eruptions and other volcanic sources as well as detrital and non-volcanic materials (Lowe and Alloway, 2015). Such analyses include the identification of mineral assemblages by optical microscopy (petrography) or X-ray diffraction, and the chemical analysis of glass shards or crystals (e.g. biotite, titanomagnetite) using the electron microprobe and other tools (Table 1). Analyses of melt inclusions - glass preserved within crystals including quartz and other host minerals (Fig. 1c) - also provide a possible 'window' into the history of magmatic evolution and composition leading up to eruption (and hence potentially furnish 'fingerprints' for correlation). 
Table 1. Analytical methods used to characterize volcanic glass, melt inclusions, and mineralogical components in tephra or cryptotephra deposits (after Lowe, 2011).

\begin{tabular}{|c|c|c|}
\hline Tephra component/properties & Method of analysis ${ }^{\mathrm{a}}$ & Key references/examples ${ }^{\mathrm{e}}$ \\
\hline \multicolumn{3}{|l|}{ Glass shards or selvedges ${ }^{b}$} \\
\hline \multicolumn{3}{|l|}{ Grain specific analysis } \\
\hline Major and minor elements ${ }^{c}$ & Electron microprobe & $11,23,50,109,112$ \\
\hline Major, minor, and trace elements ${ }^{c}$ & LA-ICP-MS, LIBS $^{d}$ & $\begin{array}{l}2,12,18,57,58,70,72,73 \\
106,114\end{array}$ \\
\hline $\mathrm{Pb}$ isotopes & LA-ICP-MS & 110,113 \\
\hline \multicolumn{3}{|l|}{ Areal density of spontaneous } \\
\hline fission tracks & Optical microscope & 115 \\
\hline \multicolumn{3}{|l|}{ Bulk sample analysis } \\
\hline \multirow[t]{4}{*}{ Trace elements } & SN-ICP-MS & 47,78 \\
\hline & ICP-AES & 105 \\
\hline & INAA & $5,51,52,53,83,84,86$ \\
\hline & SIMS & $8,14,25,28,96,98$ \\
\hline \multirow[t]{2}{*}{$\mathrm{Sr}, \mathrm{Nd}$, and $\mathrm{Pb}$ isotopes } & TIMS & $22,30,82,103$ \\
\hline & NSC-MCMS & $7,34,79$ \\
\hline \multicolumn{3}{|l|}{ Melt inclusions (glass) } \\
\hline Major elements & Electron microprobe & $9,13,24,38,39,60,96,98$ \\
\hline Trace elements including $\mathrm{N}$ & SIMS & $3,28,80,97,98$ \\
\hline \multicolumn{3}{|c|}{$\begin{array}{l}\text { Feldspars: plagioclase, anorthoclase, or } \\
\text { sanidine crystals/phenocrysts }\end{array}$} \\
\hline Major elements & Electron microprobe & $\begin{array}{l}31,33,44,55,64,65,74,96 \\
100,102,111\end{array}$ \\
\hline $\mathrm{Pb}$ isotopes & LA-MC-ICP-MS & 40 \\
\hline \multicolumn{3}{|l|}{ Ferromagnesian silicate minerals } \\
\hline \multirow[t]{2}{*}{ Assemblages } & Petrographic microscope & $56,59,86,101,102$ \\
\hline & X-ray diffraction & 41 \\
\hline $\begin{array}{l}\text { Pyroxenes, amphiboles, } \\
\text { olivine, biotite, or titanite crystals/ } \\
\text { phenocrysts }\end{array}$ & Electron microprobe & $\begin{array}{l}1,16,17,27,31,40,59,62 \\
63,64,65,66,67,94,96,100 \\
102,111\end{array}$ \\
\hline \multicolumn{3}{|l|}{ Apatite, zircon } \\
\hline Apatite crystals/phenocrysts & Electron microprobe & $88,89,90,104$ \\
\hline Zircon crystals & TIMS-TEA & $6,15,35,87$ \\
\hline \multicolumn{3}{|l|}{ Fe-Ti oxides } \\
\hline \multirow[t]{3}{*}{$\begin{array}{l}\text { Major and minor elements in } \\
\text { crystals }\end{array}$} & Electron microprobe & $\begin{array}{l}19,20,64,65,77,79,91,92 \\
93,96,102,108\end{array}$ \\
\hline & Mössbauer spectroscopy & 21,45 \\
\hline & LA-ICP-MS & 68 \\
\hline $\begin{array}{l}\text { Eruption temperatures, oxygen } \\
\text { fugacities (geothermometry) }\end{array}$ & Electron microprobe & $78,95,96,101,102$ \\
\hline \multicolumn{3}{|l|}{$\begin{array}{l}\text { Glass-shard or ash-particle } \\
\text { morphology, crystal or phenocryst } \\
\text { geometry or texture }\end{array}$} \\
\hline Shard morphology & Optical microscope, SEM & $\begin{array}{l}10,26,32,37,43,46,49,71 \\
75,76,85,99\end{array}$ \\
\hline $\begin{array}{l}\text { Image particle analysis (shard } \\
\text { texture, vesicularity; ash-grain } \\
\text { morphometry) }\end{array}$ & BSE-mode SEM, SEM & $4,42,54$ \\
\hline Olivine crystal geometry & Optical microscope, SEM & 27 \\
\hline Apatite crystal geometry & Optical microscope, SEM & 88 \\
\hline
\end{tabular}


Titanomagnetite phenocryst

textures

Refractive index

Glass

Ferromagnesian silicate minerals (crystals)
Reflected light microscope 107

Petrographic microscope, $\quad 26,36,69,116$ immersion thermal

method

As above

${ }^{\mathrm{a}} \mathrm{LA}-$ or S(N)-ICP-MS or LA-MC-ICP-MS, laser ablation or solution nebulisation or multicollector inductively coupled plasma mass spectrometry; ICP-AES, inductively coupled plasma atomic emission spectrometry; LIBS, laser-induced breakdown spectroscopy; INAA, instrumental neutronactivation analysis; SIMS, secondary ionization mass spectrometry (known also as ion probe/ion microprobe); NSC-MCMS, nuclide single-collector or multi-collector mass spectrometry; BSE, backscattered electron; SEM, scanning electron microscopy; TIMS(-TEA), thermal ionization mass spectrometry (-trace element analysis). XRF may also be used in some circumstances (see text). bMay also include matrix glass in pumice clasts (e.g. Shane et al., 2005a, 2005b, 2008b, 2008c; Allan et al., 2013; Robinson, 2016). The attachment of glass selvedges to crystals such as Fe-Ti oxides indicates a primary origin because contaminant or reworked grains do not usually have such glassy coats (e.g. Wilcox and Naeser, 1992; Preece et al., 2011a; Matsu'ura and Komatsubara, 2017).

Iverson et al. (2017) documented protocols for analysing sparse and fine-grained $(<5 \mu \mathrm{m})$ glass shards, including unpolished, from ice cores.

${ }^{\mathrm{c}}$ Major elements expressed as oxides are usually defined as $>1 \mathrm{wt} \%$, minor element oxides as 0.1 to 1 $\mathrm{wt} \%$, and trace elements as $<0.1 \mathrm{wt} \%$ or $<1000$ parts per million (ppm) of the element.

${ }^{\mathrm{d} C}$ Currently applied in forensic analyses of glass (e.g. from cars) (see Almirall and Trejos, 2006; Grainger et al., 2012). e

\begin{tabular}{|c|c|c|}
\hline 1 Allan et al. 2013 & 41 Inoue et al. 2009 & 81 Rodriguez-Cellis et al. 2008 \\
\hline 2 Almirall et al. 2012 & 42 Iverson et al. 2014 & 82 Roulleau et al. 2009 \\
\hline 3 Auer et al. 2008 & 43 Izert 1981 & 83 Saminger et al. 2000 \\
\hline 4 Avery et al. 2017 & 44 Jouannic et al. 2015 & 84 Sarna-Wojcicki 1979 \\
\hline 5 Baccolo et al. 2015 & 45 Julian et al. 1988 & 85 Sarna-Wojcicki 2000 \\
\hline 6 Barham et al. 2016 & 46 Knott et al. 1999 & 86 Sarna-Wojcicki et al. 1984 \\
\hline 7 Basile et al. 2001 & 47 Knott et al. 2007 & 87 Schoene et al. 2010 \\
\hline 8 Begét \& Keskinen 2003 & 48 Kotaki et al. 2011 & 88 Sell \& Samson 2011a \\
\hline 9 Borisova et al. 2008 & 49 Kuehn \& Froese 2010 & 89 Sell \& Samson $2011 b$ \\
\hline 10 Bourne et al. 2010 & 50 Kuehn et al. 2011 & 90 Sell et al. 2015 \\
\hline 11 Bourne et al. 2015 & 51 Lim et al. 2008 & 91 Shane 1994 \\
\hline 12 Bridge et al. 2006 & 52 Lim et al. 2013 & 92 Shane 1998 \\
\hline 13 Chesner \& Luhr 2010 & 53 Lim et al. 2014 & 93 Shane \& Zawalna-Geer 2011 \\
\hline 14 Clift et al. 2003 & 54 Liu et al. 2016 & 94 Shane et al. 2003 \\
\hline 15 Coffey et al. 2014 & 55 Lowe 1988 & 95 Shane et al. $2005 b$ \\
\hline 16 Cronin et al. $1996 \mathrm{a}$ & 56 Lowe et al. 2008 & 96 Shane et al. 2007 \\
\hline 17 Cronin et al. $1996 \mathrm{~b}$ & 57 Maruyama et al. $2016 \mathrm{a}$ & 97 Shane et al. $2008 \mathrm{~b}$ \\
\hline 18 Cullen et al. 2014 & 58 Maruyama et al. $2016 \mathrm{~b}$ & 98 Shane et al. $2008 \mathrm{c}$ \\
\hline 19 Damaschke et al. 2017a & 59 Matsu'ura \& Komatsubara 2017 & 99 Smith \& Houghton 1995 \\
\hline 20 Damaschke et al. $2017 \mathrm{~b}$ & 60 Matsu'ura et al. 2011a & 100 Smith et al. 2004 \\
\hline 21 Daniels et al. 1985 & 61 Matsu'ura et al. 2011b & 101 Smith et al. 2005 \\
\hline 22 D'Antonio et al. 2016 & 62 Matsu'ura et al. 2012 & 102 Smith et al. 2006 \\
\hline 23 Davies et al. 2016 & 63 Matsu'ura et al. 2014 & 103 Stern 2008 \\
\hline 24 Delano et al. 1995 & $64 \mathrm{McHenry} 2005$ & 104 Takashima et al. 2017 \\
\hline 25 Denton $\&$ Pearce 2008 & 65 McHenry 2012 & 105 Tamura et al. 2008 \\
\hline 26 Derkachev et al. 2012 & $66 \mathrm{McHenry}$ et al. 2011 & 106 Tomlinson et al. 2015 \\
\hline 27 Donoghue et al. 1991 & $67 \mathrm{McHenry}$ et al. 2013 & 107 Turner et al. 2008 \\
\hline 28 Dunbar \& Kyle 1993 & 68 Nadoll \& Koenig 2011 & 108 Turner et al. 2009 \\
\hline
\end{tabular}




\begin{tabular}{|l|l|l|}
\hline 29 Enache \& Cumming 2006 & 69 Nakamura et al. 2002 & 109 Turney et al. 2004 \\
\hline 30 Giaccio et al. 2013 & 70 Negre et al. 2015 2003 \\
\hline 31 Habermann et al. 2016 & 71 Nelson et al. 1985 & 110 Ukstins Peate et al. 20 \\
\hline 32 Hamann et al. 2010 & 72 Pearce 2014 & 111 Westgate et al. 1985 \\
\hline 33 Harangi et al. 2005 & 73 Pearce et al. 2011 & 112 Westgate et al. 2008 \\
\hline 34 Hart et al. 1992 & 74 Placzek et al. 2009 & 113 Westgate et al. 2011 \\
\hline 35 Harvey 2014 & 75 Preece et al. 1999 & 114 Westgate et al. 2013c \\
\hline 36 Hodder 1978 & 76 Preece et al. 2000 & 115 Westgate et al. 2014 \\
\hline 37 Housley et al. 2013 & 77 Preece et al. 2011a & 116 Wilcox 1983 \\
\hline 38 Huff 2016 & 78 Preece et al. 2011b & \\
\hline 39 Huff et al. 1996 & 79 Preece et al. 2014 & \\
\hline 40 Ickert et al. 2015 & 80 Regier et al. 2016 & \\
\hline
\end{tabular}

Wherever possible, such analytical data are very markedly supported and more readily interpreted by the attainment of numerical ages on tephras (Turner et al., 2011b; Green et al., 2014; Damaschke et al., 2017a). Dating techniques applied to tephras include: (i) radiometric, for example radiocarbon $\left({ }^{14} \mathrm{C}\right)$, fission track, luminescence, ${ }^{40} \mathrm{Ar} /{ }^{39} \mathrm{Ar}, \mathrm{U}-\mathrm{Th}$-disequilibrium/U-Pb and (U-Th)/He zircon dating (e.g. Biswas et al., 2013; Westgate et al., 2013a; Coble et al., 2017; Danišík et al., 2017; Giaccio et al., 2017; Leonard et al., 2017); (ii) incremental, such as dendrochronology, varves, icecore layering (e.g. Kurbatov et al., 2006; Hogg et al., 2012; Abbott and Davies, 2012; Lane et al., 2013b); (iii) age-equivalence, for example magnetic polarity, orbital or icecore tuning, palynostratigraphy (e.g. Newnham et al., 2004; Alloway et al., 2005; Lohne et al., 2013); (iv) relative dating, such as amino-acid geochronology (e.g. Kimber et al., 1994); (v) historical observations including eye-witness accounts and remote sensing (e.g. Dugmore et al., 2004); and (vi) age modelling including wiggle-match dating 
sequences of contiguous ${ }^{14} \mathrm{C}$-dated tree rings (e.g. Hogg et al., 2012; Friedrich et al., 2006; Yin et al., 2012), and Bayesian and other statistical depositional age modelling relating to the above methods (e.g. Kaufman et al., 2012; Lowe et al., 2013; Bronk Ramsey et al., 2015a; Schmid et al., 2017). Multiple dating methods are being applied increasingly in lacustrine and marine sequences that contain tephra or cryptotephra deposits (e.g. Sirocko et al., 2013; Staff et al., 2013; Hopkins et al., 2015; Matsu'ura and Komatsubara 2017), a key aim being to generate independent chronologies (Brauer et al., 2014).

The correlation of tephras or cryptotephras from one site to the next requires the use of stratigraphy (stratigraphic position in a sequence and relationship to other deposits or a defined age datum) and age together with comparison of the inherent compositional features of the deposits and the associated palaeoenvironmental (e.g. biostratigraphic or climatostratigraphic associations) or archaeological or palaeoanthropological contexts (e.g. Feibel, 1999; Davies et al., 2004; Riede and Thastrup, 2013; Turner et al., 2013; Westgate et al., 2013b; Harper et al., 2015; Westgate and Pearce, 2017). In effect, such correlation is based on the degree of similarity or otherwise of the lithostratigraphic, contextual, compositional, and chronological data pertaining to one deposit with those of others. Typically it is the combination of these various lines of evidence - multiple parameters - that allow for 
the most secure correlations to be made (e.g. Lowe et al., 2008; Westgate et al., 2008; Habermann et al., 2016; Damaschke et al., 2017a).

Once a close match or correlation is established with confidence, the relative or numerical age or date attached to a tephra or cryptotephra deposit at one site is transferable to other sites where the same deposit is identified. Used this way, tephrochronology is a powerful age-equivalent (or correlational) dating tool, the tephra/cryptotephra providing a tie-point of known age in relevant depositional sequences. The age transfer, a key principle in tephrochronology, is valid because most tephras are erupted and deposited virtually instantaneously (usually within hours or days of an eruption event) so that primary tephra deposits (i.e. those not substantially reworked after deposition) have the same short time interval from eruption to deposition everywhere they occur, forming isochrons or chronostratigraphic marker beds (Lowe, 2011; Dugmore and Newton, 2012).

\subsection{Outline of remainder of paper}

We focus firstly on more recent developments and advances in analytical methods used to characterize or 'fingerprint' tephra layers and cryptotephra deposits by quantitative analysis of constituent glass components, with special consideration of the forensic-like analysis of small glass shards $<32 \mu \mathrm{m}$ in size, which we define as 'microshards' (Sections 2 to 4). Secondly, we describe and evaluate numerical and 
statistical methods, including multivariate analysis, used to assist with and effect their correlation (Sections 5 to 9). We examine this second topic in detail using a multidisciplinary approach (Tingley et al., 2012). Thus, Section 5 introduces concepts in correlation and includes short discussions on the roles of stratigraphy and chronology and the importance of scale in tephra correlation studies. It is followed in Section $\mathbf{6}$ by description and discussion of various numerical and statistical methods, including cluster analysis and machine learning methods, used in correlation, and treatment of outliers. Transformation, scaling, and testing are then evaluated in Section 7. In Section $\mathbf{8}$, we provide a simplified step-by-step guide to tephra correlation, in effect a summary of key points and recommendations from the previous three sections. We then illustrate a range of statistical methods, including the use of data both untransformed and transformed, utilizing three case studies in Section 9 before the summary and conclusions (Section 10).

\section{Characterizing or 'fingerprinting' tephras and cryptotephras via glass analysis}

\subsection{Electron probe microanalysis and laser ablation inductively coupled plasma-mass} spectrometry 
Two analytical techniques are now in common or increasing use for tephra or cryptotephra analysis, namely (i) electron probe microanalysis (EPMA) and (ii) laser ablation inductively coupled plasma-mass spectrometry (LA-ICP-MS) (Table 1). EPMA is widely used for determining the major- and minor-element composition of individual glass shards, glassy coatings on crystals, pumice fragments, melt inclusions, and 'free' or loose crystals/crystal fragments, or phenocrysts, such as plagioclase, anorthoclase, olivine, pyroxenes, amphiboles, apatite, or Fe-Ti oxides such as titanomagnetite (e.g. Marcaida et al., 2014; Habermann et a., 2016; Damaschke et al., 2017a). In many cases, such crystals are formed during crystallization of the magma from which a particular tephra is produced and hence are potentially useful for characterizing it for correlational purposes (Table 1). In some cases, however, antecedent xenocrystic material may be entrained from earlier events, and therefore can generate potentially spurious data (e.g. Liu et al., 2006).

Major elements expressed as oxides usually are defined as $>1 \mathrm{wt} \%$, minor element oxides as 0.1 to $1 \mathrm{wt} \%$, and trace elements as $<0.1 \mathrm{wt} \%$ or $<1000$ parts per million (ppm) by weight of the element (not oxide) (Winter, 2009, p. 135).

In this section we target the microanalysis of well-preserved glass. Methods of sample separation and extraction and the preparation of glass shards for EPMA have been documented previously by, for example, Froggatt (1992), Turney (1998), Blockley et al. (2005), Davies et al. (2010b), Kuehn and Froese (2010), Kuehn et al. (2011), 
Preece et al. (2011a), Hall and Hayward (2014), Roland et al. (2015), and Iverson et al. (2017). LA-ICP-MS is a more recently developed technique used predominantly to obtain trace element compositions of individual glass shards that now has the capacity to analyze shards with a $10 \mu \mathrm{m}$ diameter beam or smaller (e.g. Pearce et al., 2011, 2014b).

\subsubsection{Advantages of single-grain techniques for analyzing individual glass shards}

In applying both EPMA and LA-ICP-MS methods, the ability to analyze individual glass shards confers many advantages compared with other methods, such as XRF or instrumental neutron activation analysis (INAA), that analyze bulk tephra material or multiple grains such as 'purified' glass separates (Table 1). Firstly, such grain-specific methods are essential because $(i)$ bulk samples often vary in composition with distance from volcanic source because of differential settling of lithics, crystals, and glass shards, and therefore relative abundances (e.g. Sarna-Wojcicki et al., 1981; Juvigné and Porter, 1985); (ii) xenocrysts, xenoliths, and detrital contaminants (i.e. accessory or accidental material as well as juvenile or 'new' magmatic material) may be incorporated into tephra deposits; (iii) bulk analyses fail to distinguish multiple populations and other variations in glass compositions that can arise from magmatic heterogeneity (e.g. Shane et al., 2008a; Ukstins Peate et al., 2008; Tomlinson et al., 
2012; Westgate et al., 2013c; Pearce et al., 2014a; Abbott et al., 2016; Alloway et al., 2016) or from post-depositional mixing processes (e.g. Óladóttir et al., 2011; Tryon et al., 2011; Swindles et al., 2013; Cerovski-Darriau et al., 2014); and (iv) bulk analysis would generate anomalous values for various elements where glass had undergone postdepositional chemical alteration, such as palagonitization or zeolitization (Thorseth et al., 1991; Kraus and Kurbatov, 2010; McHenry et al., 2011; Churchman and Lowe, 2012), or vesicular infilling by pyritization in marine settings (Nelson et al., 1985; Hunt et al., 1995).

We recognise that analyses of glass separates, or bulk ('whole-rock') samples, by XRF or other methods such as solution ICP-MS, especially for trace elements, nevertheless remain useful where compositional differences relating to potential tephra provenance (source volcanoes) are marked (e.g. Sarna-Wojcicki et al., 1987; Shane, 1994; Pearce et al., 1999; Hermanns and Schellenberger, 2008; Tamura et al., 2008; Kraus and Kurbatov, 2010; Watt et al., 2011; Petrelli et al., 2017); in trace-elementbased correlation projects (Knott et al., 2007; Preece et al., 2011b); in detailed petrological investigations (Smith et al., 2005; Donoghue et al., 2007; Shane et al., 2008c; Allan et al., 2013); in provenance studies where large-size samples of homogenous obsidian are the analytical target (Barberena et al., 2011; Sheppard et al., 2011); or simply to detect rather than analyze very thin tephra layers or cryptotephras in peat or sediment cores, such as by using $\mu$-XRF core scanners (e.g. Gehrels et al., 2008; 
Vogel et al., 2009; Kylander et al., 2012; Damaschke et al., 2013; Fortin et al., 2013;

Cassidy et al., 2014). Note that such $\mu$-XRF core scanning detects elemental differences between a possible tephra or cryptotephra occurrence and the enclosing sediment unless the tephra layer is relatively thick (e.g. Peti and Augustinus, 2017). In some cases where samples are optimal (glass is abundant), conventional XRF analyses have been used to cross-check results obtained by EPMA and to obtain some useful minor or trace element data (Sarna-Wojcicki et al., 2005). However, in some archives, especially ice cores and distal peat bogs or lakes, there are commonly insufficient numbers of shards to permit bulk analysis by XRF, INAA, or solution ICP-MS, and microbeam methods are the sole means of characterizing the glass composition.

Using EPMA-derived major element analyses of individual glass shards from a suite of tephras in marine cores from near New Zealand (Shane et al., 2006), we illustrate that four of the tephras are essentially homogenous with regard to $\mathrm{K}_{2} \mathrm{O}$ and $\mathrm{CaO}$, and match compositional fields for the same oxides of known on-shore (terrestrial) correlatives (Fig. 2a). In contrast, the EPMA data show that some shards from Maketu tephra have low-CaO contents not represented in the analyses presented for the on-shore deposits (Fig. 2b). These 'outliers' could either represent minor accidental ejecta or components of another tephra (Te Mahoe) that display a similar compositional range and which occurs onshore stratigraphically above Maketu tephra with few or no intervening deposits (Smith et al., 2002; Shane et al., 2006). In Figs. 2c 
and $2 \mathrm{~d}$, the glass-shard data are heterogeneous. They show on one hand that a single tephra (Hauparu tephra in this case) can display a wide compositional range relating to source magma variations (Fig. 2c) (Shane et al., 2005a) (or shards can potentially derive from a compositionally zoned magma body). On the other hand the heterogeneity is likely to be indicative of post-depositional mixing (reworking) of shards from different tephras (or shards from different magma sources) (Fig. 2d).
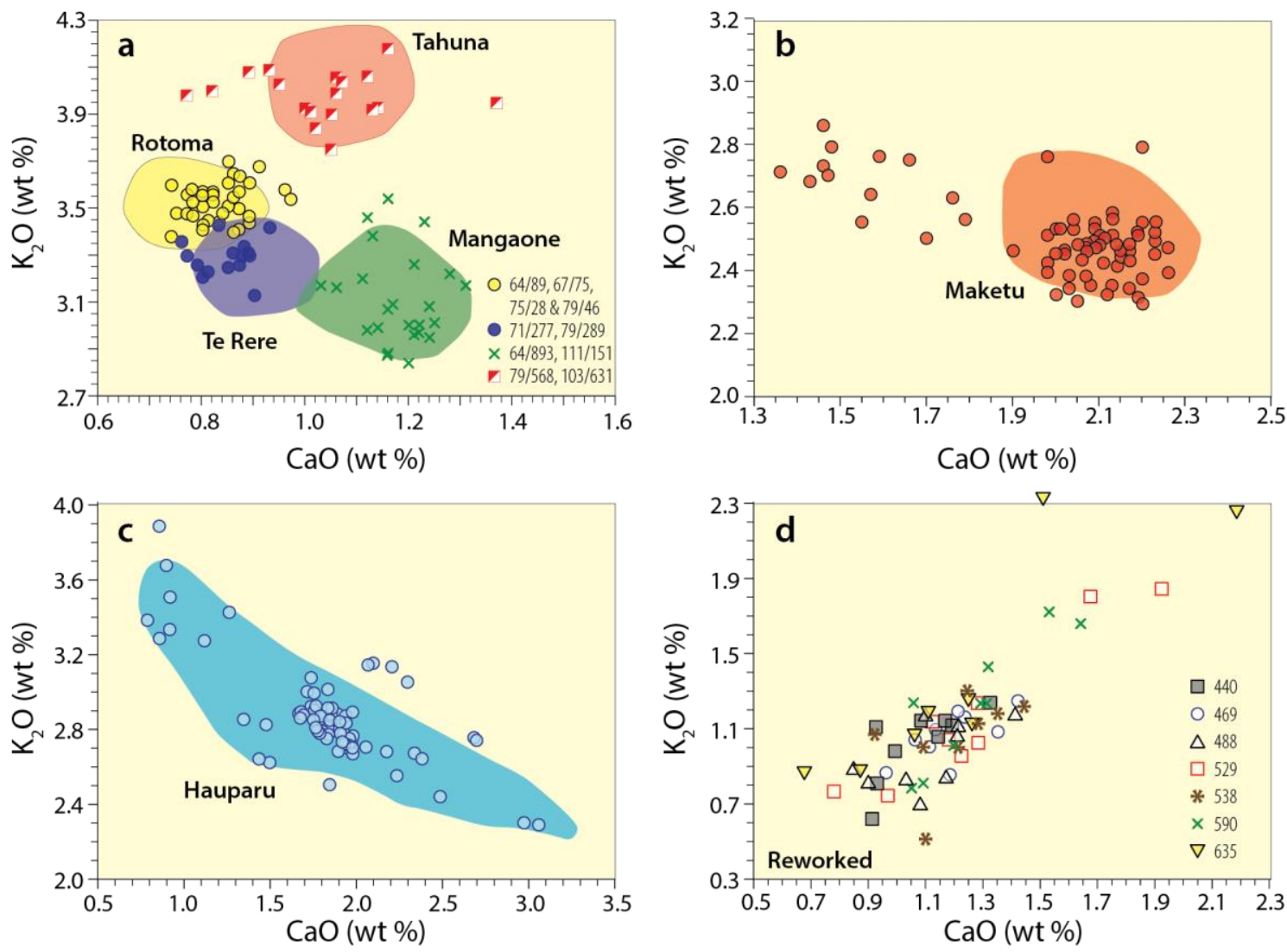
Fig. 2. Compositions as bivariate plots of $\mathrm{K}_{2} \mathrm{O} v s \mathrm{CaO}$ in wt $\%$ of individual glass shards (obtained using EPMA) from tephra layers in 16 marine cores from Bay of Plenty, northern New Zealand (redrawn from Shane et al., 2006, p. 283). (a) Examples of homogeneous shard compositions from four marine tephra layers plotted (as individual points) with the compositional fields (polygons) of known on-shore correlatives, showing the on-shore/off-shore similarities. Sample numbers are core sites/core depths in centimetres. (b) Composition of shards from marine tephra layers identified as Maketu tephra (samples from 10 cores) plotted with the compositional field (polygon) of the on-shore correlative. Note the 'tail' of low-CaO glasses $(<1.9$ wt \%) that are not represented in lapilli of on-shore eruptives. (c) Composition of shards from tephra layers identified as Hauparu tephra (samples from 11 cores) plotted with the compositional field of the on-shore eruptives, showing the characteristic wide spread of $\mathrm{CaO}$ content that probably reflects heterogeneities in the source magmas (Shane et al., 2005a). (d) Heterogeneous compositions of shards from seven deposits in core 67 (depths in centimetres as noted) (Shane et al., 2006). These glass analyses, which may represent reworked and mixed shards, or shards from different magmas (notably low in $\mathrm{K}_{2} \mathrm{O}$ ), cannot be easily correlated visually with those of known eruptions.

A second advantage is that glass compositions may be potentially more distinctive than crystal compositions because ( $i$ ) glass compositions are not limited by crystalline structures or stoichiometry, and (ii) the compositions of glasses, which represent the melt fraction of erupted magmas as noted earlier, can be changed significantly, particularly in terms of their trace element compositions, by relatively small amounts of fractional crystallization occurring between successive eruptions. The major element composition of magmas is, however, more constrained than the trace element composition, being controlled (in simple evolving systems) by magmatic evolution along compositionally narrow phase boundaries. Many basaltic magmas, for example, erupt at the surface as cotectic liquids (crystallising plagioclase and clinopyroxene), and 
their major element composition is forced to evolve along the cotectic phase boundary by continued extraction of mineral phases (fractional crystallization) between successive eruptions. In contrast, many rhyolitic magmas are either eutectic or minimum melts, the major element compositions of which do not, or only barely, change with continued crystallisation. These differences are exemplified by the rhyolitic magmas of the three major eruptions from the Yellowstone caldera in USA over the past two million years (e.g. Perkins and Nash, 2002), which have indistinguishable (granite minimum) major element compositions (see Sarna-Wojcicki and Davis, 1991; Pearce et al., 2004a, 2007). In contrast, basaltic melts from individual Icelandic volcanic centres show major element evolution by fractional crystallization between eruptions (e.g. Abbott et al., 2012; Óladóttir et al., 2012). Trace element abundances, however, generally are not controlled directly by phase relationships within the magma but by their partitioning between crystallizing phases and the melt which, because of large variations in mineral/melt distribution coefficients, can cause readily detectable variations in trace element composition with only small amounts of crystallization (Pearce et al., 2008a; Westgate et al., 2013c).

\subsection{Reference glasses and secondary standards}


In all cases where geochemical analyses are performed on either bulk or single grain (glass or mineral) material derived from tephra or cryptotephra deposits, it is imperative that reference material data are presented alongside the new analytical data in each study. In the following sections we describe microbeam analyses of glass separates by EPMA and LA-ICP-MS (for major and trace element analyses, respectively). In instances where elemental data are presented, data from an appropriate reference glass or well-characterized secondary standard should also be published. Ideally the reference standard should have a matrix composition similar to that of the sample because a poor choice of calibration standard may produce differential elemental response in the standard and sample (matrix effects) during the analysis, resulting in the generation of inaccurate data (e.g. Kroslakova and Günther, 2007; Allan et al., 2008; Gaboardi and Humayun, 2009). Reference materials include, among others, the rhyolitic Lipari obsidian (major elements), the USGS glasses (e.g. BCR-2G, BHVO-2G for major and trace elements, isotope ratios) (Wolf and Wilson, 2007), Smithsonian microbeam standards (e.g. USNM 111240 VG-2, USNM 113498 A-99, USNM 72854 VG-568: Jarosewich et al., 1980; Jarosewich, 2002), or the MPI-DING suite of glasses (e.g. ATHO-G) from the Max Plank Institute (major, trace, and isotope analyses: Jochum et al., 2005, 2006, 2011; Jochum and Stoll, 2008; Borisova et al., 2010; Ulrich and Kamber, 2013; Westgate et al., 2013c). It is worth noting that there may be problems related to the analyses of relatively new (synthesized) reference materials 
which only come to light with continued analyses, such as possible heterogeneity issues (e.g. Borisova et al., 2010) or the methods employed in characterizing the material. We note here, for example, that the reference $\mathrm{Na}_{2} \mathrm{O}$ concentrations in ATHO-G (e.g. Jochum et al., 2006) are, in our view, somewhat too low because of certain EPMA procedures used in its assessment (especially the combination of beam diameter, beam current, and analysis time) (see also Hunt and Hill, 2001).

Analyses of these standards by EPMA or LA-ICP-MS, when interspersed with unknown samples throughout an analytical session, can be used to identify and correct for drift and session-to-session variation, and to provide data for publication. Published secondary standard data allow analytical quality to be independently verified, and enable data to be compared between laboratories with greater confidence (e.g. Kuehn et al., 2011; Bourne et al., 2013; Westgate et al., 2013c). Their use applies equally to major element, trace element, and isotope ratio analysis. At present the list of appropriately certified trace element standards is still relatively limited, but is growing steadily as more materials become more widely available and better certified.

\section{Advances in electron probe microanalysis of glass}

\subsection{Inter-laboratory comparisons and development of revised and new protocols}


One feature of major element glass analysis by EPMA that has become more evident in recent times is that although analytical differences between many tephras are often substantial, in other instances the differences can be subtle for the reasons just described (Westgate et al., 2008; Kuehn et al., 2009). In addition, the use of published data is complicated by small differences between results produced by different laboratories. Consequently, high levels of precision, accuracy, and long-term intra- and inter-laboratory reproducibility, are required for the reliable identification of individual tephra beds, especially those with relatively similar glass compositions. A desire to assess the quality of data currently being produced via EPMA, and to stimulate improvements in analytical protocols and data reporting to improve the efficacy and quality of tephra fingerprinting and correlation, motivated the EPMA laboratory intercomparison exercise of the International Focus Group on Tephrochronology and Volcanism (INTAV) (Kuehn et al., 2011). The exercise followed previous but less extensive studies undertaken by Jarosewich et al. (1979), Froggatt (1992), Hunt and Hill (1996), Suzuki (1996), Hunt et al. (1998), Potts et al. (2002), Turney et al. (2004), and Coulter et al. (2010) (see also discussions by Bennett, 1994; Hunt and Hill, 1994). Despite substantial variety in procedures and calibration standards, most mean values obtained on a purpose-developed set of reference standards by 24 participating laboratories compared favourably on a laboratory-to-laboratory basis and with other reference data. Ten key recommendations for improving accuracy, precision, and 
reporting of data on glass obtained by EPMA were provided by Kuehn et al. (2011). (See Vander Heyden and Smeyers-Verbeke, 2007, regarding interlaboratory studies from a statistical viewpoint.) These recommendations built on the protocols initially recommended by Froggatt (1992). In particular, the routine analysis of secondary standards is demonstrably a powerful tool for maximizing and documenting data accuracy. In addition to the routine analysis of reference glasses, Jensen et al. (2008) and Preece et al. (2011a, 2011b), working in Alaska and the Yukon Territory, used existing EPMA-based geochemical databases and the Old Crow tephra as a 'regional' secondary standard to facilitate tephra correlations. They also re-analyzed samples of potential or likely correlatives from reference collections during the same sessions in which they analyzed the glass from unknown tephras to help eliminate possible small, day-to-day differences in electron microprobe calibration. This side-by-side analysis of unknown and reference tephra samples - preferably at the same laboratory and using the same methodology (consistent beam currents, defocussing techniques, counting criteria), secondary standards with concentrations similar to those of the unknowns and of the same broad compositional series (i.e. calc-alkaline, alkaline, peralkaline) - is advocated as a means to achieve the most robust and precise correlations, as demonstrated by Westgate et al. (2013c) and Monteath et al. (2017). Westgate et al. (2013c) reported in a study of the Toba tuffs that their calibration scheme remained the same over the two-year period during which the samples were analyzed, hence 
minimizing any compositional variance arising from analytical conditions. The EPMA stability was confirmed by analysis of reference materials including the rhyolitic (Lipari) obsidian, UA5831, and the Toba glass sample UT778 was also included in most runs as a secondary monitor of calibration differences, i.e. an in-house standard (Westgate et al., 2013c).

\subsection{Analysis of microshards by electron probe microanalysis}

Another development in the use of EPMA has been the ability to reliably analyze glass shards (or melt inclusions) using a narrow beam only $\sim 5 \mu \mathrm{m}$ in diameter, which is considerably narrower than previously possible (Hayward, 2012; Hall and Hayward, 2014; Pearce et al., 2014b; Kuehn, 2016). Usually a defocussed beam 10-20 $\mu \mathrm{m}$ in diameter, or a rastered beam extending over an area of $5 \times 5 \mu \mathrm{m}$ for example, and moderate beam current, are deployed in EPMA to minimize mobilization of alkalis ( $\mathrm{Na}$ and to a lesser extent $\mathrm{K}$ ) which can lead to underestimation of $\mathrm{Na}$ and $\mathrm{K}$ concentrations and overestimation of $\mathrm{Si}$ and $\mathrm{Al}$ concentrations, especially in glasses that are more siliceous, more alkaline, or more hydrated (Smith and Westgate, 1968; Froggatt, 1983, 1992; Hunt and Hill, 1993; Morgan and London, 1996, 2005; Coulter et al., 2010; Kuehn et al., 2011). The very small sizes of glass shards from distal or ultra-distal deposits, including shards in ice cores, or small melt inclusions (Fig. 1c), often 
necessitate the use of narrow beam diameters. We suggest the term 'microshards', defined as shards $<32 \mu \mathrm{m}$ in diameter (i.e., finer than $5 \mathrm{phi}$ ), is useful here. Shards smaller than $32 \mu \mathrm{m}$, especially those much smaller $(<\sim 10-20 \mu \mathrm{m})$, typically pose the greatest challenges in acquiring sound analyses. Extremely small microshards, $<3 \mu \mathrm{m}$ in diameter, were collected as airborne particles during the Eyjafjallajökull eruption in Iceland in 2010 (Dellino et al., 2012), and Kearns and Buse (2012) stabilised such glasses for analysis by EPMA using a stage cooled by liquid nitrogen. Although Hunt and Hill (2001) showed that reducing beam sizes for EPMA of microshards, or the thin glass vesicle walls within small pumiceous pyroclasts, could lead to unreliable or distorted geochemical analyses and hence potentially invalidate correlations, Hayward (2012) have developed robust protocols that enable the routine use of narrow beam diameters of $5 \mu \mathrm{m}$, and as low as $3 \mu \mathrm{m}$, without loss of Na. The efficacy of this approach was demonstrated by Wastegård and Davies (2009), who applied Hayward's (2012) protocols in their study, and subsequently by others including Pyne-O’Donnell et al. (2012), Abbott et al. (2013), Bourne et al. (2013), Lilja et al. (2013), and Pouget et al. (2014a).

Zander et al. (2013) also demonstrated the routine use of a $\sim 5 \mu \mathrm{m}$ beam and 10 nA current to analyze glass shards. They generally employed a time-varying intensity correction for $\mathrm{Na}, \mathrm{Si}$, and $\mathrm{Al}$ to minimize alkali element migration (with an analysis time for $\mathrm{Na}$ of $30 \mathrm{~s}$ ), and a voltage slightly lower than the typical $15 \mathrm{kV}$ to shrink the 
analysis volume. A $3 \mu \mathrm{m}$ beam diameter was used successfully for microlite-rich basaltic to andesitic glass samples even though results, judging from the use of high-Na standards (Sheep Track and Lipari: Kuehn et al., 2011), were not quite as good as those derived from using a $5 \mu \mathrm{m}$ beam (Zander et al., 2013).

Such a development - the reliable use of narrow beam diameters for glass-shard or melt-inclusion analysis by EPMA - is extremely important generally because $(i)$ it enables many fine-grained samples to be analyzed from more distal geographic locations than previously possible; (ii) it reduces or prevents bias in data collection because most or all shards in a sample set can be analyzed; (iii) it enables more shards that are vesicular or microlite-rich, as occur frequently in andesitic or basaltic tephras (e.g. Clift et al., 2003; Platz et al., 2007; Shane and Zawalna-Geer, 2011), to be analyzed than previously possible; (iv) it enables small melt inclusions to be analyzed (e.g. a $4 \mu \mathrm{m}$ EPMA grid was used by Matsu'ura et al., 2011a, to analyze melt inclusions $7-20 \mu \mathrm{m}$ in diameter); and (v) the acquisition of EPMA data is more easily automated and hence potentially more cost-effective (Hayward, 2012).

Nevertheless, issues of Na migration for some rhyolitic tephras, and those with both sodic and hydrous glass, remain (Hayward, 2012). Possible hazards may arise during analyses in some circumstances, and caution is needed. Firstly, in analyzing very small microshards, typical X-ray matrix corrections assume the sample has an "infinite" lateral and depth extent. At around $5 \mu \mathrm{m}$, this assumption begins to break down, and 
particle geometry starts to become important (Kearns and Buse, 2012). In addition, the volume of material excited by the electron beam may not be fully contained within the sample. Both of these effects can skew the results, and so it is best to proceed carefully. Software exists which can model the interactions and allow the extent of the problem to be examined (e.g. see Casino, Win X-ray, LMS-MC:

http://www.lehigh.edu/ maw3/link/mssoft/mcsim.html). A lower accelerating voltage may be used to shrink the source volume of the X-rays, and analyzing reference material of the same very-fine particle size may also help to make the data more comparable (Pearce et al., 2014b).

Secondly, the fluorescence of secondary X-rays in crystals in close proximity to the glass being analyzed in a microlite-rich shard may lead to an element present in a crystal being over-estimated in the adjoining glass, i.e. it is possible to analyze glass close to a boundary with a microlite and unwittingly generate and acquire X-rays from the (micro)crystal, which becomes significant if the element is at minor to trace concentrations in the glass but at major element concentration in the adjacent (micro)crystal, e.g. Ca in plagioclases in a rhyolitic, low-Ca, glass (Fournelle, 2007; Jerram and Martin, 2008; Reed, 2010, p. 123). However, in basalts (in which crystals are fast-forming), the same elements that constitute common crystals (e.g. Fe, $\mathrm{Mg}$ in olivine; Ca in plagioclase) are also abundant in the associated glass. Shane and Zawalna-Geer (2011) reported that EPMA of randomly selected basaltic glass shards 
from the Mt Wellington volcano in the Auckland Volcanic Field (AVF), New Zealand, showed only limited variation within samples $\left( \pm 1 \mathrm{wt} \% \mathrm{SiO}_{2}\right)$, suggesting that variable microlite formation had limited or little effect on the residue melt. Larger compositional differences such as those between samples from different morphological parts of the Mt Wellington volcano (tuff ring versus main cinder cone) also did not appear to be related to microlite formation because both deposits manifested a similar range in microlite content. Shane and Zawalna-Geer (2011) additionally observed that the microlite variation between shards is greater within some samples than between samples from different sites, and that the compositional differences between deposits were also reflected in the Fe-Ti oxide compositions, hence suggesting magmatic control was via composition and/or intensive parameters, rather than via micro-crystallization.

The problem is greater in andesites and especially in rhyolites, where low concentrations of $\mathrm{Ti}, \mathrm{Fe}, \mathrm{Ca}$, and $\mathrm{Mg}$ could be affected by secondary fluorescence from nearby microlites of Fe-Ti oxides, pyroxenes, amphiboles, or feldspars too small to be detected microscopically or using back-scattered electron (BSE) imagery (see also Allan et al., 2013). Hunt and Hill (2001) examined this phase-boundary effect in detail for eruptives from Hekla volcano in Iceland of 1970, 1980, and 1991, and showed that hybrid analyses may be encountered in glass fragments containing micron-sized microlites of feldspar. One of the authors (Stephen Kuehn) has begun using quick (30 sec to $1 \mathrm{~min}$ ) X-ray maps of microlite-rich shards to help avoid microcrystals that are 
not always clearly visible in BSE images because of low contrast (although X-ray mapping if prolonged can cause $\mathrm{Na}$ mobilization in the glass). BSE contrast relates to the average atomic mass, $\mathrm{Z}$, of the target, and in some cases minerals may have a very similar average $\mathrm{Z}$ to that of their host. The availability of silicon-drift detector-based energy-dispersive X-ray spectrometers with large detectors that can collect many X-rays quickly has made this test feasible. X-ray maps also reflect the contents of the full X-ray analytical volume whereas the BSE images reflect a smaller/shallower volume.

Consequently, X-ray maps help in two ways: $(i)$ overcoming potential low (BSE) contrast between some microlite and glass compositions, and (ii), by sampling the full volume, include microlites just below the surface, or deeper, that can be missed by BSE imaging. Calcium and aluminium maps are useful for highlighting plagioclase crystals which can have BSE intensities that are very close to those of intermediate (andesitic) matrix glasses. In tephras lacking mica or sanidine, potassium maps tend to highlight the glass because $\mathrm{K}$ concentrates in the glass. Olivines, pyroxenes, and Fe-Ti oxides generally are easy to spot with the BSE imaging alone (ideally using a low current, such as $1 \mathrm{nA}$, to prevent Na mobilization in glass).

Platz et al. (2007) developed an evaluation procedure using least-squares mixing calculations based on bivariate oxide diagrams, comprising a compatible and an incompatible oxide of the most common groundmass mineral phase (plagioclase in this case) to classify andesitic glass data sets for hybrid analyses impacted by the presence 
of microlites, and to estimate the proportions of the main contaminant microlite phase (e.g. via bivariate plots of $\mathrm{Al}_{2} \mathrm{O}_{3}$ vs $\mathrm{FeO}_{t}, \mathrm{SiO}_{2}$ vs $\mathrm{K}_{2} \mathrm{O}$, and $\mathrm{K}_{2} \mathrm{O}$ vs $\mathrm{Na}_{2} \mathrm{O}$ : Platz et al., 2007; Karátson et al., 2016). These and other authors (e.g. Damaschke et al., 2017a) imply the need for 'sensible' error analysis of glass microprobe data, and that outliers not able to be explained as glass/mineral mixtures should be removed from the database because they contribute needlessly to large variations in glass compositional datasets. Such 'error analysis' uses prior expert knowledge - for example, knowing from previous assays that anomalously high $\mathrm{Al}$ and $\mathrm{Ca}$ levels suggest a glass/plagioclase mixture - to help inform data acquisition and quality.

Thirdly, analyses from melt inclusions must be interpreted cautiously. Although some studies show that the glass inclusion analyses tend to mirror those of matrix glasses or loose glass shards, as demonstrated for some tephras in New Zealand and Japan (Horrocks, 2000; Shane et al., 2005b; Matsu'ura et al., 2011a) (Fig. 3), others show that glass inclusion analyses may not reflect the full compositional range of matrix glasses or shards (e.g. Shane et al., 2007, 2008b, 2008c; Chesner and Luhr, 2010; Allan et al., 2013), or they may show a different pattern from that associated with matrix (groundmass) glass analyses (e.g. Kilgour et al., 2013; Neave et al., 2015). Such a mismatch may arise because melt inclusion glass is older (i.e. derived from magma trapped during crystal growth at some time before the final eruption of a magmatic cycle) and thus generally less evolved (more primitive) than the glass that is erupted as 
shards, or because the host crystals are xenocrysts (wholly or partly foreign crystals) or antecrysts (recycled crystals from earlier cycles of the same magmatic system) incorporated in an eruption.

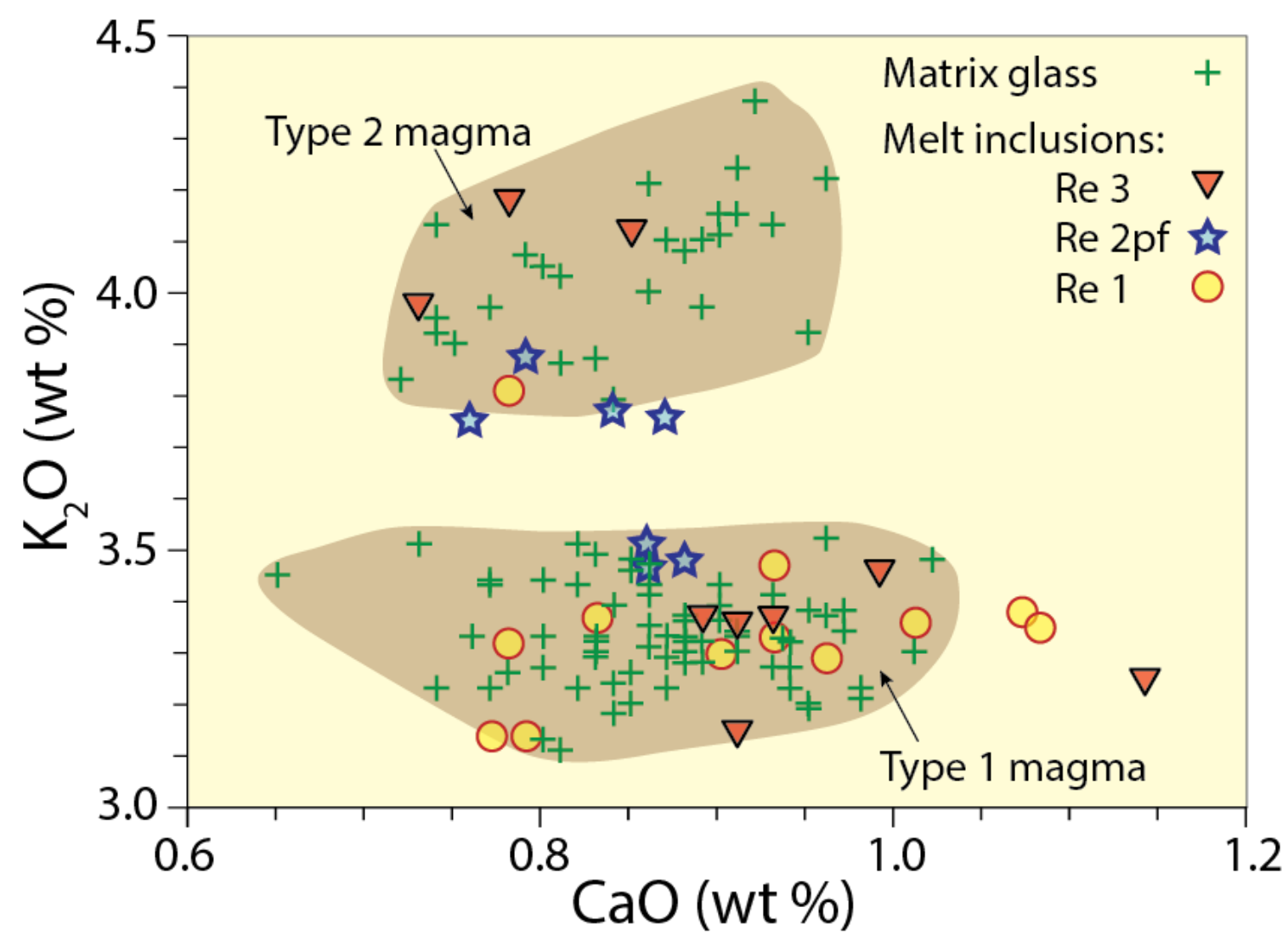

Fig. 3. Comparison of bivariate analyses $\left(\mathrm{K}_{2} \mathrm{O} v s \mathrm{CaO}\right.$ in wt \%) of individual melt inclusions in quartz with analyses of matrix glass and shards from the same Rotoiti eruptives in northern New Zealand (redrawn from Shane et al., 2005b, p. 300). Samples Re1, Re2pf (from pyroclastic flow deposits), and Re3 represent early to late pyroclastic eruptives, respectively, in the Rotoiti tephra sequence. Composition fields of type 1 and type 2 magmas (defined in Shane et al., 2005b) are also shown. Matrix glass fields are shaded for clarity. 
Analysis using such highly focussed beams requires the use of extremely low beam currents, 0.5 to $2 \mathrm{nA}$, for measurement of alkalis, Si, and Al. Such analyses are thus best facilitated with a microprobe equipped with four or, ideally, five wavelengthdispersive spectrometers, a large TAP analysing crystal for maximum Na sensitivity, and the ability to measure at two or three different beam currents during each analysis both to prevent $\mathrm{Na}$ loss and to provide adequate count rates for good analytical precision for other elements (Hayward, 2012). We note here that in some circumstances, a time-varying-intensity correction approach with the appropriate automation software (e.g. Cameca PeakSight or Probe for EPMA) can be used successfully, even on older microprobes which cannot run multiple currents and which do not have large analyzing crystals (Kuehn, 2016). This approach can allow higher currents and longer $\mathrm{Na}$ analysis times than would otherwise be possible on such instruments (see also Zander et al., 2013).

\subsection{Normalizing electron probe microanalysis-derived glass analyses}

EPMA-derived glass analyses typically are normalized to a volatile-free basis i.e. re-calculated to sum to $100 \%$, most of the deficit being attributable to water (both primary magmatic and secondary) - to avoid the effects of variable post-depositional 
hydration and to enable valid comparison of analyses for tephra deposits from different environments (Allan et al., 2008; Pearce et al., 2008a, 2014; Lowe, 2011). Water content can be estimated in various ways including EPMA, ion probe, and Fouriertransform infrared spectroscopy (e.g. Froggatt, 1983; Nash, 1992; Dunbar and Kyle, 1993; Devine et al., 1995; Clift et al., 2003; Humphreys et al., 2006; Chesner and Luhr, 2010; Kearns and Buse, 2012; Kilgour et al., 2013). However, the need for normalization has been disputed because any analytical deficit (below a total of $100 \%$ ) is not entirely attributable to water. Instead the deficit may be the result of spectrometer drift, charging, or mobilization of a specific element (Hunt and Hill, 1993; Pollard et al., 2006), the omission of volatile and trace elements from the analysis (e.g. Mn, P, Cl, F, S), the lack of a correction for the substitution of halogens for oxygen, poor sample positioning during analysis (both horizontal and vertical focus), and the penetration of the beam through thin shards (Kuehn et al., 2011). The incorrect or incomplete assignment of $\mathrm{Fe}$ to its variable oxidation states (e.g. assuming all $\mathrm{Fe}$ is $\mathrm{FeO}$ ) may also be problematic, particularly in mafic tephras with higher Fe concentrations. Surface roughness from imperfect polishing can also reduce analytical totals (Shane et al., 2005b; Platz et al., 2007). If a loss of alkalis occurs then Si and Al concentrations especially may be artificially inflated. Side-by-side EPMA analyses, however, would overcome many of the (analytical) problems described above, and issues such as differences in redox state of elements such as Fe (e.g. Brown et al., 1992) would be 
minimized in the analysis of similar materials. Once datasets are normalized then it has been argued that statistical treatments of data are compromised because they fail to take into account the condition that the relative abundances of the measured oxides sum to $100 \%$ (Aitchison, 1982; Pouget et al., 2014a).

In contrast, others maintain that normalization is very helpful if not essential (e.g. Sarna-Wojcicki and Davis, 1991; Froggatt, 1992; Shane, 2000; Allan et al., 2008; Pearce et al., 2008a; Shane et al., 2008c; Preece et al., 2011a; Coulter et al., 2012; Smith et al., 2013; Westgate et al., 2013b, 2014; Mackay et al., 2016), especially for marine tephras according to Albert et al. (2012) and Pearce et al. (2014b) (cf. Salisbury et al., 2012). Normalization results in consistent elemental abundances, suggesting that the water is accommodated within the glass structure without chemical alteration, and in much tighter clustering of the analyses for each sample with outliers more readily seen (Pearce et al., 2008a). This contention is supported by EPMA analyses (with defocussed beam and low beam current) undertaken by Nairn et al. (2004) of rhyolitic melt inclusions completely encased in uncracked quartz in Kaharoa pyroclastic eruptives in New Zealand. They argued that the water totals in such completely-sealed melt inclusions, between $\sim 6.1$ and $\sim 6.5 \mathrm{wt} \%$, must represent the primary, dissolved $\mathrm{H}_{2} \mathrm{O}$ content of the magma prior to eruption. We also record that the total alkalis-silica classification must be undertaken on analyses normalized to an anhydrous basis (Le Maitre, 2002). 
For these reasons, we support this latter view that normalization is useful although we recognise the theoretical objections - and follow the rationale advocated by Baxter $(2008,2016)$ that it is usually better to work pragmatically with an 'incorrect' method that on the whole produces fruitful results rather than a 'correct' method that is less consistently useful in answering research questions. To support this argument, Baxter (2008, p. 976) drew an analogy with single-linkage cluster analysis (described later):

"According to some accounts, this is one of the few theoretically sound methods of cluster analysis available (it satisfies theoretically prescribed desiderata). It is used very little in archaeometry because the results produced are often uninterpretable, unless the data structure is so obvious that any sensible method would reveal it".

Normalizing or not seems to make little difference to the outcome of statistical applications for correlation in studies where it has been evaluated (e.g. Stokes and Lowe, 1988; Charman and Grattan, 1999; Tryon et al., 2009, 2010). In any event, Kuehn et al. (2011) recommended that all acquired compositional data, including the analytical totals, should be published. For all cases, these totals should therefore be listed, either as 'raw' non-normalized data or given as the difference between the 
original totals and $100 \%$ (typically expressed as 'water by difference') (Froggatt, 1992). Publishing the original totals or 'water' amounts allows the non-normalized results to be reconstituted if necessary (rather like reporting conventional radiocarbon ages as well as calibrated ages because the former do not change when new calibration curves are published). One good approach has been to present normalized data (always identified as such) in tables and figures in the text of a paper and to include raw compositional data in supplementary materials (e.g. Smith et al., 2013; Hopkins et al., 2017).

Pouget et al. (2014a) suggested that plotting ratios of oxides in bivariate plots, rather than plotting normalized oxide data, would overcome the need for the relative abundances of major oxides to sum to $100 \%$. We think that this approach complicates the simplicity of a two-oxide scatterplot for little gain, but if it is utilised then we generally agree with the suggestion to use (for example) $\mathrm{K}_{2} \mathrm{O}$ as a divisor for basaltic tephras. This oxide is appropriate for such compositions because it is incompatible, meaning that it concentrates in the glass, and hence the ensuing ratios are much less affected than would be the case if a divisor with low abundance were used (such an oxide with low abundance as a divisor would generate very large and variable ratios, and the ensuing ratio values would excessively reflect the divisor oxide). However, in more evolved eruptives (dacites, trachytes, rhyolites, phonolites), $\mathrm{K}_{2} \mathrm{O}$ is compatible in the alkali feldspars (and biotites) that typically form in these and so would not normally 
be an appropriate divisor. Another option is $\mathrm{Al}_{2} \mathrm{O}_{3}$, which varies in abundance much less than most other elements across the spectrum from mafic to felsic compositions, and so patterns on plots involving $\mathrm{Al}_{2} \mathrm{O}_{3}$ would be more similar to the plots of normalized data to which many are accustomed. Additionally, $\mathrm{Al}$ is often the second-most abundant metal after $\mathrm{Si}$ and therefore is analysed with high precision. Using $\mathrm{Al}_{2} \mathrm{O}_{3}$ as a divisor might also help highlight mixed glass-feldspar analyses.

\section{Advances in laser ablation inductively coupled plasma-mass spectrometric analysis of glass}

\subsection{Advantages of trace-element analyses of glass}

Although the recent advances in EPMA have enabled quite subtle differences in glass major-element compositions to be detected accurately and precisely (and on much smaller shards than it was possible to analyze before), there remain instances where individual tephra layers may not be distinguishable uniquely by glass-based major elements alone. In these cases, other analytical methods are needed (Fig. 4). Trace element analyses of glass separates from tephra deposits offer a greater range of elements to be used in correlation studies, and can also provide additional information 
on petrogenesis as well as provenance. Allan et al. (2008) for example found the most useful elements for correlating and distinguishing between 70 tephras $(<1.65 \mathrm{Ma})$ preserved in cores from Ocean Drilling Program Site 1123 (in the southwest Pacific Ocean $\sim 1200 \mathrm{~km}$ east of New Zealand) to be the abundances of Rb, Ba, Sr, Y, Zr, Hf, $\mathrm{Mg}, \mathrm{Mn}$, and Ti, along with trace element ratios such as $\mathrm{Rb} / \mathrm{Sr}, \mathrm{Ba} / \mathrm{Sr}, \mathrm{Zr} / \mathrm{Y}, \mathrm{Y} / \mathrm{Th}$, $\mathrm{Ba} / \mathrm{Th}$, and $\mathrm{Rb} / \mathrm{Sm}$. Based on trace element data acquired for glass shards using LAICP-MS, Allan et al. (2008) illustrated how two stratigraphically adjacent tephras with similar major element compositions were easily distinguishable (Fig. 4). They also used glass trace element data to show that two confusing sections of the cores $1123 \mathrm{~A}(\sim 4.5 \mathrm{~m}$ long) and 1123C ( 7.9 $\mathrm{m}$ long), unable to be resolved by visual inspection, nor from the glass major element data, had been repeated (possibly by a localised sedimentary slide) (Allan et al., 2008). 

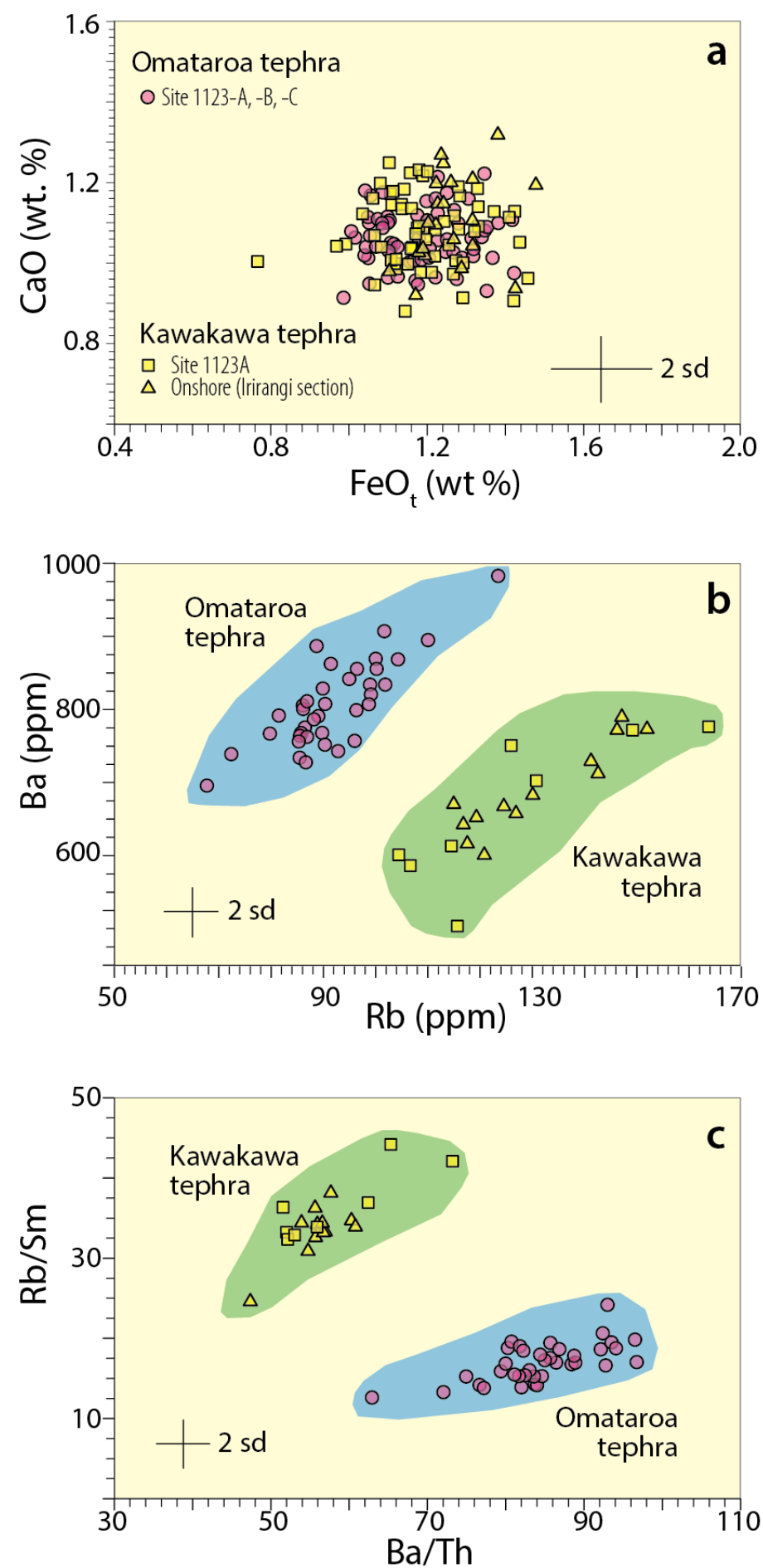
Fig. 4. Bivariate plots for selected major and trace elements derived from analyses of individual glass shards from two New Zealand tephras, Omataroa ( 31.6 cal. ka, erupted from Okataina Volcanic Centre, pink circles) and Kawakawa ( 25.4 cal. ka, erupted from Taupo Volcanic Centre, yellow squares and triangles), identified in marine cores A, B, and C from ODP Site 1123, which is $\sim 1200 \mathrm{~km}$ east of New Zealand (from Lowe and Alloway, 2015, p. 792, redrawn from Allan et al., 2008, p. 2351). (a) CaO vs $\mathrm{FeO}_{\mathrm{t}}$ (total iron expressed as $\mathrm{FeO}$ ) derived by EPMA. Glass analyses from an on-shore occurrence of Kawakawa tephra (at Irirangi) are also shown for comparison. The plot shows ( $i$ ) that the analyses of glass from marine and on-shore samples of Kawakawa tephra are the same, and (ii) that Kawakawa and Omataroa tephras cannot be distinguished using these two oxides alone ( $c f$. Fig. 13). In contrast, trace element concentrations (in ppm), derived by LA-ICP-MS, in (b) and (c), show that the tephras are distinctly different with respect to these elements/element ratios. The trace-element analyses for glasses of Kawakawa tephra from the marine samples (yellow squares) and on-shore samples (yellow triangles) are the same. Fields are shaded for clarity.

Similarly, Westgate et al. (2013c) and Pearce et al. (2014a) showed that all three Toba tuffs (erupted from the Toba caldera complex of northern Sumatra) can be readily recognized by their glass trace element compositions, but not the major elements which are essentially uniform. Strontium, Ba, and Y were identified as the best discriminators. This finding contrasts with that of Smith et al. (2011), who suggested, from a more limited set of data, that the major and trace element compositions of glass shards could not be used to distinguish between the Youngest Toba Tuff tephra (YTT, 75 ka), the Middle Toba Tuff (MTT, 500 ka), and the Oldest Toba Tuff (OTT, 800 ka); instead, Smith et al. (2011) used biotite compositions which allow these three major eruptive units to be distinguished. The revelation by Westgate et al. (2013c) of four primary glass populations (initially termed I-IV), with the recognition of a fifth population (termed IVa and IVb) by Pearce et al. (2014a), in the YTT using trace elements enables 
the tephra to be easily and reliably recognised across its very wide fallout zone: within each glass population, trace element variations are broadly consistent with the fractional crystallization of phenocryst phases observed within YTT, and the variations between the average glass compositions for individual populations mirror bulk pumice compositional data, also suggesting that magmatic evolution was dominated by fractional crystallization (Westgate et al., 2013c; see also Chesner and Luhr, 2010).

Until relatively recently, the trace element analysis of glass required the separation typically of between $0.1 \mathrm{~g}$ and $10 \mathrm{~g}$ of 'pure' glass for bulk analysis by XRF, INAA, or SN-ICP-MS or ICP-AES (Table 1), although Pearce et al. (2004a) and Knott et al. (2007) successfully analyzed separates as small as $\sim 0.03 \mathrm{~g}$ for SN-ICP-MS. It is only in the last $\sim 15$ years that trace element techniques with spatial resolutions comparable to those of EPMA have become more common, the most widely available of these being LA-ICP-MS (Pearce et al., 2004a, 2007, 2011; Tomlinson et al., 2010; Jenner and O’Neil, 2012; Pearce, 2014). This method, which is relatively inexpensive compared with others such as the ion probe, is now being used widely (e.g. Harangi et al., 2005; Ukstins Peate et al., 2008; Preece et al., 2011b; Albert et al., 2012; Ponomareva et al., 2013; Westgate et al., 2013c; Tomlinson et al., 2015). In the analysis of individual glass shards, around 200 individual grains can be analyzed for about 30 trace elements in the course of a typical day in an LA-ICP-MS laboratory. 
Although Pearce et al. (2007) demonstrated the broad similarity of analyses of trace elements in glass (from the Santorini and Aniakchak eruptions) derived using three different methods, namely LA-ICP-MS, solution ICP-MS, and the ion probe, subtle differences in elements associated with phenocrysts of plagioclase not removed completely from the bulk sample were evident (e.g. Sr; see also Pearce et al., 2002). Depending on microlite loading in the glass, which can be detected using microbeam analyses (see Pearce, 2014), comparison of results from bulk analyses of glass concentrates with those from microbeam analyses of the pure glass phase can be fraught with problems, and thus concentrations in glass from tephra beds obtained using one method do not necessarily compare well with analyses using others (see, for example, Pearce et al., 2002). Consequently, trace element data should be compared directly only when they are produced by analysis of the same type of material, i.e. compare bulk sample analyses with data from other bulk methods, or compare only microbeam data. In some cases, ratios of highly incompatible elements may compare between bulk and microbeam analyses (e.g. Martin Jones et al., 2017), but care needs to be exercised in mixing data acquired by different methods.

Before describing the preparation of samples and functioning of LA-ICP-MS, we note that it is possible to analyze trace elements in glass down to $\sim 100 \mathrm{ppm}$ routinely with EPMA although this is slow. It is envisaged that by using analytical routines specifically designed for trace element work, it should be feasible to evaluate some of 
the more abundant trace elements (several hundred ppm) by EPMA with enough precision to be potentially useful in tephrochronology. Such methods are currently being developed by one of the authors (Stephen Kuehn) using USGS reference glasses, and good results have been attained thus far for $\mathrm{Ba}, \mathrm{V}, \mathrm{Cr}, \mathrm{Co}, \mathrm{Ni}$, and $\mathrm{S}$, where analyses of Ba by EPMA, for example, would be sufficient to discriminate between the Toba tephra deposits.

\subsection{Glass sample preparation and analysis by LA-ICP-MS}

To undertake LA-ICP-MS, cleaned and picked glass shards, mounted, polished, carbon coated, and analyzed previously by EPMA, are placed in the ablation chamber of the laser system and, by using annotated images (maps) acquired during the EPMA analysis, or an $x-y$ coordinate system (see below), the same shards can be relocated on the sample mount for analysis by LA-ICP-MS (Pearce et al., 2007, 2011; Lowe, 2011; Pearce, 2014). Using three reference points marked onto mounts enables such relocations to be undertaken accurately using a spreadsheet developed by Kuehn and Froese (2010) that is based on the coordinate transform mathematics described by Admon et al. (2005) (the spreadsheet is available from Stephen Kuehn on request, or at Kuehn, 2017). The spreadsheet takes as input the $x$-y stage coordinates of the three reference positions measured on the source and the target instrument and the grain 
(glass shard) coordinates from the source instruments. Pearce et al. (2011) advocated that such referencing be adopted as a matter of routine during the EPMA analysis of glass shards so that if the need arises for trace element analyses by LA-ICP-MS, then the same shards can be relocated and analyzed without recourse to further EPMA analyses. Alternatively, BSE (or other appropriate high resolution) images of each grain or mount could be acquired and marked to show the location of individual analyses so that closely-adjacent sites could be re-analyzed for trace element content by LA-ICPMS (e.g. Allan et al., 2008). Note that ideally the same spot should not be analyzed by EPMA and LA-ICP-MS because of the risk of damage to the glass by electron beam radiation (Pearce et al., 2014b), but for small shards this risk is impossible to avoid.

Calibration of analyses in LA-ICP-MS requires the knowledge of one element (usually determined by EPMA) in the sample to act as an internal standard. Pearce et al. (2007) suggested that preferaby analyses would be undertaken using both $\mathrm{Si}$ and $\mathrm{Ca}$ as internal standards for different elements, but recognized that generally low concentrations of $\mathrm{Ca}$ in rhyolitic glasses (often $<1 \mathrm{wt} \%$ ) usually make it unsuitable as an internal standard (Pearce, 2014). Hence Si is normally the first choice (see below). The use of an internal standard accounts for any variation in the amount of ablated material reaching the plasma (the 'ablation yield') between samples and calibration standards, and any differences in concentration of the internal standard are corrected during the calculation of concentrations (Pearce et al., 2007; Pearce, 2014). 
As with use of the microprobe, there is a possibility of microlites affecting trace element characterizations of individual shards via LA-ICP-MS, especially as the volume analyzed during LA-ICP-MS is considerably larger than that used for EPMA (Pearce et al., 2011; Abbott et al., 2013; Pearce, 2014). Consequently, it could be appropriate to use LA-ICP-MS data determined from shards outlying the main major element geochemical population to check for anomalous elemental concentrations (e.g. high $\mathrm{Sr}$ from a feldspar inclusion) and the possibility that a microlite had contributed to the $\mathrm{X}$ ray signal during the EPMA. Abbott et al. (2013) suggested that any such 'analytical' outliers so identified should be excluded from further analysis and the reasons for exclusion documented, as advocated earlier for microprobe data. Ideally, complete results, including outliers, with analysis-by-analysis comments as needed, could be published in supplementary data files.

\subsection{Analysis of microshards by LA-ICP-MS}

The most recent advances in LA-ICP-MS have been driven by the need and desire to analyze small grains of glass $<32 \mu \mathrm{m}$ in diameter (microshards) from distal localities, including ice cores, using ablation craters of $20 \mu \mathrm{m}, 10 \mu \mathrm{m}$, or smaller (Fig. 5; Pearce et al., 2011; Pearce, 2014). As ablation crater sizes become smaller, however, issues surrounding instrumental blanks, calibration, and possible matrix effects become 
more significant. Developments in laser ablation systems, such as the move to deep UV wavelengths (for instance $193 \mathrm{~nm}$ Excimer lasers), and increases in ICP-MS sensitivity, allow current LA-ICP-MS systems to achieve detection limits below parts per million for most trace elements of petrogenetic significance from craters well below $20 \mu \mathrm{m}$ in diameter.

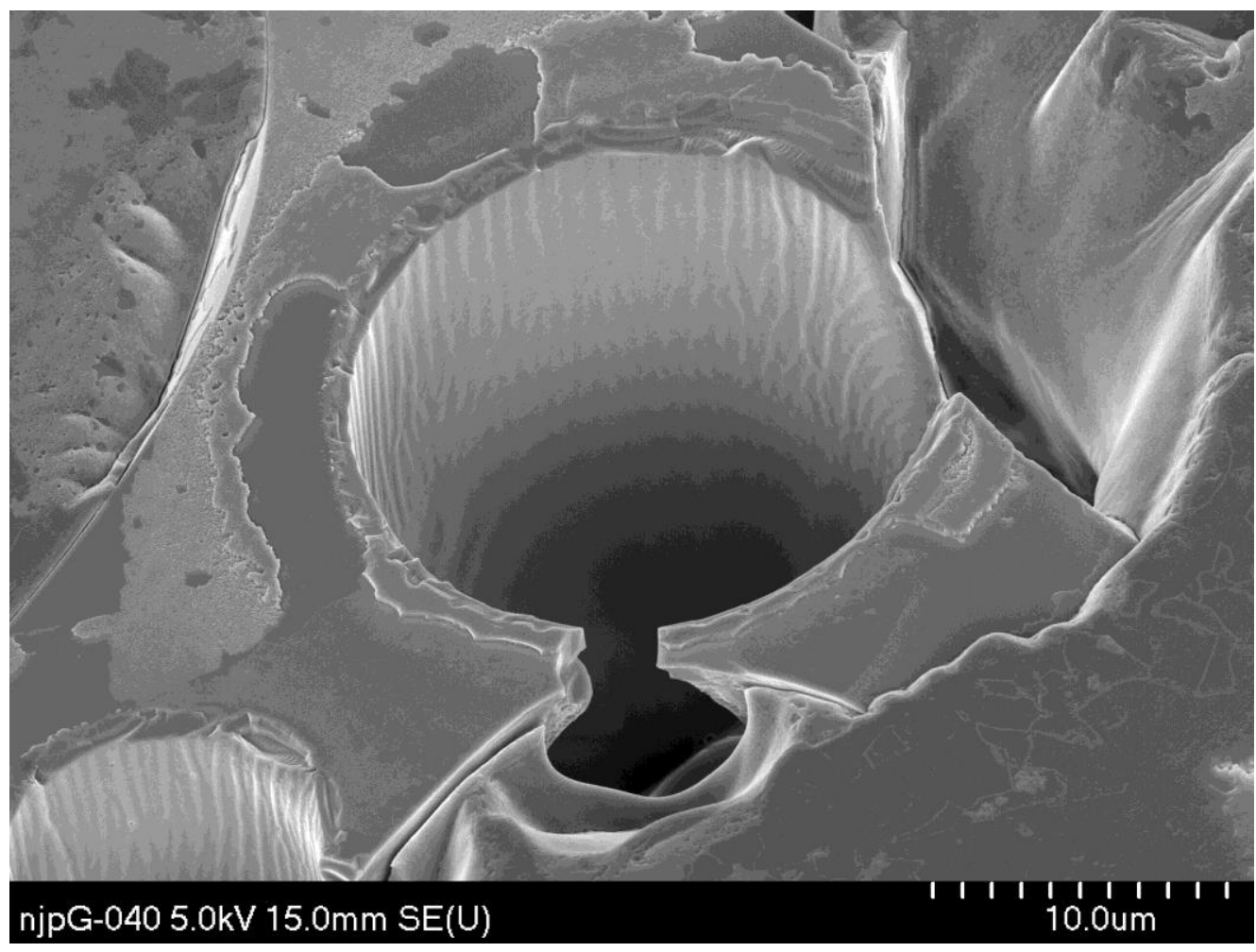

Fig. 5. Laser-induced 'craters', one $\sim 20 \mu \mathrm{m}$ in diameter (in middle of shard) and another $\sim 10 \mu \mathrm{m}$ in diameter (visible in part at bottom left), in a glass shard derived from the Minoan eruption deposit on Santorini, Greece. The craters were formed during LAICP-MS analysis at Aberystwyth University using a Coherent GeoLas 193nm ArF Excimer laser ablation system (see Pearce et al., 2002, 2011). 
By way of comparison, detection limits of $<1 \mathrm{ppm}$ from $40 \mu \mathrm{m}$ craters were attained previously by Pearce et al. (2004a, 2007) using $266 \mathrm{~nm}$ laser systems and older ICP-MS systems. Pearce et al. (2011) and Pearce (2014) have now shown that LA-ICPMS systems can produce ablation craters as small as $4 \mu \mathrm{m}$, and that analyses of individual glass shards with crater diameters of $20 \mu \mathrm{m}$ and $10 \mu \mathrm{m}$ are essentially routine, with good accuracy measured from reference materials, provided account is taken of issues related to elemental fractionation at such small crater diameters. Element fractionation is likely to differ from instrument to instrument because this is an issue related to laser-sample interaction, and needs to be assessed in each laboratory by the use of appropriate reference materials. Analytical precision varies with element concentration and crater diameter, being around $\pm 15-30 \%$ at $1 \mathrm{ppm}$ and around \pm $2-3 \%$ at 500 ppm from a $10 \mu \mathrm{m}$ ablation crater. Lower limits of detection are below 1 ppm for most petrogenetically significant elements from $10 \mu \mathrm{m}$ craters, when $25-28$ trace elements are determined in a 20-second analysis (Pearce et al., 2011). Again, being instrumentation based, these measures are likely to vary from laboratory to laboratory.

Neither ${ }^{44} \mathrm{Ca}$ nor ${ }^{43} \mathrm{Ca}$ can be used reliably as the internal standard for the analysis of rhyolitic (Si-rich) glasses at 10 or $20 \mu \mathrm{m}$ because $\mathrm{CaO}$ (at $\sim 1$ wt $\%$ ) is close to the lower limit of quantitation (LLQ), and has some fractionation problems in rhyolites, hence Si must be used, although either element could be used in the analysis 
of basaltic (Si-poor) or andesitic glasses at 10 or $20 \mu \mathrm{m}$ (Pearce et al., 2014b). The use of $\mathrm{Si}$ as the internal standard in LA-ICP-MS also allows the accidental ablation of phenocrystic material to be identified more readily than when $\mathrm{Ca}$ is used, particularly in rhyolites where the majority of phenocrysts encountered are Ca-rich. The increase in $\mathrm{Sr}$ when a plagioclase is ablated is useful to indicate that the analysis has been contaminated by a mineral inclusion, but using $\mathrm{Ca}$ as the internal standard (also high in the plagioclase) can cause the $\mathrm{Sr} / \mathrm{Ca}$ ratio to decrease, and hide the increase in $\mathrm{Sr}$ in the analysis. This is not seen using $\mathrm{Si}$ as the internal standard which would report both high $\mathrm{Sr}$ and $\mathrm{Ca}$, and identify ablation of the plagioclase grains (Pearce, 2014). With analyses at $6 \mu \mathrm{m}$ or $4 \mu \mathrm{m}$, many of the most abundant trace elements remain above the LLQ (e.g. in rhyolitic glasses these include $\mathrm{Zr}$, Ba, light rare earth elements [LREEs], $\mathrm{Y}, \mathrm{Rb}, \mathrm{U}$, Th), but even in basic or intermediate glasses only Si can be used as the internal standard because Ca concentrations (and thus counts) are too low to be quantified (Pearce et al., 2011). Hence, in most analyses, $\mathrm{SiO}_{2}$ (determined by EPMA) is used to calibrate each analysis, and for comparison with the EPMA data, the Si concentration is normalised to an anhydrous basis (Pearce et al., 2011; Westgate et al., 2013c; Pearce, 2014). With likely future improvements in ICP-MS sensitivity, some of these problems may become resolved.

Element fractionation (using the $193 \mathrm{~nm}$ Excimer laser as applied by author Nick Pearce) is an issue for ablation craters $\sim 30 \mu \mathrm{m}$ in diameter, becoming increasingly 
problematic in small $(<10 \mu \mathrm{m})$ craters, because the volume of a thin film of melt which forms on the walls of the crater becomes an increasingly significant proportion of the volume of the ablated material (Pearce et al., 2011; see also Sylvester, 2008). The surface area/volume ratio of the ablated crater increases as crater diameters become smaller, and element retention or volatility from this film of melt formed on the crater walls appears to cause much of the fractionation. The initial studies of Pearce et al. (2011) suggested that, for many elements, there seems to be a systematic variation in the degree of fractionation with the degree of polymerisation of the glass and thus melt film, which is in turn related to the glass composition (see also Westgate et al., 2013c). This systematic behaviour, however, offers the possibility for the analysis of a selection of abundant trace elements in individual shards of glass using ablation craters of $6 \mu \mathrm{m}$ and $4 \mu \mathrm{m}$ in diameter (Pearce et al., 2011). Lasers with shorter pulse lengths in the femtosecond (fs) rather than nanosecond (ns) range offer the promise of analyses with less elemental fractionation (e.g. see Borisova et al., 2010; Maruyama et al., 2016b), but currently these are less widely available than solid-state or Excimer UV or deep-UV lasers.

Thus, in summary, the LA-ICP-MS technique provides an efficient, accurate, and appropriately precise method for determining abundances of a wide variety of trace elements including REEs at low concentrations in individual glass shards with ablation craters as small as $10 \mu \mathrm{m}$ in diameter. We note here that some laboratories are now 
using LA-ICP-MS to analyse some major elements along with trace elements (e.g. Maruyama et al., 2017). Currently the precision of LA-ICP-MS major element analyses is worse than that for EPMA, although accuracies for many (but not all) elements are comparable, and these factors would have an impact on the utility of such major element determinations in tephra correlation studies. For the smaller crater sizes the physical process of ablation causes elemental fractionation although that may be correctable where it is consistent. Such advances in spatial resolution and sensitivity make it possible generally now to fingerprint fine-grained glass in tephra or cryptotephra deposits using a full suite of major-, minor-, and trace-element data, and will greatly extend the range over which correlation of tephras potentially can be undertaken.

As with EPMA, to avoid any possible differences in trace element microbeam analyses it may be advantageous to perform side-by-side analyses of potential tephra correlatives to provide the most robust comparisons. These differences may be instrumental between different wavelength laser ablation systems where fractionation may differ and/or be corrected for different internal standard choices and spatial resolution, which may both have an impact associated with microlite contamination (Pearce, 2014), or simply possible minor day-to-day sensitivity, blank, and calibration differences which may have a slight impact on data quality. Trace element analyses also provide key information about magmatic setting, and thus can point towards likely 
source volcanoes of tephras, as well as enabling multiple compositional modes (heterogeneities) within populations of shards from individual tephra beds to be identified and evaluated.

A guide to the main issues in undertaking major- and trace-element analyses of microshards by EPMA and LA-ICP-MS, and the main indicators of, and solutions to, the issues as discussed in previous sections, is summarised in Table 2. 
Table 2. Quick guide to the main issues, indicators, and possible approaches for successful analysis of glass microshards $(<32 \mu \mathrm{m})$ using EPMA or LA-ICP-MS.

\begin{tabular}{|c|c|c|c|}
\hline Analytical issues & $\begin{array}{c}\text { Indicators } \\
\text { (observations) }\end{array}$ & Approaches & $\begin{array}{l}\text { Subsection } \\
\text { (s) and key } \\
\text { references }^{\mathrm{a}} \\
\end{array}$ \\
\hline \multicolumn{4}{|c|}{ EPMA (Section 3 of text) } \\
\hline Alkali mobilisation & $\begin{array}{l}\text { Underestimated } \mathrm{Na} \text { and } \mathrm{K} \\
\text { concentrations; inflated } \\
\mathrm{Si} \text { and } \mathrm{Al}(\mathrm{K} \text { can also be } \\
\text { inflated in some cases) }\end{array}$ & $\begin{array}{l}\text { Narrow beam diameter and } \\
\text { low currents; time-varying } \\
\text { intensity corrections, slightly } \\
\text { lower accelerating voltage }\end{array}$ & $\begin{array}{l}\mathbf{s 3 . 2} \\
2,3,7,15, \\
20\end{array}$ \\
\hline $\begin{array}{l}\text { Shard size and thickness } \\
\text { (geometry) too small to } \\
\text { accommodate X-ray- } \\
\text { generated volume }\end{array}$ & Irregular and low totals & $\begin{array}{l}\text { Reduce accelerating voltage; } \\
\text { select largest area available } \\
\text { for analysis; analyse reference } \\
\text { material of same small size }\end{array}$ & $\begin{array}{l}\mathbf{s 3 . 2} \\
6,15\end{array}$ \\
\hline $\begin{array}{l}\text { Microlite-rich shards } \\
\text { (fluorescence of } \\
\text { secondary X-rays in } \\
\text { crystals) }\end{array}$ & $\begin{array}{l}\text { Overestimation of } \\
\text { elements in glass } \\
\text { adjoining crystals or } \\
\text { microcrysts }\end{array}$ & $\begin{array}{l}\text { e.g. Bivariate plots of certain } \\
\text { elements show impact of } \\
\text { microlites (e.g. high } \mathrm{Al} \text { and } \\
\text { Ca levels indicate } \\
\text { plagioclase); back-scattered } \\
\text { electron (BSE) images at low } \\
\text { current, possibly quick X-ray } \\
\text { maps (avoid Na mobilisation) }\end{array}$ & $\begin{array}{l}\mathbf{s 3 . 2} \\
4,15,16\end{array}$ \\
\hline $\begin{array}{l}\text { Calibration, accuracy, } \\
\text { precision, instrumental } \\
\text { drift }\end{array}$ & & $\begin{array}{l}\text { Reference or secondary } \\
\text { standard analysis; side-by- } \\
\text { side analysis of unknown and } \\
\text { reference tephra sample }\end{array}$ & $\begin{array}{l}\mathbf{s 3 . 1} \\
5,7,17,19\end{array}$ \\
\hline \multicolumn{4}{|c|}{ LA-ICP-MS (Section 4 of text) } \\
\hline $\begin{array}{l}\text { Elemental fractionation: } \\
\text { hardware specific issues }\end{array}$ & $\begin{array}{l}\text { Non-stoichiometric } \\
\text { removal of elements from } \\
\text { glass. Worse at longer } \\
\text { pulse lengths and longer } \\
\text { wavelenghths }\end{array}$ & $\begin{array}{l}\text { Analyse appropriate matrix } \\
\text { matched reference material }\end{array}$ & $\begin{array}{l}4.3 \\
14\end{array}$ \\
\hline $\begin{array}{l}\text { Elemental fractionation: } \\
\text { analytical } \\
\text { considerations }\end{array}$ & $\begin{array}{l}\text { Worse with smaller } \\
\text { craters (and thus smaller } \\
\text { shards) }\end{array}$ & $\begin{array}{l}\text { Optimise method (sensitivity, } \\
\text { crater size, fluence etc) and } \\
\text { use consistent analytical } \\
\text { rationale. Side-by-side } \\
\text { analyses }\end{array}$ & $\begin{array}{l}\mathbf{s} .3 \\
14,19\end{array}$ \\
\hline $\begin{array}{l}\text { Choice of internal } \\
\text { standard (IS) }\end{array}$ & $\begin{array}{l}\text { Usually Si or Ca (if using } \\
\text { NIST } 61 \mathrm{x} \text { glasses), other } \\
\text { major elements possible } \\
\text { if using other calibration } \\
\text { standards (e.g. Fe) }\end{array}$ & $\begin{array}{l}\text { Depends on instrument } \\
\text { detection limits, usually Si for } \\
\text { rhyolites, } \mathrm{Si} \text { or Ca for basalts } \\
\text { (but see below) }\end{array}$ & $\begin{array}{l}\mathbf{s} 4.2 \\
9,10,12, \\
13\end{array}$ \\
\hline $\begin{array}{l}\text { Ablation of microlites } \\
\text { (i) }\end{array}$ & $\begin{array}{l}\text { Check for elevated } \\
\text { compatible elements in } \\
\text { analyses (e.g. Sr from } \\
\text { plagioclase, } \mathrm{Zr} \text { from } \\
\text { zircon) }\end{array}$ & $\begin{array}{l}\text { Problems with mineral } \\
\text { contamination being hidden. } \\
\text { Depends on IS choice (e.g. } \\
\mathrm{Sr} / \mathrm{Ca} \text { ratios in feldspar) }\end{array}$ & $\begin{array}{l}\mathbf{s} 4.2 \\
1,8,11,15\end{array}$ \\
\hline
\end{tabular}




\begin{tabular}{|l|l|l|l|}
\hline $\begin{array}{l}\text { Ablation of microlites } \\
\text { (ii) }\end{array}$ & $\begin{array}{l}\text { Bigger spots or rasters (to } \\
\text { increase sensitivity) } \\
\text { ablate more microlites }\end{array}$ & $\begin{array}{l}\text { Choose smallest practical spot } \\
\text { size to obtain purest glass } \\
\text { analysis; be cautious when } \\
\text { rastering surface of (big or } \\
\text { long, thin) shards to increase } \\
\text { counts }\end{array}$ & 8,18 \\
\hline $\begin{array}{l}\text { Calibration: accuracy, } \\
\text { precision, instrumental } \\
\text { drift }\end{array}$ & $\begin{array}{l}\text { Analyses of homogeneous } \\
\text { reference glasses. } \\
\text { Side-by-side analyses with } \\
\text { reference tephra sample for } \\
\text { critical correlations }\end{array}$ & $\mathbf{s 4 . 2} 1,14,15$ \\
\hline
\end{tabular}

a

\begin{tabular}{|l|l|l|l|}
\hline 1 Abbott et al. 2013 & 6 Kearns \& Buse 2012 & 11 Pearce et al. 2002 & 16 Platz et al. 2007 \\
\hline 2 Hall \& Hayward 2014 & 7 Kuehn et al. 2011 & 12 Pearce et al. 2004a & 17 Preece et al. 2011b \\
\hline 3 Hayward 2012 & 8 Pearce 2014 & 13 Pearce et al. 2007 & 18 Tomlinson et al. 2010 \\
\hline 4 Hunt \& Hill 2001 & 9 Pearce et al. 1996 & 14 Pearce et al. 2011 & 19 Westgate et al. 2013c \\
\hline 5 Jensen et al. 2008 & 10 Pearce et al. 1999 & 15 Pearce et al. 2014b & 20 Zander et al. 2013 \\
\hline
\end{tabular}

\section{Correlating tephras and cryptotephras}

\subsection{General concepts including role of databases}

Correlations between tephra or cryptotephra deposits are best considered testable hypotheses, subject to continual revision with expanded datasets. Consequently, the strongest correlations are those that show concordance between multiple independent datasets, including lithostratigraphic, palaeoenvironmental or archaeological data, 
chronological data, and mineralogical and geochemical evidence (e.g. Westgate and Gorton, 1981; Lowe, 1988; Sarna-Wojcicki, 2000; Pearce et al., 2008a; Housley et al., 2012; Davies et al., 2016). In effect, prior correlations proposed on the basis of age equivalence (i.e. stratigraphic criteria including palaeoecological or archaeological context) are tested by examining potential correlatives suggested by mineralogical variations or by compositional variation within the glass or crystal/phenocryst (mineral) phases of tephra deposits, or by dating appropriate materials associated with the tephras either locally or at sites elsewhere. As tephra studies have developed, publications of stratigraphic, age, and compositional data have emerged on a local or regional basis, and these have been used as the essential prior information to facilitate new correlations. In many cases, however, the necessary comprehensive and analytically-coherent geochemical databases have not been developed for many volcanic centres, an observation reported (for example) for the Mediterranean region by Bourne et al. (2010) and for West Antarctica by Dunbar and Kurbatov (2011). Even at the single volcano level (especially andesitic volcanoes), despite a few notable exceptions (e.g. Andreastuti et al., 2000; Moebis et al., 2011; Cassidy et al., 2014; Ponomareva et al., 2015b; Damaschke et al., 2017b), accurate datasets are inherently difficult to compile even if one or more well-dated eruption records are available. For example, a single record typically under-represents the eruption frequency, while combining two or more records 
may result in an over-representation (Turner et al., 2009; see also Bebbington and Cronin, 2011; Green et al., 2014; Hopkins et al., 2015, 2017; Damaschke et al., 2017a). Hence it is becoming clear that the systematic compilation of accurate local and regional information pertaining to tephras into appropriate databases is an increasingly important requirement for improving correlation efficiency and soundness. Examples of published databases or regional compilations include those described by Froggatt and Lowe (1990), Sarna-Wojcicki et al. (2005), Newton et al. (2007), Lowe et al. (2008), Preece et al. (2011a), Riede et al. (2011), Coulter et al. (2012), Lawson et al. (2012), Kraus et al. (2013), Smith et al. (2013), Ponomareva et al. (2015b, 2017), Tomlinson et al., (2015), Strong et al. (2016), and Petrelli et al. (2017). Perhaps the most advanced currently is the online database derived from the RESET project based at University of Oxford (http://c14.arch.ox.ac.uk/reset/index.html) (Bronk Ramsey et al., 2015b). Now owned by the Natural Environmental Research Council, UK, it is designed to link all data to secondary standards to allow users to check accuracy and precision of these data, a critical step for reliable tephrochronology. It currently holds considerable European data and the future inclusion of data on tephras from South America, Africa, and Japan is planned (Victoria Smith pers. comm., 2017).

The development of an open, online database, which would become used routinely globally, is therefore strongly encouraged, but of course it must be extremely robust with multiple criteria to minimise misuse and to avoid spurious correlations 
being made. Kuehn et al. $(2013,2014)$ suggested that such a development would facilitate progress towards an integrated tephrostratigraphic framework for different regions, thereby increasing efficacy and confidence in tephra correlation, and substantially enhance progress on questions relating to volcanology and petrology as well. Kuehn et al. (2013) envisaged a series of steps to attain an online database: $(i)$ integration of decades of tephra data and available metadata into a system with a single point of access for all data types; (ii) development of an interface and mechanism for multiparameter searching; (iii) development of protocols for more routine collection and reporting of physical data for tephra samples, and better collection and reporting of metadata; and (iv) simplification of data entry to encourage routine submission of new data. This prospective database could take a system-of-systems approach that links together and extends the capabilities of existing repositories, each of which focuses on different geographic regions, data types (e.g. samples, geochemistry, ages, published articles, laboratories, people), and sample contexts (e.g. marine sediment cores, lake sediment cores, ice cores, proximal or distal terrestrial samples). With such a model, it does not matter where any specific data are stored. All of the linked systems could be searched simultaneously, the results aggregated, and then fed into tools for (e.g.) plotting geochemistry, mapping locations, modelling ages, or calculating tephra volumes. Technological tools to undertake such analyses are now becoming available, such as that described by Mair (2016), which covers (using open source solutions that 
run on all major operating systems) domains of data storage and archiving, a computational statistical environment for writing reproducible code, and dynamic report generation that combines the syntax from the statistical analysis with word processing. A researcher could also, for example, discover a potential correlation based on geochemistry and age and then follow linked data to find out which laboratory undertook the analyses, who has samples, and from which core the samples were collected; then the researcher could obtain photos of the core and perhaps even make a request to the core repository to see it in person.

To enable tephra correlations to be properly evaluated and to facilitate the robust application of statistical methods, we re-iterate the importance of publishing all EPMAor LA-ICP-MS-derived grain-by-grain glass data (probably as supplementary material available online) including analytical conditions, primary and secondary standards, and any other relevant analytical parameters and comments (such as any outlier filtering performed formally or informally).

\subsubsection{Introduction to numerical and statistical methods}

Numerical or statistical methods to help suggest or refute correlations in a quantifiable way have been used for more than three decades in tephrochronology (Table 3). Baxter (2008) reported that in recent times there has been a convergence in 
statistical methodologies used by practitioners from different disciplines (e.g. archaeology, palaeoecology, computing, and forensic science alongside the geosciences), and we describe some of the common methods below. Before doing so we emphasise that straightforward visual (graphical) methods such as the use of bivariate ( $x-y$ element-element) plots of geochemical data are normally among the most useful ways of inspecting and displaying compositional data (e.g. Fig. 2), and should be undertaken, as advocated by Baxter $(2008,2016)$ and Pearce et al. $(2008 \mathrm{a})$, whether or not more formal methods are also used. Carr (2017) and Janoušek et al. (2006, 2015) provide software that allows such data to be plotted rapidly. In many cases, bivariate plots alone can provide sufficient guidance to enable anomalous data points to be identified (e.g. Fig. 2b), and possibly explained using comprehensive databases of compositional analyses for comparison (Shane et al., 2006; Abbott et al., 2013) (see also discussion in Section 7.3 about using loadings derived from principal components analysis [PCA] to help inform the selection of bivariate plots likely to be most useful). Often, 'expert knowledge' will allow an analyst to know that an unusually high $\mathrm{Ca}$ major element analysis may derive from a plagioclase, or a high $\mathrm{Zr}$ and heavy REE analysis from the unintentional ablation of a zircon. It has been argued that if PCA is undertaken then plots of the PCA scores are sufficient without additional oxide plots. It should be pointed out, however, that the loadings of the oxides on the principal components differ between different sets of data, and hence, if plots obtained from 
different datasets are to be compared, oxides rather than principal components should be used. (An alternative in this case would be to plot, for each dataset, the principal components obtained from the pooled covariance matrix.) We note also that there is potential for miscorrelation because of the limited dimensionality of such plots (Stokes and Lowe, 1988; Snow, 2006; Li et al., 2015; Petrelli et al., 2017). Moreover, Pearce et al. (2008a) showed that some selectivity is needed in the choice of elements/oxides used for correlation/discrimination using PCA because the key variations in some elements/oxides which discriminate between separate deposits (e.g. $\mathrm{Al}_{2} \mathrm{O}_{3}$ ) can become "swamped" in the PCA calculations by the similarities in all the other elements/oxides. By reducing the number of variables considered, the importance of those key discriminating elements becomes more apparent (Pearce et al., 2008a; Baxter, 2016; $c f$. Pollard et al., 2006). Nevertheless, potential correlations or otherwise can be established with reasonable confidence, especially where multiple criteria provide independent support, such as concordance of glass major- and trace-element data together with mineral assemblage and crystal or phenocryst compositional data (e.g. Cronin et al., 1996a; Preece et al., 1999, 2011b). 
Table 3. Methods usable to compare or match compositional data obtained on glass (or crystals/phenocrysts) from tephras or cryptotephras and to judge or quantify similarities or differences to help determine correlations.

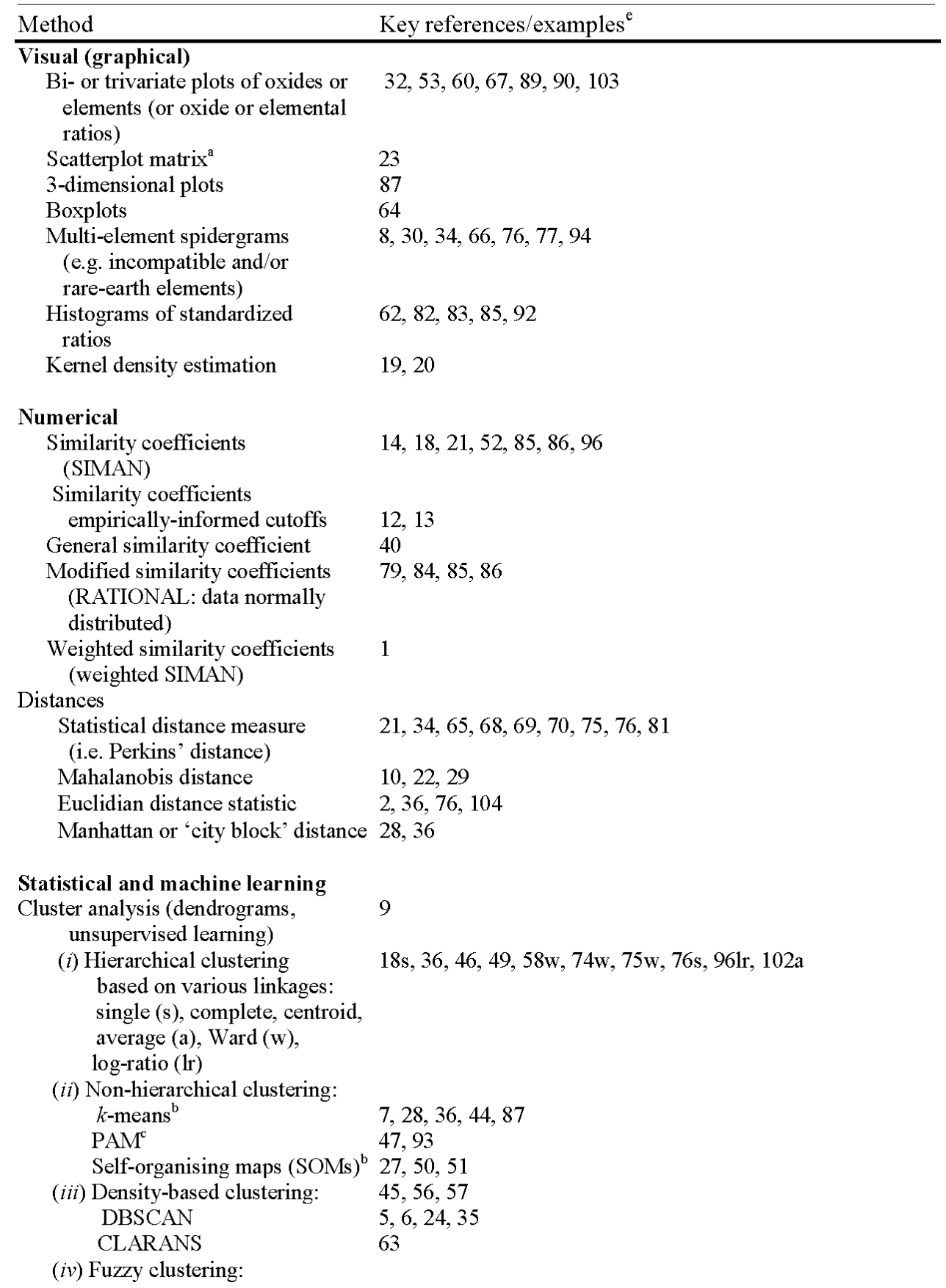




\begin{tabular}{|c|c|}
\hline Fuzzy $c$-means & 11,54 \\
\hline FANNY & 47,93 \\
\hline Model-based clustering & 37,38 \\
\hline \multicolumn{2}{|l|}{ Combinations of cluster analyses: } \\
\hline Hybrid evidential clustering & 73,8 \\
\hline Clustering ensembles & 39 , \\
\hline ed learning & 9 \\
\hline
\end{tabular}

Supervised learning 9

(i) Discriminant function analysis $16,25,29,42,59,88,97,100$

(discriminant analysis)

(ii) Support vector machines

24,71

Other statistical methods

Principal components analysis $17,26,31,42,67,72,78,87,98,99$

Canonical variates analysis

$55,92,97,101$

Multidimensional scaling (MDS) ${ }^{\mathbf{d}} 15,41,78$

Hotelling's two-sample $\mathrm{T}^{2}$ test $\quad 22,23,98$

MANOVA

Student's $t$-test

98

Bootstrap sampling 96, 102

Randomization (permutation) tests $4,22,33,61$

ANOVA

$3,43,91$

${ }^{\mathrm{a}}$ Function pairs ( ) in R, Graph $\gg$ Matrix plot in Minitab, PROC SGSCATTER in SAS/GRAPH

${ }^{\mathrm{b}}$ The main difference between SOMs (also called Kohonen maps) and $k$-means is that SOMs impose a planar, 2-dimensional structure on the set of representative points. SOM has some advantages over $k$ means for visualization when the 2-dimensional representation is appropriate.

${ }^{c}$ Partitioning around medoids (see Section 6.5).

${ }^{d} \mathrm{MDS}$ is an exploratory statistical technique with an ability to represent measurements of similarity (or dissimilarity) between 'objects' in a small number of dimensions (Borg and Groenen, 2005). MDS $\underset{\mathrm{e}}{\mathrm{m}}$ ethods include principle components analysis and canonical variates analysis, and non-metric MDS.

\begin{tabular}{|c|c|c|}
\hline 1 Addison et al. 2010 & 36 Everitt et al. 2011 & 71 Petrelli et al. 2017 \\
\hline 2 Aksu et al. 2008 & 37 Fraley \& Raftery 1999 & 72 Pouget et al. $2014 a$ \\
\hline 3 Almiral et al. 2012 & 38 Fraley \& Raftery 2002 & 73 Pouget et al. $2014 \mathrm{~b}$ \\
\hline 4 Anderson 2001 & 39 Ghaemi et al. 2009 & 74 Preece et al. 1999 \\
\hline 5 Argote-Espino et al. 2012 & 40 Gower 1971 & 75 Preece et al. 2000 \\
\hline 6 Argote-Espino et al. 2013 & 41 Greenough \& Owen 2003 & 76 Preece et al. $2011 \mathrm{~b}$ \\
\hline 7 Avery et al. 2017 & 42 Habermann et al. 2016 & 77 Preece et al. 2014 \\
\hline 8 Baccolo et al. 2015 & 43 Hamann et al. 2010 & 78 Prentice 1980 \\
\hline 9 Baxter 2006 & 44 Hamm ond \& Ward 2001 & 79 Rieck et al. 1992 \\
\hline 10 Baxter 2008 & 45 Hartigan 1975 & 80 Rogova et al. 2008 \\
\hline 11 Bezdek et al. 1984 & 46 Jordan et al. 2006 & 81Salisbury et al. 2012 \\
\hline 12 Blegen et al. 2015 & 47 Kaufman \& Rousseeuw 1990 & 82 Sarna-Wojcicki 1979 \\
\hline 13 Blegen et al. 2016 & 48 Keenan 2003 & 83 Sarna-Wojcicki 2000 \\
\hline 14 Borchardt 1974 & 49 King et al. 1982 & 84 Sarna-Wojcicki \& Davis 1991 \\
\hline 15 Borg \& Groenen 2005 & 50 Kohonen 1995 & 85 Sarna-Wojcicki et al. 1984 \\
\hline 16 Bourne et al. 2010 & 51 Kohonen 2001 & 86 Sarna-Wojcicki et al. 1987 \\
\hline 17 Brathwaite et al. 2017 & 52 Kuehn \& Foit 2006 & 87 Sell \& Samson 2011a \\
\hline 18 Brendryen et al. 2010 & 53 Kuehn et al. 2009 & 88 Shane \& Froggatt 1994 \\
\hline 19 Bronk Ramsey 2011 & 54 Kruiver et al. 1999 & 89 Shane \& Wright 2011 \\
\hline 20 Bronk Ramsey et al. $2015 b$ & 55 Krzanowski 1988 & 90 Shane et al. $2008 \mathrm{a}$ \\
\hline 21 Cage et al. 2011 & 56 Ling 1972 & 91 Sigman 2010 \\
\hline 22 Campbell \& Curran 2009 & 57 Ling 1973 & 92 Stokes et al. 1992 \\
\hline 23 Campbell et al. 2011 & 58 Liu et al. 2016 & 93 Struyf et al. 1997 \\
\hline 24 Cannata et al. 2011 & 59 Lowe et al. 2007 & 94 Tomlinson et al. 2010 \\
\hline 25 Cerovski-Darriau et al. 2014 & 60 Mackay et al. 2016 & 95 Topchy et al. 2005 \\
\hline
\end{tabular}




\begin{tabular}{|l|l|l|}
\hline 26 Chiasera \& Cortés 2011 & 61 Manly 2007 & 96 Tryon et al. 2008 \\
\hline 27 Corsaro et al. 2013 & 62 Nelson et al. 1985 & 97 Tryon et al. 2009 \\
\hline 28 Cortés et al. 2007 & 63 Ng \& Han 2002 & 98 Tryon et al. 2010 \\
\hline 29 Cronin et al. 1997 & 64 Park et al. 2007 & 99 Turner et al. 2009 \\
\hline 30 Daga et al. 2008 & 65 Pearce et al. 2004b & 100 Turner et al. 2011b \\
\hline 31 D’Antonio et al. 2016 & 66 Pearce et al. 2007 & 101 Venables \& Ripley 2002 \\
\hline 32 Davies et al. 2010b & 67 Pearce et al. 2008a & 102 Watson et al. 2017b \\
\hline 33 D'Costa et al. 2011 & 68 Pearce et al. 2008b & 103 Westgate e al. 2013c \\
\hline 34 Denton \& Pearce 2008 & 69 Perkins et al. 1995 & 104 Xia et al. 2007 \\
\hline 35 Ester et al. 1996 & 70 Perkins et al. 1998 & \\
\hline
\end{tabular}

Many statistical packages, for example Minitab (Minitab, Inc., 2017) and $R$ (R Core Team, 2017), have the capability to display what is called a scatterplot matrix, a matrix-like array of bivariate plots (Fig. 6). The $R$ software is especially recommended because it is very comprehensive as well as being free and open source. Bivariate (or trivariate) plots can readily demonstrate, for example, $(i)$ the range of compositions for a specific sample and any trends within that data; (ii) compositional overlaps or differences between samples; (iii) the presence of any 'outliers' within a sample that plot away from the main group (see Section 6.5 below); (iv) the possible presence of contaminants (seen as multiple compositional modes) from an older tephra within a younger one; or $(v)$ compositionally bimodal or trimodal eruptives where two or three modes are erupted at the same time or sequentially in the same eruption episode - e.g. the Laacher See eruption, Germany (Bogaard and Schminke, 1985); the Aniakchak eruption, Alaska (Pearce et al., 2004b; Denton and Pearce, 2008; Monteath et al., 2017); and multiple late Quaternary eruptions from Okataina Volcanic Centre, New Zealand 
(Smith et al., 2004, 2005, 2006; Shane et al., 2007, 2008a, 2008c; Kilgour and Smith, 2008). Statistical procedures such as PCA and canonical variates analysis (CVA) also lead to plots which can be used to address these questions, as discussed below. We note that a useful glossary of terms and concepts pertaining to numerical and statistical techniques (including those used in our paper) is provided by Birks (2012); Baxter (2016) is also a valuable text encompassing many of the methods and terms discussed here. 


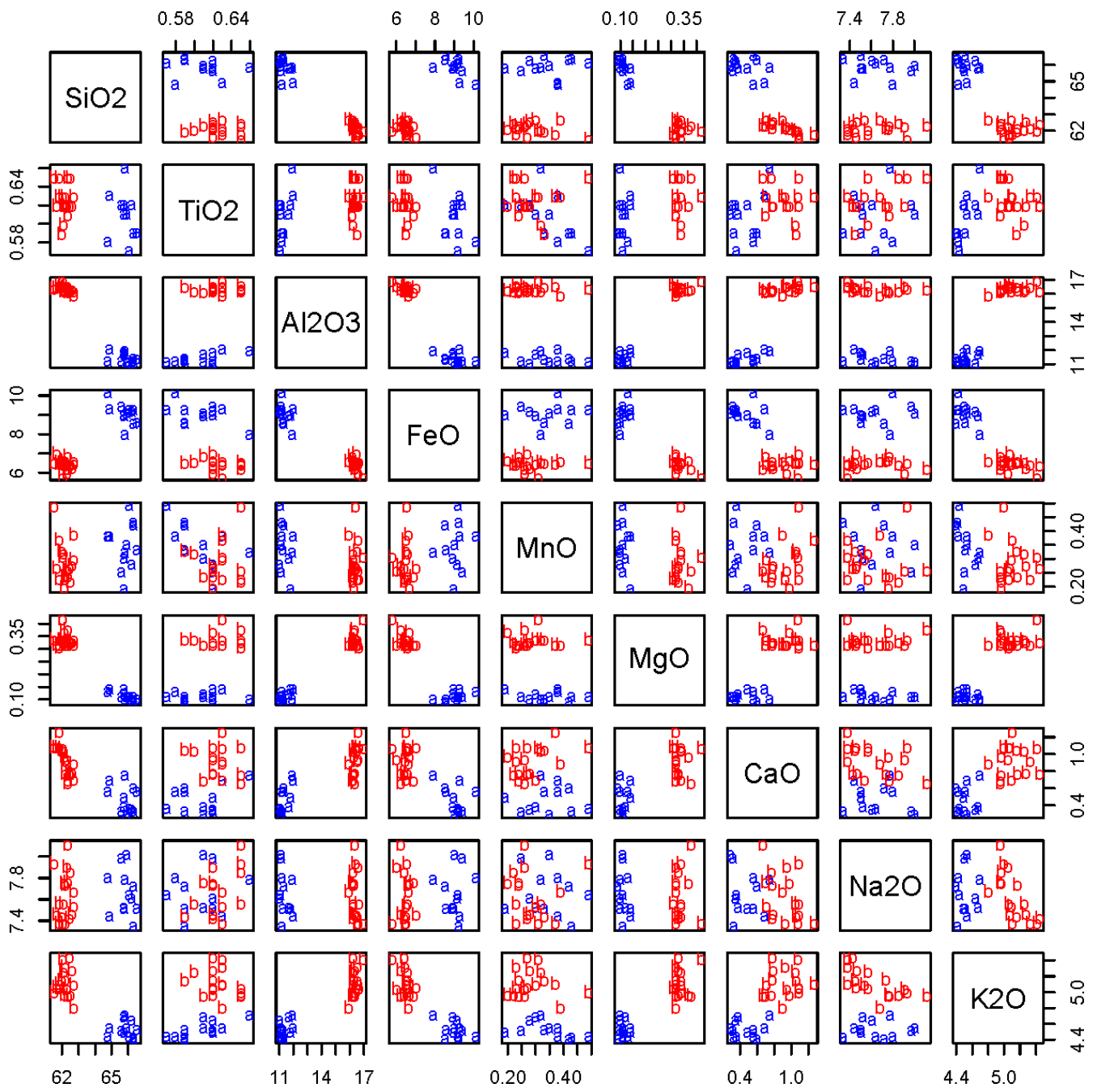

Fig. 6. Scatterplot matrix constructed using $R$ (R Core Team, 2017) of nine major element oxide analyses derived via EPMA for the observations (individual glass-shard analyses) in samples CAT09-02a and CAT09-02b (represented by a and b, respectively) obtained from tephra deposits in the Wasiriya Beds, Kenya (after Tryon et al., 2010). Values on axes are abundances of oxides (in wt \%). A similar matrix can be produced (with correlation coefficients) in GCDkit (Janousek et al., 2006) which runs under R from the pairsMjr ( ) or pairstrc ( ) commands. The data in this figure, and in others below, are provided in supplementary data Table S1. 


\subsubsection{Advantages and limitations of statistical methods}

The advances in analytical techniques that enable tephras to be characterized much more rapidly and with better accuracy and precision than before has led to increasingly large datasets. Statistical methods offer a way not only of reducing such datasets but also to enable decisions to be made about whether or not any two or more tephra deposits are correlative using non-subjective and formalised protocols. Statistical methods thus help to provide an objective (non-subjective) means of dealing with data pertaining to tephra components to develop a better understanding of relationships among the data from multiple viewpoints and in some cases enabling otherwise confused or ambiguous relationships to become clearer, thereby helping to quantify the degree of certainty or uncertainty in establishing correlations using quantifiable confidence limits (Stokes et al., 1992; Bourne et al., 2010; Lowe et al., 2011). As emphasised already, graphical methods such as bivariate plots of geochemical data are extremely useful ways of inspecting and displaying compositional data, particularly if the observations are plotted against the first two principal components or the first two canonical variates. If bivariate plots of oxides are used, the choice of elements for such plots remains subjective. Most of the statistical methods we illustrate are complemented with graphics that act as a check on the statistics by demonstrating that the matching of tephras suggested by the statistics is reasonable. For example, Bourne et al. (2010) 
noted that bivariate plots and outputs from discriminant function analysis (DFA) from glass major element data on the same deposit in their study of marine cryptotephras did not always generate concordant results or interpretations (see also Pearce et al., 2008a). In using numerical or statistical methods to establish sample equivalence or difference, however, it must be appreciated that all methods have limitations to some degree. For example, the standard similarity coefficient (SC) method used to make comparisons of glass compositions (as discussed in Section 6 below) is difficult to use for making inferences of correlation because it does not have a normal distribution (Sarna-Wojcicki and Davis, 1991; Addison et al., 2010; see also Pollard et al., 2006). In addition, the SC cut-off point for correlatives is not definitive (e.g. it can vary from 0.90 to 0.96 ) because each case is dependent on analytical uncertainty and other factors (Lowe, 2011), such as silica variability and the numbers of glass shards able to be analyzed to generate sample populations. Blegen et al. (2015) offer one alternative, which they termed 'empirically informed SCs': they used data from a 'type sample' for a given deposit as the basis for 5,000 normally distributed randomized samples of the type tephra. SCs calculated between each of the 5000 replicates and the type sample were used to generate a frequency distribution of expected SC values and to define a lower SC value for accepted correlations with the type sample that included the upper $95 \%$ of the observations. Because $\mathrm{SiO}_{2}$ concentrations in glass can vary widely from tephra to tephra, such variations can impact markedly on any statistical measures 
involving mean concentrations (and were excluded from analysis by Blegen et al., 2015, 2016). Many cryptotephra deposits comprise only a few glass shards and hence minimum numbers of analyses to define a population cannot be prescribed. Moreover, there is no consensus as to the optimum specific elements for SC calculations, nor how they might be weighted (Stokes et al., 1992; Hallett et al., 2001; Hillenbrand et al., 2008). The difficulty in choosing a cut-off value for the SC in a hierarchical cluster analysis (discussed below in Section 6.3) is well-known to many disciplines (e.g. Everitt et al., 2011, section 4.4.4).

The statistical distance measure of Perkins et al. $(1995,1998)$ is also not easy to apply to the trace-element analyses derived by SN-ICP-MS of single samples because it can be difficult to obtain a realistic measure of analytical error/precision (Preece et al., 2011b). Similarly, the successful use of DFA is directly reliant upon both the quality and comprehensiveness of the reference sets (database), statistically representative numbers of samples (Petrelli and Perugini, 2016), and the recognition of heterogeneity in glass-shard assemblages from some single eruptive episodes (Kuehn and Foit, 2006; Lowe, 2011; Petrelli et al., 2017). Further limitations, as well as attributes, of numerical or statistical approaches were discussed in detail by Pollard et al. (2006), Pearce et al. (2008a), and Pouget et al. (2014b).

\subsection{Stratigraphy and age}


As noted earlier, the law of superposition and the relative positions of layers or deposits, and their associations with other deposits (or a known age datum such as a change in magnetic polarity) within sequences, are fundamental tenets used widely in the correlation of tephra deposits from place to place (Lowe, 2011; Preece et al., 2011a; Bourne et al., 2013). More than 25 years ago, Sarna-Wojcicki and Davis (1991) indicated that if the same stratigraphic sequence of tephra layers (or cryptotephras), as defined by physical properties or geochemical criteria, is found at two or more localities, then the likelihood that the respective tephra layers of the sequence correlate increases with the number of these localities. Such increased likelihood is true only if it can be shown that the sequence did not form by chance or by 'cyclic differentiation' processes in the past (i.e. as a compositionally identical but older sequence of eruptives). The number of possible combinations of a sequence increases with the number of layers (or glass shard/crystal concentration zones) in the sequence, the number of locations where the sequence is found, and the number of independent variables used to characterize (identify) the members of the sequence (Sarna-Wojcicki and Davis, 1991). The probability that such sequences is due to chance decreases concomitantly with the increase in these parameters.

The other possibility, that a sequence of tephra layers or cryptotephra deposits with the same set of characteristics can be duplicated at different times by a cyclic 
magmatic process, can be eliminated by informed field work, or age or compositional data, and historical observations of the eruptive behaviour of relevant volcanoes. Thus, because chance and cyclicity are usually able to be virtually eliminated as probable causes of the repetition of tephra/cryptotephra sequences at different localities, then the identification of characteristic sequences becomes strong evidence supporting correlation of the tephra layers or cryptotephra deposits in these sequences via geochemical and statistical approaches (Sarna-Wojcicki and Davis, 1991).

The generation of compositionally-similar batches of magma (repeating geochemical cycles) through time is known to occur, however, as illustrated for instance by Turner et al. (2011a), Albert et al. (2012), Jennings et al. (2014), Hopkins et al. (2015, 2017), and Damaschke et al. (2017b). In such cases, stratigraphic ordering, age, or other (non-compositional) criteria such as thickness and location (spatial information), are needed to inform the likelihood of correlation or not (e.g. Bebbington and Cronin, 2011; Turner et al., 2011b; Green et al., 2016). Use of trace element data may also be appropriate where compositional similarity has been based solely on major elements (e.g. Westgate et al., 2008; Davies et al., 2012; Hopkins et al., 2015, 2017). In another study, Lane et al. (2012) demonstrated that the 12,100 cal.-yr BP Vedde Ash, the most widely dispersed late Quaternary tephra deposit from Iceland, was generated by the mixing of separate rhyolitic and basaltic magma batches, but that several compositionally similar tephra layers were unable to be distinguished from the 
Vedde Ash rhyolitic fraction using major and trace element composition alone. Because these eruptions were well spaced in time, however, Lane et al. (2012) were able to show that it should be possible to assign an unknown distal tephra deposit to the correct volcanic event by taking into account associated stratigraphic (or age) information. Similarly, Bourne et al. (2013) showed that the Faroe Marine Ash Zone (FMAZ) III in the marine realm is most likely a complex ash zone that represents a series of closely timed Grimsvötn eruptions (on Iceland) that currently can only be stratigraphically separated in the high-resolution ice-core records. Previously, Davies et al. (2010b) had identified a very thin visible tephra layer at $2066.95 \mathrm{~m}$ in the North Greenland Ice Core Project (NGRIP) ice core that they subsequently correlated to the FMAZ III layer in marine sediments on the basis of overlapping major element signatures. That correlation was shown by Bourne et al. (2013) to be erroneous. Such miscorrelations - arising for example by errors in field work, assignments of incorrect ages, incompleteness of stratigraphic records (which can lead to a potentially erroneous 'counting back' approach when attempting to match newly-identified deposits to those of antecedent records), inadequacy of characterization data - and their possible resolution using secure and detailed stratigraphic and age data, were emphasised by Westgate et al. (2008), Lowe (2011), Damaschke et al. (2017b), and Timms et al. (2017). The study by Bourne et al. (2013) also highlighted the differing resolution of different palaeorecords and the compositional similarities of Icelandic Grimsvötn tephras. Subtle compositional 
differences further emphasize the importance of obtaining robust glass-shard chemical data, bracketed by analysis of secondary standards.

Green et al. (2014) used a stochastic local optimization technique (related to the field of operations research and optimization) to develop an automated procedure for correlating tephra deposits in sediments at five maar sites in the AVF, Auckland, New Zealand. The first step in an iterative approach to find the most likely 'arrangement' of tephras across the sites (stratigraphic inter-relationships) was to establish tephra ages using both radiometric dates (derived both locally and transferred from elsewhere via tephrochronology) and stratigraphic superpositioning and juxtapositioning within and between cores, respectively. The ages and associated errors provided the basis of the algorithm to connect the tephras from one site to the next. In the second step, the tephra correlations were confirmed or ruled out on the basis of mineralogical and geochemical data (Green et al., 2014). A subsequent variation on this approach was reported by Kawabata et al. (2016).

Further analysis of mainly basaltic tephra/cryptotephra deposits in the AVF was undertaken in a separate study by Hopkins et al. (2015). By applying multiple analytical techniques (including X-ray density scanning of sediment cores to help identify primary versus reworked tephras/cryptotephras), they were able to correlate some tephras on the basis of glass major element oxides, and some (where oxide signatures were inadequate) using incompatible trace elements (mainly REEs) and trace element ratios (e.g. 
HFSE/Yb) of glass shards. However, Hopkins et al. $(2015,2017)$ emphasised that the glass-based chemistry (both major and trace) was insufficiently diverse to be used alone as a definitive correlation tool in the AVF because each volcanic centre does not have a unique geochemical signature in the field as a whole. This constraint prevented unambiguous correlation of tephras to source centre using only geochemistry. Consequently, stratigraphic relationships (including use of well-dated rhyolitic tephra marker beds), ages (via Ar/Ar dating and paleomagnetic data: Leonard et al., 2017), eruption scale, spatial relationships (locations of centres and sites sampled), provided additional constraints essential for cross-core correlations and hence resolution of the relative ordering of 48 out of 53 vents in the AVF. In addition, these new chronostratigraphic findings (Hopkins et al., 2017) indicate that the prior statistical correlation models for the AVF-derived tephras, powerful though they are, had been constrained by input data excessively weighted by a cluster of tephras around 30 cal. ka in the modelled ages (Leonard et al. 2017).

Parallel conclusions have been drawn from North Atlantic and northern/western European studies regarding the difficulties of correlating temporally closely-spaced, multiple cryptotephra deposits with indistinguishable glass-shard compositions (Jones et al., 2017). For example, the problematic late glacial Borrobol and Penifiler tephras (Pyne-O’Donnell et al., 2008; Lind et al., 2016; Jones et al., 2017), and the c. 10 cal. ka Saksunarvatn tephra, which seems to represent a conflation of five or more separate 
eruptives deposited over a 500-year interval (e.g. Bramham-Law et al., 2013; Jennings et al., 2014; Timms et al., 2017), provide significant challenges to identify individual eruptives, especially when one or more eruptives of the 'full' depositional sequence is/are missing from any specific site, or where reworking has occurred. Another example concerns the Sheep Creek tephra. Previously thought to be a single widespread tephra in central Alaska and western Yukon Territory, it is now known to comprise five separate stratigraphic units (Westgate et al., 2008). In any event, analysis of multiple sediment cores, and high-resolution contiguous rather than 'rangefinder-based' sampling methods, are required to develop a comprehensive (crypto)tephrostratigraphy using superpositioning and age (both relative and numerical) as key criteria (Jones et al., 2017; Timms et al., 2017).

Turner et al. (2011b) and Damaschke et al. (2017a) also used temporally and geochemically defined groups together with prior information about stratigraphic superpositioning to help understand the chemically diverse, variable, and spatially restricted tephras associated with Holocene andesitic volcanism of Mt Taranaki, a stratovolcano in western North Island, New Zealand.

\subsection{Scale}


In examining the concept of scale in tephrostratigraphy, Tryon et al. (2011) commented, firstly, that issues of scale include the type of volcanic deposit being studied and sampled so that the spatial and temporal 'scope' of a study may thus range from $(i)$ a volcano, to (ii) decimetre- or centimetre-thick layers of tephras, to (iii) individual glass shards, or crystals or phenocrysts/microphenocrysts, within a tephra layer (or cryptotephra deposit). These different targets are exemplified, respectively, by the studies of (i) Stokes and Lowe (1988), who correlated tephras to an array of different source volcanoes; (ii) Stokes et al. (1992), who correlated multiple tephras associated with specific individual volcanoes; and (iii) Shane et al. (2007, 2008a), who identified and correlated multiple heterogeneous tephra beds deriving from single eruption events. In a grain-by-grain study on titanomagnetite microphenocrysts from andesitic tephra layers, Turner et al. (2008) showed that the degree (scale) of solid-state exsolution of titano-haematite/ilmenite lamellae was related to the ascent rate of magmas, with fast-ascent titanomagnetites devoid of, and slow-ascent magmas enriched in, such lamellae. This distinction provided a useful correlational criterion for very finegrained distal tephras as well as contributing petrological and volcanological information (Turner et al., 2008).

Secondly, Tryon et al. (2011) observed that compositional data are also collected at scales that range from grain-discrete to bulk techniques (see Table 1) and may include elemental abundances ranging from weight percentage to parts per million or less. Much 
earlier, Hodder and Wilson (1976) developed a parallel concept of tephra analysis though application of a hierarchy of methods from multicomponent (e.g. analysis of mineral assemblages), to single component (e.g. analysis of glass shards in bulk), to single particle (e.g. analysis of individual glass shards or crystals/phenocrysts). Consequently, in determining which of a multitude of techniques to use to establish a correlation on the basis of compositional data relating to certain components, the scale of the question and the resolution of the data determine which method or methods are best suited to assess the probability of correlation. Ultimately, Tryon et al. (2011) concluded that the ability to construct sequences of correlated tephra deposits requires analytical flexibility and an increased awareness of the importance of scale. In brief, they stated (p. 125):

"There is no single best method for correlating among tephra deposits on the basis of geochemical compositional data. The resolution of the data and the scale of the proposed questions determine which method is most appropriate." Similarly, in demonstrating the efficacy of apatite trace-element analyses for correlating both fresh and strongly weathered tephras, Sell and Samson (2011a, p. 162) observed, correctly, that no single tephrochronological method is infallible. 


\section{Numerical and statistical approaches to correlation using compositional data}

\subsection{Introduction}

Many numerical or statistical studies of quantitative compositional data acquired from tephra components for the purpose of correlating tephras use a two-stage approach. The first stage is to examine mean abundances (of major elements expressed as oxides, for example, as obtained from glass shards via EPMA) to identify potential candidates for correlation and to characterize the general structure of the data (discussed further below), the idea being to compare the differences in means between the candidate pairs with those found between other samples or layers/deposits. The second stage compares differences between candidate-pair means in relation to the compositional variance between samples taken from within each candidate layer or deposit.

The first stage can be undertaken via the calculation of SCs or distances for all possible sample pairs (discussed below), and via cluster analysis (Campisano and Feibel, 2008; Tryon et al., 2008) (Table 3). Sarna-Wojcicki (1976) was a pioneer in these applications for large tephra-based datasets. PCA is another useful tool in this regard (e.g. Gonzalez et al., 1999). Cluster analysis methods are many and varied but all 
are concerned with sorting a collection of objects into a number of groups in such a way that the objects in each group are as similar as possible, each object having a number of variables, features, or characters measured on it (Kaufman and Rousseeuw, 1990). In our case the objects are pyrogenic components of tephra-derived samples as represented by the results of a set of chemical analyses for the constituent oxides or elements of glass shards or minerals (as free crystals or crystal fragments, or as phenocrysts). Statistically, cluster analysis methods may be said to be descriptive in that their outcome is a set of groups that may suggest a matching between samples, but such groupings alone can never prove definitively that the matched samples belong to the same eruption event. Nor will the failure of two samples to be grouped necessarily prove that they do not belong to the same eruption.

Discriminant analysis, like cluster analysis, is concerned with the grouping of objects. However, in discriminant analysis there is an existing classification of objects into groups and the aim is to develop a rule to assign new, unclassified, objects into one of the existing groups (or perhaps to reject the object as not belonging to any of the known groups). In the computing literature, cluster analysis and discriminant analysis are both regarded as belonging to the field of 'machine learning' and are viewed, respectively, as examples of 'unsupervised learning' and 'supervised learning' (e.g. Han et al., 2012, mainly chapters 8-11; James et al., 2013, mainly chapters 4, 9, 10) (Table 3). Petrelli et al. (2017) tested the application of a machine learning technique termed 
support vector machines (SVMs) (Han et al., 2012, chapter 9.3; James et al., 2013, chapter 9) to attempt to correlate tephra deposits in Italy. In common with DFA, a training set of major and trace element data relating to whole-rock and glass-shard analyses was established using a machine learning algorithm; then 'unknown' tephra sample analyses were matched to ultimately determine their specific volcanic source as 'Roman Magmatic Province'. Petrelli et al. (2017) showed that the SVM application, despite considerable volcanic complexity (high dimensionality), was successful (on the basis of comparisons with a suite of qualitative geochemical analyses) whereas bivariate discriminant plots both of major and trace element data (for whole rock, glass, or melt inclusions in pyroxene) were mainly ineffective in the study.

The form of cluster analysis most commonly used in geochemistry is agglomerative hierarchical clustering (Everitt et al., 2011, p. 73ff). Such clustering begins with as many groups as there are objects. Progressively the groups are combined until at the end all objects have been merged into a single group. After this, the pattern of group combinations is reviewed and a decision is made on the number of groups to adopt as best representing the structure of the data. For convenience we use 'cluster analysis' to mean 'agglomerative hierarchical clustering'. Other forms of clustering are given their more specific names.

\subsection{Forming matrices of similarities and distances}


Cluster analysis is based on a symmetric matrix of inter-point distances or similarities, analogous to a mileage table of distances between towns on a touring map. Although this matrix may be directly available, it usually needs to be calculated from an $n$ by $p$ matrix of $X=\left(x_{i j}\right)$ of data containing the results of $p$ variables taken on $n$ objects. Usually in geochemistry the variables are the amount of each of $p$ oxides or elements found in $n$ glass or mineral samples. Distance and similarity measures of this kind appropriate for continuous variables were described by Everitt et al. (2011, p. 49ff), and in particular we mention the Euclidean ('straight line') distance

$$
d_{i j}=\left[\sum_{k=1}^{p} w_{k}^{2}\left(x_{i k}-x_{j k}\right)^{2}\right]^{\frac{1}{2}}
$$

and the Manhattan (or 'city block') distance

$$
d_{i j}=\sum_{k=1}^{p} w_{k}\left|x_{i k}-x_{j k}\right|
$$

Here $i$ and $j$ range from 1 to $n$, the number of objects. The constants $w_{k}$ are positive weights, with a value of 1 if the variables are equally weighted. The choice of the weights $w_{k}$ is discussed below.

A similarity matrix has the form $S=\left(s_{i j}\right)$ where $s_{i j}$ expresses the similarity of object $i$ to object $j$, taken to be between 0 and 1 . The diagonal elements $s_{i i}$ and $s_{j j}$ are all equal to 1 . Gower (1966) showed that if a similarity matrix satisfies a certain 
mathematical condition (it has all eigenvalues positive), then it may be transformed into a distance matrix by $d_{i j}=\sqrt{1-s_{i j}}$. This result was discussed by Everitt et al. (2011). The resulting distance has the property that a configuration of points exists in multidimensional space whose Euclidean distances reproduce the distances in the matrix. For this reason, this transformation is often applied to convert similarity matrices into distance matrices and vice versa. Cluster analysis can be applied to either similarity or distance matrices and the results tend to be similar.

Gower's 'general coefficient of similarity' (Gower, 1971) is a flexible SC which allows for the incorporation of both continuous and categorical variables within the one coefficient. It could be of value in a situation, for example, where the absolute (numerical) weight percentage of an oxide ( a 'continuous' variable) could not be determined precisely but could be reliably graded as 'high', 'medium', or 'low' (a 'categorical' variable). This case may arise in tephra studies where, for example, SEMbased analyses of minute, sparse glass shards from an ice core (e.g. Kuehn and Froese, 2010; Iverson et al., 2017) are not well characterized, or if calibration is less than optimum. Other situations could involve, for example, different shard morphologies or, when working with proximal samples, different types of lithic clasts (e.g. platy shards, or certain lithics, might be 'abundant', 'common', or 'rare'), or potentially with respect to approximate age (e.g. Holocene versus Pleistocene), or to a stratigraphic event (e.g. before or after it). The Gower SC has been widely implemented in statistical software. 
If the variables are left unweighted the major constituent variables will tend to dominate the distance or similarity measure. If this were considered undesirable, then choosing a weighting $w_{k}=\left(s d_{k}\right)^{-1}$ where

$$
s d_{k}=\sqrt{\frac{\sum_{i=1}^{n}\left(x_{i k}-\bar{x}_{k}\right)^{2}}{n-1}}
$$

is the standard deviation of constituent variable $k$, will have the effect of evening out the effect of all variables. This type of weighting is equivalent to dividing each variable value by its standard deviation and then using unweighted distance measures, and may be very important if the dataset being compared contains elements that are determined with variable degrees of analytical precision - for example, $\mathrm{SiO}_{2}$ (high precision) and $\mathrm{MgO}$ (relatively poor precision) in rhyolites - or because of different degrees of interlaboratory reproducibility (e.g. Na analyses of the same glass/tephra might vary more from laboratory to laboratory than might $\mathrm{Ca}$ analyses because of differences in dealing with alkali element migration; consequently, $\mathrm{Na}$ might be less reliable and therefore downweighted). We discuss such standardization further below in Section 6.3.

A distance measure used quite frequently in this field is the distance

$$
D^{2}=d_{i j}^{2}=\sum_{k=1}^{p} \frac{\left(x_{i k}-x_{j k}\right)^{2}}{2 \sigma_{k}^{2}}
$$


introduced in Appendix B of Perkins et al. (1995). Note that $D^{2}$ is an example of the Euclidean distance where the weights are given by $w_{k}^{2}=1 /\left(2 \sigma_{k}^{2}\right)$. Here, $\sigma_{k}^{2}$ is for the analytical variance for variable $k$ but might better be defined to also include known within-tephra variance, such as compositional variation which may result from the eruption of a zoned magma chamber, as might be built up over much field or laboratorybased experience. Variance $\left(\sigma^{2}\right)$ is the square of standard deviation. Mardia et al. (1979) referred to this distance as 'Karl Pearson distance', but we refer to it as 'Perkins' distance' because of its initial and subsequent application in tephra studies (Table 3).

The most famous multivariate distance measure is that proposed by the Indian statistician Prasanta Chandra Mahalanobis. The Mahalanobis distance can be best explained by regarding the composition of a glass shard as a vector of $p$ different oxide or elemental quantities (weight percentages or ppm). If $\mathbf{x}_{i}^{\prime}=\left(x_{i 1}, x_{i 2}, \ldots, x_{i p}\right)$ and $\mathbf{x}_{j}^{\prime}=\left(x_{j 1}, x_{j 2}, \ldots, x_{j p}\right)$ are two vectors of observations from a multivariate distribution, with covariance matrix $\Sigma$, then the (squared) Mahalanobis distance between the two vectors with respect to $\Sigma$ is given by

$$
D_{m}^{2}=\left(\mathbf{x}_{i}-\mathbf{x}_{j}\right) \Sigma^{-1}\left(\mathbf{x}_{i}-\mathbf{x}_{j}\right)^{\prime}
$$

where the prime indicates a matrix transpose. $D_{m}^{2}$ is a multivariate analogue of a squared difference divided by a variance. Mahalanobis distance is similar to Perkins' 
distance but takes into account the covariance between variables as well as their variances. Mahalanobis distance is not often used in clustering of individual observations because an appropriate $\Sigma$ is not usually known. It can be used for clustering groups of observations (Mardia et al. 1979, p. 368). When calculating an empirical covariance matrix $\hat{\Sigma}$ from compositional data for use in a Mahalanobis distance, one variable should be dropped because the sum-to-one property means that the covariance matrix inverse will not exist. It does not matter which variable is dropped - the same Mahalanobis distance is obtained.

\subsection{Hierarchical cluster analysis}

Once the matrix of similarities and distances is formed by one of the methods discussed above, the cluster analysis can begin. Firstly, the smallest distance (or greatest similarity) in the matrix is located. This distance corresponds to the two objects that are closest (or most similar). These two objects are merged into a group and the distance matrix is re-calculated for the reduced set of $n-1$ objects. The new, smaller, distance matrix is again scanned for its smallest element and the process repeats until all objects are merged. The distance values at which a merger takes place are recorded.

In order to carry out the algorithm, it must be specified what is meant by the distance between an object and a group of objects and the distance between two groups 
of objects. Everitt et al. (2011, p. 76ff) discussed a number of these options, some of which are illustrated in Fig. 7: single linkage (also called the nearest neighbour, Fig. 7a), complete linkage (furthest neighbour, Fig. 7b), centroid linkage (which uses the distance between the centroids of the two groups, Fig. 7c), average linkage (which uses the average distance between all pairs of objects in groups), and Ward linkage (a measure of variability within each group to evaluate the similarity between groups) (see examples in Table 3 and discussion in Cortés et al., 2007). For most applications the single linkage method is not recommended because it can lead to the formation of clusters that are not very homogeneous (Baxter et al., 2005, p. 185). 
(a)

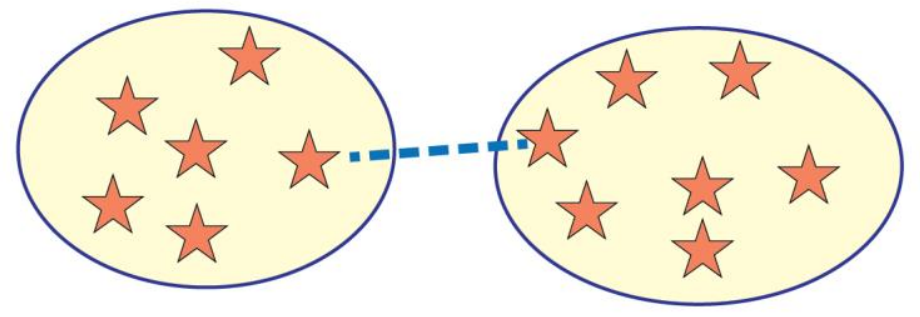

(b)

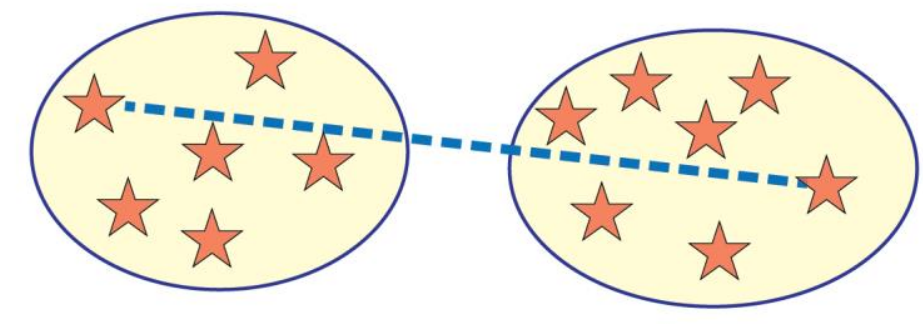

(c)

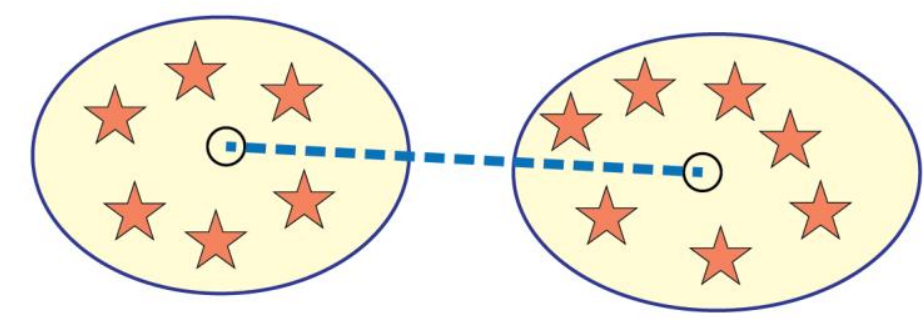

Fig. 7. Graphical representation of the main hierarchical methods used for cluster analysis: (a) single linkage or nearest neighbour; (b) complete linkage or furthest neighbour; (c) centroid linkage or average linkage (redrawn from Cortés et al., 2007, p. 167). The stars represent individual samples within the groups defined by the ellipses. In (c) the encircled dot represents a mean.

Brendryen et al. (2010) used freely available software known as PAST (Hammer et al., 2001) to develop a dendrogram from cluster analysis of SC data based on the single linkage (nearest neighbour) protocol. Preece et al. $(1999,2000)$ used Ward 
minimum variance linkages in their study of Type I and Type II tephra beds (derived from different source volcanic regions) in the Yukon Territory. Their cluster analysis enabled 41 samples to be matched to one of 12 distinct beds, 11 of which are shown in Fig. 8. Note that this two-fold classification (Type I vs Type II beds) has been modified as a result of subsequent analytical work in the region that has shown greater compositional diversity (Preece et al., 2011a).
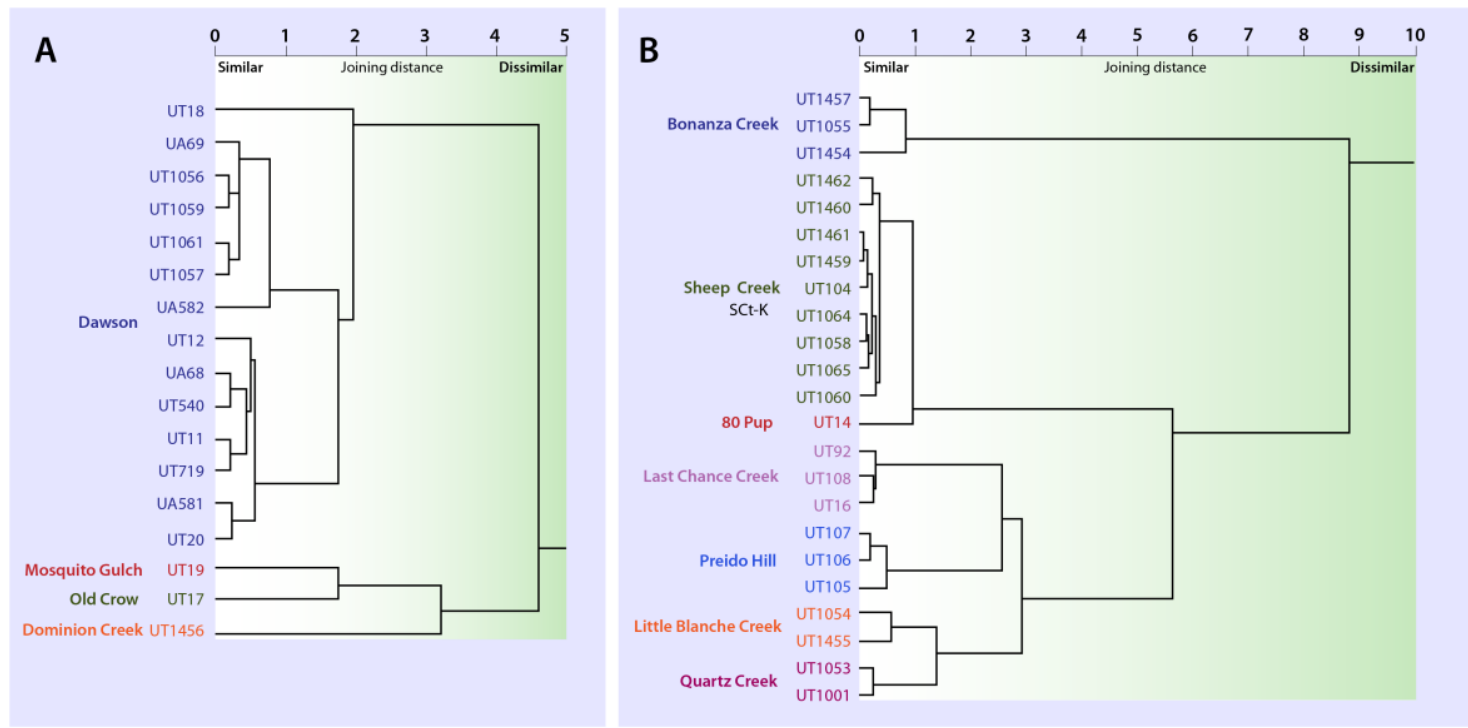

Fig. 8. Cluster analysis of glass-shard major element analyses of two sets of tephras, Type I and Type II, in central Yukon Territory (Canada) showing their degree of similarity/dissimilarity based on the joining distance: samples are most similar where the horizontal line lengths are shortest. Adjacent nearest neighbours in the clusters were assigned to the same tephra bed if they clustered in the same group, had the same trace element and petrographic characteristics, and had compatible stratigraphic positions (after Lowe, 2011, p.133, redrawn from Preece et al., 2000, pp. 992-993). (A) Four Type-I tephra beds derived from vents in the Aleutian arc-Alaskan Peninsula region. (B) Seven Type-II tephra beds derived from vents in the Wrangell volcanic field or Hayes volcano. Note that this dichotomous classification was modified by Preece et al. (2011a). 
The most common way to communicate the results of a cluster analysis is via a tree-diagram known as a dendrogram, as shown in Fig. 8 (see also Fig. 15 in Section 9 below). The objects are at the tips of branches and the branches are joined in the diagram each time a merger takes place in the algorithm. A dendrogram may be drawn either horizontally or vertically. A joining or merging distance (or similarity) axis is drawn alongside the dendrogram so that the distance value at a merger may be read off the axis. A line drawn at right angles to the axis is said to 'cut' the dendrogram and it corresponds to a partition of the objects into a number of groups, each of which is defined as a cluster. Thus, to define a partition it is necessary to make a choice of the appropriate distance value to cut the tree. This choice is ultimately subjective but it is logical to choose a distance value near a point at which not many mergers are taking place as this avoids having objects nearly equidistant from more than one cluster being almost arbitrarily assigned to a particular cluster.

In Preece et al. (2011b), a spreadsheet (Microsoft Excel) was used to calculate both the distance statistic (as $D^{2}$ ) and the Euclidean distance measure for major-element oxide data and trace-element data, respectively, and then single-linkage cluster analysis for each matrix was performed using the Stata 10 software package (available at http://www.stata.com/). The resulting dendrograms demonstrated for both sets of analyses that numerous occurrences of the Old Crow tephra across Alaska and the Yukon Territory (the object of the study) were tightly clustered together at low joining 
distances and were separate from other tephra beds. The combination of graphical and statistical techniques demonstrated that Old Crow tephra could easily be distinguished from a number of compositionally similar rhyolitic tephra beds (Preece et al., 2011b).

In Iceland, Jones et al. (2007) identified tephras preserved as glass shards within siliceous sinters at Geysir using cluster analysis of major element compositions of the shards. Dendrograms were based on Euclidean space, and generated using routines in Gigawiz Aabel v.1.6 (http://www.gigawiz.com/). Such dendrograms revealed distinct clusters that were easy to delineate visually.

In their study of tephra beds from Silali volcano in eastern Africa, Tryon et al. (2008) developed a dendrogram using hierarchical cluster analysis (based on average linkages) and calculated the degree of sample similarity (measured by Euclidean distance) using Multivariate Statistical Package version 3.13 (Kovach Computing Services, 2008). Clustering was based on centred log-ratio-transformed mean values of all available element oxides. The centred log-ratio is the natural log of the ratio of each oxide value to the geometric mean of all oxides in a particular sample. Such transformations of data are discussed further in Section 7.

Baron et al. (2008) undertook hierarchical clustering of analyses of a series of samples of tephras from California to compare with analyses of the Kern River ash. They adopted three steps: ( $i$ ) finding dissimilarity or similarity between pairs of objects in the dataset (using Euclidean distance); (ii) grouping the objects into a binary 
hierarchical dendrogram (the linkage method was not reported); and (iii) determining where to cut the dendrogram into clusters. The groups on the dendrograms displaying the shortest (joining) distances were more closely correlated. A cophenetic correlation coefficient, $C$, discussed shortly, was calculated using the cophenet function in MatLab, which was used by Baron et al. (2008) for all these statistical procedures.

A new distance measure between objects can be read off the dendrogram. The cophenetic distance between two objects can be defined as the distance value at which the two objects are merged in the dendrogram. The original matrix of distances between objects may be compared with the new matrix of cophenetic distances by calculating the Pearson correlation between the $p(p-1) / 2$ original distances with the corresponding cophenetic distances. (Note that if we have $p$ localities there are $p(p-1) / 2$ distances between them, as displayed in a mileage table, noted earlier.) The result is called the cophenetic correlation and is a measure of how faithful the clustering has been to the original distances between the objects. (The closer to 1, the better the dendrogram reflects the true relative distances between pairs of objects.) This cophenetic correlation can give some evidence to help decide between alternative linkage methods in the clustering. In the study on Kern River ash, a $C$ value calculated at 0.81 indicated that the (unstated) linkage method that Baron et al. (2008) used gave a dendrogram that was a good reflection of the Euclidean distance matrix on which it was based. 
It is often useful and appropriate to combine cluster analysis with PCA, which finds the directions in multi-dimensional space in which a set of variables vary most. The aim is to provide potentially interesting lower-dimensional projections of multivariate data. When the variables are measured on different scales it is necessary to 'standardize' each variable by dividing by its standard error. When variables are measured on the same scale it may also be useful to standardize them in cases where there is a wide disparity in standard deviations, but nevertheless all variables are considered to be important. For example, in observations on human beings two variables may be height and hair thickness, both measured in millimetres. In this situation hair thickness would be effectively eliminated from consideration unless the variables were both standardized.

If the variable standard deviations differ markedly the principal components found will reflect predominantly the more dispersed (i.e. the most imprecisely determined) variable (see Pearce et al., 2008a). A bivariate scatterplot of the first two principal component scores (or occasionally higher principal components) can be useful when the groups of objects are identified on the diagram (Fig. 9). Scatterplots of pairs of constituent variables are also useful, as shown, for example, by Preece et al. (2011b) where a cluster analysis was used in combination with scatterplots (noted earlier). Classification trees (Sheppard et al., 2011) can be fruitful for selecting pairs of variables that separate groups of samples well. An example of such use is given in Fig. 10. 
Another method for selecting the most useful bivariate plots is through the identification of loadings using PCA that show which elements explain most of the differences between samples in PCA plots, as illustrated in Fig. 11 (discussed further below).

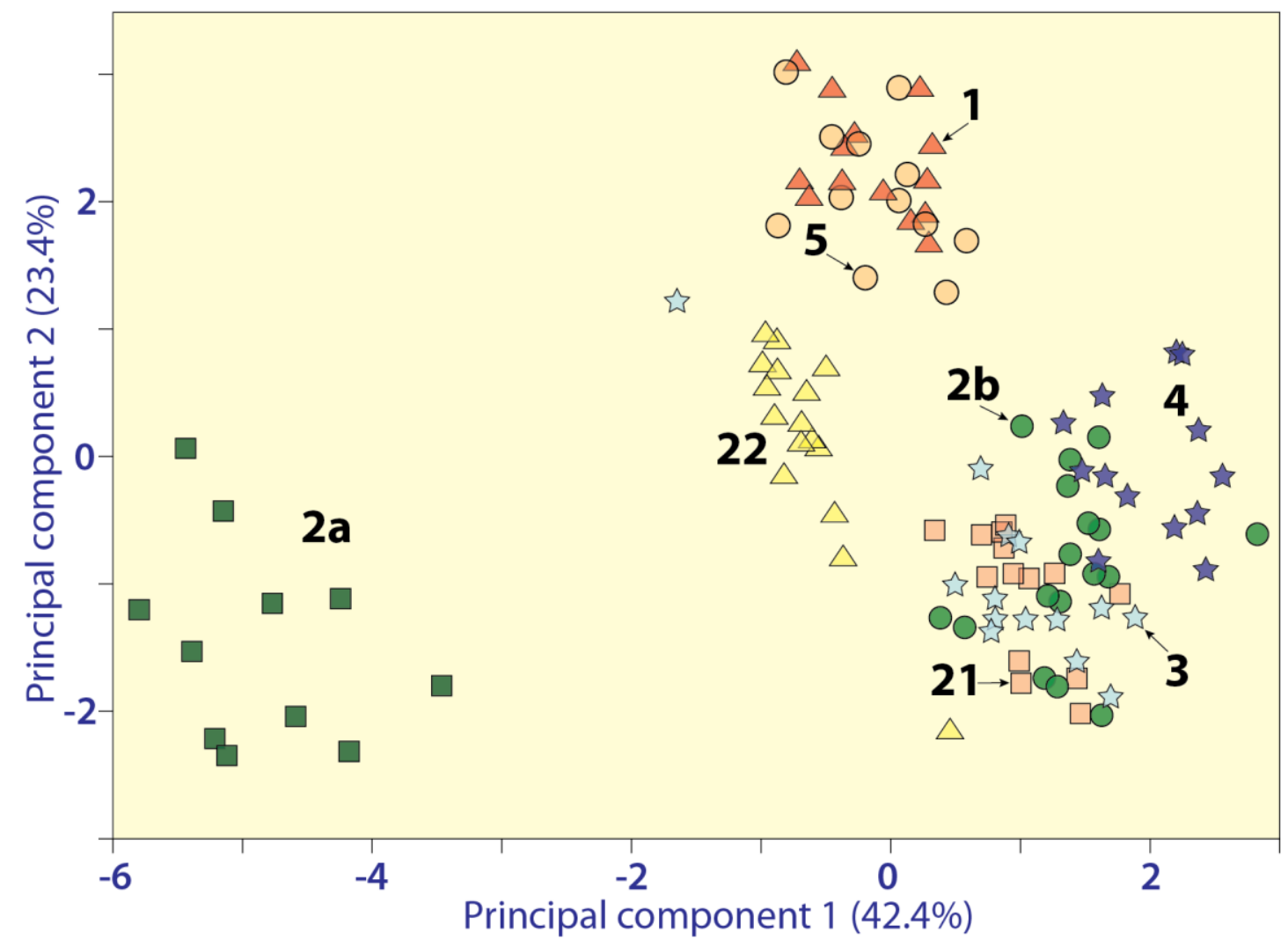

Fig. 9. Example of use of principal components analysis, expressed as a plot of first and second axes (multivariate ordination), to compare oxide abundances of glass shards from tephra deposits in the Wasiriya Beds, Kenya. For clarity, the prefix CAT09- used by Tryon et al. (2010) to denote sample numbers has been omitted here. Samples that are not significantly different, numbers 1 and 5, are equivalent and thus likely correlatives, as are samples in a second group, numbers $2 \mathrm{~b}, 3$, and 21 . However, samples $2 \mathrm{a}, 4$, and 22 differ from one another (analyses are not equivalent) and hence cannot be correlatives (redrawn from Tryon et al., 2010, p. 662). Results from a multivariate analysis of variance (MANOVA) of the geochemical centroids supported these interpretations. 


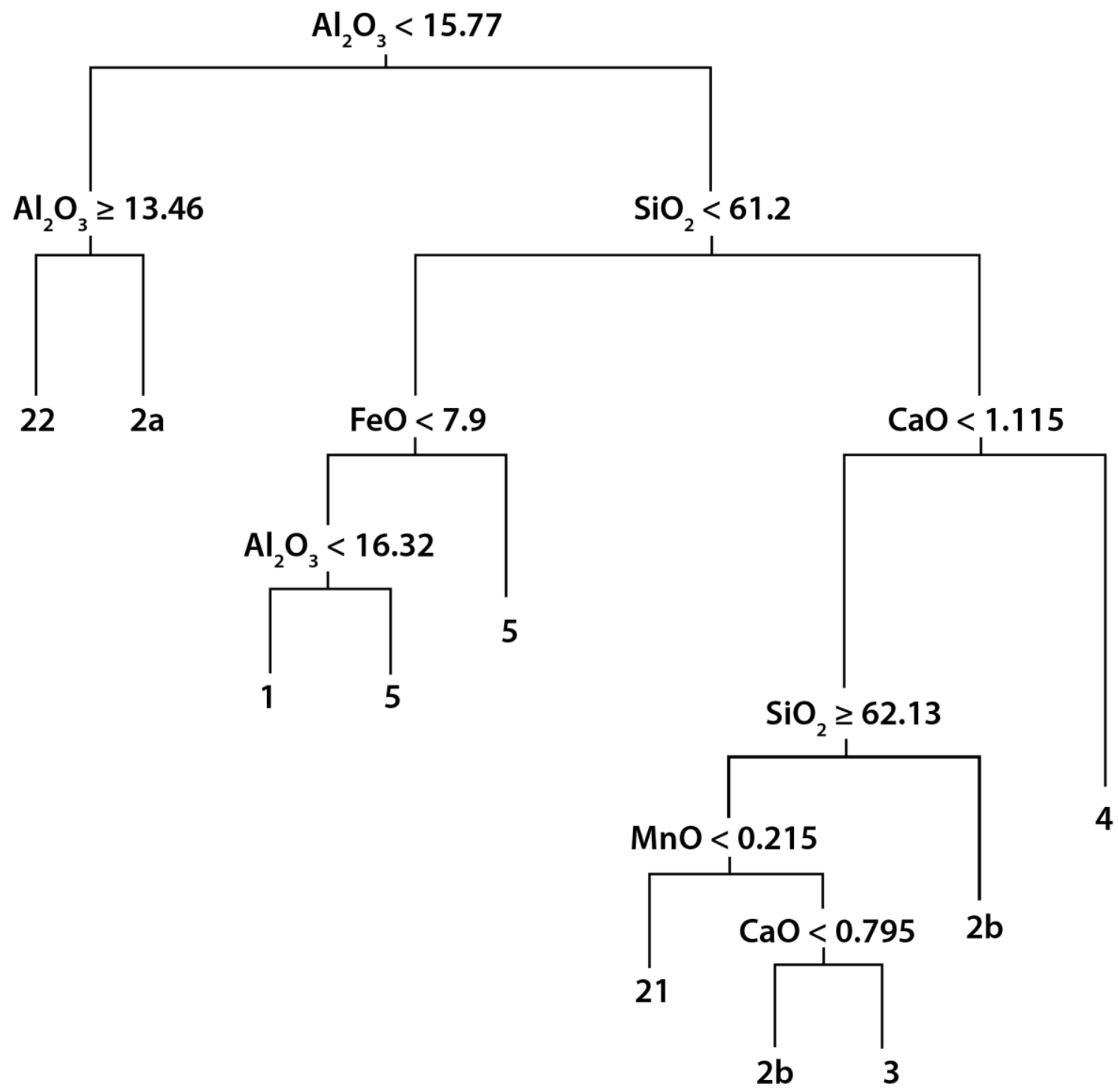

Fig. 10. Classification tree predicting sample group from values of non-normalized oxides of glass shards from tephra deposits of the Kenyan Wasiriya Beds (data from Table S1). For clarity, the prefix CAT09- used by Tryon et al. (2010) to denote sample numbers has been omitted. 
A possible source of confusion is the term 'biplot' which has been used in geochemical papers to mean a bivariate scatterplot but which is defined in multivariate statistics as a plot similar to the plot of two principal components to which has been added a vector for each variable showing how that variable relates to the two principal components (Aitchison, 1983; Aitchison and Greenacre, 2002; Baxter et al., 2005, 2006). 'Biplot' in Aitchison's sense combines the PC1 vs PC2 plot with the 'loading' plot although it may also be constructed for PCA based on covariance matrices.

\subsection{Non-hierarchical cluster analysis}

Hierarchical cluster analysis, considered in the previous section, is the form of cluster analysis most commonly used in tephrochronology. The nested form of the clusters that it produces, as indexed by the dendrogram also produced, are indeed helpful when a natural nesting of clusters is present in the data. For example, clusters corresponding to tephras derived from particular volcanic events might be grouped, at a higher level, into clusters corresponding to particular volcanic sources. However, there is no guarantee that tephra clusters in a sample will be nested in this way, nor, even when they are, that the hierarchy produced when hierarchical cluster analysis is employed can be interpreted in this way. 
Some drawbacks to hierarchical cluster analysis include the fact that the similarities or distances may be defined in many ways and a number of different linkage methods leading to a large number of possible clustering methods. If the tephras are "well-separated" in their properties then the clusters constructed may not be sensitive to these choices, but otherwise they can be.

Where the clusters found by hierarchical cluster analysis are well-separated there is no need to analyse further, but if this is not the case it is sensible to consider what alternative clustering methods might suggest.

Some alternative methods of cluster analysis, not commonly used in tephrochronology thus far, are now considered (Table 3). Partitioning methods form another class of cluster analysis methods. In these methods, the number of clusters, $k$, is taken as known. From some initial cluster assignment, continual perturbations are made with the goal of optimising a criterion. A number of criteria are available, usually based on $W$, the within-cluster covariance matrix, $B$, the between-cluster covariance matrix, and $T$, their total, the overall covariance matrix. The goal is to choose clusters making $W$ small in some sense. The $k$-means clustering algorithm, an unsupervised learning algorithm, is usually considered to be a partitioning algorithm, although it does not directly seek to optimise a criterion. It starts from $k$ points rather than $k$ clusters. At each step all objects are associated with their closest point and then the points are moved to be the mean of their associated objects. It is necessary to run the algorithm many times 
from different starting configurations because the results depend on the initial starting position. The solutions found are rated by the mean of the squared Euclidean distances from the points to the cluster centre, smaller being better. Partitioning methods are discussed in detail by Everitt et al. (2011, chapter 8). A difficulty with applying these methods is that in practice $k$ is not known. It is necessary to form the cluster solutions for a range of $k$ values and compare them with regard to a criterion. Increasing the number of clusters will usually improve the mean squared Euclidean distance criterion, but there will be 'diminishing returns' and a plot of the criterion against $k$ will usually suggest a good choice for $k$.

An example of the use of $k$-means clustering to help stratify analytical data to enable more robust multivariate statistical tests to be undertaken is illustrated in Fig. 11. This figure is derived from a study on the use of apatite trace-element compositions to correlate a sequence of weathered tephras, namely Late Ordovician K-bentonites in Pennsylvania, by Sell and Samson (2011a), who initially used PCA to help distinguish nine different beds in the sequence (Fig. 11a). The data were analyzed for principal components using the nonlinear iterative partial least squares (NIPALS) algorithm in the software package The Unscrambler®. The PCA results were compared with other statistical software that showed similar results, and the analysis was repeated after removing outliers that were greater than 3-sigma of the sample population (Sell and Samson, 2011a). 

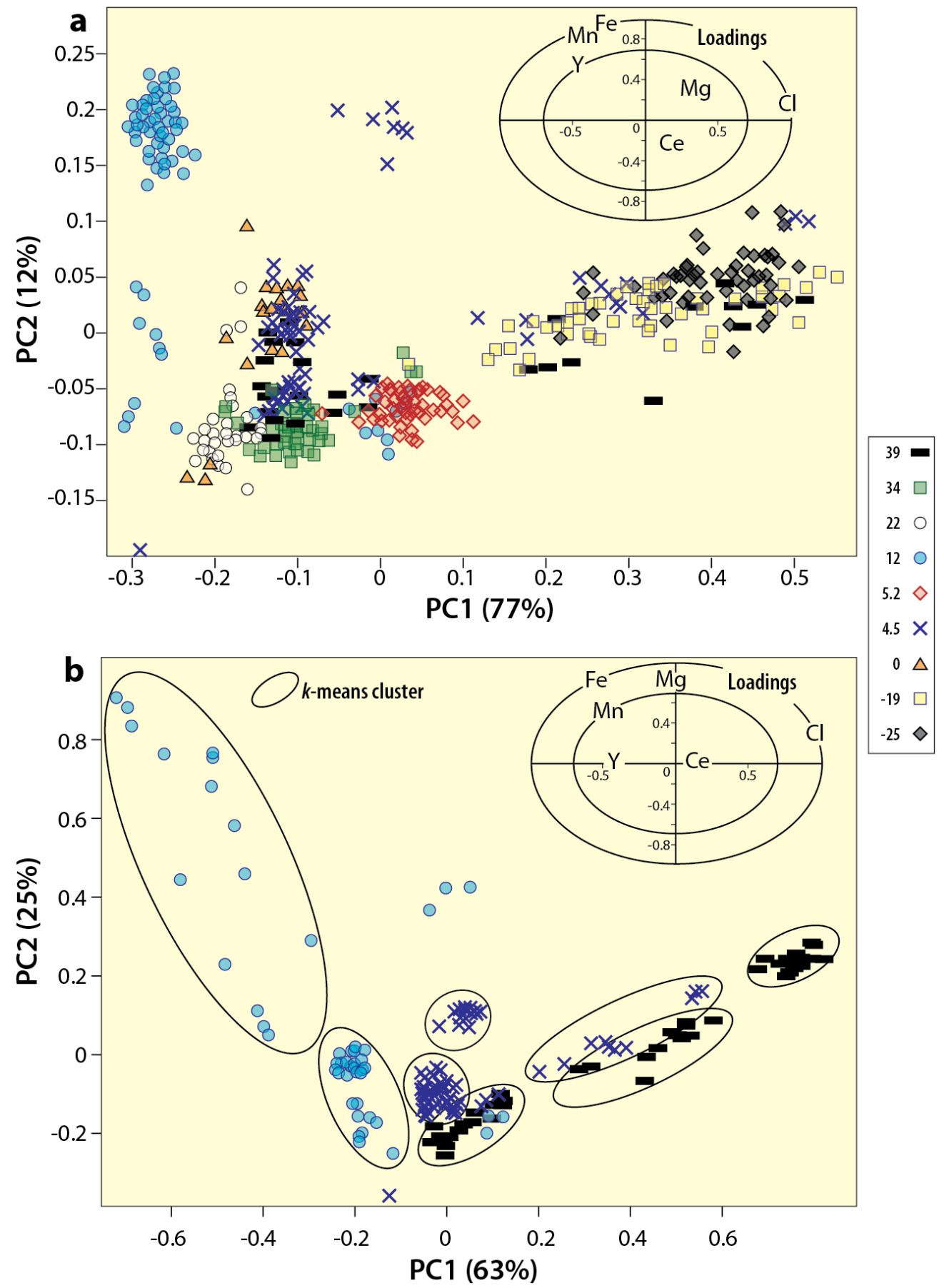
Fig. 11. PCA of trace element analyses of apatite crystals from nine closely-spaced Late Ordovician altered tephra deposits (K-bentonites) in Pennsylvania, USA (redrawn from Sell and Samson, 2011a, p. 164). Sample numbers in the key represent stratigraphic depths in the sequence (metres). Plot (a) shows the PCA of all samples minus outliers. Plot (b) shows the PCA of the three multi-component samples $(4.5,12$, and 39) that contain the outliers, the separate units identified within each sample being depicted using $k$-means clusters. The loadings, shown as ellipses, document which elements (those in the outer ellipse) explain most of the differences between samples in each PCA plot. Thus in (a) the three most important elements in the PCA are $\mathrm{Cl}, \mathrm{Mn}$, and $\mathrm{Fe}$, but in (b) these elements are $\mathrm{Cl}, \mathrm{Fe}$, and $\mathrm{Mg}$, with $\mathrm{Mn}$ losing its ability to be a powerful discriminator (i.e. the importance of a specific element for distinguishing samples can vary from sample to sample).

The ellipses, designated 'loadings' in each PCA plot, indicate which elements explain most of the differences between the samples, those in the outer ellipse being dominant - i.e. $\mathrm{Cl}, \mathrm{Mn}$, and Fe in Fig. 11a; and $\mathrm{Cl}, \mathrm{Fe}$, and $\mathrm{Mg}$ in Fig. 11b. These differences (especially the lesser importance of Mn in Fig. 11b) show that the importance of a specific element for distinguishing samples can vary from sample to sample.

In any event, and irrespective of which elements contribute to the greatest variance between samples, the analyses for beds 4.5, 12, and 39 in Fig. 11a are nonnormally distributed because the apatite crystals evidently represent different populations from the mixing of two or more magmas, or the post-depositional mixing of tephra layers from several different eruptions, or both. Sell and Samson (2011a) therefore applied a $k$-means algorithm to group the data pertaining to samples $4.5,12$, and 39 into more homogenous or normal distributions (on the assumption that the 
apatite trace-element variations in these samples represent distinct crystal groups as occur in magmas: e.g. Jerram and Martin, 2008). These clusters were then able to be visualised in the PCA bivariate plot in Fig. 11b (and which subsequently could be tested using, for example, DFA or the Hotelling $T^{2}$ test, described below in Section 7.3). Any further overlap in such subsets of data would indicate that more multivariate analyses are needed to fully characterize the sample(s) (Sell and Samson, 2011a).

A second example of the use of $k$-means clustering is that of Avery et al. (2017) who differentiated tephra deposits on the basis of ash-particle morphometries (ultimately to evaluate diverse volcanic eruption styles and fragmentation mechanisms). They also employed factor analysis (via R software), the selection of the smallest number of factors to account for most of the variance of the observed parameters being informed by PCA (as in the example above), along with DFA.

\subsection{Outliers and robust methods}

Outliers, or extreme data, are known to have a disruptive effect on many statistical analyses and it is possible to distinguish between statistical procedures that are sensitive to extreme data, such as the mean, and those that are not, such as the median. The latter are called robust (Hampel et al., 2011). When using divisive, distance-matrix based methods with a sensibly-defined distance (or similarity measure), 
outliers are not really a problem because they will separate early from the majority of the observations and hence will have no effect on the subsequent splitting up of the rest. Indeed, this attribute might be taken as a definition of "outlier".

This will not necessarily be true of other clustering methods. Many statistical methods are based on sums of squared differences (the so-called $L_{2}$ norm). These methods are nonrobust. The mean, which minimizes the sum of squared distances to the data points, is nonrobust; and the median which minimizes the sum of absolute distances (the $L_{l}$ norm) to the data points, is robust.

Kaufman and Rousseeuw (1990) developed a set of robust clustering programs based on $L_{1}$ norm methods. Initially these were stand-alone programs but they were rewritten as a library for the statistical language S-PLUS (Struyf et al., 1997). At present, these programs are most commonly used via the "cluster" package of the R statistical language (R Core Team, 2017). As the syntax of R and S-PLUS is very similar, Struyf et al. (1997) remains a key reference for the use of these programs. It is noteworthy that the "cluster" package forms a part of the base distribution of $\mathrm{R}$ and is thus available from every working copy of R. This accessibility is a sign both of the level of usage of the functions of "cluster" and of the confidence shown by the R Core Team in the package.

A brief summary of these seven robust clustering programs is given in the supplementary data (Table S2). 
Multivariate procedures such as principal components analysis are basically $L_{2}$ norm methods and are consequently at risk of being seriously affected by outliers. It is common to remove outliers before carrying out PCA but an alternative is to base the PCA on a covariance matrix that has been estimated by a robust method. The $\mathrm{R}$ function COVRob ( ) in the package robust is one easily available means of obtaining such a robust covariance matrix. The help page for this function lists references underlying the algorithms used. The use of a robust method avoids the necessity of classifying observations as outlying or non-outlying. PCA can be done under both robust and standard covariance estimation and the results compared. Features that emerge under both PCAs can be trusted more than those which appear in one only.

\section{Transformation, scaling, and testing}

It is common for tephra analysts to make judgements about equality of tephras using plots and visual comparisons. Although these can be powerful tools in the hands of expert practitioners (and they often provide compelling evidence for correlations), they are undeniably subjective and there are several reasons why it may be desirable to "calibrate" them against statistical procedures. For example, it may be necessary for the work to be carried out by a less experienced individual for whom the interpretation of some plots without numerical guidance may be difficult. Another situation occurs when 
combining earlier analyses of tephra deposits in neighbouring areas that have previously been identified (effectively classified) by different experts. In reporting the combined analysis it is desirable that the same basis for correlational judgements be made throughout the region. Statistical methods assure this. Finally, when analysing very large collections of tephra-derived compositional data, visual methods become impractical whereas numerical or statistical methods may be incorporated into a program.

\subsection{Transformation}

A number of transformations have been recommended for use with compositional data (although the need and most appropriate choice of transform remain disputed; e.g. see Baxter, 2008, 2016). These transformations may be used prior to subjecting the data to multivariate statistical procedures such as the calculation of distance matrices, hierarchical cluster analysis, and PCA. Baxter (1995) recommended a rank transformation in which each variable has its values replaced by ranks. Scealy and Welsh (2011) suggested a transformation in which the raw data are replaced by the square root of the proportion of each variable. By far the most commonly recommended transformation for compositional data, however, is the centred log-ratio transformation advocated by Aitchison (1986) and Aitchison et al. (2002) and discussed by Stokes and 
Lowe (1988), Pollard et al. (2006), and Pouget et al. (2014b). Campbell et al. (2011) give computational details. This transformation is the log of the ratio of the variable to the geometric mean of all variables. A related transformation is the additive log-ratio transformation (Aitchison, 1986; Campbell et al., 2011) which selects one variable as a 'reference' (e.g. $\mathrm{Al}_{2} \mathrm{O}_{3}$ from EPMA analyses) and forms the logs of the ratios of all other variables to this reference variable.

Transforming data via log ratios before undertaking canonical variates analysis (CVA), or PCA, places more emphasis on the most imprecisely determined element oxides (e.g. $\mathrm{MnO}, \mathrm{MgO}, \mathrm{TiO}_{2}$, which in rhyolites typically have the lowest abundance and poorest analytical precision) by enhancing their variability at the expense of abundant well-determined oxides (such as $\mathrm{SiO}_{2}$ or $\mathrm{Al}_{2} \mathrm{O}_{3}$ ), whose influence in the CVA/PCA is reduced (see Pearce et al., 2008a). Thus the weight of discrimination can be biased in favour of the most poorly determined elements, and hence log transformation followed by CVA or PCA should be used with caution (Baxter et al., 2005; Baxter, 2008, 2016; Pearce et al., 2008a). (CVA is discussed further below.) The square root transformation also focuses more attention on smaller components but to a lesser degree than the log-ratio transformation. It also can cope with zero concentrations, which frustrate the log-ratio transformation as the logarithm of zero is not defined, preventing the calculation of the geometric mean. These effects can be overstated, however. It is not uncommon for log-ratio analysis to give almost identical 
PCA and CVA plots as the corresponding plots from the analysis of untransformed data. Indeed, if this fails to be the case it would be advisable to see if a poorly determined element/oxide is the cause and to consider excluding it from the analyses (see, for example, Pearce et al., 2008a; Baxter, 2016, pp. 93-99). This comment probably applies to most transformations.

\subsection{Scaling}

It is common to scale variables by dividing each by their standard deviation prior to PCA. For example, Baxter et al. (2005) compared the results of scaling with those of log-ratio transformation in undertaking PCA and found transformation to be less effective. Note that scaling the variables prior to applying the log-ratio transformation would have essentially no effect because the transformed variables would only differ by a constant from their unscaled values. Scaling may be applied prior to calculating a distance matrix for use in cluster analysis: essentially Perkins' $D^{2}$ is an unweighted Euclidean distance on the scaled data.

\subsection{Sample variance and testing}


In returning to the two-stage approach noted near the start of Section 6 (the first stage being to examine mean values to identify potential candidates for correlation and to characterize the general structure of the data), the second stage in numerical or statistical studies involves the examination of sample variance (which may show unimodal, polymodal, or broad compositional ranges: Perkins, 2005) to more precisely evaluate the degree of compositional similarity amongst samples (Tryon et al., 2008) (see also general texts such as Walford, 2011). As well as using simple bivariate plots (e.g. Figs. 2 and 6) to seek petrologically meaningful patterns in the data, a range of techniques can be employed including the use of bootstrap sampling (re-calculating the statistics for multiple datasets derived from the original data by sampling with replacement) to test for pair-wise differences between the means of each sample (Tryon et al., 2008; Watson et al., 2017b), Student's $t$-test, and DFA (Table 3).

Another methodology that could be used for this purpose is randomization testing (Manly, 2007). Randomization tests (also known as permutation tests, e.g. Anderson, 2001) are similar to those based on bootstrap sampling and neither approach requires knowledge of the distribution of the test statistic under the null hypothesis, which is certainly an advantage not only when that distribution is totally unknown but also when the assumptions that it has a traditional form (such as a normal distribution) are dubious. Randomization/permutation tests were used, for example, by D'Costa et al. (2011), although not to correlate tephras. 
It is very desirable when suggesting a 'match' or 'correlation' between tephra samples at different sites on geochemical grounds to have a reasonable number of replicates at each site in order that reliable values of Perkins' $D^{2}$ or Mahalanobis $D_{m}^{2}$ statistics may be calculated to obtain distances between the means of match candidates and also between the means of other pairs of tephra samples in the area. (Strictly, we mean Perkins'-like statistics with the analytical variance replaced by within-group variance; in other words, Mahalanobis distances with all covariances taken to be zero. Note, though, that the Perkins' $D^{2}$ has an extra divisor of 2.) Such replication is also valuable for graphical presentation in plots of two elements/oxides of scores from principal components or canonical variates.

The Mahalanobis $D_{m}^{2}$ statistic is closely related to the Hotelling two-sample $T^{2}$ test (Mardia et al., 1979, p. 139). This test is a multivariate generalization of the common two-sample $t$-test for the equality of the means of two populations. The most commonly encountered version of the two-sample $t$-test assumes that the populations are both normally distributed with equal variance, which is estimated for the test by a 'pooled' variance estimate that combines the variance information from both samples. The Hotelling two-sample $T^{2}$ test, applied to $k$-variate data from two samples, tests the hypothesis that the population mean of each of the $k$ variables is the same in both populations. A significant result (small $p$-value) on this test for two tephra sample groups is evidence that the mean compositions of the two tephra populations are 
different, and accordingly that the two groups cannot be a match. The test statistic for the Hotelling two-sample $T^{2}$ test is a multiple of the $D_{m}^{2}$ between the two groups that is based on the pooled variance-covariance matrix. It is intuitive that a large $D_{m}^{2}$ gives evidence against a match but the test provides a way of calibrating this. Analogously to the one-dimensional two-sample $t$-test, the Hotelling two-sample $T^{2}$ test assumes that both populations have equal variance-covariance matrices and that both are ( $k$-variate) normally distributed. Doubts about the equality of two variance-covariance matrices would not undermine a conclusion from a significant test that two tephras did not match because, if the population variance-covariance matrices were not equal, that finding in itself would mean that the two tephras did not match. An alternative to assuming normality and equal variance-covariance matrices is to use the randomization or permutation test methods mentioned above to calculate the $p$-value, as suggested by Campbell and Curran (2009). The R function hotelling.test in the package Hotelling can carry out a Hotelling two-sample $T^{2}$ and has an option to calculate the $p$-value by randomization test methods. PAST software will also provide Hotelling $T^{2}$ values (Hammer et al., 2001).

Chiasera and Cortés (2011) have developed a modified PCA-based method to define a predictive region based on the calculation of the eigenvalues and eigenvectors of the covariance matrix of a log-ratio-transformed dataset. A predictive region cannot be constructed for the raw data because of the singularity of the covariance matrix of the 
raw data because of the closure problem. The predictive region, also known as the tolerance region, is the zone 'drawn' around the mean of the transformed data enclosing the region where individual samples of a single population should be with a given probability. In a plot of the two larger principal components of the data (PC1, PC2), such a prediction region becomes an ellipse. Pouget et al. (2014a) applied this method using the first two principal components to successfully distinguish Mono, Trego Hot Springs, and Rockland tephras, and other samples, in northern California. The main use for the loadings (variable coefficients in the principal components obtained from a PCA based on the correlational matrix of the variables) is choosing which bivariate plots will be most informative. For this large loadings are needed, but not too similar. For example, in Fig. 11a, Mn, Fe, and $\mathrm{Cl}$ stand out with large loadings, but we would not plot Mn vs Fe because their loadings on PC1 and PC2 are similar. Instead, we would plot $\mathrm{Fe}$ vs $\mathrm{Cl}$ because they are nearly at right angles. If another element $\mathrm{X}$ were at 190 degrees in the plot (just into the third quadrant), we would not plot $\mathrm{X}$ vs $\mathrm{Cl}$ because $\mathrm{X}$ and $\mathrm{Cl}$ define almost the same line through the origin and so would be very similar. Perhaps an ironical point here is that most geoscientists studying geochemical data typically generate bivariate plots before undertaking PCA - e.g. using Igpet (Carr, 2017) or GCDkit (Janoušek et al., 2006) as noted earlier - but it is the loadings from the PCA that provide the information on which bivariate plots will be most informative. (Petrogenetic geochemical knowledge is also useful here, using Sr for example as an 
indicator of plagioclase extraction.) Ideally, both the predictive regions and the Hotelling $T^{2}$ analyses should be examined: they will usually line up with each other and the outlier trimming used by Pouget et al. (2014a) is good practice provided it is not pushed too far.

Canonical discriminant analysis is used to refer to one of two closely related statistical methods, canonical variates analysis (CVA) and discriminant function analysis (also known as discriminant analysis). Both are concerned with distinguishing between two or more groups of multivariate observations. CVA is a statistical technique related to PCA that reduces the dimensionality of data (such as compositional analyses) with a large number of independent variables (Mardia et al., 1979, chapter 11.5) (Table 4). As with PCA, CVA is an algebraic technique that results in several new variables that are linear combinations of the original variables. These are called the first, second, etc, canonical variates, analogous to the first, second, etc, principal components. Plots with respect to the canonical variates tend to separate groups better than plots with respect to the original variables. DFA adopts a model formulation assuming a multivariate normal distribution for the populations from which each group is sampled (Table 4). Once the model is fitted to the data it can be used to assign new observations that are known to belong to one of the groups, to the group to which it has the greatest likelihood of belonging (Mardia et al., 1979, chapter 11). This turns out to be the group closest to the new observation in Mahalanobis distance. When all groups are assumed to 
have a common covariance matrix, the likelihood functions for assigning new

observations to classes can be shown to have a simple relationship to the canonical variates (Venables and Ripley, 2002, p. 334).

Table 4. Comparison of discriminant function analysis (DFA) and canonical variates analysis (CVA) .

\begin{tabular}{|l|l|l|}
\hline Characteristic & \multicolumn{1}{|c|}{ DFA } & \multicolumn{1}{|c|}{ CVA } \\
\hline Purpose & $\begin{array}{l}\text { Assign new samples to their closest } \\
\text { group. }\end{array}$ & $\begin{array}{l}\text { Form 'canonical' variates which contrast } \\
\text { the groups. }\end{array}$ \\
\hline Assumptions & $\begin{array}{l}\text { Samples in each group come from a } \\
\text { multivariate normal distribution with a } \\
\text { covariance matrix common to all } \\
\text { groups. }\end{array}$ & $\begin{array}{l}\text { No distributional assumptions but results } \\
\text { best if the within-group covariance matrices } \\
\text { are similar. }\end{array}$ \\
\hline Outputs & $\begin{array}{l}\text { For each sample to be classified, the } \\
\text { Mahalanobis 'distance' to the centroid } \\
\text { of each group or a number related to } \\
\text { this. (Assignment to the group with } \\
\text { closest centroid is usually implied.) }\end{array}$ & $\begin{array}{l}\text { Several (up to one fewer than the number of } \\
\text { groups) canonical variates that are linear } \\
\text { combinations of the original variables. }\end{array}$ \\
$\begin{array}{l}\text { For each sample to be classified and } \\
\text { each group, the estimated probability } \\
\text { that the sample belongs to the group, } \\
\text { given that it belongs to one of the } \\
\text { groups. }\end{array}$ & $\begin{array}{l}\text { If only two (oxide) variables are used, } \\
\text { the regions assigned to each group } \\
\text { may be shown on the scatterplot of the } \\
\text { two oxides. If more variables are used } \\
\text { the regions are higher-dimensional and } \\
\text { difficult to plot. }\end{array}$ & $\begin{array}{l}\text { A measure of the percentage of the } \\
\text { each canonical variate. }\end{array}$ \\
\hline Graphics & $\begin{array}{l}\text { Typically the first two canonical variates } \\
\text { account for most of the between-group } \\
\text { variance, and a scatterplot of these with } \\
\text { the degree of separation of the groups. } \\
\text { (This scatterplot can be constructed so long } \\
\text { as at least two non-collinear oxide variables } \\
\text { are among those used in the CVA, for } \\
\text { which it is necessary but not sufficient that } \\
\text { at least three oxide variables are used.) }\end{array}$ \\
\hline
\end{tabular}

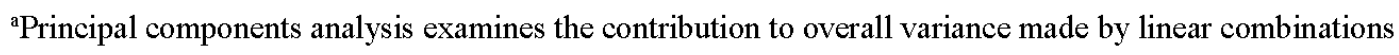
(principal components) of the original variables. CVA does the same thing for the between-group variance but for variables that have been standardized by the root-mean-square within-group standard deviation. Intuitively CVA examines between-group variation on a scale determined by within-group variation. For details see Ripley (2007, section 3.1, p. 92ff). 
On the other hand, CVA produces a small number of linear combinations of the quantitative variables which best discriminate pre-defined groups of observations or analyses. Consequently, instead of working with, say, nine or ten oxide analyses of glass to discriminate groups of samples, one or two canonical variables may contain most of the relevant information. A reference (or training) set of analyses with predefined groupings must first be set up, and DFA may be used to produce a discriminant model or classification that can be used to classify unknown observations or analyses using the reference set (e.g. Lowe et al., 2007; Bourne et al., 2010; Cerovski-Darriau et al., 2014; Habermann et al., 2016). Such a training set may comprise analyses of 'type' or well-established 'reference' samples for a specific tephra, or a comprehensive suite of analyses of stratigraphically constrained proximal eruptives to which analyses from possible distal correlatives can be compared.

CVA has an important application to the graphical display of several groups of samples. Plotting the groups of samples with respect to the first and second (and possibly higher) canonical variate scores gives a picture of the data in which the different groups of samples tend to be well separated. If two groups fail to be separated in such plots they are possibly a match (correlation) (e.g. see Fig. 14 in Section 9.3).

\section{Guide to tephra correlation: recommendations}


We have discussed many different statistical approaches to establish the equivalence of tephra deposits using their intrinsic, grain-by-grain, glass or mineral compositions. Although we strongly advocate the use of quantitative approaches to assess what is essentially the degree of confidence in our correlations, we caution against a wholly "black box" approach. That is, it is often the case that if a correlation can only be established using a very sophisticated statistical approach, then that correlation may be highly suspect. Also unsupported are correlations made solely on the basis of geochemical compositional data that violate basic stratigraphic observations or chronological data. As is the case with many things in life, the principles of Occam's Razor from the $14^{\text {th }}$ century are useful in tephrostratigraphy. With this in mind, we outline here a broad step-by-step approach (Fig. 12) for the correlation of tephra deposits that draws on the methods described earlier in this paper, followed in Section 9 by new and published examples using a common set of data to show different results. For each step, the reader is referred to the previous text for in-depth explanations, examples, and references. Because tephras have multiple origins and compositions, and potentially complex patterns of distribution and varying degrees of preservation, we firmly emphasise that it is not possible to cover all circumstances with a "one-size-fitsall" approach to tephra or indeed cryptotephra correlation, and so Fig. 12 is necessarily generalised. 


\section{Sample collection and context}

e.g. observations from core or outcrop including stratigraphy, age, physical properties, depositional context

$\downarrow$

Analysis of sample components (e.g. glass) e.g. EPMA, LA-ICP-MS

Data inspection

e.g. single or multiple populations?

\section{Data transformation}

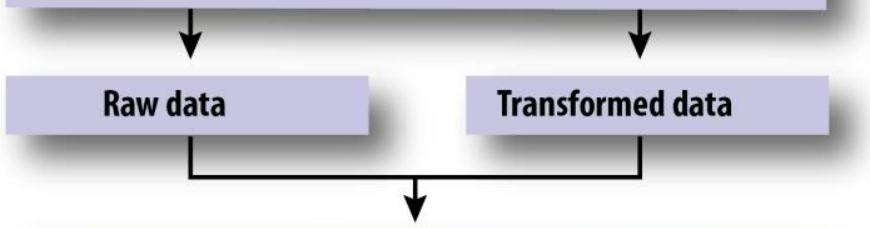

\section{Data exploration}

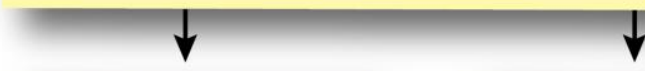

Visual approaches

e.g. bivariate plots, PCA, cluster analysis Numerical approaches e.g. iterative sorting
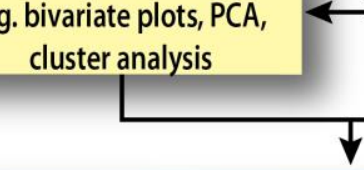

\section{Hypothesis testing}

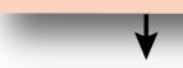

Comparisons to known e.g. DFA, CVA

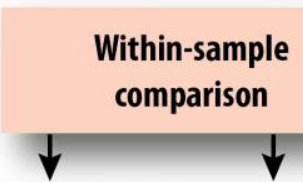

Sample mean/variance Single measure e.g. $t$-test, bootstrapping, e.g. Perkins' $D^{2}, S C$ Hotelling's $T^{2}$, ANOVA, MANOVA 
Fig. 12. General step-by-step guide for the correlation of tephra deposits that draws on the methods described earlier in this paper. It is important to use (and document) currently accepted analytical protocols in acquiring compositional data.

\subsection{Field setting provides stratigraphic context}

As described elsewhere (Section 5), the stratigraphic position, age, and physical properties of a tephra layer (or cryptotephra deposit) in an outcrop or in a core - the field setting - form the essential starting point and basis for any chemical analyses to characterize a deposit and its components (such as glass shards) to help enable its correlation. We are dealing here entirely with glass or mineral chemical data and the presentation and statistics associated with such data. Other information, such as mafic (ferromagnesian) mineralogy or glass-shard morphology (or magnetostratigraphy, for example), can also be important, which is why there is a 'feedback' loop from the base of Fig. 12 to the top to ensure that correlations based on geochemical and statistical inferences are consistent with the field setting and context, or with the chronostratigraphic evidence associated with a sediment core. If not, questions need to be asked.

\subsection{Data inspection}


Following the generation of compositional data by EMPA, LA-ICP-MS, or other approaches, the first step is an initial inspection of data to identify degree of homogeneity or heterogeneity, outliers, cases of poor or incorrectly entered data, or results that fail some other minimal criterion for an acceptable analysis, such as analytical totals $<90 \mathrm{wt} \%$ in the case of glass. Although this step can be done by inspecting tables of analytical data, it is perhaps most readily performed graphically using visualization tools available in Excel or other readily available software to aid the process (noted previously). There are no fixed "rules" to this process, which is often based on expert knowledge or experience - for example, having a prior understanding of the compositional range of the deposits associated with a potential source volcano, or spotting a glass analysis that unwittingly included a feldspar microcryst.

\subsection{Data transformation}

At this point, the decision should be made whether or not to transform the (raw) compositional data and, if so, which approach to use. We advocate generally a conservative approach, with data analysis performed using both raw and transformed data. In our experience, the results are often the same (e.g. see example in Section 9.3), but different results between raw and transformed data may be useful for highlighting important features within the dataset. These features might arise from differences in 
variance or abundance among elements, or measurement precision. Several different types of data transformation are available, from the relatively common normalization of analytical totals of glass major-elements to sum to $100 \%$ on the assumption that the difference is due to water (Section 3.3) or to ensure the same range of elements is compared from different laboratories, to more complex approaches, such as use of the centered log-ratio transformation, that attempt to standardize variables to measure differences between them that may be more meaningful.

\subsection{Data exploration}

This step represents initial exploration of the dataset to begin to develop testable hypotheses, i.e. pairs or groups of tephra suspected to be equivalent, informed perhaps by stratigraphic or other considerations such as age or mafic mineralogy. There are various ways to do this, and much of it is a matter of personal preference between numerical and various visual approaches. One numerical approach is to use a process of iterative sorting on an element-by-element basis in Excel or other database to group objects into sets that are most alike.

The simplest visual approach is the bivariate plot (or sets of them, as in a scatterplot matrix, e.g. Fig. 6), where the values of pairs of element oxides are shown on an $x-y$ grid. This approach can be undertaken with any available software, and bivariate 
plots by far are the most common method of data presentation in tephrostratigraphic studies (e.g. Pearce et al., 2008a). Several points must be made about them. First, any given bivariate plot is useful only in suggesting a potential correlation. For example, that sample A and sample $\mathrm{B}$ overlap perfectly in, say, a plot of $\mathrm{FeO} v s \mathrm{TiO}_{2}$ may be insufficient to establish correlation if those same two samples show substantial divergence in the abundance of, say, $\mathrm{CaO}$ or $\mathrm{Al}_{2} \mathrm{O}_{3}$, or in trace elements (e.g. Fig. 4). As a result, bivariate plots on their own can be more useful for identifying sample pairs that are not the same rather than demonstrating equivalence. If all plots overlap for all the elements that have been determined, then a correlation is strongly indicated. However, sample pairs that do not show some form of overlap in a simple bivariate plot are most likely not equivalent, regardless of the complexity of the computational algorithm used.

A complication here is that some tephras may have multiple "fingerprints", shown usually by heterogeneous glass populations, because they derived from compositionally-zoned magma chambers or from an eruption that tapped several magma chambers simultaneously or sequentially, or they comprise the products of magmamingling. Consequently, different stages of the eruption episode may have generated a series of closely-spaced tephras with very different compositions temporally and spatially if they were dispersed in different directions away from the source volcano over time (e.g. Bacon and Druitt, 1988; Lowe et al., 2008). Such internal heterogeneity within a tephra ostensibly derived from a 'single' eruption episode highlights the 
inadequacy of characterizing a tephra from a small number of samples of restricted dispersal (e.g. Shane et al., 2008a).

Principle components analysis (PCA) and various forms of cluster analysis also provide relatively simple data reduction and visualization tools that recognize the multivariate nature of geochemical data, but reduce this variance into a few axes or measures. Typically, a plot of the first two (or sometimes three) axes of a PCA will demonstrate the major structure within a dataset, and identify potential correlatives (e.g. Fig. 9). Similarly, although we have outlined a number of different types of cluster analysis, in most cases, the major 'cuts' or groupings produced tend to differ little for a given dataset, and thus we advocate use of any of the cluster analyses as an exploratory tool. Hierarchical clustering with average or Ward's linkages is often recommended as a default. When the number of tephras to be clustered is large, we may expect some data quality problems, suggesting the use of a more robust method, such as AGNES or FANNY from Table S2. Of course, the grouping of particular samples or analyses may vary with method, but these sorts of differences can be more formally explored or tested in the next step.

\subsection{Hypothesis testing and the identification of correlative deposits}


Once potentially equivalent samples have been identified, more formal statistical testing of the hypothesized correlations can be attempted. The approach used depends in part on the nature of the proposed correlations and the questions being asked, and the compositional complexity of the deposits. For example, if the question is, "Does distal tephra sample X come from volcano Y?" and if the geochemical compositions of glasses (and/or crystals) of tephra eruptives of volcano Y are known from single-grain analyses, then approaches suited to comparing samples of 'unknown' distal tephras to those of 'known' composition from the source volcano are ideal. We warn there that $(i)$ it is imperative that 'like is compared with like' so that single-grain analyses of glass shards in distal samples should be compared with similarly-analysed individual glass shards close to source (i.e. rather than with bulk proximal analytical data on either pyroclastic material or lava) to ensure that any heterogeneity or magma mixing or postdepositional mixing is identified; and (ii) the proximal stratigraphy may not be completely known nor fully analysed. The most widely used of these statistical tools are discriminant function analysis (DFA) and the closely related canonical variates analysis (CVA) (Table 4). DFA provides quantitative measures of the goodness-of-fit of various 'unknown' samples to possible 'known' correlates, but interpreting the results depends strongly on the nature and completeness of the 'known' dataset. If, after years of study, a new eruptive phase on volcano $\mathrm{Y}$ is discovered and characterized, the DFA/CVA 
would need to be repeated to account for the presence of new analyses within the expanded 'known' dataset, which may result in a different set of correlations.

Perhaps a more common, and less assumption-laden approach, is to simply seek correlations between samples or analyses within a given dataset. A typical question in this approach might be "Do sample D and sample E represent the same eruption/depositional event?" There will always be some compositional variance between shards from a single eruption (variation caused by magmatic processes or eruption from multiple magma bodies, post-eruption or post-depositional alteration, or instrumental issues, described earlier). Because of this, and in addition to adherence to analytical protocols defined earlier, we advocate measures that recognize sample variance and co-variance be used to establish equivalence among that subset of samples identified during the data exploration step. These include methods that compare the mean and standard deviation of different element oxides between pairs or groups of samples, such as Student's $t$-test, bootstrapping, Hotelling's $T^{2}$, analyses of variance (ANOVA), or multiple analyses of variance (MANOVA). Other approaches generate single values for a given sample (assessing multiple variables simultaneously) that can be used to assess the similarity of a given pair of samples, including the $t$-test, Perkins $D^{2}$ statistic, or some derivative of the similarity coefficient (SC) approach.

The point of the hypothesis testing step is simply to provide some quantified measure of similarity as a means to assess the strength or confidence in a given 
correlation, whether expressed in terms of formal statistical probability (e.g. $p<0.05$, or there being a less than $5 \%$ chance that a difference as great or greater than that observed would be encountered were each of the pair to come from the same source) or according to some arbitrarily but clearly defined cut-off (e.g. correlative deposits are potentially those with an SC >0.95).

\subsection{Back to first principles}

Geochemical data are subject to statistical manipulation in the same way that any other numerical data are, and we have outlined a number of different ways to examine, plot, transform, and compare the suite of elemental abundances used to characterize tephra through analysis of its primary components, especially glass shards (Fig. 12). The advantage of these numerical data is that they can be subjected to rigorous statistical analyses, something we feel has still not yet become standard tephrostratigraphic practice, although ideally it should. However, the final step in our recommended analytical scheme is to re-examine any correlations proposed by statistical analyses by comparing them against basic stratigraphic observations and other supporting data such as tephra age, physical properties (e.g. grain size), mineral assemblage, phenocryst or crystal composition, the effects of magmatic processes which may operate to cause compositional change during eruptions, and associated 
information such as depositional context of the site (e.g. palynology may indicate glacial $v s$ interglacial conditions at the time of tephra deposition). This step will serve to identify false-positives, and also likely provide a useful springboard for further research. For example, $(i)$ potential correlates and chemically similar tephra or cryptotephra deposits derived from a single volcano undergoing a repetitive eruptive cycle might in fact represent multiple eruptives separated in age by several thousands of years rather than representing the product of a single eruption event (Section 5.2); (ii) two compositionally different deposits from different locations may be linked as products of the eruption of a zoned magma chamber, or an eruption from multiple magma chambers, dispersed in different directions; or (iii) the 'surprise' or aberrant identification of correlative deposits can help in the identification of a previously unrecognized fault, sediment slump, or re-depositional event (e.g. Lowe, 2011).

In some cases where geochemical data have been used to affect correlations that seem to contradict new findings, it may also be necessary to re-examine the data underpinning the previously-proposed correlations because an error (miscorrelation) in an antecedent paper could lead to perpetuation of that error in later ones.

\section{Case studies using statistical methods}




\subsection{PCA, MANOVA, and Hotelling $T^{2}$ test (Kenyan tephra data)}

Tryon et al. (2010) published a study using a number of the statistical methods mentioned above. PCA, as noted earlier, is a data reduction technique designed to identify and visualize the major axes (components) of variability in a matrix of data. Tryon et al. (2010) used PCA to examine sample equivalence between eight groups of observations taken from analyses of glass in tephras from within the sedimentary Wasiriya Beds in Rusinga Island, Lake Victoria, Kenya (Fig. 9). The data comprise the amounts (weight percentages) of nine major element oxides in glass shards from the trachytic and phonolitic Wasiriya tephra deposits as determined by EPMA (listed in supplementary data Table S1). (Strictly speaking, the use of PCA belongs to the first stage of statistical analysis as it is based on overall variation, not within-group variation.) Tryon et al. (2010) then tested that sample equivalence using multivariate analysis of variance (MANOVA), the first tephra study to do so, together with Hotelling's two-sample $T^{2}$ test amongst others. PCA was used to visualize the distribution of samples in a low-dimensional space (Fig. 9) with MANOVA, and Hotelling's two-sample $T^{2}$ test was then used to determine if geochemical centroids of different samples were significantly different. Samples that were found not to differ statistically were likely to be correlatives (Tryon et al., 2010), or at least had passed a major barrier against being regarded as such. Results of the one-way MANOVA 
indicated that there were significant differences in the geochemical composition of different samples in the total sample pool examined by Tryon et al. (2010), suggesting that it was highly unlikely $(p<0.0001)$ that all sampled tephra deposits were derived from a single eruption, thus confirming stratigraphic observations of multiple, separate depositional events. The statistical analyses also provide independent support (in this instance) for the interpretation of various bivariate plots that visually show similar separations.

\subsection{DFA (New Zealand tephra data)}

An example of how DFA was used, in conjunction with stratigraphic and mineralogical data, to distinguish and correlate late Quaternary rhyolitic tephras in North Island, New Zealand, is shown in Fig. 13 as the first part of the second case study. The tephras were divided into two stratigraphically distinct groups of tephras using a regional marker bed (Kawakawa tephra) so that two relatively simple discriminant models were developed rather than a single but more complex model (Stokes and Lowe, 1988; Cronin et al., 1997; Lowe, 2011). From this study, based on seven (log-transformed) major element oxides obtained from the EMPA of glass, it is evident that two very widespread late Quaternary tephras such as the Kawakawa and Rotoehu tephras would be unlikely to be misidentified if only one of them were present 
in an exposure or core at a distal site. The least similar (most different) tephras are Hauparu and Tihoi, which plot far apart in Fig. 13. The distance measure used was the squared Mahalanobis distance, $D_{m}^{2}$, with a value of 262 in this case. In contrast, the Kawakawa and Okaia tephras (both erupted from Taupo volcano within about $~ 3000$ years of each other: Lowe et al., 2013) are indistinguishable on the basis of glass majorelement composition (the $D_{m}^{2}$ value is only 7.3 in this instance) (Cronin et al., 1997). Note that Omataroa and Kawakawa tephras, although relatively close $\left(D_{m}^{2}\right.$ is 25), are separable using DFA, whereas they cannot be distinguished using the bivariate plot of $\mathrm{CaO}$ vs $\mathrm{FeO}$ glass content as presented in Fig. 4a. It is evident from analytical data that the oxides of Omataroa and Kawakawa glasses are essentially identical except for $\mathrm{Na}_{2} \mathrm{O}$, which is higher in Omataroa (Cronin et al., 1997; see also Smith et al., 2005). This relatively small difference appears sufficient to provide the DFA-based separation. 


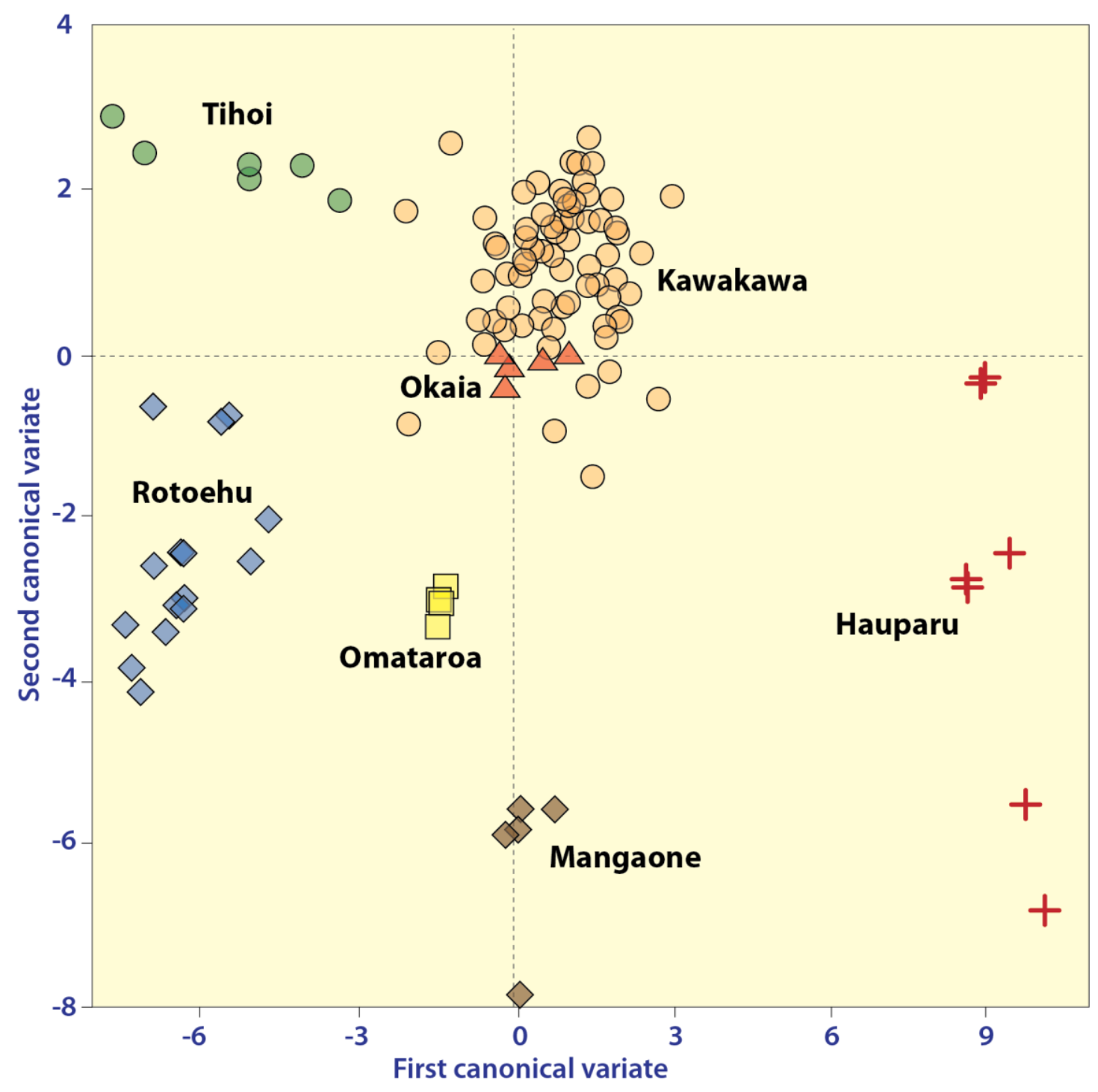

Fig. 13. Example of use of DFA to compare degree of similarity of seven late Quaternary rhyolitic tephras in central North Island, New Zealand. Glass compositions of each tephra were combined using DFA into the first two canonical variates. The Mahalanobis distance between groups $\left(D_{m}^{2}\right)$ is a direct measure of their multivariate similarity/dissimilarity based on all seven major oxides analyzed, not just two or three (from Lowe, 2011, p. 135, redrawn from Cronin et al., 1997, p. 182). Note that this DFA plot using multiple elements distinguishes Omataroa and Kawakawa tephras, in contrast to the single bivariate plot of Fig. 4a. 
Another New Zealand study that used DFA of EPMA-derived analyses of Fe-Ti oxides (titanomagnetite crystals), rather than glass shards, is that of Turner et al. (2011b). They correlated andesitic tephras preserved in lake sediments with sub-aerial (dry-land) proximal tephras associated with Mt Taranaki. In many instances the DFAbased correlations, afforded by the smallest $D_{m}^{2}$ values, provided more than one possible correlation for each individual tephra. This ambiguity arose because the titanomagnetites in some tephras from different eruptions were similar compositionally because of magmatic cycling (and magma temperature variations) at Mt Taranaki, as documented by Turner et al. (2011a). Therefore, only the DFA-based correlations that were consistent with the observed stratigraphy (stratigraphic ordering) were adopted.

\subsection{Classification and clustering methods including use of transformations (Kenyan tephra data)}

As a third example we consider again the tephra samples from the Wasiriya Beds in Kenya. Seven samples (comprising multiple glass shard analyses: Table S1) were labelled CAT09-01, CAT09-02, CAT09-03, CAT09-04, CAT09-05, CAT09-21 and CAT09-22 (Tryon et al., 2010, their fig. 3). Heterogeneity was detected in CAT0902, which was subdivided into two subsamples, CAT09-02a and CAT09-02b (Fig. 9). 
We illustrated earlier in Fig. 6 the use of a scatterplot matrix to show the clear-cut nature of the separation between CAT09-02a and CAT09-02b. Notice in that matrix that oxides $\mathrm{SiO}_{2}, \mathrm{Al}_{2} \mathrm{O}_{3}$, and $\mathrm{MgO}$ are particularly effective in separating the two subpopulations, and pairs of these yet more so (Fig. 6). Fig. 10 shows a classification tree for all eight sample groups obtained using the rpart package of $R$ (R Core Team, 2017) in which the sample group is predicted from the non-normalized oxide values. This package is an $R$ implementation of the routines of Therneau and Atkinson (1997) written to carry out the algorithms of Breiman et al. (1984). It should be cautioned that this classification tree is not suitable for matching two sample groups: in the classification tree the groups CAT09-02a and CAT09-22 could appear to be matched, but it is evident in Fig. 9 - and also in further statistical tests described below - that this is far from true. It could, however, be used to allocate a new sample to one of the eight groups if it were known to belong to one of them. The classification tree suggests that a scatterplot of $\mathrm{SiO}_{2}$ vs $\mathrm{Al}_{2} \mathrm{O}_{3}$ with different symbols for each group could be useful.

We considered multivariate analyses of both the untransformed data and the logratio transformed data for tephras of the Wasiriya Beds. For the log-ratio transformation we chose a reference group for the formation of the ratios. It is advisable to choose a reference element with a coefficient of variation as small as possible, or, almost equivalently, a standard deviation of the log-transformed data as small as possible (Table 5). 
Table 5. Coefficients of variation (CV) and standard deviation of the natural log of the normalized glass-shard analytical data (sd.log) of tephra sample groups from the Kenyan Wasiriya Beds (data from Table S1, after Tryon et al., 2010).

$\begin{array}{lccccccccc} & \mathrm{SiO}_{2} & \mathrm{TiO}_{2} & \mathrm{Al}_{2} \mathrm{O}_{3} & \mathrm{FeO} & \mathrm{MnO} & \mathrm{MgO} & \mathrm{CaO} & \mathrm{Na}_{2} \mathrm{O} & \mathrm{K}_{2} \mathrm{O} \\ \mathrm{CV} & 0.0253 & 0.0612 & 0.0963 & 0.1268 & 0.2485 & 0.2425 & 0.2818 & 0.0833 & 0.0518 \\ \text { sd. } \log & 0.0251 & 0.0616 & 0.1097 & 0.1231 & 0.2486 & 0.3406 & 0.3225 & 0.0827 & 0.0518\end{array}$

In Table 6 we compare the correlation coefficients of log-ratios for the choices of $\mathrm{SiO}_{2}$ and $\mathrm{MgO}$ as reference oxides. The much higher relative variability of $\mathrm{MgO}$ causes $\mathrm{MgO}$-based log-ratios to be highly correlated and hence harder to interpret (Table 6a). Accordingly, we used $\mathrm{SiO}_{2}$ as the reference oxide in our log-ratio transformations (Table 6b).

Table 6 (a). Correlation coefficients of $\log$ ratios with $\mathrm{MgO}$ divisor of tephra sample groups from the Kenyan Wasiriya Beds (glass-shard data from Table S1).

$\begin{array}{lllllllll} & \mathrm{SiO}_{2} & \mathrm{TiO}_{2} & \mathrm{Al}_{2} \mathrm{O}_{3} & \mathrm{FeO} & \mathrm{MnO} & \mathrm{CaO} & \mathrm{Na}_{2} \mathrm{O} & \mathrm{K}_{2} \mathrm{O} \\ \mathrm{SiO}_{2} & 1.000 & 0.988 & 0.983 & 0.972 & 0.855 & 0.455 & 0.961 & 0.991 \\ \mathrm{TiO}_{2} & 0.988 & 1.000 & 0.969 & 0.942 & 0.835 & 0.452 & 0.933 & 0.982 \\ \mathrm{Al}_{2} \mathrm{O}_{3} & 0.983 & 0.969 & 1.000 & 0.959 & 0.858 & 0.542 & 0.975 & 0.982 \\ \mathrm{FeO} & 0.972 & 0.942 & 0.959 & 1.000 & 0.861 & 0.424 & 0.972 & 0.957 \\ \mathrm{MnO} & 0.855 & 0.835 & 0.858 & 0.861 & 1.000 & 0.415 & 0.876 & 0.849 \\ \mathrm{CaO} & 0.455 & 0.452 & 0.542 & 0.424 & 0.415 & 1.000 & 0.492 & 0.468 \\ \mathrm{Na} 2 & 0.961 & 0.933 & 0.975 & 0.972 & 0.876 & 0.492 & 1.000 & 0.952 \\ \mathrm{~K}_{2} \mathrm{O} & 0.991 & 0.982 & 0.982 & 0.957 & 0.849 & 0.468 & 0.952 & 1.000\end{array}$


Table 6 (b). Correlation coefficients of $\log$ ratios with $\mathrm{SiO}_{2}$ divisor of tephra sample groups from the Kenyan Wasiriya Beds (glass-shard data from Table S1).

\begin{tabular}{lrrrrrrrr} 
& $\mathrm{TiO}_{2}$ & $\mathrm{Al}_{2} \mathrm{O}_{3}$ & \multicolumn{1}{c}{$\mathrm{FeO}$} & \multicolumn{1}{c}{$\mathrm{MnO}$} & \multicolumn{1}{c}{$\mathrm{MgO}$} & $\mathrm{CaO}$ & $\mathrm{Na}_{2} \mathrm{O}$ & \multicolumn{1}{c}{$\mathrm{K}_{2} \mathrm{O}$} \\
$\mathrm{TiO}_{2}$ & 1.000 & 0.297 & -0.578 & -0.180 & 0.345 & 0.245 & -0.302 & 0.338 \\
$\mathrm{Al}_{2} \mathrm{O}_{3}$ & 0.297 & 1.000 & -0.477 & -0.117 & 0.940 & 0.783 & 0.347 & 0.773 \\
$\mathrm{FeO}$ & -0.578 & -0.477 & 1.000 & 0.309 & -0.533 & -0.416 & 0.403 & -0.503 \\
$\mathrm{MnO}$ & -0.180 & -0.117 & 0.309 & 1.000 & -0.191 & -0.090 & 0.341 & -0.121 \\
$\mathrm{MgO}$ & 0.345 & 0.940 & -0.533 & -0.191 & 1.000 & 0.679 & 0.158 & 0.741 \\
$\mathrm{CaO}$ & 0.245 & 0.783 & -0.416 & -0.090 & 0.679 & 1.000 & 0.267 & 0.572 \\
$\mathrm{Na} 2 \mathrm{O}$ & -0.302 & 0.347 & 0.403 & 0.341 & 0.158 & 0.267 & 1.000 & 0.115 \\
$\mathrm{~K}_{2} \mathrm{O}$ & 0.338 & 0.773 & -0.503 & -0.121 & 0.741 & 0.572 & 0.115 & 1.000
\end{tabular}

The scatterplot matrices of the element oxides (Fig. 6) do not show any other cases of clear separation between groups apart from that between CAT09-02a and CAT09-02b, and in fact between CAT09-02a and all other sample groups. CAT09-02a remains a locally distinctive trachytic tephra, even with a substantially expanded comparative database for the Lake Victoria region (Blegen et al., 2015). Because of its distinctiveness, we dropped the group CAT09-02a and submitted the remaining groups to canonical variates analysis (Figs. 14a, 14b). The first two canonical variates explain 91.82\% (untransformed) (Fig. 14a) and 93.85\% (log-ratio transformed) (Fig. 14b) of the variance in the observations. The plots are almost identical (bearing in mind that axis orientation is arbitrary) and show three clusters of points: CAT09-22 by itself (almost); CAT09-01 and CAT09-05; and a looser cluster containing CAT09-02b, CAT09-03, CAT09-04, and CAT09-21. A single analyzed shard from CAT09-03 (pale blue star) is located in both plots close to CAT09-22 and remote from its own group. 
This positioning might or might not be a misidentified or mis-entered observation, or it may simply represent variation present in the bed resulting from post-depositional mixing of shards from two formerly separate eruptives (e.g. Fig. 2d; see also Boygle, 1999; Pyne-O’Donnell, 2011; Guðmundsdóttir et al., 2012; Pouget et al., 2014b).

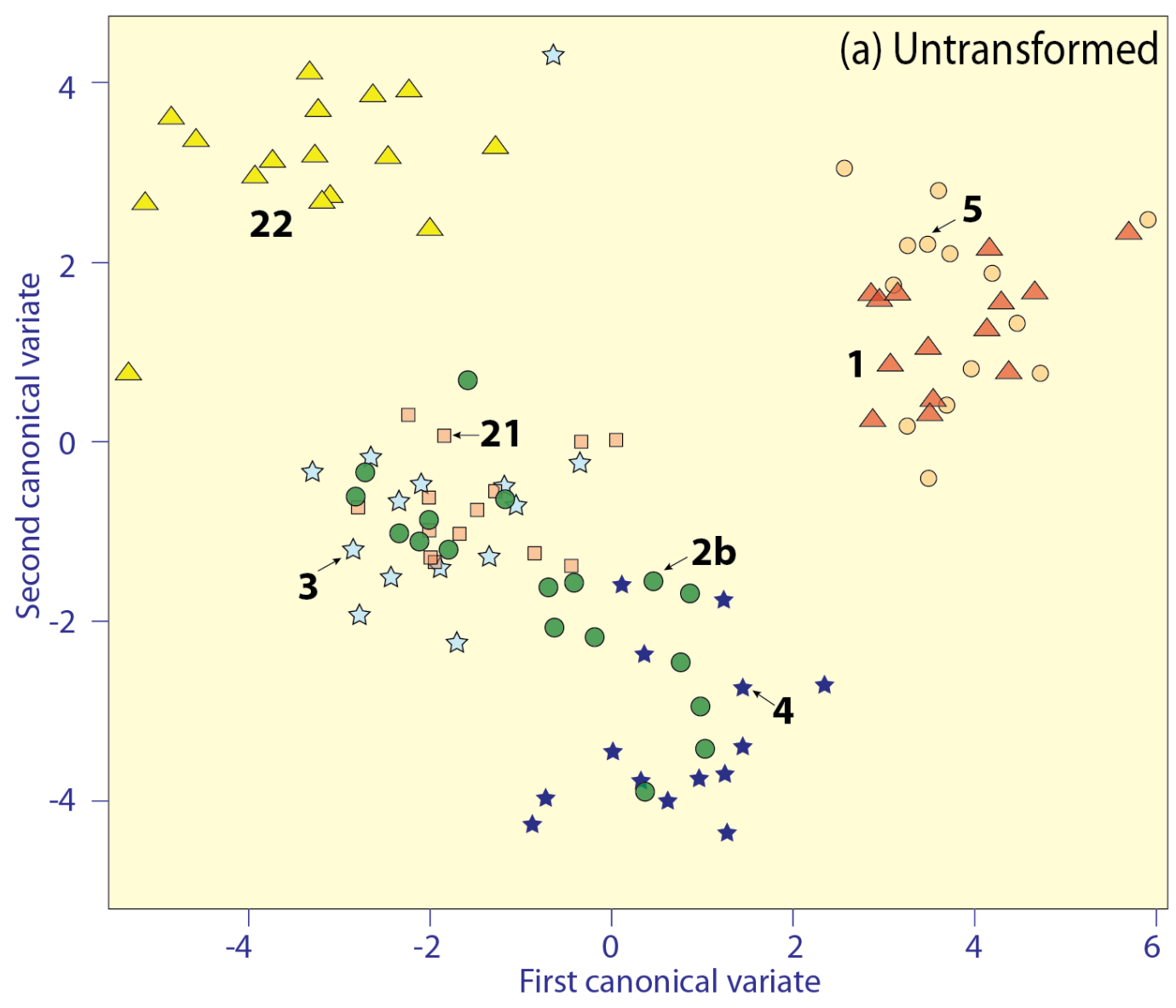




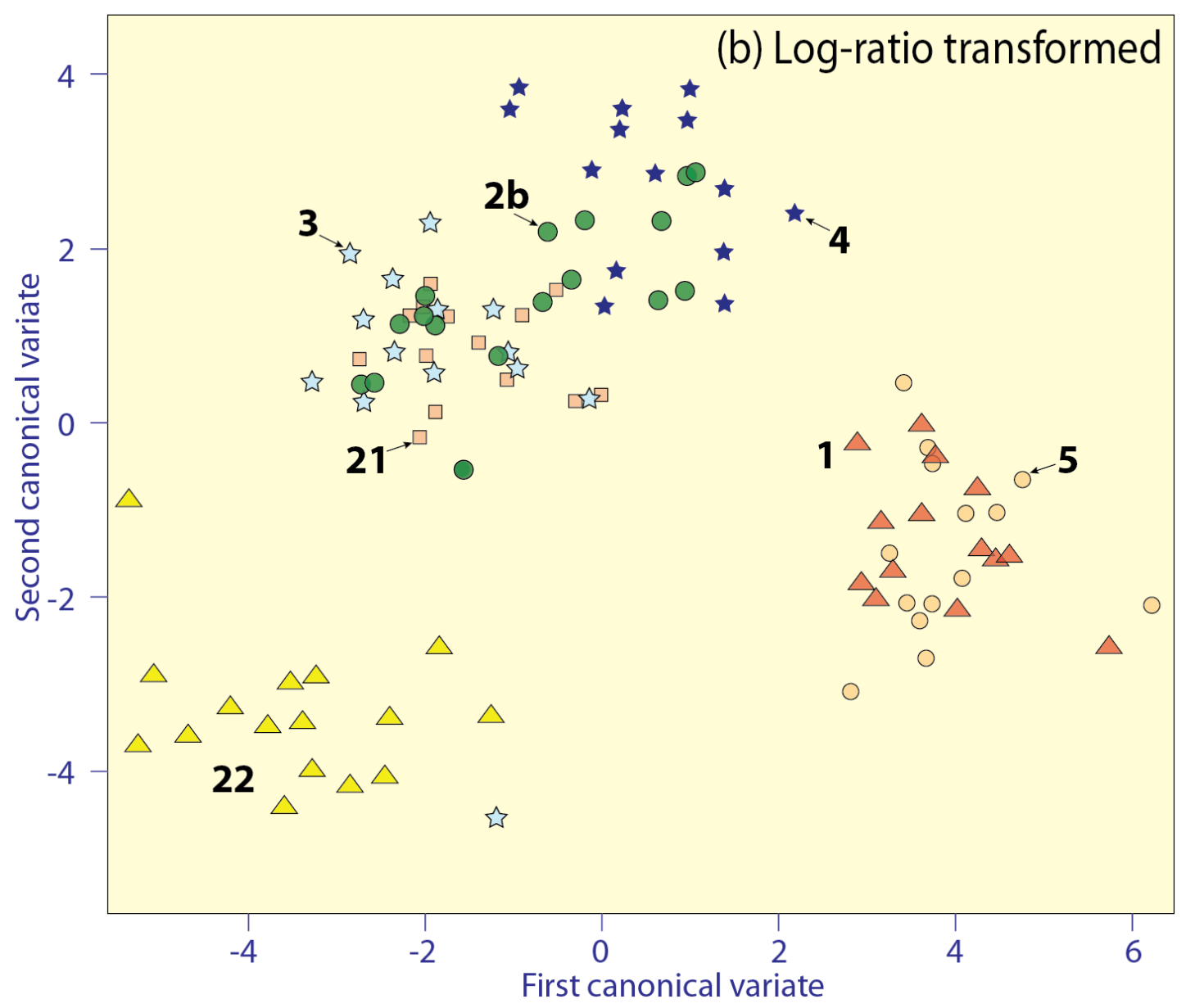

Fig. 14. CVA plot of oxide abundances of glass shards from tephra deposits in the Kenyan Wasiriya Beds shown as (a) untransformed normalized data, and (b) log-ratio transformed data (data from Table S1). For clarity, the prefix CAT09- used by Tryon et al. (2010) to denote sample numbers has been omitted.

Mahalanobis distance may be used to cluster the groups by successively merging groups separated by the smallest Mahalanobis distance. In considering the untransformed data first, the Mahalanobis distances are shown in Table 7a. At each step in the process a table of Mahalanobis distances between groups is formed. The groups 
that are closest are then merged and the distances involving the merged groups are recalculated. The process continues until all groups are merged. The resulting dendrogram is shown in Fig. 15a. Because of the high skewness of the $D_{m}^{2}$ values, the joining 'distance' is shown in terms of $D_{m}$ rather than $D_{m}^{2}$.

Table 7 (a). Squared Mahalanobis distances between groups (untransformed normalized data, calculated on a pairwise basis using the pooled within-groups covariance matrix) of tephra sample groups from the Kenyan Wasiriya Beds (data from Table S1).

$\begin{array}{lrrrrrrr} & \text { CAT09-01 } & \text { CAT09-02a } & \text { CAT09-02b } & \text { CAT09-03 } & \text { CA 09-04 } & \text { CAT09-05 } & \text { CAT09-21 } \\ \text { CAT09-02a } & 1062.5 & & & & & & \\ \text { CAT09-02b } & 70.6 & 624.1 & & & & & \\ \text { CAT09-03 } & 53.3 & 780.5 & 1.8 & & & & \\ \text { CAT09-04 } & 84.0 & 496.3 & 12.0 & 33.9 & & & \\ \text { CAT09-05 } & 1.6 & 664.9 & 56.8 & 60.8 & 48.2 & & \\ \text { CAT09-21 } & 83.6 & 695.8 & 2.6 & 1.4 & 33.8 & 87.1 & \\ \text { CAT09-22 } & 156.7 & 577.7 & 37.0 & 24.8 & 168.1 & 97.6 & 100.1\end{array}$

Table 7 (b). Squared Mahalanobis distances between groups (log-ratio data calculated on a pairwise basis using the pooled within-groups covariance matrix) of tephra sample groups from the Kenyan Wasiriya Beds (data from Table S1).

$\begin{array}{lrrrrrrr} & \text { CAT09-01 } & \text { CAT09-02a } & \text { CAT09-02b } & \text { CAT09-03 } & \text { CA 09-04 } & \text { CAT09-05 } & \text { CAT09-21 } \\ \text { CAT09-02a } & 949.2 & & & & & & \\ \text { CAT09-02b } & 73.3 & 599.4 & & & & & \\ \text { CAT09-03 } & 57.8 & 635.4 & 1.8 & & & & \\ \text { CAT09-04 } & 89.9 & 413.7 & 9.8 & 25.0 & & & \\ \text { CAT09-05 } & 1.5 & 668.0 & 59.0 & 68.1 & 50.0 & & \\ \text { CAT09-21 } & 84.4 & 616.1 & 2.7 & 1.4 & 29.7 & 89.6 & \\ \text { CAT09-22 } & 148.8 & 414.5 & 36.5 & 25.6 & 179.8 & 98.6 & 103.3\end{array}$


The pairwise Mahalanobis distance $D_{m}^{2}$ is closely related to the two-sample Hotelling $T^{2}$ statistic and so the equality of group means can be tested before they are merged. We would not consider as equivalent any groups with significantly different variable means, and hence we need only continue the merging until significance is found. However, on this occasion we carried out the full process and the merging $D_{m}^{2}$ and the test results are shown in Table 8 . In Tables $6 \mathrm{~b}$ and $7 \mathrm{~b}$, and Fig. $15 \mathrm{~b}$, the same information is repeated for the log-ratio transformed data. The results for the untransformed and log-ratio transformed data are very similar and, in particular, the groups merge in the same sequence. The clustering suggests the equivalence of the pair CAT09-03 and CAT09-21, and also the pair CAT09-01 and CAT09-05. No other pairs are equivalent. The equivalences are 'suggested' rather than 'established' because questions of statistical power and what differences may be tolerated between means of equivalent groups have not been examined. 
Table 8 (a). Steps in the clustering of tephra sample groups from the Kenyan Wasiriya Beds by Mahalanobis distance (untransformed normalized data) (data from Table $\mathrm{S} 1$ ).

\begin{tabular}{|c|c|c|c|c|c|}
\hline Step & Groups to merge & Merged group & Mahalanobis $D_{m}^{2}$ & Hotelling F statistic & p-value \\
\hline 1. & CAT09-03 and CAT09-21 & $\mathrm{c} 03 \mathrm{e} 21$ & 1.362 & 0.871 & 0.5571 \\
\hline 2. & CAT09-01 and CAT09-05 & $\mathrm{c} 01 \mathrm{c} 05$ & 1.631 & 1.043 & 0.4398 \\
\hline 3. & $\mathrm{c} 21 \mathrm{c} 03$ and CAT09-02b & $\mathrm{c} 21 \mathrm{c} 03 \mathrm{c} 02 \mathrm{~b}$ & 2.053 & 2.364 & 0.0364 \\
\hline 4. & CAT09-04 and c21c03c02b & $\mathrm{c} 04 \mathrm{c} 21 \mathrm{c} 03 \mathrm{c} 02 \mathrm{~b}$ & 10.427 & 12.301 & $1.3 \times 10^{-9}$ \\
\hline 5. & CAT09-22, c04c $21 \mathrm{c} 03 \mathrm{c} 02 \mathrm{~b}$ & $\mathrm{c} 22 \mathrm{c} 04 \mathrm{c} 21 \mathrm{c} 03 \mathrm{c} 02 \mathrm{~b}$ & 21.395 & 30.586 & $1.6 \times 10^{-19}$ \\
\hline 6. & $\mathrm{c} 22 \mathrm{c} 04 \mathrm{c} 21 \mathrm{c} 03 \mathrm{c} 02 \mathrm{~b}, \mathrm{c} 01 \mathrm{c} 05$ & $\mathrm{c} 22 \mathrm{c} 04 \mathrm{c} 21 \mathrm{c} 03 \mathrm{c} 02 \mathrm{bc} 01 \mathrm{c} 05$ & 29.784 & 70.951 & $1.1 \times 10^{-36}$ \\
\hline 7. & CAT09-02a, c22c04c21c03c02bc01c05 & 05 everything & 322.966 & 407.664 & $1.8 \times 10^{-76}$ \\
\hline
\end{tabular}

Table 8 (b). Steps in the clustering of tephra sample groups from the Kenyan Wasiriya Beds by Mahalanobis distance (log-ratio data) (data from Table S1).

\begin{tabular}{|c|c|c|c|c|c|}
\hline Step & Groups to merge & Merged group & Mahalanobis $D_{m}^{2}$ & Hotelling F statistic & p-value \\
\hline 1. & CAT09-03 and CAT09-21 & $\mathrm{c} 03 \mathrm{c} 21$ & 1.442 & 0.922 & 0.5201 \\
\hline 2. & CAT09-01 and CAT09-05 & $\mathrm{c} 01 \mathrm{c} 05$ & 1.495 & 0.956 & 0.4967 \\
\hline 3. & $\mathrm{c} 21 \mathrm{c} 03$ and $\mathrm{CAT} 09-02 \mathrm{~b}$ & $\mathrm{c} 21 \mathrm{c} 03 \mathrm{c} 02 \mathrm{~b}$ & 2.110 & 2.430 & 0.0320 \\
\hline 4. & CAT09-04 and $\mathrm{e} 21 \mathrm{c} 03 \mathrm{c} 02 \mathrm{~b}$ & $\mathrm{c} 04 \mathrm{c} 21 \mathrm{c} 03 \mathrm{c} 02 \mathrm{~b}$ & 7.546 & 8.902 & $1.6 \times 10^{-7}$ \\
\hline 5. & CAT09-22, $\mathrm{c} 04 \mathrm{c} 21 \mathrm{c} 03 \mathrm{c} 02 \mathrm{~b}$ & $\mathrm{c} 22 \mathrm{c} 04 \mathrm{c} 21 \mathrm{c} 03 \mathrm{c} 02 \mathrm{~b}$ & 22.111 & 31.609 & $6.8 \times 10^{-20}$ \\
\hline 6. & $\mathrm{c} 22 \mathrm{c} 04 \mathrm{c} 21 \mathrm{c} 03 \mathrm{c} 02 \mathrm{~b}, \mathrm{c} 01 \mathrm{c} 05$ & $\mathrm{c} 22 \mathrm{c} 04 \mathrm{c} 21 \mathrm{c} 03 \mathrm{c} 02 \mathrm{bc} 01 \mathrm{c} 05$ & 30.295 & 72.167 & $5.5 \times 10^{-37}$ \\
\hline 7. & САТ09-02a, $\mathrm{c} 22 \mathrm{c} 04 \mathrm{c} 21 \mathrm{c} 03 \mathrm{c} 02 \mathrm{bc} 01 \mathrm{c} 03$ & 5 everything & 429.161 & 541.709 & $7.2 \times 10^{-83}$ \\
\hline
\end{tabular}




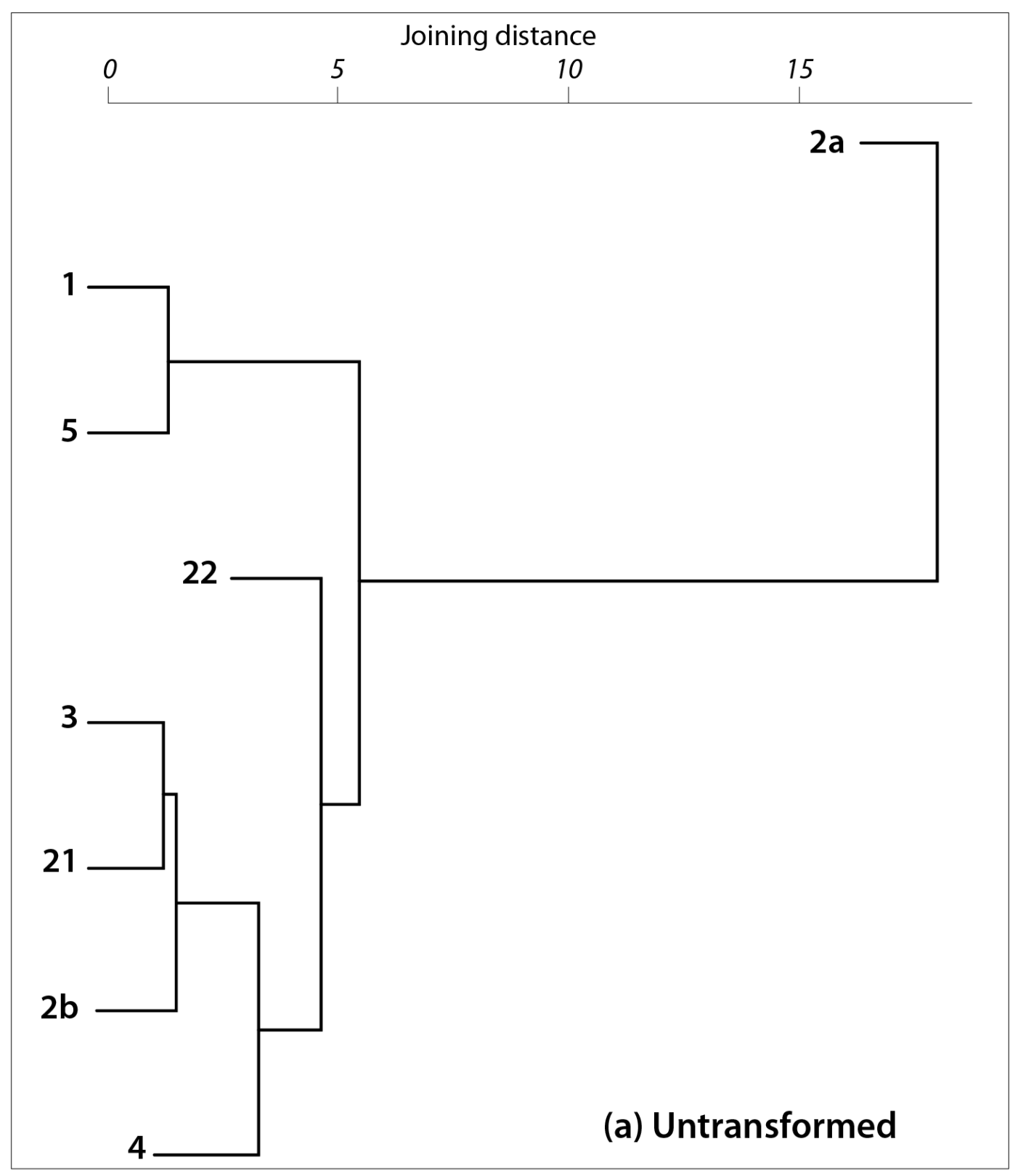




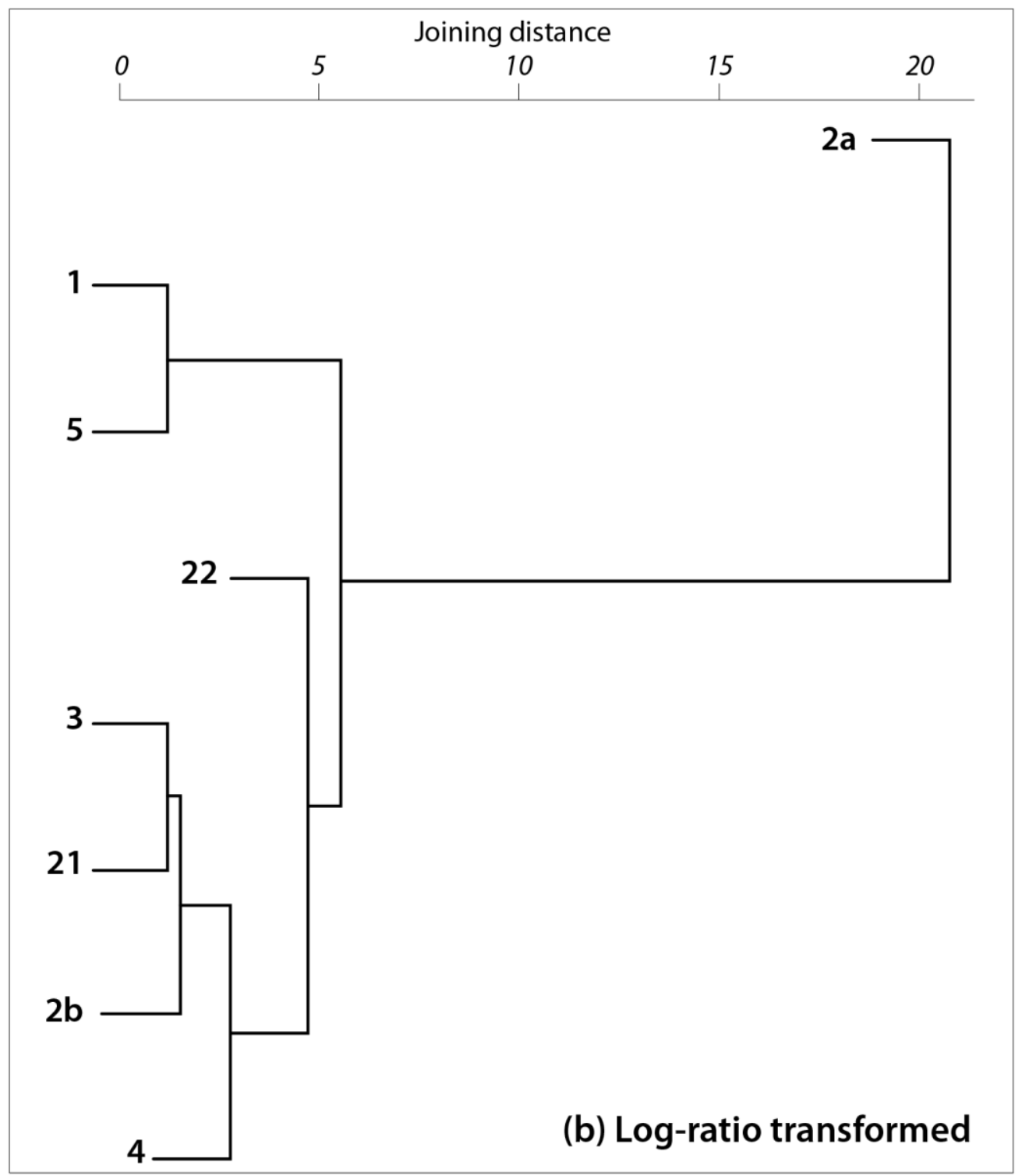

Fig. 15. Dendrograms for clustering of tephra sample groups of the Kenyan Wasiriya Beds separated by Mahalanobis distance as (a) untransformed normalized data, and (b) log-ratio transformed data (data from Table S1). For clarity, the prefix CAT09- used by Tryon et al. (2010) to denote sample numbers has been omitted. The dendrograms are very similar (but not identical). 


\subsection{Limitations}

Methods based on Mahalanobis distance and Hotelling tests may be expected to encounter difficulties if the number of variables is large or the number of samples per group is small, or both (Blegen et al., 2015, faced a parallel problem with SCs and hence developed the randomized version of SCs to cope with a large sample size). They also depend on the multivariate normality of the samples. Campbell and Curran (2009) discussed some techniques for making Hotelling tests more robust in a related forensic situation.

Other studies also show that in some cases tephra samples are not easily discriminated (distinguished) from others using DFA of glass data (e.g. Charman and Grattan, 1999; Eden et al., 2001; Turney et al., 2008). Bourne et al. (2010), working mainly on cryptotephras in cores of marine sediments in the Adriatic Sea, emphasized that the efficacy of the DFA employed in their study was limited by $(i)$ training sets (i.e. databases of geochemical information pertaining to proximal eruptives) that were insufficiently comprehensive (see also Lawson et al., 2012), and (ii) because not all data were well clustered (ordered). DFA nevertheless has several advantages, the most important being that all or most elements in the analyses are taken into account nonsubjectively, the relative probabilities that a sample comes from each of the tephras under study may be estimated, and their degree of similarity or dissimilarity is reflected 
by $D_{m}^{2}$ (Lowe, 2011). It may also be remarked that the descriptive value of the closely related CVA plots is not affected by the failure of the database to be comprehensive or the failure of the observations to clearly cluster. The efficacy of the technique can be tested using iterative or jackknifing procedures (e.g. see Stokes et al., 1992; Cronin et al., 1997), or cross-validation (e.g. Habermann et al., 2016), to measure classification efficiency - in effect, the probability of misclassification. As noted previously, DFA relies directly on high quality data and comprehensive reference sets against which unknowns are compared; the recognition of multiple glass-shard compositions in some tephra units from single eruptive episodes adds complexity (Lowe, 2011). Finally, Tryon et al. (2009) showed that the model they generated using CVA and DFA was robust enough to overcome any errors of precision within their dataset arising from interlaboratory variation.

A problem with the use of hypothesis testing methodology in testing the correlation of tephras is that we essentially wish to establish that the null hypothesis is true (the meaning of equivalence). Unfortunately, failing to reject the null hypothesis does not establish it as true. As well as in tephrochronology, this is a problem of some importance in pharmaceutics where biostatisticians have developed methodologies for testing 'bioequivalence'. Even in that field, bioequivalence is not usually studied in a multivariate way, Wang et al. (1999) being one of a few academic papers on the topic. The consequences of falsely assuming medical drugs to be equivalent can be serious, 
and it is not surprising that these methodologies have been slow to spread. For tephrochronology the most practical approach would be to ensure that, for the most important variables, confidence intervals for differences in means $(i)$ contain zero, and (ii) are short.

\section{Summary and conclusions}

10.1. Advances in analyzing constituent glass to characterize tephras and cryptotephras to help facilitate their correlation

Tephrochronology involves the characterization and use of tephra layers or cryptotephra deposits as stratigraphic correlational and dating tools. The ability to correlate tephra deposits requires recognition of the importance of spatial and temporal scale, which dictate the range of approaches and applications that are necessary to answer geoscientific questions, together with analytical flexibility (Tryon et al., 2011). In this review, we have initially outlined some of the latest developments in analytical methods used to characterize or 'fingerprint' glass from tephra or cryptotephra deposits to aid their correlation. New protocols in the use of EPMA have been developed mainly since $c .2010$ to help ensure major- and minor-element data of very high quality can now be attained, allowing subtle differences in composition to be distinguished more 
reliably than previously (Pearce et al., 2014b). As well, individual glass shards (or glass selvedges/rims on crystals, or melt inclusions) can be analyzed using beam diameters considerably narrower than previously possible $(\sim 5 \mu \mathrm{m}$ to $3 \mu \mathrm{m})$, thereby enabling many fine-grained samples, including the smallest of the microshards (shards $<32 \mu \mathrm{m}$ in diameter), to be analyzed from wider and more distal geographic locations. This advance also enables the compositions of vesicular or microlite-rich glasses, and small melt inclusions, to be obtained more readily (Hayward, 2012). Previously, these shards or inclusions typically could not be analyzed reliably.

Possible difficulties may arise during such analyses, however. Firstly, in analyzing very small microshards of $\leq \sim 5 \mu \mathrm{m}$ diameter, the assumption of an infinite lateral and depth extent of the sample, which is built into the X-ray matrix corrections, starts to break down, and particle geometry becomes important (Kearns and Buse, 2012). At such small sizes, it could be helpful to analyze reference material of the same particle size, and it may also be useful to use a lower beam voltage on the instrument to shrink the source volume of the X-rays (Table 2). Secondly, the fluorescence of secondary X-rays in crystals in close proximity to the glass being analyzed in a microlite-rich shard may lead to a hybrid analysis with an element present in a crystal being over-represented in the adjoining glass (especially if the element is at minor to trace concentrations in the glass but at major element concentration in the adjacent crystal/microcrystal) (Hunt and Hill, 2001; Reed, 2010). 
To enable the sound evaluation of tephra correlations and to facilitate the robust application of statistical methods, all EPMA-derived glass data should be published (possibly as 'supplementary material') including analytical conditions, primary and secondary standards, as should all other relevant analytical parameters (Kuehn et al., 2011). In the near future, the data may also be submitted to open-access databases along with all relevant sample and analytical metadata. Reasons for discarding inappropriate analytical data (effectively an informal 'discard protocol') prior to data reduction or statistical manipulation should be considered carefully (Abbott et al., 2013). A similar advocacy is invoked for LA-ICP-MS-acquired glass data and their evaluation for undertaking correlations (Pearce et al., 2011; Westgate et al., 2013c).

Using LA-ICP-MS, analyses of individual glass shards with crater diameters of $20 \mu \mathrm{m}$ and $10 \mu \mathrm{m}$ to obtain trace-element data are now essentially routine, and some 200 grains of glass can be analyzed for about 30 trace elements in the course of a typical day in the laboratory, making this a relatively low-cost method (Pearce et al., 2011; Pearce, 2014). Smaller (sub-10 $\mu \mathrm{m}$ ) ablation craters suffer increasingly from the effects of element fractionation during analysis, but the systematic relationships of this fractionation with glass composition suggests that analyses for the more abundant trace elements may be quantifiable, and advances in laser technology, related to shorter pulse lengths, may improve or overcome this. 


\subsection{Correlating tephras or cryptotephras using numerical and statistical methods}

In the second part of the review, we have described and evaluated various ways in which tephras can be correlated using geochemical (compositional) data, mainly for individual glass shards or minerals (crystals or phenocrysts), with emphasis on numerical or statistical methods (especially multivariate methods) used in this process (e.g. Fig. 12). Statistical methods provide a less subjective means of dealing with data pertaining to tephra components than alternative methods. They enable a better understanding of relationships among the data to be developed from multiple viewpoints, and help to quantify the degree of uncertainty in establishing correlations. In applying statistical methods to establish sample equivalence or difference, we emphasise that all methods have some degree of limitation. Furthermore, using statistical analysis of tephra compositional data, it is much easier to prove a difference between two samples than it is to prove they are the same. Bivariate plots, where all analyses overlap for all analyzed elements, or an inability to separate two samples by PCA or other analyses, do not prove that the two samples are necessarily the same. More analyses may show differences in a particular parameter, or they may not, and if not, then the evidence builds that the two samples being compared are putative correlatives - but it is still an 'increasingly likely' rather than 'definite' correlation. Adding multiple criteria such as stratigraphic, chronological, mineralogical, 
palaeoenvironmental, or archaeological (contextual) data allows for increasingly sturdy correlations to be made. In a number of studies such data have been essential for enabling correlations to be made where compositional data for glass or mineral phases have been inadequately diverse on their own (e.g. Hopkins et al., 2015, 2017; Damaschke et al., 2017a).

A two-stage approach has been used in recent times, the first stage being to identify the main data structure by way of simple but useful, and visually compelling, scatterplot matrices (bivariate plots) before undertaking statistical distance measures, SCs, hierarchical cluster analysis (which may be informed by distance measures or similarity or cophenetic coefficients), non-hierarchical cluster analysis using $k$-means, and PCA. Some of these methods (e.g. cluster analysis) are also referred to as machine learning in the field of computer science. Quite often, graphical methods such as bivariate plots (including use of ratios) or trivariate plots are sufficient, and sophisticated statistical techniques are not necessary. In some cases there is potential for miscorrelation because of the limited dimensionality of such plots (Petrelli et al., 2017). Loadings obtained by PCA (variable coefficients in the principal components obtained from a PCA based on the correlational matrix of the variables) can provide useful information about which bivariate plots will be most informative, however.

The second stage typically examines sample variance and the degree of compositional similarity so that sample equivalence or otherwise can be established on 
a statistical basis. This stage has involved DFA, CVA, and analysis of variance (ANOVA) or MANOVA (or its two-sample special case, the Hotelling two-sample $T^{2}$ test) (Fig. 12). We have suggested that where distributional assumptions such as multivariate normality underlying parametric tests are doubtful then randomization (permutation) tests can be considered.

A number of transformations and scalings may be applied to compositional data prior to subjecting the data to multivariate statistical procedures such as the calculation of distance matrices, hierarchical cluster analysis, and PCA. Such transformations may make the assumption of multivariate normality more appropriate. A sequential procedure using Mahalanobis distance and the Hotelling two-sample $T^{2}$ test has been illustrated for identifying correlated tephra deposits using Kenyan glass-shard major element data from Tryon et al. (2010).

We emphasise that all these methods require that $(i)$ stratigraphic and allied information - such as age and spatial data - are available, and (ii) that compositional data are of high quality and sufficiently comprehensive so that 'unknowns' can be compared with reference (training) sets that are sufficiently complete to account for all possible correlatives including tephras with heterogeneous glasses that have multiple fingerprints. Limited databases are tending to restrict correlation efficacy in some studies at the present time. The development of an open, high-quality online database 
would facilitate progress towards an integrated tephrostratigraphic framework for different regions, thereby increasing effectiveness and confidence in tephra correlation.

\section{Acknowledgements}

We appreciate encouragement initially from former editor Colin MurrayWallace and then Claude Hillaire-Marcel to prepare this article, together with valued support from Tim Horscroft and Debbie Barrett of Elsevier. Shane Cronin, Siwan Davies, Andrei Sarna-Wojcicki, Shari Preece, Jeff Knott, John Hunt, and three other (anonymous) referees are especially thanked for very helpful reviews, as are Kieran McNulty (who conducted the original PCA and MANOVA analyses of the tephras of the Wasiriya Beds that are further developed here), Tim Warner, Matthew Tocheri, Nick Blegen, Tyler Faith, and Earl Bardsley for useful comments. Jo Horrocks allowed us to cite her unpublished PhD thesis. Figs. 1a, 1b, and 1c were provided by Stuart Kearns, Maria Gehrels, and Tabito Matsu'ura, respectively, and Marie-Josée Duquette provided the photograph of Stephen Stokes for the dedication; Max Oulton drafted most remaining figures. Hayward acknowledges the support of NERC for the Tephra Analysis Unit at Edinburgh. Lowe thanks the Japan Society for the Promotion of Science, and Hiroshi Moriwaki, for support that enabled him to attend the "Active Tephra" conference in Kirishima in 2010, Caitlin Buck for facilitating his earlier visit to 
the UK to take part in the SUPRAnet workshop, and Marcus Bursik for enabling his participation in the INTAV tephra workshop in Portland, USA, in 2017 on "Best Practices in Tephra Collection, Analysis, and Reporting: Leading Toward Better Tephra Databases". As well as SUPRAnet, the paper is an output of the EXTRAS project "EXTending TephRAS as a global geoscientific research tool stratigraphically, spatially, analytically, and temporally within the Quaternary" (objectives 2 and 4), an initiative of INTAV supported by SACCOM, and of the SHAPE IFG "Southern Hemisphere Assessment of PalaeoEnvironments", supported by PALCOM, of the International Union for Quaternary Research (INQUA).

\section{Dedication}

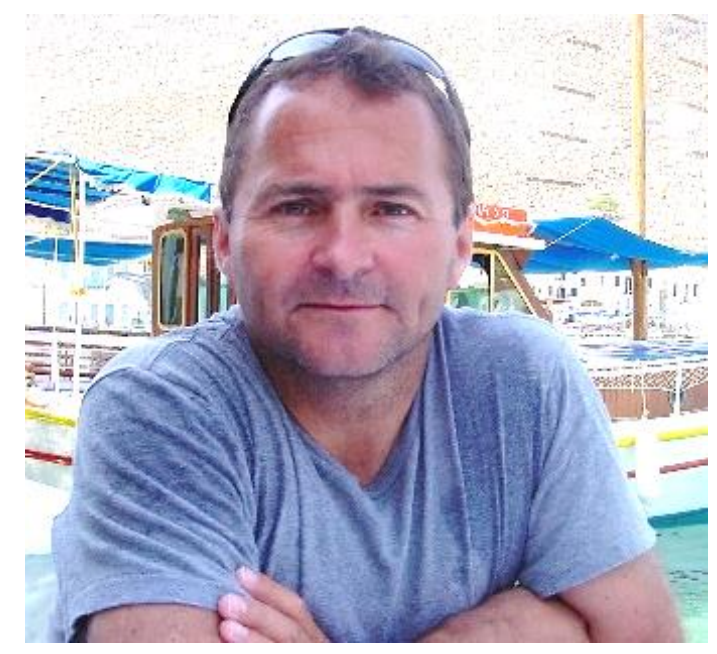


This paper is dedicated to the memory of colleague and friend Dr Stephen Stokes (1964-2014) (pictured), geochronologist, Quaternary scientist, and university teacher/mentor. Stephen began his research career in Earth sciences at the University of Waikato, Hamiton, New Zealand, completing an MSc (1987) and then an MPhil (1989) 'for fun' in sedimentology while employed to run the scanning electron microscope facility for a year or so as he awaited scholarship funding to enrol at the University of Oxford in the UK. During this period, Stephen made a significant contribution to statistical correlation methodology in tephra studies by undertaking discriminant function analysis (DFA) on major-element glass-derived data, firstly to match tephras to source volcanic centres in New Zealand (Stokes and Lowe, 1988; cited >53 times Google Scholar, GS) and then to correlate individual eruptives derived from each centre (Stokes et al., 1992; cited >69 times, GS), being inspired in part by the seminal papers of King et al. (1982) and Beaudoin and King (1986). He presented his DFA findings at the inter-INQUA tephrochronology field conference held at Mammoth Hot Springs in Yellowstone National Park in June, 1990. Stephen by then was enrolled at Oxford for his DPhil research as a Commonwealth Scholar, entering and soon shining in the world of optically-stimulated luminescence (OSL) dating. He became an internationallyrecognised practitioner of OSL dating and its application in a range of environments, including remote and dangerous deserts. Irrepressible in character and big-hearted, 
despite his limited stature, and a loyal colleague and generous mentor for his students at all levels, Stephen achieved much. He is greatly missed.

\section{Appendix A. Supplementary data - see after references References}

Abbott, P.M., Davies, S.M., 2012. Volcanism and the Greenland ice-cores: the tephra record. Earth-Science Reviews 115, 173-191.

Abbott, P.M., Davies, S.M., Steffensen, J.-P., Pearce, N.J.G., Bigler, M., Johnsen, S.J., Seierstad, I.K., Svensson, A., Wastegård, S., 2012. A detailed framework of Marine Isotope Stages 4 and 5 volcanic events recorded in two Greenland Ice-cores. Quaternary Science Reviews 36, 59-77.

Abbott, P.M., Austin, W.E.N., Davies, S.M., Pearce, N.J.G., Hibbert, F.D., 2013. Cryptotephrochronology of the Eemian and the last interglacial-glacial transition in the north east Atlantic. Journal of Quaternary Science 28, 501-514.

Abbott, P.M., Bourne, A.J., Purcell, C.S., Davies, S.M., Scourse, J.D., Pearce, N.J.G., 2016. Last glacial period cryptotephra deposits in an eastern North Atlantic marine sequence: exploring linkages to the Greenland ice-cores. Quaternary Geochronology $31,62-76$.

Addison, J.A., Begét, J.E., Ager, T.A., Finney, B.P., 2010. Marine tephrochronology of the Mt. Edgecumbe Volcanic Field, southeast Alaska, USA. Quaternary Research 73, 277-292. 
Admon, U., Donohue, D., Aigner, H., Tamborini, G., Bildstein, O., Betti, M., 2005. Multiple-instrument analyses of single micron-size particles. Microscopy and Microanalysis 11, 354-362.

Aitchison, J., 1982. The statistical analysis of compositional data. Journal of the Royal Statistical Society, Series B (Methodological) 44, 139-177.

Aitchison, J., 1983. Principal components analysis of compositional data. Biometrika $70,57-65$.

Aitchison, J., 1986. The Statistical Analysis of Compositional Data. Monographs on Statistics and Applied Probability. Chapman and Hall, New York, 416 pp.

Aitchison, J., Greenacre, M., 2002. Biplots of compositional data. Journal of the Royal Statistical Society, Series C (Applied Statistics) 51, 375-392.

Aitchison, J., Barceló-Vidal, C., Pawlowsky-Glahn, V., 2002. Some comments on compositional data analysis in archaeometry, in particular the fallacies in Tangri and Wright's dismissal of log ratio analysis. Archaeometry 44, 295-304.

Aksu, A.E., Jenner, G., Hiscott, R.N., İşler, E.B., 2008. Occurrence, stratigraphy and geochemistry of Late Quaternary tephra layers in the Aegean Sea and the Marmara Sea. Marine Geology 252, 174-192.

Albert, P.G., Tomlinson, E.L., Smith, V.C., Di Roberto, A., Todman, A., Rosi, M., Marani, M., Muller, W., Menzies, M.A., 2012. Marine-continental tephra correlations: volcanic glass geochemistry from the Marsili Basin and the Aeolian 
Islands, Southern Tyrrhenian Sea, Italy. Journal of Volcanology and Geothermal Research 229-230, 74-94.

Allan, A.S.R., Baker, J.A., Carter, L., Wysoczanksi, R.J., 2008. Reconstructing the Quaternary evolution of the world's most active silicic volcanic system: insights from a $\sim 1.65 \mathrm{Ma}$ deep ocean tephra record sourced from the Taupo Volcanic Zone, New Zealand. Quaternary Science Reviews 27, 2341-2360.

Allan, A.S.R., Morgan, D.J., Wilson, C.J.N., Millet, M.-A., 2013. From mush to eruption in centuries: assembly of the super-sized Oruanui magma body. Contributions to Mineralogy and Petrology 166, 143-164.

Alloway, B.V., Pillans, B.J., Carter, L., Naish, T., Westgate, J.A., 2005. Onshoreoffshore correlation of Pleistocene rhyolitic eruptions from New Zealand: Implications for TVZ eruptive history and paleoenvironmental construction. Quaternary Science Reviews 24, 1601-1622.

Alloway, B.V., Lowe, D.J., Larsen, G., Shane, P.A.R., Westgate, J.A., 2013. Tephrochronology. In: Elias, S.A., Mock, C.J. (Eds.), The Encyclopaedia of Quaternary Science, $2^{\text {nd }}$ edition, Vol. 4. Elsevier, Amsterdam, pp. 277-304.

Alloway, B.V., Pearce, N.J.G., Villarosa, G., Outes, V., Moreno, P.I., 2016. Multiple melt bodies fed the AD 2011 eruption of Puyehue-Cordón Caulle, Chile. Scientific Reports 5, 17589, doi: 10.1038/srep17589 (pp. 1-8). 
Alloway, B.V., Andreastuti, S., Setiawan, R., Miksic, J., Hua, Q., 2017. Archaeological implications of a widespread 13th Century tephra marker across the central Indonesian Archipelago. Quaternary Science Reviews 155, 86-99.

Almirall, J.R., Trejos, T., 2006. Advances in the forensic analysis of glass fragments: a review with focus on refractive index and elemental analysis. Forensic Science Review 18, 74-95.

Almirall, J.R., Naes, B., Cahoon, E., Trejos, T., 2012. Elemental analysis of glass by SEM-EDS, $\mu$ XRF, LIBS and LA-ICP-MS. U.S. Department of Justice, Final Technical Report, 2005-IJ-CX-K069. 87 pp.

Anderson, M.J., 2001. Permutation tests for univariate or multivariate analysis of variance and regression. Canadian Journal of Fisheries and Aquatic Sciences 58, 626639.

Andreastuti, S.D., Alloway, B.V., Smith, I.E.M., 2000. A detailed tephrostratigraphic framework at Merapi Volcano, Central Java, Indonesia: implications for eruption predictions and hazard assessment. Journal of Volcanology and Geothermal Research $100,51-67$.

Argote-Espino, D., Solé, J., López-Garcia, P., Sterpone, O., 2012.Obsidian subsource identification in the Sierra de Pachuca and Otumba Volcanic Regions, central Mexico, by ICP-MS and DBSCAN statistical analysis. Geoarchaeology 27, 48-62. 
Argote-Espino, D., Solé, J., López-Garcia, P., Sterpone, O., 2013. Geochemical characterisation of Otumba obsidian sub-sources (Central Mexico) by inductively coupled plasma mass spectrometry and density-based spatial clustering of applications with noise statistical analysis. Open Journal of Archaeometry 1:e18, 85-88.

Auer, S., Bindeman, I., Wallace, P., Ponomareva, V., Portnyagin, M., 2008. The origin of hydrous, high- $\delta^{18} \mathrm{O}$ voluminous volcanism: diverse oxygen isotope values and high magmatic water contents within the volcanic record of Klyuchevskoy volcano, Kamchatka, Russia. Contributions to Mineralogy and Petrology 157, 209-230.

Avery, M.R., Panter, K.S., Gorsevski, P.V., 2017. Distinguishing styles of explosive eruptions at Erebus, Redoubt and Taupo volcanoes using multivariate analysis of ash morphometrics. Journal of Volcanology and Geothermal Research 332, 1-13.

Baccolo, G., Clemenza, M., Delmonte, B., Maffezzoli, N., Nastasi, M., 3,4 Previtali, E. Maggi, V. , 2015. Assessing the geochemical fingerprint of the 2010 Eyjafjallajökull tephra through instrumental neutron activation analysis: a trace element approach. Journal of Radioanalytical and Nuclear Chemistry 306, 7 pp.

Bacon, C.R., Druitt, T.H., 1988. Compositional evolution of the zoned calkalkaline magma chamber of Mount Mazama, Crater Lake, Oregon. Contributions to Mineralogy and Petrology 98, 224-256.

Barberena, R., Hajduk, A., Gil, A.F., Neme, G.A., Durán, V., Glascock, M.D., Giesso, M., Borrazzo, K., de la Paz Pompei, M., Salgán, M.L., Cortegoso, V., Villarosa, G., 
Rughini, A.A., 2011. Obsidian in the south-central Andes: geological, geochemical, and archaeological assessment of north Patagonian sources (Argentina). Quaternary International 245, 25-36.

Barham, M., Kirkland, Reynolds, S., O’Leary, M.J., Evans, N.J., Allen, H., Haines, P.W., Hocking, R.M., McDonald, B.J., Belousova, E., Goodall, J., 2016. The answers are blowin' in the wind: ultra-distal ashfall zircons, indicators of Cretaceous supereruptions in eastern Gondwana. Geology 44, 643-646.

Baron, D., Negrini, R.M., Golob, E.M., Miller, D., Sarna-Wojcicki, A.M., Fleck, R.J., Hacker, B., Erendi, A., 2008. Geochemical correlation and ${ }^{40} \mathrm{Ar} /{ }^{39} \mathrm{Ar}$ dating of the Kern River ash bed and related tephra layers: implications for the stratigraphy of petroleum-bearing formations in the San Joaquin Valley, California. Quaternary International 178, 246-260.

Basile, I., Petit, J., Touron, S., Grousset, F., Barkov, N., 2001. Volcanic layers in Antarctic (Vostok) ice cores: source identification and atmospheric implications. Journal of Geophysical Research 106 (D23), 31,915-31,931.

Baxter, M.J., 1995. Standardization and transformation in principal component analysis, with applications to archaeometry. Applied Statistics 44, 513-527.

Baxter, M.J., 2006. A review of supervised and unsupervised pattern recognition in archaeometry. Archaeometry 48, 671-694. 
Baxter, M.J., 2008. Mathematics, statistics and archaeometry: the past 50 years or so. Archaeometry 50, 968-982.

Baxter, M.J., 2016. Multivariate Analysis of Archaeometric Data: An introduction, 131 pp. https://www.academia.edu/24456912/Multivariate_Analysis_of_Archaeometric_Data _An_Introduction

Baxter, M.J., Beardah, C.C., Cool, H.E.M., Jackson, C.M., 2005. Compositional data analysis of some alkaline glasses. Mathematical Geology 37, 183-196.

Baxter, M.J., Cool, H.E.M., Jackson, C.M., 2006. Comparing glass compositional analyses. Archaeometry 48, 399-414.

Beaudoin, A.B., King, R.H., 1986. Using discriminant function analysis to identify Holocene tephras based on magnetite composition: a case study from the Sunwapta Pass area, Jasper National Park. Canadian Journal of Earth Sciences 2, 804-812.

Bebbington, M.S., Cronin, S.J., 2011. Spatio-temporal hazard estimation in the Auckland Volcanic Field, New Zealand, with a new event-order model. Bulletin of Volcanology $73,55-72$.

Begét, J.E., Keskinen, M.J., 2003. Trace-element geochemistry of individual glass shards of the Old Crow tephra and the age of the Delta glaciation, central Alaska. Quaternary Research 60, 63-69. 
Bennett, K.D., 1994. Tephra geochemistry: a comment on Hunt and Hill. The Holocene 4, 435-438.

Bezdek, J.C., Ehrlich, R., Full, W., 1984. FCM: The fuzzy c-means clustering algorithm. Computers and Geosciences 10, 191-203.

Birks, H.J.B, 2012. Glossary. In: Birks, H.J.B., Lotter, A.F., Juggins, S., Smol, J.P. (Eds.), Tracking Environmental Change Using Lake Sediments: Data Handling and Numerical Techniques. Developments in Paleoenvironmental Research 5, 675-716.

Biswas, R.H., Williams, M.A.J., Raj, R., Juyal, N., Singhvi, A.K., 2013. Methodological studies on luminescence dating of volcanic ashes. Quaternary Geochronology 17, 1425.

Blegen, N., Tryon, C.A., Faith, J.T., Peppe, D.J., Beverly, E.J., Li, B., Jacobs, Z. 2015. Distal tephras of the eastern Lake Victoria basin, equatorial East Africa: correlations, chronology and a context for early modern humans. Quaternary Science Reviews 122, 89-111.

Blegen, N.,Brown, F.H., Jicha, B.R.,Binetti, K.M., Faith, J.T.,Ferraro, J.V., Gathogo, P.N., Richardson, J.L., Tryon, C.A., 2016. The Menengai Tuff: a 36 ka widespread tephra and its chronological relevance to Late Pleistocene human evolution in East Africa. Quaternary Science Reviews 152, 152-168.

Blockley, S.P.E., Pyne-O’Donnell, S.D.F., Lowe, J.J., Mathews, I.P., Stone, A., Pollard, A.M., Turney, C.S.M., Molyneux, E.G., 2005. A new and less destructive laboratory 
procedure for the physical separation of distal tephra glass shards from sediments.

Quaternary Science Reviews 24, 1952-1960.

Bogaard, P.v.d., Schminke, H.-U., 1985. Laacher See tephra: A widespread isochronous late Quaternary tephra layer in central and northern Europe. Bulletin of the Geological Society of America 96, 1554-1571.

Borchardt, G.A., 1974. The SIMAN coefficient for similarity analysis. Classification Society Bulletin 3, 2-8.

Borg, I., Groenen, P.J.F. 2005. Modern Multidimensional Scaling: Theory and Applications. Springer-Verlag, New York, 614 pp.

Borisova, A.Y., Freydier, R., Polvé, M., Salvi, S., Candaudap, F., Aigouy, T., 2008. In situ multi-element analysis of the Mount Pinatubo quartz-hosted melt inclusions by NIR femtosecond laser ablation-inductively coupled plasma-mass spectrometry. Geostandards and Geoanalytical Research 32, 209-229.

Borisova, A.Y., Freydier, R., Polvé, M., Jochum, K.P., Candaudap, F., 2010. Multielemental analysis of ATHO-G rhyolitic glass (MPI-DING reference material) by femtosecond and nanosecond LA-ICP-MS: evidence for significant heterogeneity of $\mathrm{B}, \mathrm{V}, \mathrm{Zn}, \mathrm{Mo}, \mathrm{Sn}, \mathrm{Sb}, \mathrm{Cs}, \mathrm{W}, \mathrm{Pt}$ and $\mathrm{Pb}$ at the millimetre scale. Geostandards and Geoanalytical Research 34, 245-255.

Bourne, A.J., Lowe, J.J., Trincardi, F., Asioli, A., Blockley, S.P.E., Wulf, S., Matthews, I.P., Piva, A., Vigliotti, L., 2010. Distal tephra record of the last c. 105,000 years 
from core PRAD 1-2 in the central Adriatic Sea: implications for marine tephrostratigraphy. Quaternary Science Reviews 29, 3079-3094.

Bourne, A.J., Davies, S.M., Abbott, P.M., Rasmussen, S.O., Steffensen, J.P., Svensson, A., 2013. Revisiting the Faroe Marine Ash Zone III in two Greenland ice cores: implications for marine-ice correlations. Journal of Quaternary Science 28, 641-646.

Bourne, A.J., Albert, P.G., Matthews, I.P., Trincardi, F., Wulf, S., Asioli, A., Blockley, S.P.E., Keller, J., Lowe, J.J., 2015. Tephrochronology of core PRAD 1-2 from the Adriatic Sea: insights into Italian explosive volcanism for the period 200-80 ka. Quaternary Science Reviews 116, 28-43.

Bourne, A.J., Abbott, P.M., Albert, P.G., Cook, E., Pearce, N.J.G., Ponomareva, V., Svensson, A., Davies, S.M. 2016. Risks of recurrent long-range ash dispersal from northern Pacific Arc volcanoes. Scientific Reports 6, 29837, doi: 10.1038/srep29837 (pp. 1-8).

Boygle, J., 1999. Variability of tephra in lake and catchment sediments, Svínavatn, Iceland. Global and Planetary Change 21, 129-149.

Bramham-Law, C.W.F., Theuerkauf, M., Lane, C.S., Mangerud, J., 2013. New findings regarding the Saksunarvatn Ash in Germany. Journal of Quaternary Science 28, 248257. 
Brathwaite, R.L., Gazley, M.F., Christie, A.B., 2017. Provenance of titanomagnetite in ironsands on the west coast of the North Island, New Zealand. Journal of Geochemical Exploration 178, 23-34.

Brauer, A., Hajdas, I., Blockley, S.P.E., Bronk Ramsey, C., Christl, M., Ivy-Ochs, S., Mosely, G.E., Nowaczyk, N.N., Rasmussen, S.O., Roberts, H.M., Spötl, C., Staff, R.A., Svensson, A., 2014. The importance of independent chronology in integrating records of past climate change for the 60-8 ka INTIMATE time interval. Quaternary Science Reviews 106, 47-66.

Breiman, L., Friedman, J.H., Olshen, R.A., Stone, C.J., 1984. Classification and Regression Trees. Wadsworth International, Belmont, CA, 368 pp.

Brendryen J., Haflidason H., Sejrup H.P., 2010. Norwegian Sea tephrostratigraphy of marine isotope stages 4 and 5: prospects and problems for tephrochronology in the North Atlantic region. Quaternary Science Reviews 29, 847-864.

Bridge, C.M., Powell J., Steele K.L., Williams M., MacInnis J.M., Sigman M.E., 2006. Characterization of automobile float glass with laser-induced breakdown spectroscopy and laser ablation inductively coupled plasma mass spectrometry. Applied Spectroscopy 60, 1181-1187.

Bronk Ramsey, C., 2011. The use of kernel density estimates to assist in the identification of volcanic tephra. Quaternary International 279-280, 70. 
Bronk Ramsey, C., Albert, P.G., Blockley, S.P., Hardiman, M., Lane, C.S., Lee, S., Matthews, I.P., Smith, V.C., Lowe, J. 2015a. Improved age estimates for key Late Quaternary European tephra horizons in the RESET lattice. Quaternary Science Reviews 118, 18-32.

Bronk Ramsey, C., Housley, R.A., Lane, C.S., Smith, V.C., Pollard, A.M. 2015b. The RESET tephra database and associated analytical tools. Quaternary Science Reviews $118,33-47$.

Brown, F.H., Sarna-Wojcicki, A.M., Meyer, C.E., Haileab, B., 1992. Correlation of Pliocene and Pleistocene tephra layers between the Turkana Basin of East Africa and the Gulf of Aden. Quaternary International 13-14, 55-67.

Cage, A.G., Davies, S.M., Wastegård, S., Austin, W.E., 2011. Identification of the Icelandic Landnám tephra (AD $871 \pm 2$ ) in Scottish fjordic sediment. Quaternary International 246, 168-176.

Campbell, G.P., Curran, J.M., 2009. The interpretation of elemental composition measurements from forensic glass evidence III. Science and Justice 49, 2-7.

Campbell, G.P., Curran, J.M., Miskelly, G.M., Coulson, S., Yaxley, G.M., Grunsky, E.C., Cox, S.C., 2011. Compositional data analysis for elemental data in forensic science. Forensic Science International 188, 81-90.

Campisano, C.J., Feibel, C.S., 2008. Tephrostratigraphy of the Hadar and Busidima Formations at Hadar, Afar Depression, Ethiopia. In: Quade, J., Wynn, J.D. (Eds.), 
The Geology of Early Humans in the Horn of Africa. Geological Society of America Special Paper 446, 135-162.

Cannata, A., Montalto, P., Aliotta, M., Cassisi, C., Pulvirenti, A., Privitera, E., Patanè, D., 2011. Clustering and classification of infrasonic events at Mount Etna using pattern recognition techniques. Geophysical Journal International 185, 253-264.

Carr, M.J., 2017. Igpet for Windows. Terra Softa Inc. Version: 23 February, 2017. Available at https://sites.google.com/site/igpethome/home

Cassidy, M., Watt, S.F.L., Palmer, M.R., Trofimovs, J., Symons, W., Maclachlan, S.E., Stinton, A.J., 2014. Construction of volcanic records from marine sediment cores: a review and case study (Montserrat, West Indies). Earth-science Reviews 138, 137155.

Cerovski-Darriau, C., Roering, J.J., Marden, M., Palmer, A.S., Bilderback, E. L., 2014. Quantifying temporal variations in landslide-driven sediment production by reconstructing paleolandscapes using tephrochronol ogy and lidar: Waipaoa River, New Zealand, Geochemistry, Geophysics, Geosystems 15, 4117-4136.

Chan, W.S., Mah, M.L., Bay, R.C., Talghader, J.J. 2016. Long-wavelength optical logging for high-resolution detection of ash layers in glacier ice. Journal of Glaciology (5 pp.), doi: 10.1017/jog.2016.105. 
Charman, D.J., Grattan J., 1999. An assessment of discriminant function analysis in the identification and correlation of distal Icelandic tephras in the British Isles.

Geological Society (London) Special Publication 161, 147-160.

Chesner, C.A., Luhr, J.F., 2010. A melt inclusion study of the Toba Tuffs, Sumatra, Indonesia. Journal of Volcanology and Geothermal Research 197, 259-278.

Chiasera, B., Cortés, J.A., 2011. Predictive regions for geochemical compositional data of volcanic systems. Journal of Volcanology and Geothermal Research 207, 83-92.

Churchman, G.J., Lowe, D.J., 2012. Alteration, formation, and occurrence of minerals in soils. In: Huang, P.M., Li, Y., Sumner, M.E. (Eds), Handbook of Soil Sciences, $2^{\text {nd }}$ edition, Vol. 1: Properties and Processes. CRC Press, Boca Raton, FL, pp. 20.120.72 .

Clift, P.D., Layne, G.D., Najman, Y.M.R., Kopf, A., Shimizu, N., Hunt, J., 2003. Temporal evolution of boron flux in the NE Japan and Izu arcs measured by ion microprobe from the forearc tephra record. Journal of Petrology 44, 1211-1236.

Coble, M.A., Burgess, S.D., Klemetti, E.W., 2017. New zircon (U-Th)/He and U/Pb eruption age for the Rockland tephra, western USA. Quat. Sci. Rev. 172, 109-117.

Coffey, K.T., Schmitt, A.K., Spera, F.J., Christensen, C., Garrison, J., 2014. Volcanic ash provenance from zircon dust with an application to Maya pottery. Geology 42, 595-598. 
Corsaro, R.A., Falsaperla, S., Langer, H., 2013. Geochemical pattern classification of recent volcanic products from Mt. Etna, Italy, based on Kohonen maps and fuzzy clustering. International Journal of Earth Sciences 102, 1151-1164.

Cortés, J.A., Palma, J.L., Wilson, M., 2007. Deciphering magma mixing: the application of cluster analysis to the mineral chemistry of crystal populations. Journal of Volcanology and Geothermal Research 165, 163-188.

Coulter, S.E., Pilcher, J.R., Hall, V.A., Davies, S.M., 2010. Testing the reliability of the JEOL FEGSEM 6500F electron microprobe for quantitative major element analysis of glass shards from rhyolitic tephra. Boreas 39, 163-169.

Coulter, S.E., Pilcher, J.R., Plunkett, G., Baillie, M., Hall, V.A., Steffensen, J.P., Vinther, B.M., Clausen, H.B., Johnsen, S.J., 2012. Holocene tephras highlight complexity of volcanic signals in Greenland ice cores. Journal of Geophysical Research 117, D21303 (pp. 1-11), doi: 10.1029/2012JD017698.

Cronin, S.J., Neall, V.E., Stewart, R.B., Palmer, A.S., 1996a. A multiple-parameter approach to andesitic tephra correlation, Ruapehu volcano, New Zealand. Journal of Volcanology and Geothermal Research 72, 199-215.

Cronin, S.J., Wallace, R.C., Neall V.E., 1996b. Sourcing and identifying andesitic tephras using major oxide titanomagnetite and hornblende chemistry, Egmont volcano and Tongariro Volcanic Centre, New Zealand. Bulletin of Volcanology 58, 33-40. 
Cronin, S.J., Neall, V.E., Palmer, A.S., Stewart, R.B., 1997. Methods of identifying late Quaternary tephras on the ring plains of Ruapehu and Tongariro volcanoes, New Zealand. New Zealand Journal of Geology and Geophysics 40, 175-184.

Cullen, V.C., Smith, V.C., Arz, H.W., 2014. The detailed tephrostratigraphy of a core from the south-east Black Sea spanning the last $~ 60 \mathrm{ka}$. Journal of Quaternary Science 29, 675-690.

Daga, R., Guevara, S.R., Sanchez, M.L., Arribere, M., 2008. Source identification of volcanic ashes by geochemical analysis of well preserved lacustrine tephras in Nahuel Huapi National Park. Applied Radiation and Isotopes 66, 1325-1336.

Damaschke, M., Sulpizio, R., Zanchetta, G., Wagner, B., Böhm, A., Nowaczyk, N., Hilgers, A., 2013. Tephrostratigraphic studies on a sediment core from Lake Prespa in the Balkans. Climate of the Past 7, 267-287.

Damaschke, M., Cronin, S.J., Holt, K.A., Bebbington, M.S., Hogg, A.G., 2017a. A 30,000 yr high-precision eruption history for the andesitic Mt Taranaki, North Island, New Zealand. Quaternary Research 87, 1-23.

Damaschke, M., Cronin, S.J., Torres-Orozco, R., Wallace, R.C., 2017b. Unifying tephrostratigraphic approaches to redefine major Holocene marker tephras, Mt. Taranaki, New Zealand. Journal of Volcanology and Geothermal Research 337, 2943. 
Daniels, J.M., Lam, H.-Y., Rancourt, D.G., Westgate, J.A., York, D., 1985. The discrimination of pyroclastic deposits on the basis of the Mössbauer spectra of their magnetites: a preliminary test. Earth and Planetary Science Letters 73, 430-438.

Danišík, M., Schmitt, A.K., Lovera, O.M., Dunkl, I., Evans, N.J., 2017. Application of the combined U-Th-disequilibrium/U-Pb and (U-Th)/He zircon dating to tephrochronology. Quaternary Geochronology 40, 23-32.

D’Antonio, M., Mariconte, R., Arienzo, I., Mazzeo, F.C., Carandente, A., Perugini, Petrelli, D., Corselli, G., Orsi, M.G., Principato, M.S., Civetta, L., 2016. Combined Sr-Nd isotopic and geochemical fingerprinting as a tool for identifying tephra layers: application to deep-sea cores from eastern Mediterranean Sea. Chemical Geology $443,121-136$.

Davies, S.M., 2015. Cryptotephras: the revolution in correlation and precision dating. Journal of Quaternary Science 30, 114-130.

Davies, S.M., Wohlfarth, B., Wastegård, S., Andersson, M., Blockley, S., Possnet, G., 2004. Were there two Borrobol tephras during the early Late Glacial period: implications for tephrochronology. Quaternary Science Reviews 23, 581-589.

Davies, S.M., Larsen, G., Wastegård, S., Turney, C.S., Hall, V.A., Coyle, L., Thordarson, T., 2010a. Widespread dispersal of Icelandic tephra: how does the Eyjafjöll eruption of 2010 compare to past Icelandic events? Journal of Quaternary Science 25, 605-611. 
Davies, S.M., Wastegård, S., Abbott, P.M., Barbante, C., Bigler, M., Johnsen, S.J., Rasmussen, T.L., Steffensen, J.P., Svensson, A., 2010b. Tracing volcanic events in the NGRIP ice-core and synchronising North Atlantic marine records during the last glacial period. Earth and Planetary Science Letters 294, 69-79.

Davies, S.M., Abbott, P.M., Pearce, N.J., Wastegård, S., Blockley, S.P., 2012. Integrating the INTIMATE records using tephrochronology: rising to the challenge. Quaternary Science Reviews 36, 11-27.

Davies, L.J., Jensen, B.J.L., Froese, D.G., Wallace, K.L., 2016. Late Pleistocene and Holocene tephrostratigraphy of interior Alaska and Yukon: key beds and chronologies over the past 30,000 years. Quaternary Science Reviews 146, 28-53

D’Costa, V.M., King, C.E., Kalan, L., Morar, M., Sung, W.W.L., Schwarz, C., Froese, D., Zazula, G., Calmel, F., Debruyne, R., Golding, G.B., Poinar, H.N., Wright, G.D., 2011. Antibiotic resistance is ancient. Nature 477, 457-461.

Delano, J.W., Tice, S.J., Mitchell, C.E., Goldman, D., 1995. Rhyolitic glass in Ordovician K-bentonites: a new stratigraphic tool. Geology 22, 115-118.

Dellino, P., Gudmundsson, M.T., Larsen, G., Mele, D., Stevenson, J.A., Thordarson, T., Zimanowski, B., 2012. Ash from the Eyjafjallajökull eruption (Iceland): Fragmentation processes and aerodynamic behaviour. Journal of Geophysical Research 117, B00C04, doi: 10.1029/2011JB008726 (pp. 1-10). 
Denton, J.S., Pearce, N.J.G., 2008. Comment on "A synchronized dating of three Greenland ice cores through the Holocene" by B.M. Vinther et al.: No Minoan tephra in the 1642 B.C. layer of the GRIP ice core. Journal of Geophysical Research 113, D04303, doi: 10.1029/2007JD008970 (pp. 1-7).

Derkachev, A.N., Nikolaeva, A., Gorbarenko, S.A., Harada, N., Sakamoto, T., Iijima, K., Sakhno, V.G., Hua Hua, Lv., Wang, K., 2012. Characteristics and ages of tephra layers in the central Okhotsk Sea over the last 350 kyr. Deep-Sea Research II 61-64, 179-192.

Devine, J.D., Gardner, J.E., Brack, H.P., Layne, G.D., Rutherford, M.J., 1995. Comparison of microanalytical methods for estimating $\mathrm{H}_{2} \mathrm{O}$ contents of silicic volcanic glasses. American Mineralogist 80, 319-328.

Donoghue, S.L., Stewart, R.B., Palmer, A.S., 1991. Morphology and chemistry of olivine phenocrysts of Mangamate Tephra, Tongariro Volcanic Centre, New Zealand. Journal of the Royal Society of New Zealand 21, 225-236.

Donoghue, S.L., Vallance, J., Smith, I.E.M., Stewart, R.B., 2007. Using geochemistry as a tool for correlating proximal andesitic tephras: case studies from Mt Rainier (USA) and Mt Ruapehu (New Zealand). Journal of Quaternary Science 22, 395-410.

Dugmore, A.J., Newton, A.J., 2012. Isochrons and beyond: maximising the use of tephrochronology in geomorphology. Jökull 62, 39-52. 
Dugmore, A.J., Larsen, G., Newton, A.J., 2004. Tephrochronology and its application to Late Quaternary environmental reconstruction, with special reference to the North Atlantic islands. In: Buck, C.E., Millard, A.R. (Eds), Tools for Constructing Chronologies: Crossing Disciplinary Boundaries. Springer, New York, pp. 173-188.

Dunbar, N.W., Kyle, P.R., 1993. Lack of volatile gradient in the Taupo plinianignimbrite transition: evidence from melt inclusion analysis. American Mineralogist $78,612-618$.

Dunbar, N.W., Kurbatov, A.V., 2011. Tephrochronology of the Siple Dome ice core, West Antarctica: correlations and sources. Quaternary Science Reviews 30, 16021614.

Durkee, H., Brown, F.H., 2014. Correlation of volcanic ash layers between the Early Pleistocene Acheulean sites of Isinya, Kariandusi, and Olorgesailie, Kenya. Journal of Archaeological Science 49, 510-517.

Eden, D.N., Palmer, A.S., Cronin, S.J., Marden, M., Berryman, K.R., 2001. Dating the culmination of river aggradation at the end of the last glaciation using distal tephra compositions, eastern North Island, New Zealand. Geomorphology 38, 133-151.

Edmonds, M., Wallace, P.J., 2017. Volatiles and exsolved vapor in volcanic systems. Elements 13, 29-34. 
Enache, M.D., Cumming, B.F., 2006. The morphological and optical properties of volcanic glass: a tool to assess density-induced vertical migration of tephra in sediment cores. Journal of Paleolimnology 35, 661-667.

Ester, M., Kriegel, H.-P., Sander, J., Xu, X., 1996. A density-based algorithm for discovering clusters in large spatial databases with noise. Proceedings International Conference on Knowledge Discovery and Data Mining (KDD96), pp. 226-231.

Everitt, B.S., Landau, S., Leese, M., Stahl, D., 2011. Cluster Analysis, $5^{\text {th }}$ edition. Wiley, Chichester, 330 pp.

Feibel, C.S., 1999. Tephrostratigraphy and geological context in paleoanthropology. Evolutionary Anthropology 8, 87-100.

Fisher, R.V., Schminke H.-U., 1984. Pyroclastic Rocks. Springer, Berlin, 472 pp.

Fortin, D., Francus, P., Gebhardt, A.C., Hahn, A., Kliem, P., Lisé-Pronovost, A., StOnge, G., PASADO Science Team, 2013. Destructive and non-destructive density determination: method comparison and evaluation from the Laguna Potrok Aike sedimentary record. Quaternary Science Reviews 71, 147-153.

Fournelle, J., 2007. Problems in trace element EPMA: modeling secondary fluorescence with PENEPMA. Eos Transactions, American Geophysical Union 88 (52), Fall Meeting Supplement, Abstract V51A-0329.

Fraley, C., Raftery, A.E., 1999. MCLUST: Software for model-based cluster analysis. Journal of Classification 16, 297-306. 
Fraley, C., Raftery, A.E., 2002. Model-based clustering, discriminant analysis, and density estimation. Journal of the American Statistical Association 97, 611-631.

Friedrich, W.L., Kromer, B., Friedrich, M., Heinemeier, J., Pfeiffer, T., Talamo, S., 2006. Santorini eruption radiocarbon dated to $1627-1600$ B.C. Science $312,548$.

Froggatt, P.C., 1983. Toward a comprehensive Upper Quaternary tephra and ignimbrite stratigraphy in New Zealand using electron microprobe analysis of glass shards. Quaternary Research 19, 188-200.

Froggatt, P.C., 1992. Standardization of the chemical analysis of tephra deposits. Report of the ICCT working group. Quaternary International 13-14, 93-96.

Froggatt, P.C., Lowe, D.J., 1990. A review of late Quaternary silicic and some other tephra formations from New Zealand: their stratigraphy, nomenclature, distribution, volume, and age. New Zealand Journal of Geology and Geophysics 33, 89-109.

Froggatt, P.C., Nelson, C.S., Carter, L., Griggs, G., Black, K.P., 1986. An exceptionally large late Quaternary eruption from New Zealand. Nature 319, 578-582.

Gaboardi, M., Humayun, M., 2009. Elemental fractionation during LA-ICP-MS analysis of silicate glasses: implications for matrix-independent standardization. Journal of Analytical Atomic Spectrometry 24, 1188-1197.

Gehrels, M.J., Newnham, R.M., Lowe, D.J., Wynne, S., Hazell, Z.J., Caseldine, C., 2008. Towards rapid assay of cryptotephra in peat cores: review and evaluation of various methods. Quaternary International 178, 68-84. 
Ghaemi, R., Sulaiman, Md. N., Ibrahim, H., Mustapha, N., 2009. A survey: clustering ensemble techniques. World Academy of Science, Engineering and Technology 26, 636-645.

Giaccio, R., Arienzo, I., Sottili, G., Castorina, F., Gaeta, M.,Nomade, S. Galli, P., Messina, P., 2013. Isotopic (Sr-Nd) and major element fingerprinting of distal tephras: an application to the Middle-Late Pleistocene markers from the Colli Albani volcano, central Italy. Quaternary Science Reviews 67, 190-206.

Giaccio, B., Hajdas, I., Isaia, R., Deino, A., Nomade, S., 2017. High-precision ${ }^{14} \mathrm{C}$ and ${ }^{40} \mathrm{Ar} /{ }^{39} \mathrm{Ar}$ dating of the Campanian Ignimbrite (Y-5) reconciles the time-scales of climatic-cultural processes at $40 \mathrm{ka}$. Scientific Reports 7, 45940, doi: 10.1038/srep45940 (pp. 1-10).

Gonzalez, S., Jones, J.M., Williams, D.L., 1999. Characterisation of tephras using magnetic properties: an example from SE Iceland. Geological Society (London) Special Publication 161, 125-145.

Gower, J.C., 1966. Some distance properties of latent root and vector methods used in multivariate analysis. Biometrika 53, 325-338.

Gower, J.C., 1971. A general coefficient of similarity and some of its properties. Biometrics 27, 857-871. 
Grainger, M.N.C., Manley-Harris, M., Coulson, S., 2012. Classification and discrimination of automotive glass using LA-ICP-MS. Journal of Analytical Atomic Spectrometry 27, 1413-1422.

Green, R.M., Bebbington, M.S., Cronin, S.J., Jones, G., 2014. Automated statistical matching of multiple tephra records exemplified using five long maar sequences younger than 75 ka, Auckland, New Zealand. Quaternary Research 82, 405-419.

Green, R.M., Bebbington, M.S., Jones, G., Cronin, S.J., Turner, M.B., 2016. Estimation of tephra volumes from sparse and incompletely observed deposit thicknesses. Bulletin of Volcanology 78, 1-18.

Greenough, J.D., Owen, J.V., 2003. A petrochemical study of basaltic layering at Henley Harbour, Labrador, using multidimensional scaling. Atlantic Geology 38, $161-175$.

Griggs, A.J., Davies, S.M., Abbott, P.M., Rasmussen, T.L., Palmer, A.P. 2014. Optimising the use of marine tephrochronology in the North Atlantic: a detailed investigation of the Faroe Marine Ash Zones II, III and IV. Quaternary Science Reviews 106, 122-139.

Griggs, A.J., Davies, S.M., Abbott, P.M., Coleman, M., Palmer, A.P., Rasmussen, T.L., Johnston, R. 2015. Visualising tephra deposits and sedimentary processes in the marine environment: the potential of X-ray microtomography. Geochemistry, Geophysics, Geosystems 16, 4329-4343. 
Guðmundsdóttir, E.R., Eiríksson, J., Larsen, G., 2012. Holocene marine tephrochronology on the Iceland shelf: an overview. Jökull 62, 53-72.

Habermann, J.M., McHenry, L.J., Stollhofen, H., Tolosana-Delgado, R., Stanistreet, I.G., Deino, A.L., 2016. Discrimination, correlation, and provenance of Bed I tephrostratigraphic markers, Olduvai Gorge, Tanzania, based on multivariate analyses of phenocryst compositions. Sedimentary Geology 339,115-133.

Hall, M., Hayward, C., 2014. Preparation of micro- and crypto-tephras for quantitative microbeam analysis. Geological Society, London, Special Publications 398, 21-28.

Hallett, D.J., Mathewes, R.W., Foit, F.F., Jr., 2001. Mid-Holocene Glacier Peak and Mount St. Helens We tephra layers detected in lake sediments from southern British Columbia using high-resolution techniques. Quaternary Research 55, 284-292.

Hamann, Y., Wulf, S., Ersoy, D., Ehrmann, W., Aydar, E., Schmiedl, G., 2010. First evidence of a distal early Holocene ash layer in eastern Mediterranean deep-sea sediments derived from the Anatolian volcanic province. Quaternary Research 73, 497-506.

Hammer, O., Harper, D.A.T., Ryan, P.D., 2001. PAST: Paleontological statistics software package for education and data analysis. Palaeontologia Electronica 4 (1), article 4, http://palaeo-electronica.org/2001_1/past/issue1_01.htm (9 pp).

Hammond, A., Ward, W.T., 2001. Replicate means of rhyolitic tephras. (Abstracts) Geological Society of New Zealand Miscellaneous Publication 110A, 53. 
Hampel, F.R., Ronchetti, E.M., Rousseeuw, P.J., Stahel, W.A., 2011. Robust Statistics: the Approach Based on Influence Functions. Wiley, New York, 502 pp.

Han, J., Kamber, M., Pei, J., 2012. Data Mining: Concepts and Techniques, 3rd edition. Morgan Kaufmann Publishers (Elsevier), Waltham, MA, 703 pp.

Harangi, S., Mason, P.R.D., Lukács, R., 2005. Correlation and petrogenesis of silicic pyroclastic rocks in the northern Pannonian basin, east-central Europe: in situ trace element data of glass shards and mineral chemical constraints. Journal of Volcanology and Geothermal Research 143, 237-257.

Harper, M.A., Pledger, S.A., Smith, E.G., Van Eaton, A.R., Wilson, C.J.N., 2015. Eruptive and environmental processes recorded by diatoms in volcanically dispersed lake sediments from the Taupo Volcanic Zone, New Zealand. Journal of Paleolimnology 54, 263-277.

Hart, W.K., Walter, R.C., WoldeGabriel, G., 1992. Tephra sources and correlations in Ethiopia: application of elemental and neodymium isotope data. Quaternary International 13-14, 77-86.

Hartigan, J.A. 1975. Clustering Algorithms. Wiley, New York, 351 pp.

Harvey, J.C., 2014. Zircon age and oxygen isotopic correlations between Bouse Formation tephra and the Lawlor Tuff. Geosphere 10, 221-232. 
Hayward, C., 2012. High spatial resolution electron probe microanalysis of tephras and melt inclusions without beam-induced chemical modification. The Holocene 22, 119125.

Hermanns, R.L., Schellenberger, A., 2008. Quaternary tephrochronology helps define conditioning factors and triggering mechanisms of rock avalanches in NW Argentina. Quaternary International 178, 261-275.

Hillenbrand, C.-D., Moreton, S.G., Caburlotto, A., Pudsey, C.J., Lucchi, R.G., Smellie, J.L., Benetti, S., Grobe, H., Hunt, J.B., Larter, R.D., 2008. Volcanic time markers for Marine Isotopic Stages 6 and 5 in Southern Ocean sediments and Antarctic ice cores: implications for tephra correlations between palaeoclimatic records. Quaternary Science Reviews 27, 518-540.

Hodder, A.P.W., 1978. Refractive index and hydration of rhyolitic glass from Holocene tephras, North Island, New Zealand. New Zealand Journal of Geology and Geophysics 21, 155-166.

Hodder, A.P.W., Wilson, A.T., 1976. Identification and correlation of thinly bedded tephra: the Tirau and Mairoa ashes. New Zealand Journal of Geology and Geophysics 19, 663-682.

Hogg, A.G., Lowe, D.J., Palmer, J.G., Boswijk, G., Bronk Ramsey, C.J., 2012. Revised calendar date for the Taupo eruption derived by ${ }^{14} \mathrm{C}$ wiggle-matching using a New Zealand kauri ${ }^{14} \mathrm{C}$ calibration data set. The Holocene 22, 439-449. 
Hopkins, J.L., Millet, M.-A., Timm, C., Wilson, C.J.N., Leonard, G.S., Palin, J.M., Neil, H. 2015. Tools and techniques for developing tephra stratigraphies in lake cores: a case study from the basaltic Auckland Volcanic Field, New Zealand. Quaternary Science Reviews 123, 58-75.

Hopkins, J.L., Wilson, C.J.N., Millet, M.-A., Leonard, G.S., Timm, C., McGee, L.E., Smith, I.E.M., Smith, E.G.C., 2017. Multi-criteria correlation of tephra deposits to source centres applied in the Auckland Volcanic Field, New Zealand. Bulletin of Volcanology 79, 55, doi: 10.1007/s00445-017-1131-y (pp. 1-35).

Horrocks, J.L., 2000. Stratigraphy, chronology and correlation of the Plio-Pleistocene (c. 2.2-0.8 Ma) Kauroa Ash sequence, western central North Island, New Zealand. Ph.D. thesis, University of Waikato, Hamilton, New Zealand.

Housley, R.A., Lane, C.S., Cullen, V.L., Weber, .M.-J., Riede, F., Gamble, C.S., Brock, F., 2012. Icelandic volcanic ash from the Late-glacial open-air archaeological site of Ahrenshöft LA 58 D, north Germany. Journal of Archaeological Science 39, 708716.

Housley, R.A., MacLeod, A., Nalepka, D., Jurochnik, A., Masojc, M., Davies, L., Lincoln, P.C., Bronk Ramsey, C., Gamble, C.S., Lowe, J.J., 2013.

Tephrostratigraphy of a Lateglacial lake sediment sequence at Wegliny, southwest Poland. Quaternary Science Reviews 77, 4-18.

Huff, W.D., 2016. K-bentonites: a review. American Mineralogist 101, 43-70. 
Huff, W.D., Kolata, D.R., Bergstrijm, S.M., Zhang, Y-S., 1996. Large-magnitude Middle Ordovician volcanic ash falls in North America and Europe: dimensions, emplacement and post-emplacement characteristics. Journal of Volcanology and Geothermal Research 73, 285-301.

Humphreys, M.C.S., Kearns, S.L., Blundy, J.D., 2006. SIMS investigation of electronbeam damage to hydrous, rhyolitic glasses: implications for melt inclusion analysis. American Mineralogist 91, 667-679.

Hunt, J.B., Hill, P.G., 1993. Tephra geochemistry: a discussion of some persistent analytical problems. The Holocene 3, 271-278.

Hunt, J.B., Hill, P.G., 1994. Geochemical data in tephrochronology: a reply to Bennett. The Holocene 4, 436-438.

Hunt, J.B., Hill, P.G., 1996. An inter-laboratory comparison of the electron probe microanalysis of glass geochemistry. Quaternary International 34-36, 229-241.

Hunt, J.B., Hill, P.G., 2001. Tephrological implications of beam size-sample-size effects in electron microprobe analysis of glass shards. Journal of Quaternary Science 16, 105-117.

Hunt, J.B., Fannin, G.T., Hill, P.G., Peacock, J.D., 1995. The tephrochronology and radiocarbon dating of North Atlantic, Late-Quaternary sediments: an example from the St. Kilda Basin. Geological Society (London) Special Publication 90, 227-248. 
Hunt, J.B., Clift, P.D., Lacasse, C., Vallier, T.L., Werner, R., 1998. Interlaboratory comparison of electron probe microanalysis of glass geochemistry. In: Saunders, A.D., Larsen, H.C., Wise, S.W., Jr. (Eds.), Proceedings of the Ocean Drilling Program, Scientific Results 152, 85-91.

Ickert, R.B., Mulcahy, S.R., Sprain, C.J., Banaszak, J.F., Renne, P.R., 2015. Chemical and $\mathrm{Pb}$ isotope composition of phenocrysts from bentonites constrains the chronostratigraphy around the Cretaceous-Paleogene boundary in the Hell Creek region, Montana. Geochemistry, Geophysics, Geosystems 16, 2743-2761.

Inoue, Y., Baasansuren, J., Watanabe, M., Kamei, H., Lowe, D.J., 2009. Interpretation of pre-AD 472 Roman soils from physicochemical and mineralogical properties of buried tephric paleosols at Somma Vesuviana ruin, southwest Italy. Geoderma 152, 243-251.

Iverson, N.A., Kyle, P.R., Dunbar, N.W., McIntosh, W.C., Pearce, N.J.G., 2014. Eruptive history and magmatic stability of Erebus volcano, Antarctica: insights from englacial tephras. Geochemistry, Geophysics, Geosystems 15, 4180-4202.

Iverson, N.A., Kalteyer, D., Dunbar, N.W., Kurbatov, A., Yates, M., 2017. Advancements and best practices for analysis and correlation of tephra and cryptotephra in ice. Quaternary Geochronology 40, 45-55. 
Izett, G., 1981. Volcanic ash beds: recorders of upper Cenozoic silicic pyroclastic volcanism in the western United States. Journal of Geophysical Research 86 (B11), $10,200-10,222$.

James, G., Witten, D., Hastie, T., Tibshirani, R., 2013. An Introduction to Statistical Learning with Applications in R. Springer, New York, 426 pp.

Janoušek, V., Farrow, C.M., Erban, V., 2006. Interpretation of whole-rock geochemical data in igneous geochemistry: introducing Geochemical Data Toolkit (GCDkit). Journal of Petrology 47, 1255-1259. [See also http://www.gcdkit.org/.]

Janoušek, V., Moyen, J.-F., Martin, H., Erban, V., Farrow, C., 2015. Geochemical Modelling of Igneous Processes - Principles and Recipes in R Language: Bringing the Power of R to a Geochemical Community. Springer, Berlin, 346 pp.

Jarosewich, E., 2002. Smithsonian microbeam standards. Journal of Research of the National Institute of Standards and Technology 107, 681-685.

Jarosewich, E., Parkes, A.S., Wiggins, L.B., 1979. Microprobe analyses of four natural glasses and one mineral: an interlaboratory study of precision and accuracy. Smithsonian Contributions to the Earth Sciences 22, 53-67.

Jarosewich, E., Nelen, J.A., Norberg, J.A., 1980. Reference samples for electron microprobe analysis. Geostandards Newsletter 4, 43-47. 
Jenner, F.E., O’Neil, St. C., 2012. Major and trace analysis of basaltic glasses by laserablation ICP-MS. Geochemistry, Geophysics, Geosystems 13 (3), Q03003, doi: 10.1029/2011GC003890 (pp. 1-17).

Jennings, A., Thordarson, T., Zalzal, K., Stoner, J., Hayward, C., Geirsdóttir, Á., Miller, G., 2014. Holocene tephra from Iceland and Alaska in SE Greenland shelf sediments. Geological Society (London) Special Publication 398, 157-193. Jensen, B.J.L., Froese, D.G., Preece, S.J., Westgate, J.A., Stachel, T., 2008. An extensive middle to late Pleistocene tephrochronologic record from east-central Alaska. Quaternary Science Reviews 27, 411-427.

Jensen, B.J.L., Pyne-O’Donnell, S., Plunkett, G., Froese, D.G., Hughes, P.D.M., Sigl, M., McConnell, J.R., Amesbury, M.J., Blackwell, P.G., van den Bogaard, C., Buck, C.E., Charman, D.J., Clague, J.J., Hall, V.A., Koch, J., Mackay, H., Mallon, G., McColl, L., Plicher, J.R. 2014. Transatlantic distribution of the Alaskan White River Ash. Geology 42, 875-878.

Jerram, D., Martin, V., 2008. Understanding crystal populations and their significance through the magma plumbing system. Geological Society (London) Special Publications 304, 133-148.

Jochum, K.P, Stoll B., 2008. Reference materials for elemental and isotopic analysis by LA-(MC)-ICP-MS: successes and outstanding needs. In: Sylvester, P. (Ed.), Laser 
Ablation ICP-MS in the Earth Sciences: Current Practices and Outstanding Issues. Mineralogical Association of Canada, Short Course Series 40, 147-168.

Jochum, K.P., Willbold, M., Raczek, I., Stoll, B., Herwig, K., 2005. Chemical characterization of the USGS reference glasses GSA-1G, GSC-1G, GSD-1G, GSE1G, BCR-2G, BHVO-2G, and BIR-1G using EPMA, ID-TIMS, ID-ICP-MS and LAICP-MS. Geostandards and Geoanalytical Research 29, 285-302.

Jochum, K.P., Stoll, B., Herwig, K., Willbold, M., Hofmann, A.W., Amini, M., Aarburg, S., Abouchami, W., Hellebrand, E., Mocek, B., Raczek, I., Stracke, A., Alard, O., Bouman, C., Becker, S., Ducking, M., Bratz, H., Klemd, R., de Bruin, D., Canil, D., Cornell, D., de Hoog, C.J., Dalpe, C., Danyushevsky, L., Eisenhauer, A., Gao, Y.J., Snow, J.E., Goschopf, N., Gunther, D., Latkoczy, C., Guillong, M., Hauri, E.H., Hofer, H.E., Lahaye, Y., Horz, K., Jacob, D.E., Kassemann, S.A., Kent, A.J.R., Ludwig, T., Zack, T., Mason, P.R.D., Meixner, A., Rosner, M., Misawa, K.J., Nash, B.P., Pfander, J., Premo, W.R., Sun, W.D.D., Tiepolo, M., Vannucci, R., Vennemann, T., Wayne, D., Woodhead, J.D., 2006. MPI-DING reference glasses for in situ microanalysis: new reference values for element concentrations and isotope ratios. Geochemistry Geophysics Geosystems 7, Q02008, doi: 10.1029/2005GC001060 (pp. 1-45).

Jochum, K. P., Weis, U., Stoll, B., Kuzmin, D., Yang, Q., Raczek, I., Jacob, D. E., Stracke, A., Birbaum, K., Frick, D. A., Günther, D. and Enzweiler, J. 2011. 
Determination of reference values for NIST SRM 610-617 glasses following ISO guidelines. Geostandards and Geoanalytical Research 35, 397-429.

Jones, B., Renaut, R.W., Torfason, H., Owen, R.B., 2007. The geological history of Geysir, Iceland: a tephrochronological approach to the dating of sinter. Journal of the Geological Society 164, 1241-1252.

Jones, G., Lane, C.S., Brauer, A., Davies, S.M., de Bruijn, R., Engels, S., Haliuc, A., Hoek, W.Z., Merkt, J., Sachse, D., Turner, F., Wagner-Cremer, F., 2017. The Lateglacial to early Holocene tephrochronological record from Lake Hämelsee, Germany: a key site within the European tephra framework. Boreas (in press) doi: 10.1111/bor.12250.

Jordan, B.R., Sigurdsson, H., Carey, S.N., Rogers, R., Ehrenborg, J., 2006.

Geochemical correlation of Caribbean Sea tephra layers with ignimbrites in Central America. Geological Society of America Special Paper 402, 175-208.Jouannic, G., Walter-Simonnet, A.V., Bossuet, G., Begeot, C., Develle, A.-L., 2015. Feldspar composition as an efficient tool for tephra identification: a case study from Holocene and Lateglacial lacustrine sequences (Jura, France). Journal of Quaternary Science 30, 569-583.

Julian, S.R., Westgate, J.A., Daniels, J.M., Rancourt, D.G., Sullivan, P. 1988. A comparison of the titanomagnetites produced by several volcanoes in Iceland. Hyperfine Interactions 41, 807-810. 
Juvigné, E.T., Porter, S.C., 1985. Mineralogical variations within two widespread Holocene tephra layers from Cascade Range volcanoes, U.S.A. Géographie Physique et Quaternaire 39, 7-12.

Karátson, D., Wulf, S., Veres, D., Magyari, E., Gertisser, R., Timar-Gabor, A., Novothny, Á. Telbisz, T., Szalai, Z., Anechitei-Deacu, V., Appelt, O., Bormann, M., Jánosi, Cs., Schäbitz, F., 2016. The latest explosive eruptions of Ciomadul (Csomád) volcano, east Carpathians - a tephrostratigraphic approach for the 52-29 ka BP time interval. Journal of Volcanology and Geothermal Research 319, 29-51.

Kaufman, L., Rousseeuw, P.J., 1990. Finding Groups in Data: An Introduction to Cluster Analysis. Wiley, New Jersey, 342 pp.

Kaufman, D.S., Jensen, B.J.L., Reyes, A.V., Schiff, C.J., Froese, D.G., Pearce, N.J.G., 2012. Late Quaternary tephrostratigraphy, Ahklun Mountains, SW Alaska. Journal of Quaternary Science 27, 344-359.

Kawabata, E., Bebbington, M.S., Cronin, S.J., Wang, T., 2016. Optimal likelihoodbased matching of volcanic sources and deposits in the Auckland Volcanic Field. Journal of Volcanology and Geothermal Research 323, 194-208.

Kearns, L., Buse, B., 2012. X-ray microanalysis of volcanic ash. EMAS 2011: $12^{\text {th }}$ European Workshop on Modern Developments in Microbeam Analysis. IOP Conference Series: Materials Science and Engineering 32, 012013, doi:10.1088/1757-899X/32/1/012013 (pp. 1-11). 
Keenan, D.J., 2003. Volcanic ash retrieved from the GRIP ice core is not from Thera. Geochemistry Geophysics Geosystems 4, 1097, doi: 10.1029/2003GC00068 (pp. 1$8)$.

Kilgour, G.N., Smith, R.T., 2008. Stratigraphy, dynamics, and eruption impacts of the dual magma Rotorua eruptive episode, Okataina Volcanic Centre, New Zealand. New Zealand Journal of Geology and Geophysics 51, 367-378.

Kilgour, G., Blundy, J., Cashman, K., Mader, H.M., 2013. Small volume andesite magmas and melt-mush interactions at Ruapehu, New Zealand: evidence from melt inclusions. Contributions to Mineralogy and Petrology 166, 371-392.

Kimber, R.W.L., Kennedy, N.M., Milnes, A.R., 1994. Amino acid racemization dating of a 140000 year old tephra-loess-palaeosol sequence on the Mamaku Plateau near Rotorua, New Zealand. Australian Journal of Earth Sciences 41, 19-26.

King, R.H., Kingston, M.S., Barnett, R.L., 1982. A numerical approach toward the classification of magnetites from tephra in southern Alberta. Canadian Journal of Earth Sciences 19, 2012-2019.

Knott, J.R., Sarna-Wojcicki, A.M., Meyer, C.E., Tinsley, J.C., III, Wells, S.G., Wan, E., 1999. Late Cenozoic stratigraphy and tephrochronology of the western Black Mountains piedmont, Death Valley, California: implications for the tectonic development of Death Valley. Geological Society of America Special Paper 333, 345-366. 
Knott, J.R., Sarna-Wojcicki, A.M., Montañez, I.P., Wan, E., 2007. Differentiating the Bishop ash bed and related tephra layers by elemental-based similarity coefficients of volcanic glass shards using solution inductively coupled plasma-mass spectrometry (S-ICP-MS). Quaternary International 166, 79-86.

Kohonen, T., 1995. Self-organizing Maps. Springer, Berlin-Heidelberg, 362 pp.

Kohonen, T., 2001. Self-organizing Maps, 3rd edition. Springer, Berlin-Heidelberg, 502 pp.

Kotaki, A., Katoh, S., Kitani, K., 2011. Correlation of Middle Pleistocene crystal-rich tephra layers from Daisen Volcano, southwest Japan, based on the chemical composition and refractive index of mafic minerals. Quaternary International 246, 105-117.

Kovach Computing Services, 2008. Multivariate Statistical Package for Windows, version 3.13. Kovach Computing Services, Anglesey, Wales.

Kraus, S., Kurbatov, A., 2010. Chemical fingerprinting of bulk tephra from Late Pleistocene/Holocene volcanoes in the northern Antarctic Peninsula area. In: Mulder, T.J. (Ed.), Antarctica: Global, Environmental and Economic Issues. Nova Science, New York, pp. 1-45.

Kraus, S., Kurbatov, A., Yates, M., 2013. Geochemical signatures of tephras from Quaternary Antarctic Peninsula volcanoes. Andean Geology 40, 1-40. 
Kroslakova, I., Günther, D., 2007. Elemental fractionation in laser ablation-inductively coupled plasma-mass spectrometry: evidence for mass load induced matrix effects in the ICP during ablation of a silicate glass. Journal of Analytical Atomic Spectrometry 22, 51-62.

Kruiver, P.P., Kok, Y.S., Dekkers, M.J., Langereis, C.G., Laj, C., 1999. A pseudoThellier relative palaeointensity record, and rock magnetic and geochemical parameters in relation to climate during the last $276 \mathrm{kyr}$ in the Azores region. Geophysical Journal International 136, 757-770.

Krzanowski, W.J., 1988. Principles of Multivariate Analysis: a User's Perspective. Clarendon, Oxford, 563 pp.

Kuehn, S.C., 2017. Analysis relocation spreadsheet at https://www.researchgate.net/publication/287811685_Coordinate_transformation_sp readsheet_-_Handy_for_relocating_grains_on_a_new_instrument?origin=publication_list).

Kuehn, S.C., 2016. Routine EPMA of silicate glasses using a 5 micron beam: taking advantage of TDI, combined EDS+WDS, MAN, and a multi-standard blank correction. Program guide with abstracts, Microanalysis Society Topical Conference - Electron-Probe Microanalysis (EPMA 2016). University of Wisconsin - Madison, WI, May 16-19, pp. 40-41. 
Kuehn, S.C., Foit, F.F., Jr., 2006. Correlation of widespread Holocene and Pleistocene tephra layers from Newberry Volcano, Oregon, USA, using glass compositions and numerical analysis. Quaternary International 148, 113-137.

Kuehn, S.C., Froese, D.G., 2010. Tephra from ice - a simple method to routinely mount, polish, and quantitatively analyze sparse fine particles. Microscopy and Microanalysis 16, 218-225.

Kuehn, S.C., Froese, D.G., Carrara, P.E., Foit, F.F., Jr., Pearce, N.J.G., Rotheisler, P., 2009. Major- and trace-element characterization, expanded distribution, and a new chronology for the latest Pleistocene Glacier Peak tephras in western North America. Quaternary Research 71, 201-216.

Kuehn, S.C., Froese, D.G., Shane, P.A.R., INTAV Intercomparison Participants, 2011. The INTAV intercomparison of electron-beam microanalysis of glass by tephrochronology laboratories: results and recommendations. Quaternary International 246, 19-47.

Kuehn, S.C., Bursik, M.I., Pouget, S., 2013. Improved integration and discoverability of tephra data for multidisciplinary applications. Abstract 1815416 in session V006 "Data-driven science in geochemistry, petrology, and volcanology". American Geophysical Union 46 ${ }^{\text {th }}$ annual Fall Meeting, San Francisco, 9-13 December, 2013. Kuehn, S. C., Pouget, S., Wallace, K., Bursik, M. I. 2014. Results of the Tephra 2014 Workshop on Maximizing the Potential of Tephra for Multidisciplinary Science. 
In AGU Fall Meeting Abstracts (Vol. 1, p. 4758, abstract \#V31C-4758), doi: 10.13140/RG.2.1.2454.0002.

Kurbatov, A.V., Zielinski, G.A., Dunbar, N.W., Mayewski, P.A., Meyerson, E.A., Sneed, S.B., Taylor K.C., 2006. A 12,000 year record of explosive volcanism in the Siple Dome Ice Core, West Antarctica. Journal of Geophysical Research 111, D12307, doi: 10.1029/2005JD006072 (pp. 1-18).

Kylander, M.A., Lind, E.M., Wastegård, S., Löwemark, L., 2012. Recommendations for using XRF core scanning as a tool in tephrochronology. The Holocene 22, 371-375.

Lane, C.S., Blockley, S.P.E., Mangerud, J, Smith, V.C., Lohne, Ø.S., Tomlinson, E.L., Lotter, A.F., 2012. Was the 12.1 ka Icelandic Vedde Ash one of a kind? Quaternary Science Reviews 33, 87-99.

Lane, C.S., Chorn, B.T., Johnson, T.C., 2013a. Ash from the Toba supereruption in Lake Malawi shows no volcanic winter in East Africa at $75 \mathrm{ka}$. Proceedings of the National Academy of Sciences of the United States of America 110, 8025-8029.

Lane, C.S., Brauer, A., Blockley, S.P.E., Dulski, P., 2013b. Volcanic ash reveals timetransgressive abrupt climate change during the Younger Dryas. Geology 41, 12511254.

Lane, C.S., Cullen, V.L., White, D., Bramham-Law, C.W.F., Smith, V.C., 2014. Cryptotephra as a dating and correlation tool in archaeology. Journal of Archaeological Science 42, 42-50. 
Lane, C.S., Lowe, D.J., Blockley, S.P.E., Suzuki, T., Smith, V.C. 2017. Advancing tephrochronology as a global dating tool: applications in volcanology, archaeology, and palaeoclimatic research. Quaternary Geochronology 40, 1-7.

Lawson, I.T., Swindles, G.T., Plunkett, G., Greenberg, D., 2012. The spatial distribution of Holocene cryptotephras in north-west Europe since $7 \mathrm{ka}$ : implications for understanding ash fall events from Icelandic eruptions. Quaternary Science Reviews 41, 57-66.

Le Maitre, R.W. (editor), 2002. Igneous Rocks. A Classification and Glossary of Terms. Recommendations of the International Union of Geological Sciences Subcommission on the Systematics of Igneous Rocks, 2nd edition. Cambridge University Press, Cambridge, 236 pp.

Leonard, G.S., Calvert, A.T., Hopkins, J.L., Wilson, C.J.N., Smid, E.R., Lindsay, J.M., Champion, D.E., 2017. High-precision ${ }^{40} \mathrm{Ar} /{ }^{39} \mathrm{Ar}$ dating of Quaternary basalts from Auckland Volcanic Field, New Zealand, with implications for eruption rates and paleomagnetic correlations. Journal of Volcanology and Geothermal Research 343, $60-74$.

Li, C., Arndt, N.T., Tang, Q., Ripley, E.M., 2015. Trace element indiscrimination diagrams. Lithos 232, 76-83.

Lilja, C., Lind, E.M., Morén, B., Wastegård, S., 2013. A Lateglacial-early Holocene tephrochronology for SW Sweden. Boreas 42, 544-554. 
Lim, C., Ikehara, K., Toyoda, K., 2008. Cryptotephra detection using high-resolution trace element analysis of Holocene marine sediments, southwest Japan. Geochimica et Cosmochimica Acta 72, 5022-5036.

Lim, C., Toyoda, K., Peate, D.W., 2013. Late Quaternary tephrostratigraphy of Baegdusan and Ulleung volcanoes using marine sediments in the Japan Sea/East Sea. Quaternary Research 80, 76-87.

Lim, C., Kim, S., Lee, C., 2014. Geochemical fingerprint of the primary magma composition in the marine tephras originated from the Baegdusan and Ulleung volcanoes. Journal of Asian Earth Sciences 95, 266-273.

Lind, E. M., Lilja, C., Wastegärd, S., Pearce, N.J.G. 2016. Revisiting the Borrobol Tephra. Boreas 45, 629-643.

Ling, R.F., 1972. On the theory and construction of $k$-clusters. Computer Journal 15, 326-332.

Ling, R.F., 1973. A probability theory of cluster analysis. Journal of the American Statistical Association 68, 159-164.

Liu, Z., Colin, C., Trentesaux, A., 2006. Major element geochemistry of glass shards and minerals of the Youngest Toba Tephra in the southwestern South China Sea. Journal of Asian Earth Sciences 27, 99-107.

Liu, E.J., Olivab, M., Antoniades, D., Giraltd, S., Granados, I., Pla-Rabes, S., Torog, M., Geyerd, A., 2016. Expanding the tephrostratigraphical framework for the South 
Shetland Islands, Antarctica, by combining compositional and textural tephra characterisation. Sedimentary Geology 340, 49-61.

Lohne, Ø.S., Mangerud, J., Birks, H.H., 2013. Precise ${ }^{14} \mathrm{C}$ ages of the Vedde and Saksunarvatn ashes and the Younger Dryas boundaries from western Norway and their comparison with the Greenland Ice Core (GICC05) chronology. Journal of Quaternary Science 28, 490-500.

Lowe, D.J., 1988. Late Quaternary volcanism in New Zealand: towards an integrated record using distal airfall tephras in lakes and bogs. Journal of Quaternary Science 3, 111-120.

Lowe, D.J., 2011. Tephrochronology and its application: a review. Quaternary Geochronology 6, 107-153.

Lowe, D.J., Alloway, B.V., 2015. Tephrochronology. In: Rink, W.J., Thompson, J.M. (Eds.), Encyclopaedia of Scientific Dating Methods. Springer, Dordrecht, pp. 783799.

Lowe, D.J., Shane, P.A.R., Alloway, B.V., Newnham, R.M., 2008. Fingerprints and age models for widespread New Zealand tephra marker beds erupted since 30,000 years ago: a framework for NZ-INTIMATE. Quaternary Science Reviews 27, 95-126.

Lowe, D.J., Davies, S.M., Moriwaki, H., Pearce, N.J.G., Suzuki, T., 2011. Enhancing tephrochronology and its application (INTREPID project): Hiroshi Machida commemorative volume. Quaternary International 246, 1-5. 
Lowe, D.J., Blaauw, M., Hogg, A.G., Newnham, R.M., 2013. Ages of 24 widespread tephras erupted since 30,000 years ago in New Zealand, with re-evaluation of the timing and palaeoclimatic implications of the late-glacial cool episode recorded at Kaipo bog. Quaternary Science Reviews 74, 170-194.

Lowe, J.J., Blockley, S.P.E., Trincardi, F., Asioli, A., Cattaneo, A., Matthews, I.P., Pollard, A.M., Wulf, S., 2007. Age modelling of late Quaternary marine sequences in the Adriatic: towards improved precision and accuracy using volcanic event stratigraphy. Continental Shelf Research 27, 560-582.

Lowe, J.J., Barton, N., Blockley, S.P.E., Bronk Ramsey, C., Cullen, V.L., Davies, W., Gamble, C., Grant, K., Hardiman, M., Housley, R., Lane, C.S., Lee, S., Lewis, M., MacLeod, A., Menzies, M., Müller, W., Pollard, M., Price, C., Roberts, A.P., Rohling, E.J., Satow, C., Smith, V.C., Stringer, C.B., Tomlinson, E.L., White, D., Albert, P., Arienzon, I., Barker, G., Boric, D., Carandente, A., Civette, L., Ferrier, C., Guadelli, J.-L., Karkanas, P., Koumouzelis, M., Müller, U.C., Orsi, G., Pross, J., Rosi, M., Shalamanov-Korobar, L., Sirakov, N., Tzedakis, P.C., 2012. Volcanic ash layers illuminate the resilience of Neanderthals and early modern humans to natural hazards. Proceedings of the National Academy of Sciences of the USA 109, 13,532$13,537$.

Machida, H., 2010. Outline of tectonic setting and explosive volcanism of southern Kyushu. In: Moriwaki, H., Lowe, D.J. (Eds.), Intra-conference Field Trip Guides. 
INTAV International Field Conference and Workshop on Tephrochronology, Volcanism, and Human Activity, Kirishima, Japan, 9-17 May, pp. 11-35.

Mackay, H., Hughes, P.D.M., Jensen, B.J.J., Langdon, P.G., Pyne-O’Donnell, S.D.F., Plunkett, G., Froese, D.G., Coulter, S., Gardner, J.E., 2016. A mid to late Holocene cryptotephra framework from eastern North America. Quaternary Science Reviews $132,101-113$.

Mair, P., 2016. Thou shalt be reproducible! A technology perspective. Frontiers in Psychology Technology Report 7, 1079, https://doi.org/10.3389/fpsyg.2016.01079 (pp.1-8).

Manly, B.F.J., 2007. Randomization, Bootstrap, and Monte Carlo Methods in Biology, $3^{\text {rd }}$ edition. Chapman and Hall/CRC Press, Boca Raton, 455 pp.

Marcaida, M., Mangan, M.T., Vazquez, J.A., Bursik, M., Lidzbarski, M.I., 2014. Geochemical fingerprinting of Wilson Creek formation tephra layers (Mono Basin, California) using titanomagnetite compositions. Journal of Volcanology and Geothermal Research 273, 1-14.

Mardia, K.V., Kent, J.T., Bibby, J.M., 1979. Multivariate Analysis. Academic Press, London, $521 \mathrm{pp}$.

Martin-Jones C.M., Lane C.S., Pearce N.J.G., Smith V.C., Lamb H.F., Asfawossen, A., Schabitz, F. 2017. Glass compositions and tempo of post-17 ka eruptions from the 
Afar Rift recorded in sediments from lakes Ashenge and Hayk, Ethiopia. Quaternary Geochronology 37, 15-31

Maruyama, S., Hattori, K., Hirata, T., Danhara, T., 2016a. A proposed methodology for analyses of wide-ranged elements in volcanic glass shards in widespread Quaternary tephras. Quaternary International 397, 267-280.

Maruyama, S., Hattori, K., Hirata, T., Suzuki, T., Danhara, T., 2016b. Simultaneous determination of 58 major and trace elements in volcanic glass shards from the INTAV sample mount using femtosecond laser ablation-inductively coupled plasmamass spectrometry. Geochemical Journal 50, 403-422.

Maruyama, S., Danhara, T., Hirata, T., 2017. Re-identification of Shishimuta-Pink tephra samples from the Japanese Islands based on simultaneous major- and traceelement analyses of volcanic glasses. Quaternary International (in press).

Matsu'ura, T., Komatsubara, J., 2017. Use of amphibole chemistry for detecting tephras in deep-sea sequences (Chikyu C9001C cores) and developing a middle Pleistocene tephrochronology for NE Japan. Quaternary International (in press), doi: 10.1016/j.quageo.2016.08.002.

Matsu'ura, T., Ueno, T., Furusawa, A., 2011a. Characterization and correlation of cryptotephras using major-element analyses of melt inclusions preserved in quartz in last interglacial marine sediments, southeastern Shikoku, Japan. Quaternary International 246, 48-56. 
Matsu'ura, T., Miyagi, I., Furusawa, A., 2011b. Late Quaternary cryptotephra detection and correlation in loess in northeastern Japan using cummingtonite geochemistry. Quaternary Research 75, 624-635.

Matsu'ura, T., Furusawa, A., Yanagida, M., 2012. Detection and correlation of widespread cryptotephras in middle Pleistocene loess in NE Japan using cummingtonite geochemistry. Journal of Asian Earth Sciences 60, 49-67.

Matsu'ura, T., Furusawa, A., Shimogama, K., Goto, N., Komatsubara, J., 2014. Late Quaternary tephrostratigraphy and cryptotephrostratigraphy of deep-sea sequences (Chikyu C9001C cores) as tools for marine terrace chronology in NE Japan. Quaternary Geochronology 23, 63-79.

McCanta, M.C., Hatfield, R.G., Thomson, B.J., Hook, S.J., Fisher, E., 2015. Identifying cryptotephra units using correlated rapid, nondestructive methods: VSWIR spectroscopy, X-ray fluorescence, and magnetic susceptibility. Geochemistry, Geophysics, Geosystems 16, 4029-4056.

McHenry, L.J., 2005. Phenocryst composition as a tool for correlating fresh and altered tephra, Bed I, Olduvai Gorge, Tanzania. Stratigraphy 2, 101-115.

McHenry, L.J., 2012. A revised stratigraphic framework for Olduvai Gorge Bed I based on tuff geochemistry. Journal of Human Evolution 63, 284-299. 
McHenry, L.J., Luque, L., Gómez, J.A., Diez-Martín, F., 2011. Promise and pitfalls for characterizing and correlating the zeolitically altered tephra of the Pleistocene Peninj Group, Tanzania. Quaternary Research 75, 708-720.

McHenry, L. J., Stollhofen, H., Stanistreet, I. G., 2013. Use of single-grain geochemistry of cryptic tuffs and volcaniclastic sandstones improves the tephrostratigraphic framework of Olduvai Gorge, Tanzania. Quaternary Research 80, 235-249.

McHenry, L.H., Njau, J.K., de la Torre, I., Pante, M.C., 2016. Geochemical "fingerprints" for Olduvai Gorge Bed II tuffs and implications for the OldowanAcheulean transition. Quaternary Research 85, 147-158.

Minitab, Inc., 2017. Minitab 17 Statistical Software. State College, PA. http://www.minitab.com

Moebis, A., Cronin, S.J., Neall, V.E., Smith, I.E., 2011. Unravelling a complex volcanic history from fine-grained, intricate Holocene ash sequences at the Tongariro Volcanic Centre, New Zealand. Quaternary International 246, 352-363.

Monteath, A.J., van Hardenbroek, M., Davies, L.J., Froese, D.G., Langdon, P.G., Xu, X., Edwards, M.E., 2017. Chronology and glass chemistry of tephra and cryptotephra horizons from lake sediments in northern Alaska, USA. Quaternary Research (in press) doi:10.1017/qua.2017.38 
Morgan, G.B., London, D., 1996. Optimising the electron microprobe analysis of hydrous alkali aluminosilicate glasses. American Mineralogist 81, 1176-1185.

Morgan, G.B., London, D., 2005. Effect of current density on the electron microprobe analysis of alkali aluminosilicate glasses. American Mineralogist 90, 1131-1138.

Nadoll, P., Koenig, A.E., 2011. LA-ICP-MS of magnetite: methods and reference materials. Journal of Analytical Atomic Spectrometry 26, 1872-1877.

Nairn, I.A., Shane, P.A.R., Cole, J.W., Leonard, G.J., Self, S., Pearson, N., 2004. Rhyolite magma processes of the c. AD 1315 Kaharoa eruptive episode, Tarawera volcano, New Zealand. Journal of Volcanology and Geothermal Research 131, 265294.

Nakamura. Y., Katayama, Y., Hirakawa, K., 2002. Hydration and refractive indices of Holocene tephra glass in Hokkaido, northern Japan. Journal of Volcanology and Geothermal Research 114, 499-510.

Nash, W. P., 1992. Analysis of oxygen with the electron microprobe: application to hydrous glass and minerals. American Mineralogist 77, 453-457.

Neave, D.A., Maclennan, J., Thordarson, T., Hartley, M.E., 2015. The evolution and storage of primitive melts in the Eastern Volcanic Zone of Iceland: the $10 \mathrm{ka}$ Grímsvötn tephra series (i.e. the Saksunarvatn ash). Contributions to Mineralogy and Petrology 170: 21, doi 10.1007/s00410-015-1170-3 (pp. 1-23). 
Negre, E., Motto-Ros, V., Pelascini, F., Lauper, S., Denis, D., Yu, J., 2015. On the performance of laser-induced breakdown spectroscopy for quantitative analysis of minor and trace elements in glass. Journal of Analytical Atomic Spectrometry 30, 417-425.

Nelson, C.S., Froggatt, P.C., Gosson, G.J., 1985. Nature, chemistry, and origin of late Cenozoic megascopic tephras in Leg 90 cores from the southwest Pacific. In: Kennett, J.P., von der Borch, C.C., et al. (Eds.), Initial Reports of the Deep Sea Drilling Project 90, 1160-1173.

Newnham, R.M., Lowe, D.J., Green, J.D., Turner, G.M., Harper, M.A., McGlone, M.S., Stout, S.L., Horie, S., Froggatt, P.C., 2004. A discontinuous ca. 80 ka record of Late Quaternary environmental change from Lake Omapere, Northland, New Zealand. Palaeogeography, Palaeoclimatology, Palaeoecology 207, 165-198.

Newton, A.J., Dugmore, A.J., Gittings, B.M., 2007. Tephrabase: tephrochronology and the development of a centralized European database. Journal of Quaternary Science $22,737-743$.

Ng, R.T., Han J., 2002. CLARANS: a method for clustering objects for spatial data mining. IEEE Transactions on Knowledge and Data Engineering 14, 1003-1016.

Óladóttir, B.A., Sigmarsson, O., Larsen, G., Devidal, J.-L., 2011. Provenance of basaltic tephra from Vatnajökull subglacial volcanoes, Iceland, as determined by major- and trace-element analyses. The Holocene 21, 1037-1048. 
Óladóttir, B.A., Larsen, G., Sigmarsson, O., 2012. Deciphering eruption history and magmatic processes from tephra in Iceland. Jökull 62, 21-38.

Park, M.-H., Kim, J.-H., Kil, Y.-W., 2007. Identification of the late Quaternary tephra layers in the Ulleung Basin of the East Sea using geochemical and statistical methods. Marine Geology 244, 196-208.

Pearce, N.J.G., 2014. Towards a protocol for the trace element analysis of glass from rhyolitic shards in tephra deposits by laser ablation ICP-MS. Journal of Quaternary Science, 29, 627-640.

Pearce N.J.G., Westgate J.A., Perkins W.T., 1996. Developments in the analysis of volcanic glass shards by laser ablation ICP-MS: quantitative and single internal standard-multi-element methods. Quaternary International 34-36, 213-227.

Pearce, N.J.G., Westgate, J.A., Perkins, W.T., Eastwood, W.J., Shane, P., 1999. The application of laser ablation ICP-MS to the analysis of volcanic glass shards from tephra deposits: bulk glass and single shard analysis. Global and Planetary Change $21,151-171$.

Pearce, N.J.G., Eastwood, W.J., Westgate, J.A., Perkins, W.T., 2002. Trace-element composition of single glass shards in distal Minoan tephra from SW Turkey. Journal of the Geological Society 159, 545-556. 
Pearce, N.J.G., Westgate, J.A., Perkins, W.T., Preece, S.J., 2004a. The application of IC-PMS methods to tephrochronological problems. Applied Geochemistry 19, 289322.

Pearce, N.J.G., Westgate, J.A., Eastwood, W.J., Preece, S.J., Perkins, W.T., 2004b. Identification of Aniakchak (Alaska) tephra in Greenland ice core challenges the 1645BC date for the Minoan eruption of Santorini. Geochemistry Geophysics Geosystems 5, Q03005, doi: 10.1029/2003GC000672 (pp. 1-10).

Pearce, N.J.G., Denton, J.S., Perkins, W.T., Westgate, J.A., Alloway, B.V., 2007. Correlation and characterisation of individual glass shards from tephra deposits using trace element laser ablation ICP-MS analyses: current status and future potential. Journal of Quaternary Science 22, 721-736.

Pearce, N.J.G., Bendall, C.A., Westgate, J.A., 2008a. Comment on "Some numerical considerations in the geochemical analysis of distal microtephra" by A.M. Pollard, S.P.E. Blockley, C.S. Lane [2006]. Applied Geochemistry 23, 1353-1364.

Pearce, N.J.G., Alloway, B.V., Westgate, J.A., 2008b. Mid-Pleistocene silicic tephra beds in the Auckland region, New Zealand: their correlation and origins based on the trace element analyses of single glass shards. Quaternary International 178, 16-43.

Pearce, N.J.G., Westgate, J.A., Perkins, W.T., Wade, S.C., 2011. Trace-element microanalysis by LA-ICP-MS: the quest for comprehensive chemical 
characterisation of single, sub-10 $\mu \mathrm{m}$ volcanic glass shards. Quaternary International $246,57-81$.

Pearce N.J.G., Westgate J.A., Gatti, E., Pattan J.N., Parthiban G., Achyuthan H., 2014a. Individual glass shard trace element analyses confirm that all known Toba tephra reported from India is from the c. 75-ka Youngest Toba eruption. Journal of Quaternary Science 29, 729-734.

Pearce, N.J.G., Abbott, P.M., Martin-Jones, C.M., 2014b. Microbeam methods for the analysis of glass in fine grained tephra deposits: A SMART perspective on current and future trends. Geological Society (London) Special Publication 398, 29-46.

Perkins, M.E., 2005. Correlation of tephra: insights from the late Cenozoic tephra record for the western USA. Geological Society of America Salt Lake City Annual Meeting - Abstracts with Programs 37 (7), 37.

Perkins, M.E., Nash, B.P., 2002. Explosive silicic volcanism of the Yellowstone hotspot: the ash fall tuff record. Geological Society of America Bulletin 114, 367381.

Perkins, M.E., Nash, W.P., Brown, F.H., Fleck, R.J., 1995. Fallout tuffs of Trapper Creek, Idaho - a record of Miocene explosive volcanism in the Snake River Plain volcanic province. Geological Society of America Bulletin 107, 1484-1506.

Perkins, M.E., Brown, F.H., Nash, W.P., McIntosh, W., Williams, S.K., 1998. Sequence, age, and source of silicic fallout tuffs in middle to late Miocene basins of 
the northern Basin and Range province. Geological Society of America Bulletin 110, 344-360.

Peti, L., Augustinus, P., 2017. Micro-XRF scanning: an alternative to costly geochemical fingerprinting of tephra? Abstracts, XRF Core Scanning 2017, National Taiwan University, Taipei, Taiwan, 20-24 March, p. 54 (doi: 10.13140/RG.2.2.21219.14880).

Petrelli, M., Perugini, D., 2016. Solving petrological problems through machine learning: the study case of tectonic discrimination using geochemical and isotopic data. Contributions to Mineralogy and Petrology 171: 81, doi: 10.1007/s00410-626 016-1292-2 (pp. 1-15).

Petrelli, M., Bizzarri, R., Morgavi, D., Baldanza, A., Perugini, D., 2017. Combining machine learning techniques, microanalyses and large geochemical datasets for tephrochronological studies in complex volcanic areas: new age constraints for the Pleistocene magmatism of central Italy. Quaternary Geochronology 40, 33-44.

Placzek, C., Quade, J., Rech, J.A., Patchett, P.J., Pérez de Arce, C., 2009.

Geochemistry, chronology and stratigraphy of Neogene tuffs of the central Andean region. Quaternary Geochronology 4, 22-36.

Platz, T., Cronin, S.J., Smith, I.E.M., Turner, M.B., Stewart, R.B., 2007. Improving the reliability of microprobe-based analyses of andesitic glasses for tephra correlation. The Holocene 17, 573-583. 
Pollard, A.M., Blockley, S.P.E., Lane, C.S., 2006. Some numerical considerations in the geochemical analysis of distal microtephra. Applied Geochemistry 21, 1692-1714.

Ponomareva, V., Portnyagin, M., Derkachev, A., Pendea, L.F., Bourgeois, J., Reimer, P.J., Garbe-Schonberg, D., Krasheninnikov, S., Nurnberg, D., 2013. Early Holocene M 6 explosive eruption from Plosky volcanic massif (Kamchatka) and its tephra as a link between terrestrial and marine paleoenvironmental records. International Journal of Earth Sciences 102, 1673-1699.

Ponomareva, V., Portnyagin, M., Davies, S., 2015a. Tephra without borders: Farreaching clues into past explosive eruptions. Frontiers in Earth Sciences 3 (article 83), doi: org/10.3389/feart.2015.00083 (pp. 1-16).

Ponomareva, V., Portnyagin, M., Pevzner, M., Blaauw, M., Kyle, P., Derkachev, A., 2015b. Tephra from andesitic Shiveluch volcano, Kamchatka, NW Pacific: chronology of explosive 939 eruptions and geochemical fingerprinting of volcanic glass. International Journal of Earth Sciences 104, 1459-1482.

Ponomareva, V., Portnyagin, M., Pendea, F., Zelenin, E., Bourgeois, J., Pinegina, T., Kozhurin, A., 2017. A full Holocene tephrochronology for the Kamchatsky Peninsula region: applications from Kamchatka to North America. Quaternary Science Reviews 168, 101-122. 
Potts, P.J., Thompson, M., Wilson, S., 2002. G-Probe-1 - an international proficiency test for microprobe laboratories - report on round 1: February 2002 (TB-1 basaltic glass). Journal of Geostandards and Geoanalysis 26, 197-235.

Pouget, S., Bursik, M., Cortés, J. A., Hayward, C., 2014a. Use of principal component analysis for identification of Rockland and Trego Hot Springs tephras in the Hat Creek Graben, northeastern California, USA. Quaternary Research 81, 125-137.

Pouget, S., Bursik, M., Rogova, G. 2014b. Tephra redeposition and mixing in a Lateglacial hillside basin determined by fusion of clustering analyses of glass-shard geochemistry. Journal of Quaternary Science 29, 789-802.

Preece, S.J., Westgate, J.A., Stemper, B.A., Péwé, T.L., 1999. Tephrochronology of late Cenozoic loess at Fairbanks, central Alaska. Geological Society of America Bulletin $111,71-90$.

Preece, S.J., Westgate, J.A., Alloway, B.V., Milner, M.W., 2000. Characterization, identity, distribution, and source of late Cenozoic tephra beds in the Klondike district of the Yukon, Canada. Canadian Journal of Earth Sciences 37, 983-996.

Preece, S.J., Westgate, J.A., Froese, D.G., Pearce, N.J.G., Perkins, W.T., 2011a. A catalogue of late Cenozoic tephra beds in the Klondike goldfields, Yukon. Canadian Journal of Earth Sciences 48, 1386-1418. 
Preece, S.J., Pearce, N.J.G., Westgate, J.A., Froese, D.G., Jensen, B.J.L., Perkins, W.T., 2011b. Old Crow tephra across eastern Beringia: a single cataclysmic eruption at the close of Marine Isotope Stage 6. Quaternary Science Reviews 30, 2069-2090.

Preece, S.J., McGimsey, R.G., Westgate, J.A., Pearce, N.J.G., Hart, W.K., Perkins, W.T., 2014. Chemical complexity and source of the White River Ash, Alaska and Yukon. Geosphere 10, 1020-1042.

Prentice, I.C., 1980. Multidimensional scaling as a research tool in Quaternary palynology: a review of theory and methods. Review of Palaeobotany and Palynology 31, 71-104.

Pyne-O’Donnell, S.D.F., 2011. The taphonomy of Last Glacial-Interglacial Transition (LGIT) distal volcanic ash in small Scottish lakes. Boreas, 40: 131-145.

Pyne-O’Donnell, S.D.F., Blockley, S.P.E., Turney, C.S.M., Lowe, J.J., 2008. Distal volcanic ash layers in the Lateglacial Interstadial (GI-1): problems of stratigraphic discrimination. Quaternary Science Reviews 27, 72-84.

Pyne-O’Donnell, S.D.F., Hughes, P.D.M., Froese, D.G., Jensen, B.J.L., Kuehn, S.C., Mallon, G., Amesbury, M.J., Charman, D.J., Daley, T.J., Loader, N.J., Mauquoy, D., Street-Perrott, F.A., Woodman-Ralph, J., 2012. High-precision ultra-distal Holocene tephrochronology in North America. Quaternary Science Reviews 52, 611. 
Pyne-O’Donnell, S.D.F., Cwynar, L.C., Jensen, B.J.L., Vincent, J.H., Kuehn, S.C., Spear, R., Froese, D.G., 2016. West Coast volcanic ashes provide a new continentalscale Lateglacial isochron. Quaternary Science Reviews 142, 16-25.

R Core Team, 2017. R: A language and environment for statistical computing. $\mathrm{R}$ Foundation for Statistical Computing, Vienna, Austria. http://www.R-project.org/ Reed, S.J.B., 2010. Electron Microprobe Analysis and Scanning Electron Microscopy in Geology, $2^{\text {nd }}$ edition. Cambridge University Press, Cambridge, 206 pp.

Regier, M.E., Hervig, R.L., Myers, M.L., Roggensack, K., Wilson, C.J.N., 2016. Analyzing nitrogen in natural and synthetic silicate glasses by secondary ion mass spectrometry. Chemical Geology 447, 27-39.

Rieck, H.J., Sarna-Wojcicki, A.M., Meyer, C.E., Adam, D.P., 1992. Magnetostratigraphy and tephrochronology of an upper Pliocene to Holocene record in lake sediments at Tulelake, northern California. Geological Society of America Bulletin 104, 409-428.

Riede, F., Thastrup, M.D., 2013. Tephra, tephrochronology and archaeology - a (re)view from northern Europe. Heritage Science 1 (15), http://www.heritagesciencejournal.com/content/1/1/15 (pp. 1-17).

Riede, F., Bazely, O., Newton, A.J., Lane, C.S., 2011. A Laacher See-eruption supplement to Tephrabase: investigating distal tephra fallout dynamics. Quaternary International 246, 134-144. 
Ripley, B.D. 2007. Pattern Recognition and Neural Networks. Cambridge University Press, New York, 403 pp.

Robinson, F.A., 2016. Variation in rhyolitic magma composition linked with fractionation from a common source: insights from the Rotoiti eruption, Taupo Volcanic Zone, New Zealand. International Geology Review 58, 1967-1982.

Rodriguez-Celis, E.M., Gornushkin, I.B., Almirall, J.R., Omenetto, N., Smith, B.W., Winefordner, J.D., 2008. Laser induced breakdown spectroscopy as a tool for discrimination of glass for forensic applications. Analytical and Bioanalytical Chemistry 391, 1961-1968.

Rogova, G., Bursik, M., Hanson-Hedgecock, S., 2008. Intelligent system for determining the pattern of volcanic eruptions. Journal of Advances in Information Fusion 3, 118-128.

Roland, T.P., Mackay, H., Hughes, P.D.E., 2015. Tephra analysis in ombrotrophic peatlands: a geochemical comparison of acid digestion and density separation techniques. Journal of Quaternary Science 30, 3-8.

Roulleau, E., Pinti, D.L., Rouchon, V., Quidelleur, X., Gillot, P.-Y., 2009. Tephrochronostratigraphy of the lacustrine interglacial record of Piánico, Italian southern Alps: identifying the volcanic sources using radiogenic isotopes and trace elements. Quaternary International 204, 31-43. 
Salisbury, M.J., Patton, J.R., Kent, A.J.R., Goldfinger, C., Djadjadihardja, Y., Hanifa, U., 2012. Deep-sea ash layers reveal evidence for large, late Pleistocene and Holocene explosive activity from Sumatra, Indonesia. Journal of Volcanology and Geothermal Research 231-232, 61-71.

Saminger, S., Peltz, C., Bichler, M., 2000. South Aegean volcanic glass: separation and analysis by INAA and EPMA. Journal of Analytical and Nuclear Chemistry 245, $375-383$.

Sarna-Wojcicki, A., 1976. Correlation of late Cenozoic tuffs in the central Coast Ranges of California by means of trace- and minor-element chemistry. Geological Survey Professional Paper 972, 1-30.

Sarna-Wojcicki, A.M., 2000. Tephrochronology. In: Noller, J.S., Sowers, J.M., Lettis, W.R. (Eds.), Quaternary geochronology: methods and applications. American Geophysical Union Washington, DC, AGU Reference Shelf 4, 357-377.

Sarna-Wojcicki, A., Davis, J.O., 1991. Quaternary tephrochronology. In: Morrison, R.B. (Ed.), Quaternary Nonglacial Geology: Conterminous US. The Geology of North America K-2, 93-116.

Sarna-Wojcicki, A.M., Bowman, H.W., Russell, P.C., 1979. Chemical correlation of some late Cenozoic tuffs of northern and central California by neutron activation analysis of glass and comparison with X-ray fluorescence analysis. Geological Survey Professional Paper 1147, 1-15. 
Sarna-Wojcicki, A.M., Meyer, C.E., Woodward, M.J., Lamothe, P.J., 1981.

Comparison of air-fall ash erupted on May 18, May 25, June 12, July 22, and August

7. Geological Survey Professional Paper 1250, 667-681.

Sarna-Wojcicki, A., Bowman, H.R., Meyer, C.E., Russell, P.C., Woodward, M.J.,

McCoy, G., Rowe, J.J., Jr., Baedecker, P.A., Asaro, F., Michael, H., 1984. Chemical analyses, correlations, and ages of Upper Pliocene and Pleistocene ash layers of eastcentral and southern California. Geological Survey Professional Paper 1293, 1-40.

Sarna-Wojcicki, A., Morrison, S.D., Meyer, C.E., Hillhouse, J.W., 1987. Correlation of upper Cenozoic tephra layers between sediments of the western United States and eastern Pacific Ocean and comparison with biostratigraphic and magnetostratigraphic age data. Geological Society of America Bulletin 98, 207-223.

Sarna-Wojcicki, A.M., Reheis, M.C., Pringle, M.S., Fleck, R.J., Burbank, D., Meyer, C.E., Slate, J.L., Wan, E., Budahn, Troxel, B., Walker, J.P., 2005. Tephra layers of Blind Spring Valley and related Upper Pliocene and Pleistocene tephra layers, California, Nevada, and Utah: isotopic ages, correlation, and magnetostratigraphy. Geological Survey Professional Paper 1701, 1-63.

Scaini, C., Biass, S., Galderisi, A., Bonadonna, C., Folch, A., Smith, K., Höskuldsson, A., 2014. A multi-scale risk assessment for tephra fallout and airborne concentration from multiple Icelandic volcanoes - Part 2: vulnerability and impact. Natural Hazards and Earth System Sciences 14, 2289-2312. 
Scealy, J.L., Welsh, A.H., 2011. Regression for compositional data by using distributions defined on the hypersphere. Journal of the Royal Statistical Society, Series B73, 351-375.

Schmid, R., 1981. Descriptive nomenclature and classification of pyroclastic deposits and fragments: recommendations of the IUGS Subcommission on the Systematics of Igneous Rocks. Geology 9, 41-43.

Schmid, M.M.E., Dugmore, A.J., Vésteinsson, O., Newton, A.J., 2017. Tephra isochrons and chronologies of colonization. Quaternary Geochronology 40, 56-66.

Schoene, B., Latkoczy, C., Schaltegger, C., Günther, D., 2010. A new method integrating high-precision $\mathrm{U}-\mathrm{Pb}$ geochronology with zircon trace element analysis (U-Pb TIMS-TEA). Geochimica et Cosmochimica Acta 74, 7144-7159.

Scudder, R.P., Murray, R.W., Schindlbeck, J.C., Kutterolf, S., Hauff, F., Underwood, M.B., Gwizd, S., Lauzon, R., McKinley, C.C. 2016. Geochemical approaches to the quantification of dispersed volcanic ash in marine sediment. Progress in Earth and Planetary Science 3: 1 (32 pp.)

Sell, B.K., Samson, S.D., 2011a. A tephrochronologic method based on apatite traceelement chemistry. Quaternary Research 76, 157-166.

Sell, B.K., Samson, S.D., 2011b. Apatite phenocryst compositions demonstrate a miscorrelation between the Millbrig and Kinnekulle K-bentonites of North America and Scandinavia. Geology 39, 303-306. 
Sell, B.K., Samson, S.D., Mitchell, C.E., McLaughlin, P.I., Koenig, A.E., Leslie, S.A., 2015. Stratigraphic correlations using trace elements in apatite from Late Ordovician (Sandbian-Katian) K-bentonites of eastern North America. Geological Society of America Bulletin 127, 1259-1274.

Shane, P.A.R., 1994. A widespread, early Pleistocene tephra (Potaka tephra, $1 \mathrm{Ma}$ ) in New Zealand: character, distribution, and implications. New Zealand Journal of Geology and Geophysics 37, 25-35.

Shane, P.A.R., 1998. Correlation of rhyolitic pyroclastic eruptive units from the Taupo volcanic zone by Fe-Ti oxide compositional data. Bulletin of Volcanology 60, 224238.

Shane, P.A.R., 2000. Tephrochronology: a New Zealand case study. Earth-science Reviews 49, 223-259.

Shane, P.A.R., Froggatt, P.C., 1994. Discriminant function analysis of glass chemistry of New Zealand and North American tephra deposits. Quaternary Research 41, 7081.

Shane, P.A.R., Wright, I.C., 2011. Late Quaternary tephra layers around Raoul and Macauley Islands, Kermadec Arc: implications for volcanic sources, explosive volcanism and tephrochronology. Journal of Quaternary Science 26, 422-432. 
Shane, P.A.R., Zawalna-Geer, A., 2011. Correlation of basaltic tephra from Mt

Wellington volcano: implications for the penultimate eruption from the Auckland Volcanic Field. Quaternary International 246, 374-381.

Shane, P.A.R., Smith, V.C., Nairn, I.A., 2003. Biotite composition as a tool for the identification of Quaternary tephra beds. Quaternary Research 59, 262-270.

Shane, P., Smith, V.C., Nairn, I.A., 2005a. High temperature rhyodacites of the $36 \mathrm{ka}$ Hauparu pyroclastic eruption, Okataina Volcanic Centre, New Zealand: change in a silicic magmatic system following caldera collapse. Journal of Volcanology and Geothermal Research 147, 357-376.

Shane, P.A.R., Nairn, I.A., Smith, V.C., 2005b. Magma mingling in the $~ 50$ ka Rotoiti eruption from Okataina Volcanic Centre: implications for geochemical diversity and chronology for large volume rhyolites. Journal of Volcanology and Geothermal Research 139, 295-313.

Shane, P.A.R., Sikes, E.L., Guilderson, T.P., 2006. Tephra beds in deep sea cores off northern New Zealand: implications for the history of Taupo Volcanic Zone, Mayor Island and White Island volcanoes. Journal of Volcanology and Geothermal Research 154, 276-290.

Shane, P.A.R., Martin, S.B., Smith, V.C., Beggs, K.F., Darragh, M.B., Cole, J.W., Nairn, I.A., 2007. Multiple rhyolite magmas and basaltic injection in the $17.7 \mathrm{ka}$ 
Rerewhakaaitu eruption episode from Tarawera volcanic complex, New Zealand. Journal of Volcanology and Geothermal Research 164, 1-26.

Shane, P.A.R., Nairn, I.A., Martin, S.B., Smith, V.C., 2008a. Compositional heterogeneity in tephra deposits resulting from the eruption of multiple magma bodies: implications for tephrochronology. Quaternary International 178, 44-53.

Shane, P.A.R., Smith, V.C., Nairn, I.A., 2008b. Millennial timescale resolution of rhyolite magma recharge at Tarawera volcano: insights from quartz chemistry and melt inclusions. Contributions to Mineralogy and Petrology 156, 397-411.

Shane, P.A.R., Nairn, I.A., Smith, V.C., Darragh, M., Beggs, K., Cole, J.W., 2008c.

Silicic recharge of multiple rhyolite magmas by basaltic intrusion during the $22.6 \mathrm{ka}$ Okareka eruption episode, New Zealand. Lithos 103, 527-549.

Sheppard, P.J., Irwin, G.J., Lin, S.C., McCaffrey, C.P., 2011. Characterization of New Zealand obsidian using PXRF. Journal of Archaeological Science 38, 45-56.

Sigman, M.E., 2010. Application of laser-induced breakdown spectroscopy to forensic science: analysis of paint and glass samples. U.S. Department of Justice, Final Technical Report, 2004-IJ-CX-K031. 43 pp.

Sirocko, F., Dietrich, S., Veres, D., Grootes, P.M., Schaber-Mohr, K., Seelos, K., Nadeau, M.-J., Kromer, B., Rothacker, L., Röhner, M., Krbetschek, M., Appleby, P., Hambach, U., Rolf, C., Sudo, M., Grim, S., 2013. Multi-proxy dating of Holocene 
maar lakes and Pleistocene dry maar sediments in the Eifel, Germany. Quaternary Science Reviews 62, 56-76.

Smith, R.T., Houghton, B.F., 1995. Vent migration and changing dynamics during the 1800a Taupo eruption: new evidence from the Hatepe and Rotongaio ashes. Bulletin of Volcanology 57, 432-439.

Smith, D.G.W., Westgate, J.A. 1968. Electron probe technique for characterizing pyroclastic deposits. Earth and Planetary Science Letters 5, 313-319.

Smith, V., Shane, P., Smith, I., 2002. Tephrostratigraphy and geochemical fingerprinting of the Mangaone Subgroup tephra beds, Okataina Volcanic Centre, New Zealand. New Zealand Journal of Geology and Geophysics 45, 207-219.

Smith, V.C., Shane, P.A.R., Nairn, I.A., 2004. Rotorua eruptive episode: implications for magma storage in the Okataina Volcanic Centre, New Zealand. Journal of the Geological Society 161, 757-772.

Smith, V.C., Shane, P.A.R., Nairn, I.A., 2005. Trends in rhyolite geochemistry, mineralogy, and magma storage during the last $50 \mathrm{kyr}$ at Okataina and Taupo volcanic centres, Taupo Volcanic Zone, New Zealand. Journal of Volcanology and Geothermal Research 148, 372-406.

Smith, V.C., Shane, P.A.R., Nairn, I.A., Williams, C.M., 2006. Geochemistry and magmatic properties of eruption episodes from Haroharo linear vent zone, Okataina 
Volcanic Centre, New Zealand during the last 10 kyr. Bulletin of Volcanology 69, $57-88$.

Smith, V.C., Pearce, N.J.G., Matthews, N. E., Westgate, J.A., Durant, A.J., Lane, C., Petraglia, M.D., Haslam, M., Korisettar, R., Pal, J.N., 2011. Chemically fingerprinting volcanic ash from Toba using biotite compositions. Quaternary International 246, 97-104.

Smith, V.C., Staff, R.A., Blockley, S.P.E., Bronk Ramsey, C., Nakagawa, T., Mark, D.F., Danhara, T., Suigetsu 2006 Project Members, 2013. Identification and correlation of visible tephras in the Lake Suigetsu SG06 sedimentary archive, Japan: chronostratigraphic markers for synchronising of east Asian/west Pacific palaeoclimatic records across the last 150 ka. Quaternary Science Reviews 67, 121137.

Snow, C.A., 2006. A reevaluation of tectonic discrimination diagrams and a new probabilistic approach using large geochemical databases: moving beyond binary and ternary plots. Journal of Geophysical Research 111, B06206, doi: 10.1029/2005JB003799.

Staff, R.A., Nakagawa, T., Schlolaut, G., Marshall, M.H., Brauer, A., Lamb, H.F., Bronk Ramsey, C., Bryant, C.L., Brock, F., Kitagawa, H., van der Plicht, J., Payne, R.L., Smith, V.C., Mark, D.F., MacLeod, A., Blockley, S.P.E., Schwenninger, J.-L., Tarasov, P.E., Haraguchi, T., Gotanda K., Yonenobu, H., Yokoyama, Y., Suigetsu 
2006 Project Members, 2013.The multiple chronological techniques applied to the Lake Suigetsu SG06 sediment core, central Japan. Boreas 42, 259-266.

Stern, C.R., 2008. Holocene tephrochronology record of large explosive eruptions in the southernmost Patagonian Andes. Bulletin of Volcanology 70, 435-454.

Stevenson, J.A., Loughlin, S., Rae, C., Thordarson, T., Milodowski, A. E., Gilbert, J.S., Harangi, S., Lukács, R., Højgaard, B., Árting, U., Pyne-O’Donnell, S., MacLeod, A., Whitney, B., Cassidy, M., 2012. Distal deposition of tephra from the Eyjafjallajökull 2010 summit eruption. Journal of Geophysical Research 117, B00C10, doi: 10.1029/2011JB008904 (pp. 1-10).

Stevenson, J.A., Millington, S.C., Beckett, F.M., Swindles, G.T., Thordarson, T., 2015. Big grains go far: understanding the discrepancy between tephrochronology and satellite infrared measurements of volcanic ash. Atmospheric Measurement Techniques 8, 2069-2091.

Stokes, S., Lowe, D.J., 1988. Discriminant function analysis of late Quaternary tephras from five volcanoes in New Zealand using glass shard major element chemistry. Quaternary Research 30, 270-283.

Stokes, S., Lowe, D.J., Froggatt, P.C., 1992. Discriminant function analysis and correlation of late Quaternary rhyolitic tephra deposits from Taupo and Okataina volcanoes, New Zealand, using glass shard major element composition. Quaternary International 13-14, 103-117. 
Streeter, R., Dugmore, A.J., Vésteinsson, O., 2012. Plague and landscape resilience in premodern Iceland. Proceedings of the National Academy of Sciences of the USA 109, 3664-3669.

Strong, D.T., Turnbull, R.E., Haubrock, S., Mortimer, N. 2016. Petlab: New Zealand's national rock catalogue and geoanalytical database. New Zealand Journal of Geology and Geophysics 59, 475-481.

Struyf, A., Hubert, M., Rousseeuw, P.J., 1997. Integrating robust clustering techniques in S-PLUS. Computational Statistics and Data Analysis 26, 17-37.

Suzuki, S., 1996. Chemical analysis of volcanic glass by energy dispersive X-ray spectrometry with Jeol JED-2001 and JSM-5200: analytical procedures and application. Geographical Reports of Tokyo Metropolitan University 31, 27-36.

Swindles, G. T., Galloway, J., Outram, Z., Turner, K., Schofield, J. E., Newton, A. J., Dugmore, A. J., Church, M. J., Watson, E. J., Batt, C., Bond, J., Edwards, K. J.,Turner, V., Bashford, D., 2013. Re-deposited cryptotephra layers in Holocene peats linked to anthropogenic activity. The Holocene 23, 1493-1501.

Sylvester, P.J., 2008. LA-(MC)-ICP-MS trends in 2006 and 2007 with particular emphasis on measurement uncertainties. Geostandards and Geoanalytical Research $32,469-488$. 
Takashima, R., Kuwabara, S., Sato, T., Takemura, K., Nishi, H., 2017. Utility of trace elements in apatite for discrimination and correlation of Quaternary ignimbrites and co-ignimbrite ashes, Japan. Quaternary Geochronology 41, 151-162.

Tamura, I., Yamazaki, H., Mizuno, K., 2008. Characteristics for the recognition of Pliocene and early Pleistocene marker tephras in central Japan. Quaternary International 178, 85-99.

Therneau, T.M., Atkinson, E.J., 1997. An introduction to recursive partitioning using the RPART routines. Technical Report Series No. 61, Department of Health Science Research, Mayo Clinic, Rochester, Minnesota.

Thorarinsson, S., 1981. Tephra studies and tephrochronology: a historical review with special reference to Iceland. In: Self, S., Sparks, R.S.J. (Eds.), Tephra Studies. Reidel, Dordrecht, pp. 1-12.

Thordarson, T., Self, S., 1993. The Laki (Skaftar Fires) and Grimsvötn eruptions in 1783-1785. Bulletin of Volcanology 55, 233-263.

Thorseth, I.H., Furnes, H., Tumyr, O., 1991. A textural and chemical study of Icelandic palagonite of varied composition and its bearing on the mechanism of the glasspalagonite transformation. Geochimica et Cosmochimica Acta 55, 731-749.

Timms, R.G.O., Matthews, I.P., Palmer, A.P., Candy, I., Abel, L., 2017. A highresolution tephrostratigraphy from Quoyloo Meadow, Orkney, Scotland: implications 
for the tephrostratigraphy of NW Europe during the Last Glacial-Interglacial Transition. Quaternary Geochronology 40, 67-81.

Tingley, M.P., Craigmile, P.F., Haran, M., Li, B., Mannshardt, E., Rajaratnam, B., 2012. Piecing together the past: statistical insights into paleoclimatic reconstructions. Quaternary Science Reviews 35, 1-22.

Tomlinson, E.L., Thordarson, T., Muller, W., Thirlwall, M., Menzies, M., 2010. Microanalysis of tephra by LA-ICP-MS - strategies, advantages and limitations assessed using the Thorsmork ignimbrite (Southern Iceland). Chemical Geology 279, 73-89.

Tomlinson, E.L., Arienzo, I., Civetta, L., Wulf, S., Smith, V.C., Hardiman, M., Lane, C.S., Carandente, A., Orsi, G., Rosi, M., Muller, W., Menzies, M.A., 2012. Geochemistry of the Phlegraean Fields (Italy) proximal sources for major Mediterranean tephras: implications for the dispersal of Plinian and co-ignimbritic components of explosive eruptions. Geochimica et Cosmochimica Acta 93, 102-128.

Tomlinson, E.L., Smith, V.C., Albert, P.G., Aydar, E., Civetta, L., Cioni, R., Cubukcu, E., Gertiser, R., Isaia, R., Menzies, M.A., Orsi, G., Rosi, M., Zanchetta, G. 2015. The major and trace element glass compositions of the productive Mediterranean volcanic sources: tools for correlating distal tephra layers in and around Europe. Quaternary Science Reviews 118, 48-66. 
Topchy, A., Jain, A.K., Punch, W., 2005. Clustering ensembles: models of consensus and weak partitions. IEEE Transactions on Pattern Analysis and Machine Intelligence 27, 1866-1881.

Tryon, C.A., Roach, N.T., Logan, M.A.L., 2008. The Middle Stone Age of the northern Kenyan Rift: age and context of new archaeological sites from the Kapedo Tuffs. Journal of Human Evolution 55, 652-664.

Tryon, C.A., Logan, M.A.V., Mouralis, D., Kuhn, S., Slimak, L., Balkan-Atlı, N., 2009. Building a tephrostratigraphic framework for the Paleolithic of central Anatolia, Turkey. Journal of Archaeological Science 36, 637-652.

Tryon, C.A., Faith, J.T., Peppe, D.J., Fox, D.L., Holt, K., Dunsworth, H., HarcourtSmith, W., 2010. The Pleistocene archaeology and environments of the Wasiriya Beds, Rusinga Island, Kenya. Journal of Human Evolution 59, 657-671.

Tryon, C.A., Kuhn, S., Slimak, L., Logan, M.A.V., Balkan-Atlı, N., 2011. Scale in tephrostratigraphic correlation: an example from Turkish Pleistocene archaeological sites. Quaternary International 246, 124-133.

Turner, M.B., Cronin, S.J., Stewart, R.B., Bebbington, M., Smith, I.E.M., 2008. Using titanomagnetite textures to elucidate volcanic eruption histories. Geology 36, 31-34.

Turner, M.B., Bebbington, M.S., Cronin, S.J., Stewart, R.B., 2009. Merging eruption datasets: building an integrated Holocene eruptive record for Mt Taranaki, New Zealand. Bulletin of Volcanology 71, 903-918. 
Turner, M.B., Cronin, S.J., Bebbington, M.S., Smith, I.E.M., Stewart, R.B., 2011a. Relating magma composition with eruption variability at andesitic volcanoes: a case study from Mt. Taranaki, New Zealand. Geological Society of America Bulletin 123, 2005-2015.

Turner, M.B., Cronin, S.J., Bebbington, M.S., Smith, I.E., Stewart, R.B., 2011 b. Integrating records of explosive and effusive activity from proximal and distal sequences: Mt. Taranaki, New Zealand. Quaternary International 246, 364-373.

Turner, D.G., Ward, B.C., Bond, J.D., Jensen, B.J.L., Froese, D.G., Telka, A.M., Zazula, G.D., Bigelow, N.H., 2013. Middle to Late Pleistocene ice extents, tephrochronology and paleoenvironments of the White River area, southwest Yukon. Quaternary Science Reviews 75, 59-77.

Turney, C.S.M., 1998. Extraction of rhyolitic component of Vedde microtephra from minerogenic lake sediments. Journal of Paleolimnology 19, 199-206.

Turney, C.S.M., Lowe, J.J., Davies, S.M., Hall, V.A., Lowe, D.J., Wastegård, S., Hoek, W.Z., Alloway, B.V., 2004. Tephrochronology of Last Termination sequences in Europe: a protocol for improved analytical precision and robust correlation procedures (a joint SCOTAV-INTIMATE proposal). Journal of Quaternary Science 19, 111-120.

Turney, C.S.M., Blockley, S.P.E., Lowe, J.J., Wulf, S., Branch, N.P., Mastrolorenzo, G., Swindle, G., Nathan, R., Pollard, A.M., 2008. Geochemical characterization of 
Quaternary tephras from the Campanian Province, Italy. Quaternary International $178,288-305$.

Ukstins Peate, I., Baker, J.A., Kent, A.J.R., Al-Kadasi, M., Al-Subbary, A., Ayalew, D., Menzies, M.A., 2003. Correlation of Indian Ocean tephra to individual Oligocene silicic eruptions from Afro-Arabian flood volcanism. Earth and Planetary Science Letters 211, 311-327.

Ukstins Peate, I., Kent, A.J.R., Baker, J.A., Menzies, M.A., 2008. Extreme geochemical heterogeneity in Afro-Arabian Oligocene tephras: preserving fractional crystallization and mafic recharge processes in silicic magma chambers. Lithos 102, 260-278.

Ulrich, T., Kamber, B.S., 2013. Natural obsidian glass as an external accuracy reference material in laser ablation inductively coupled plasma-mass spectrometry.

Geostandards and Geoanalytical Research 37, 169-188.

van der Bilt, W.G.M., Lane, C.S., Bakke, J., 2017. Ultra-distal Kamchatkan ash on Arctic Svalbard: towards hemispheric cryptotephra correlation. Quaternary Science Reviews 164, 230-235.

Vander Heyden, Y., Smeyers-Verbeke, J., 2007. Set-up and evaluation of interlaboratory studies. Journal of Chromatography A, 1158, 158-167.

Venables, W.N., Ripley, B.D., 2002. Modern Applied Statistics with S, $4^{\text {th }}$ edition. Springer, New York, 495 pp. 
Vogel, H., Zanchetta, G., Sulpizio, R., Wagner, B., Nowaczyk, N., 2009. A tephrostratigraphic record of the last glacial-interglacial cycle from Lake Ohrid, Albania and Macedonia. Journal of Quaternary Science 25, 320-338.

Walford, N., 2011. Practical Statistics for Geographers and Earth Scientists. WileyBlackwell, Chichester, 440 pp.

Walker, G.P.L., Self, S., Wilson, L., 1984.Tarawera 1886, New Zealand - a basaltic plinian fissure eruption. Journal of Volcanology and Geothermal Research 21, 61-78.

Wang, W., Hwang, J.T.G., Dasgupta, A., 1999. Statistical tests for multivariate bioequivalence. Biometrika 86, 395-402.

Wastegård, S., Davies, S.M., 2009. An overview of distal tephrochronology in northern Europe during the last 1000 years. Journal of Quaternary Science 24, 500-512.

Watson, E.J., Swindles, G.T., Stevenson, J.A., Savov, I., Lawson, I.T., 2016. The transport of Icelandic volcanic ash: insights from northern European cryptotephra records. Journal of Geophysical Research: Solid Earth 121, 7177-7192.

Watson, E.J., Swindles, G.T., Savov, I., Lawson, I.T., Connor, C., Wilson, J., 2017a. Estimating the frequency of volcanic ash clouds over northern Europe. Earth and Planetary Science Letters 460, 41-49.

Watson, E.J., Swindles, G.T., Lawson, I.T., Savov, I.P., Wastegård, S., 2017b. The presence of Holocene cryptotephra in Wales and southern England. Journal of Quaternary Science 32, 493-500. 
Watt, S.F.L., Pyle, D.M., Naranjo, J.A., Rosqvist, G., Mella, M., Mather, T.A., Moreno, H., 2011. Holocene tephrochronology of the Hualaihue region (Andean southern volcanic zone, $\sim 42^{\circ} \mathrm{S}$ ), southern Chile. Quaternary International 246, 324-343.

Westgate, J.A., Gorton, M.P., 1981. Correlational techniques in tephra studies. In: Self, S., Sparks, R.S.J. (Eds.), Tephra studies. Reidel, Dordrecht, pp. 73-94.

Westgate, J.A., Pearce, N.J.G., 2017. Age of some Pleistocene interglacial beds and associated fossils in eastern Beringia defined by fission tracks in glass shards of Chester Bluff tephra. Quaternary Research (in press)

Westgate, J.A., Walter, R.C., Pearce, G.W., Gorton, M.P., 1985. Distribution, stratigraphy, petrochemistry, and palaeomagnetism of the late Pleistocene Old Crow tephra in Alaska and the Yukon. Canadian Journal of Earth Sciences 22, 893-906.

Westgate, J.A., Preece, S.J., Froese, D.G., Pearce, N.J.G., Roberts, R.G., Demuro, M., Hart, W.K., Perkins, W., 2008. Changing ideas on the identity and stratigraphic significance of the Sheep Creek tephra beds in Alaska and the Yukon Territory, northwestern North America. Quaternary International 178, 183-209.

Westgate, J.A., Pearce, N.J.G., Perkins, W.T., Shane, P.A.R., Preece, S.J., 2011. Lead isotope ratios of volcanic glass by laser ablation inductively-coupled plasma mass spectrometry: application to Miocene tephra beds in Montana, USA and adjacent areas. Quaternary International 246, 89-96. 
Westgate, J. A., Naeser, N. D., Alloway, B. V., 2013a. Fission-track dating. In: Elias, S. A., Mock, C. J. (Eds.), Encyclopaedia of Quaternary Science, 2nd ed., Vol. 1. Elsevier, Amsterdam, pp. 643-662.

Westgate, J.A., Pearce, G.W., Preece, S.J., Schweger, C.E., Morlan, R.E., Pearce, N.J.G., Perkins, W.T., 2013b. Tephrochronology, magnetostratigraphy and mammalian faunas of Middle and Early Pleistocene sediments at two sites on the Old Crow River, northern Yukon Territory, Canada. Quaternary Research 79, 75-85.

Westgate, J.A., Pearce, N.J.G., Perkins, W.T., Preece, S.J., Chesner, C.A., Muhammad, R.F., 2013c. Tephrochronology of the Toba tuffs: four primary glass populations define the $75 \mathrm{ka}$ Youngest Toba Tuff, northern Sumatra, Indonesia. Journal of Quaternary Science 28, 772-776.

Westgate, J.A., Pearce, N.J.G., Gatti, E., Achyuthan, H., 2014. Distinction between the Youngest Toba Tuff and Oldest Toba Tuff from northern Sumatra based on the area density of spontaneous fission tracks in their glass shards. Quaternary Research 82, $388-393$.

White, J.D.L., Houghton, B.F., 2006. Primary volcaniclastic rocks. Geology 34, 677 680.

Wilcox, R.E., 1983. Refractive index determination using the central focus masking technique with dispersion colours. American Mineralogist 68, 1226-1236. 
Wilcox, R.E., Naeser, C.W., 1992. The Pearlette family ash beds in the Great Plains: finding their identities and their roots in the Yellowstone country. Quaternary International 13-14, 9-13.

Winter, J.D., 2009. Principles of Igneous and Metamorphic Petrology, $2^{\text {nd }}$ edition. Prentice-Hall, New York, 702 pp.

Wolf, R.E., Wilson, S.A., 2007. USGS Reference Materials Program: U.S. Geological Survey Fact Sheet 2007-3056, 4 pp.

Xia, D., Chun, X., Bloemendal, J., Chiverrell, R.C., 2007. Use of magnetic signatures to correlate tephra layers in Holocene loessial soil profiles from a small region, SE Iceland. Environmental Geology 51, 1425-1437.

Yin, J., Jull, A. J. T., Burr, G. S., Zheng, Y., 2012. A wiggle-match age for the Millennium eruption of Tianchi Volcano at Changbaishan, northeastern China. Quaternary Science Reviews 47, 150-159.

Zawalna-Geer, A., Lindsay, J.M., Davies, S., Augustinus, P., Davies, S., 2016. Extracting a primary Holocene cryptotephra record from Pupuke maar sediments, Auckland, New Zealand. Journal of Quaternary Science 31, 442-457.

Zander, P., Kaufman, D., Kuehn, S., Wallace, K., Anderson, R., 2013. Early and late Holocene glacial fluctuations and tephrostratigraphy, Cabin Lake, Alaska. Journal of Quaternary Science 28, I761-771. 


\section{Appendix A. Supplementary data}

\begin{tabular}{|c|c|c|c|c|c|c|c|c|c|c|}
\hline Sample & $\mathrm{SiO}_{2}$ & $\mathrm{TiO}_{2}$ & $\mathrm{Al}_{2} \mathrm{O}_{3}$ & $\mathrm{FeO}_{\mathrm{T}}$ & Mno & MgO & $\mathrm{CaO}$ & $\mathrm{Na}_{2} \mathrm{O}$ & $\mathrm{K}_{2} \mathrm{O}$ & Total \\
\hline cat09-22 & 59.41 & 0.56 & 14.52 & 7.44 & 0.34 & 0.31 & 0.56 & 6.96 & 4.67 & 94.78 \\
\hline cat09-22 & 60.18 & 0.53 & 14.51 & 7.19 & 0.34 & 0.31 & 0.69 & 8.04 & 4.69 & 96.48 \\
\hline at09-22 & 59.33 & 0.57 & 14.75 & 7.39 & 0.32 & 0.31 & 0.57 & 7.66 & 4.80 & 95.71 \\
\hline at $09-22$ & 59.47 & 0.55 & 14.83 & 7.25 & 0.34 & 0.31 & 0.54 & 7.38 & 4.81 & 95.47 \\
\hline at09-22 & 58.79 & 0.51 & 14.53 & 7.12 & 0.40 & 0.29 & 0.61 & 7.02 & 4.73 & 94.00 \\
\hline t09-22 & 61.76 & 0.56 & 15.03 & 7.24 & 0.22 & 0.30 & 0.56 & 8.27 & 4.91 & 98.85 \\
\hline at $09-22$ & 59.60 & 0.54 & 14.74 & 7.36 & 0.27 & 0.26 & 0.64 & 7.95 & 4.73 & 96.11 \\
\hline at09-22 & 60.28 & 0.54 & 14.60 & 8.05 & 0.20 & 0.28 & 0.67 & 8.52 & 4.78 & 97.92 \\
\hline at09-22 & 60.59 & 0.56 & 15.08 & 7.28 & 0.30 & 0.25 & 0.69 & 8.52 & 4.73 & 97.99 \\
\hline at09-22 & 59.26 & 0.52 & 14.64 & 7.34 & 0.21 & 0.33 & 0.58 & 5.46 & 4.52 & 92.86 \\
\hline at09-22 & 61.92 & 0.54 & 15.27 & 7.59 & 0.29 & 0.31 & 0.60 & 8.14 & 4.93 & 99.58 \\
\hline at09-22 & 58.31 & 0.66 & 14.61 & 7.47 & 0.22 & 0.39 & 0.54 & 6.10 & 4.53 & 92.82 \\
\hline cat09-22 & 59.65 & 0.54 & 14.69 & 6.98 & 0.34 & 0.28 & 0.61 & 7.87 & 4.89 & 95.87 \\
\hline at09-22 & 60.56 & 0.51 & 14.83 & 7.18 & 0.18 & 0.29 & 0.55 & 7.52 & 4.53 & 96.15 \\
\hline t09-22 & 59.33 & 0.53 & 14.35 & 6.74 & 0.22 & 0.30 & 0.62 & 6.96 & 4.33 & 93.39 \\
\hline at09-22 & 61.03 & 0.54 & 15.30 & 7.60 & 0.26 & 0.33 & 0.66 & 8.51 & 4.79 & 99.01 \\
\hline to9-22 average & 59.97 & 0.55 & 14.77 & 7.33 & 0.28 & 0.30 & 0.61 & 7.56 & 4.71 & 96.06 \\
\hline at09-22 std. dev. & 1.01 & 0.04 & 0.28 & 0.29 & 0.07 & 0.03 & 0.05 & 0.88 & 0.16 & \\
\hline cat09-21 & 60.84 & 0.62 & 15.82 & 6.42 & 0.15 & 0.29 & 0.74 & 7.27 & 5.21 & 97.37 \\
\hline cat09-21 & 60.32 & 0.59 & 16.14 & 6.31 & 0.25 & 0.33 & 0.70 & 7.61 & 4.74 & 96.99 \\
\hline cat09-21 & 59.69 & 0.60 & 15.70 & 6.28 & 0.35 & 0.32 & 0.77 & 7.08 & 4.92 & 95.72 \\
\hline cat09-21 & 60.11 & 0.62 & 15.84 & 6.52 & 0.22 & 0.31 & 0.58 & 7.30 & 5.04 & 96.55 \\
\hline cat09-21 & 60.57 & 0.60 & 15.61 & 6.11 & 0.39 & 0.29 & 0.77 & 7.22 & 5.12 & 96.67 \\
\hline cat09-21 & 61.56 & 0.60 & 15.88 & 6.72 & 0.26 & 0.33 & 0.95 & 7.62 & 4.66 & 98.58 \\
\hline t09-21 & 60.09 & 0.58 & 15.70 & 6.62 & 0.18 & 0.32 & 0.99 & 6.68 & 4.70 & 95.86 \\
\hline to9-21 & 61.94 & 0.62 & 16.03 & 6.25 & 0.15 & 0.33 & 0.81 & 7.84 & 4.94 & 98.92 \\
\hline t09-21 & 60.11 & 0.58 & 15.59 & 6.21 & 0.27 & 0.34 & 0.87 & 6.98 & 5.30 & 96.26 \\
\hline $09-21$ & 60.18 & 0.60 & 15.78 & 6.02 & 0.26 & 0.34 & 0.79 & 6.97 & 4.51 & 95.46 \\
\hline-21 & 62.58 & 0.61 & 16.20 & 6.45 & 0.21 & 0.30 & 0.82 & 7.40 & 4.99 & 99.54 \\
\hline t09-21 & 60.62 & 0.58 & 16.01 & 6.48 & 0.18 & 0.30 & 0.81 & 7.16 & 4.30 & 96.44 \\
\hline
\end{tabular}


Sample

cat09-21

cat09-21

cat09-21 average

cat09-21 std. dev.

cat09-03

cat09-03

cat09-03

cat09-03

cat09-03

cat09-03

cat09-03

cat09-03

cat09-03

cat09-03

cat09-03

cat09-03

cat09-03

cat09-03

cat09-03 average

cat09-03 std. dev.

cat09-01

cat09-01

cat09-01

cat09-01

cat09-01

cat09-01

cat09-01

cat09-01

cat09-01

cat09-01

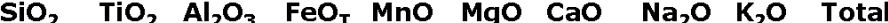

$\begin{array}{llllllllll}60.38 & 0.55 & 15.42 & 6.52 & 0.17 & 0.34 & 0.83 & 7.04 & 4.71 & 95.95\end{array}$

$\begin{array}{lllllllllll}60.35 & 0.62 & 15.90 & 6.42 & 0.22 & 0.32 & 0.88 & 7.50 & 4.66 & 96.88\end{array}$

$\begin{array}{llllllllll}60.67 & 0.60 & 15.83 & 6.38 & 0.23 & 0.32 & 0.81 & 7.26 & 4.84 & 96.94\end{array}$

$\begin{array}{lllllllll}0.81 & 0.02 & 0.22 & 0.20 & 0.07 & 0.02 & 0.10 & 0.31 & 0.28\end{array}$

$\begin{array}{rlllllllll}60.35 & 0.60 & 15.73 & 5.96 & 0.19 & 0.35 & 0.95 & 6.85 & 4.65 & 95.63 \\ 60.58 & 0.60 & 15.54 & 6.52 & 0.24 & 0.33 & 0.77 & 6.87 & 4.74 & 96.21 \\ 60.45 & 0.60 & 15.60 & 6.38 & 0.26 & 0.36 & 0.79 & 7.47 & 4.72 & 96.62 \\ 59.29 & 0.57 & 15.50 & 5.99 & 0.21 & 0.34 & 0.81 & 6.52 & 5.17 & 94.39 \\ 60.46 & 0.61 & 15.65 & 6.32 & 0.23 & 0.31 & 0.88 & 7.82 & 4.73 & 97.01 \\ 60.02 & 0.60 & 15.86 & 6.60 & 0.28 & 0.31 & 0.80 & 6.91 & 5.22 & 96.60 \\ 60.68 & 0.63 & 15.96 & 6.67 & 0.33 & 0.32 & 0.76 & 7.53 & 4.98 & 97.86 \\ 61.10 & 0.57 & 16.13 & 6.34 & 0.38 & 0.32 & 0.90 & 7.33 & 4.82 & 97.88 \\ 61.81 & 0.60 & 15.87 & 6.24 & 0.25 & 0.31 & 0.86 & 7.24 & 5.22 & 98.40 \\ 61.13 & 0.62 & 15.78 & 6.13 & 0.24 & 0.33 & 0.85 & 7.13 & 5.14 & 97.36 \\ 61.85 & 0.62 & 15.85 & 6.49 & 0.24 & 0.32 & 0.93 & 7.80 & 4.86 & 98.95 \\ 61.65 & 0.63 & 15.81 & 6.15 & 0.48 & 0.36 & 0.70 & 7.61 & 4.89 & 98.29 \\ 60.88 & 0.62 & 15.62 & 6.48 & 0.18 & 0.30 & 0.75 & 7.64 & 4.80 & 97.26 \\ 59.21 & 0.60 & 14.99 & 8.07 & 0.45 & 0.29 & 0.44 & 9.20 & 4.76 & 98.01 \\ 60.67 & 0.61 & 15.70 & 6.45 & 0.28 & 0.33 & 0.80 & 7.42 & 4.91 & 97.18\end{array}$

$\begin{array}{lllllllll}0.82 & 0.02 & 0.27 & 0.51 & 0.09 & 0.02 & 0.13 & 0.65 & 0.20\end{array}$

$\begin{array}{llllllllll}56.97 & 0.54 & 15.41 & 7.18 & 0.38 & 0.29 & 0.86 & 8.98 & 4.30 & 94.92\end{array}$

$\begin{array}{lllllllllll}58.22 & 0.55 & 15.61 & 6.68 & 0.37 & 0.29 & 0.93 & 8.49 & 4.48 & 95.63\end{array}$

$\begin{array}{llllllllll}55.94 & 0.57 & 15.32 & 7.17 & 0.32 & 0.30 & 0.83 & 7.89 & 4.65 & 92.98\end{array}$

$\begin{array}{llllllllll}58.58 & 0.55 & 15.58 & 7.58 & 0.35 & 0.28 & 0.93 & 8.37 & 4.48 & 96.68\end{array}$

$\begin{array}{llllllllll}57.29 & 0.50 & 15.34 & 7.30 & 0.27 & 0.32 & 1.01 & 8.43 & 4.60 & 95.07\end{array}$

$\begin{array}{llllllllll}58.57 & 0.53 & 15.71 & 7.22 & 0.27 & 0.29 & 0.94 & 8.52 & 4.78 & 96.81\end{array}$

$\begin{array}{lllllllllll}58.05 & 0.53 & 15.46 & 7.62 & 0.28 & 0.28 & 0.90 & 8.80 & 4.67 & 96.59\end{array}$

$\begin{array}{llllllllll}59.71 & 0.52 & 15.67 & 7.30 & 0.34 & 0.23 & 1.01 & 8.64 & 4.59 & 98.03\end{array}$

$\begin{array}{llllllllll}57.55 & 0.54 & 15.59 & 7.00 & 0.35 & 0.31 & 0.95 & 8.26 & 4.71 & 95.25\end{array}$

$\begin{array}{llllllllll}58.14 & 0.50 & 15.43 & 6.92 & 0.31 & 0.32 & 1.01 & 8.25 & 4.67 & 95.55\end{array}$ 
Sample

cat09-01

cat09-01

cat09-01

cat09-01

cat09-01 average

cat09-01 std. dev.

cat09-05

cat09-05

cat09-05

cat09-05

cat09-05

cat09-05

cat09-05

cat09-05

cat09-05

cat09-05

cat09-05

cat09-05

cat09-05

cat09-05

cat09-05 average

cat09-05 std. dev.

cat09-02a

cat09-02a

cat09-02a

cat09-02a

cat09-02a

cat09-02a

cat09-02a

cat09-02a

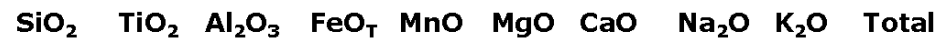

$\begin{array}{llllllllll}57.83 & 0.54 & 15.57 & 7.38 & 0.20 & 0.25 & 0.97 & 8.58 & 4.73 & 96.05\end{array}$

$\begin{array}{llllllllll}58.54 & 0.51 & 15.72 & 8.45 & 0.29 & 0.28 & 1.13 & 8.68 & 4.66 & 98.26\end{array}$

$\begin{array}{llllllllll}57.97 & 0.53 & 15.60 & 7.45 & 0.32 & 0.28 & 0.94 & 8.77 & 4.63 & 96.49\end{array}$

$\begin{array}{llllllllll}59.65 & 0.53 & 15.62 & 7.47 & 0.34 & 0.30 & 1.02 & 8.72 & 4.57 & 98.22\end{array}$

$\begin{array}{lllllllllll}58.07 & 0.53 & 15.54 & 7.34 & 0.31 & 0.29 & 0.96 & 8.53 & 4.61 & 96.18\end{array}$

$\begin{array}{lllllllll}0.99 & 0.02 & 0.13 & 0.41 & 0.05 & 0.02 & 0.08 & 0.28 & 0.12\end{array}$

$\begin{array}{llllllllll}60.25 & 0.55 & 15.98 & 7.96 & 0.281 & 0.29 & 0.897 & 8.955 & 4.9 & 100.07\end{array}$

$\begin{array}{lllllllllll}57.32 & 0.51 & 15.28 & 7.53 & 0.265 & 0.28 & 0.893 & 8.297 & 4.64 & 95.014\end{array}$

$\begin{array}{lllllllllll}58.62 & 0.54 & 15.67 & 7.24 & 0.335 & 0.26 & 1.053 & 8.737 & 4.4 & 96.863\end{array}$

$\begin{array}{lllllllllll}57.8 & 0.53 & 15.68 & 7.1 & 0.282 & 0.3 & 1.033 & 7.613 & 4.71 & 95.038\end{array}$

$\begin{array}{rlllllllll}55.98 & 0.54 & 15.42 & 8.17 & 0.346 & 0.26 & 0.896 & 8.506 & 4.5 & 94.624\end{array}$

$\begin{array}{lllllllllll}59.35 & 0.56 & 15.61 & 8.72 & 0.317 & 0.29 & 0.994 & 8.406 & 4.57 & 98.812\end{array}$

$\begin{array}{lllllllllll}57.48 & 0.57 & 15.64 & 6.86 & 0.257 & 0.27 & 0.959 & 7.902 & 4.56 & 94.504\end{array}$

$\begin{array}{llllllllll}59.95 & 0.53 & 15.64 & 8.09 & 0.33 & 0.27 & 0.9 & 8.621 & 4.81 & 99.139\end{array}$

$\begin{array}{llllllllll}56.18 & 0.52 & 15.38 & 6.77 & 0.306 & 0.29 & 0.905 & 8.43 & 4.44 & 93.226\end{array}$

$\begin{array}{lllllllllll}59.56 & 0.55 & 15.62 & 8.03 & 0.273 & 0.28 & 0.997 & 8.978 & 4.46 & 98.752\end{array}$

$\begin{array}{lllllllllll}59.15 & 0.55 & 15.71 & 7.99 & 0.261 & 0.27 & 0.953 & 9.188 & 4.73 & 98.801\end{array}$

$\begin{array}{llllllllll}56.45 & 0.54 & 15.58 & 7.03 & 0.318 & 0.31 & 0.808 & 8.011 & 4.55 & 93.592\end{array}$

$\begin{array}{llllllllll}56.54 & 0.52 & 15.23 & 7.28 & 0.252 & 0.3 & 0.817 & 7.706 & 4.61 & 93.245\end{array}$

$\begin{array}{llllllllll}57.73 & 0.56 & 15.52 & 7.56 & 0.318 & 0.3 & 1.001 & 8.396 & 4.75 & 96.13\end{array}$

$\begin{array}{llllllllll}58.03 & 0.54 & 15.57 & 7.59 & 0.30 & 0.28 & 0.94 & 8.41 & 4.62 & 96.27\end{array}$

$\begin{array}{lllllllll}1.46 & 0.02 & 0.19 & 0.58 & 0.03 & 0.02 & 0.07 & 0.48 & 0.15\end{array}$

$\begin{array}{llllllllll}61.27 & 0.55 & 10.59 & 9.56 & 0.36 & 0.13 & 0.53 & 7.38 & 4.19 & 94.55\end{array}$

$\begin{array}{llllllllll}62.11 & 0.55 & 10.63 & 8.00 & 0.39 & 0.08 & 0.56 & 7.23 & 4.12 & 93.67\end{array}$

$\begin{array}{llllllllll}62.74 & 0.55 & 10.64 & 8.07 & 0.31 & 0.10 & 0.53 & 7.08 & 4.26 & 94.27\end{array}$

$\begin{array}{llllllllll}61.79 & 0.62 & 11.21 & 7.45 & 0.30 & 0.09 & 0.70 & 7.31 & 4.41 & 93.88\end{array}$

$\begin{array}{llllllllll}61.76 & 0.60 & 11.43 & 8.83 & 0.36 & 0.13 & 0.66 & 7.08 & 4.32 & 95.17\end{array}$

$\begin{array}{llllllllll}63.58 & 0.59 & 11.30 & 8.62 & 0.29 & 0.12 & 0.37 & 7.26 & 4.52 & 96.66\end{array}$

$\begin{array}{llllllllll}63.36 & 0.58 & 10.69 & 8.68 & 0.33 & 0.10 & 0.28 & 7.69 & 4.36 & 96.09\end{array}$

$\begin{array}{llllllllll}63.84 & 0.60 & 11.44 & 8.71 & 0.19 & 0.14 & 0.48 & 7.29 & 4.36 & 97.04\end{array}$ 
Sample

cat09-02a

cat09-02a

cat09-02a

cat09-02a

cat09-02a average

cat09-02a std. dev.

cat09-02b

cat09-02b

cat09-02b

cat09-02b

cat09-02b

cat09-02b

cat09-02b

cat09-02b

cat09-02b

cat09-02b

cat09-02b

cat09-02b

cat09-02b

cat09-02b

cat09-02b

cat09-02b

cat09-02b

cat09-02b

cato9-02b average

cat09-02b std. dev.

cat09-04

cat09-04

cat09-04

cat09-04

cat09-04

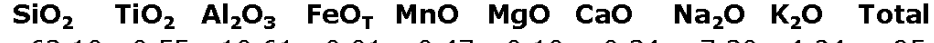

$\begin{array}{llllllllll}63.10 & 0.55 & 10.61 & 8.81 & 0.47 & 0.10 & 0.34 & 7.30 & 4.24 & 95.52\end{array}$

$\begin{array}{llllllllll}63.22 & 0.56 & 10.68 & 8.81 & 0.41 & 0.10 & 0.32 & 6.99 & 4.21 & 95.32\end{array}$

$\begin{array}{llllllllll}64.03 & 0.60 & 10.63 & 8.85 & 0.27 & 0.10 & 0.34 & 7.36 & 4.48 & 96.66\end{array}$

$\begin{array}{llllllllll}64.25 & 0.61 & 10.93 & 9.21 & 0.25 & 0.11 & 0.31 & 7.82 & 4.42 & 97.90\end{array}$

$\begin{array}{llllllllll}62.92 & 0.58 & 10.90 & 8.63 & 0.33 & 0.11 & 0.45 & 7.31 & 4.32 & 95.56\end{array}$

$\begin{array}{llllllllll}0.98 & 0.03 & 0.35 & 0.56 & 0.08 & 0.02 & 0.14 & 0.24 & 0.12\end{array}$

$\begin{array}{llllllllll}59.62 & 0.60 & 15.65 & 6.41 & 0.19 & 0.35 & 0.94 & 7.45 & 4.77 & 95.99\end{array}$

$\begin{array}{llllllllll}59.09 & 0.60 & 15.71 & 6.12 & 0.22 & 0.30 & 0.89 & 7.01 & 5.06 & 95.00\end{array}$

$\begin{array}{llllllllll}58.54 & 0.59 & 15.74 & 6.16 & 0.35 & 0.31 & 1.20 & 6.99 & 4.84 & 94.71\end{array}$

$\begin{array}{llllllllll}59.22 & 0.59 & 15.77 & 5.72 & 0.24 & 0.30 & 0.90 & 7.52 & 4.80 & 95.07\end{array}$

$\begin{array}{llllllllll}59.12 & 0.62 & 15.78 & 6.30 & 0.47 & 0.33 & 1.05 & 7.64 & 4.81 & 96.13\end{array}$

$\begin{array}{llllllllll}58.55 & 0.61 & 15.80 & 6.25 & 0.22 & 0.30 & 1.03 & 7.17 & 4.79 & 94.72\end{array}$

$\begin{array}{llllllllll}59.80 & 0.57 & 15.96 & 6.29 & 0.32 & 0.32 & 1.02 & 7.18 & 4.98 & 96.45\end{array}$

$\begin{array}{llllllllll}61.61 & 0.60 & 16.09 & 6.55 & 0.31 & 0.33 & 1.04 & 7.52 & 5.22 & 99.27\end{array}$

$\begin{array}{llllllllll}58.98 & 0.60 & 16.09 & 5.51 & 0.30 & 0.40 & 1.02 & 7.01 & 5.15 & 95.06\end{array}$

$\begin{array}{llllllllll}60.76 & 0.61 & 16.20 & 6.92 & 0.27 & 0.32 & 1.07 & 7.34 & 4.99 & 98.48\end{array}$

$\begin{array}{llllllllll}60.09 & 0.60 & 15.71 & 6.00 & 0.27 & 0.31 & 0.75 & 7.17 & 5.06 & 95.97\end{array}$

$\begin{array}{llllllllll}60.52 & 0.63 & 15.87 & 6.06 & 0.25 & 0.37 & 0.65 & 7.88 & 4.81 & 97.04\end{array}$

$\begin{array}{llllllllll}61.60 & 0.64 & 16.02 & 6.34 & 0.22 & 0.33 & 0.76 & 7.75 & 4.90 & 98.56\end{array}$

$\begin{array}{llllllllll}62.01 & 0.62 & 16.13 & 6.36 & 0.27 & 0.33 & 0.77 & 7.38 & 5.42 & 99.29\end{array}$

$\begin{array}{rrrrrrrrrr}61.43 & 0.62 & 15.87 & 6.36 & 0.29 & 0.33 & 0.70 & 7.39 & 5.00 & 97.99\end{array}$

$\begin{array}{llllllllll}62.44 & 0.63 & 16.37 & 6.63 & 0.24 & 0.32 & 0.79 & 7.76 & 5.19 & 100.37\end{array}$

$\begin{array}{rrrrrrrrrrr}63.02 & 0.63 & 16.00 & 6.68 & 0.39 & 0.32 & 0.91 & 7.72 & 4.83 & 100.49\end{array}$

$\begin{array}{llllllllll}61.84 & 0.61 & 16.02 & 6.86 & 0.23 & 0.31 & 0.70 & 7.71 & 4.92 & 99.20\end{array}$

$\begin{array}{llllllllll}60.46 & 0.61 & 15.93 & 6.31 & 0.28 & 0.33 & 0.90 & 7.42 & 4.98 & 97.21\end{array}$

$\begin{array}{lllllllll}1.42 & 0.02 & 0.20 & 0.36 & 0.07 & 0.02 & 0.16 & 0.29 & 0.18\end{array}$

$\begin{array}{llllllllll}59.62 & 0.59 & 15.97 & 5.61 & 0.27 & 0.29 & 1.198 & 7.072 & 5.08 & 95.70\end{array}$

$\begin{array}{llllllllll}60.4 & 0.57 & 15.82 & 6.62 & 0.24 & 0.34 & 1.231 & 7.052 & 4.96 & 97.24\end{array}$

$\begin{array}{llllllllll}58.93 & 0.56 & 15.55 & 6.37 & 0.18 & 0.34 & 1.362 & 6.777 & 5.07 & 95.14\end{array}$

$\begin{array}{lllllllllll}58.68 & 0.57 & 15.93 & 6.17 & 0.21 & 0.33 & 1.174 & 7.139 & 4.56 & 94.76\end{array}$

$\begin{array}{llllllllll}59.26 & 0.59 & 15.62 & 6.31 & 0.22 & 0.37 & 1.223 & 6.893 & 4.94 & 95.42\end{array}$ 


\begin{tabular}{|c|c|c|c|c|c|c|c|c|c|c|}
\hline Sample & $\mathrm{SiO}_{2}$ & $\mathrm{TiO}_{2}$ & $\mathrm{Al}_{2} \mathrm{O}_{3}$ & $\mathbf{F e O}_{\mathbf{T}}$ & Mno & MgO & $\mathrm{CaO}$ & $\mathrm{Na}_{2} \mathrm{O}$ & $\mathrm{K}_{\mathbf{2}} \mathrm{O}$ & Total \\
\hline at09-04 & 57.84 & 0.59 & 15.27 & 7.01 & 0.22 & 0.49 & 1.323 & 6.886 & 4.31 & 93.93 \\
\hline at09-04 & 57.95 & 0.54 & 15.61 & 5.23 & 0.22 & 0.33 & 1.169 & 7.178 & 4.71 & 92.94 \\
\hline at09-04 & 59.64 & 0.57 & 15.94 & 6.7 & 0.28 & 0.29 & 1.111 & 7.251 & 5.18 & 96.97 \\
\hline at09-04 & 59.21 & 0.61 & 15.54 & 5.46 & 0.32 & 0.33 & 1.135 & 7.319 & 4.49 & 94.41 \\
\hline at09-04 & 58.25 & 0.59 & 15.51 & 5.62 & 0.27 & 0.3 & 1.16 & 7.06 & 4.36 & 93.12 \\
\hline at09-04 & 59.09 & 0.6 & 15.55 & 5.82 & 0.21 & 0.32 & 1.16 & 7.02 & 5.11 & 94.88 \\
\hline at09-04 & 60.41 & 0.6 & 15.78 & 7.08 & 0.18 & 0.33 & 1.112 & 7.138 & 4.96 & 97.60 \\
\hline at09-04 & 58.67 & 0.59 & 15.79 & 5.68 & 0.29 & 0.36 & 1.255 & 7.291 & 4.81 & 94.73 \\
\hline at09-04 & 59.76 & 0.61 & 15.94 & 6.62 & 0.28 & 0.31 & 1.294 & 7.427 & 4.86 & 97.10 \\
\hline cat09-04 av & 59.12 & 0.58 & 15.70 & 6.16 & 0.24 & 0.34 & 1.21 & 7.11 & 4.81 & 95.28 \\
\hline cat 09-04 std & 0.81 & 0.02 & 0.21 & 0.60 & 0.04 & 0.05 & 0.08 & 0.18 & 0.29 & \\
\hline \multicolumn{11}{|c|}{ Reference materials analyzed as unknowns ${ }^{b}$} \\
\hline Kakanui hornblende $U$ & 40.29 & 4.74 & 14.43 & 9.81 & 0.05 & 12.58 & 10.39 & 2.35 & 2.13 & 96.77 \\
\hline Kak & 40.69 & 4.75 & 14.61 & 10.99 & 0.00 & 12.47 & 10.10 & 2.40 & 2.06 & 98.07 \\
\hline 43065 & 39.49 & 4.68 & 14.51 & 9.65 & 0.06 & 12.47 & 10.10 & 2.27 & 2.12 & 95.34 \\
\hline Kaka & 40.15 & 4.72 & 14.52 & 10.15 & 0.04 & 12.51 & 10.19 & 2.34 & 2.10 & 96.73 \\
\hline Kakanui hornblende std. dev. & 0.61 & 0.04 & 0.09 & 0.73 & 0.03 & 0.06 & 0.17 & 0.07 & 0.04 & \\
\hline & & 0.5 & & 5.17 & 0.10 & 1.48 & 2.66 & 0.86 & 1.94 & \\
\hline 3 & 76.34 & 0.48 & 11.39 & 4.85 & 0.20 & 1.48 & 2.55 & 0.98 & 1.91 & 100.18 \\
\hline M 2213 & 76.43 & 0.50 & 11.52 & 5.17 & 0.16 & 1.50 & 2.63 & 1.01 & 1.86 & 100.79 \\
\hline glass average & 76.49 & 0.50 & 11.34 & 5.07 & 0.15 & 1.49 & 2.61 & 0.95 & 1.90 & 100.49 \\
\hline Synthetic tektite glass std. dev. & 0.17 & 0.02 & 0.21 & 0.19 & 0.05 & 0.01 & 0.06 & 0.08 & 0.04 & \\
\hline
\end{tabular}

${ }^{a}$ Analysis accidentally left out of Tryon et al. (2010); inclusion or exclusion has no effect on the proposed correlations. ${ }^{\mathrm{b}} \mathrm{See}$ Jarosewich et al. (1980) for details on reference materials. 
Table S2. Summary of robust clustering programs based on $\mathrm{L}_{1}$ norm methods (see Section 6.5 of main text).

(i) DAISY (R function "daisy") computes dissimilarity matrix from data matrix. DAISY "slightly extends a definition of Gower (1971)" to combine different data types.

(ii) PAM (R function "pam") is an acronym for "partitioning around medoids" and is a nonhierarchical clustering method having similarity to $k$-means. PAM aims to choose a partition into $k$ classes and $k$ representatives, "medoids", from the classes such that the total distance from each point to its representative is minimised. Roughly speaking, PAM is to $k$-means as the median is to the mean. Examples of its usage (for palaeoecological purposes) include those of Jovanovska et al. (2016) and Wells et al. (2016).

(iii) CLARA (R function "clara") is a version of PAM designed for clustering large datasets. Unlike PAM it does not need to store the full $k$ by $k$ dissimilarity matrix.

(iv) FANNY (R function "fanny") is a "fuzzy" clustering method similar to $k$-means and PAM except the observations are given fractional memberships in more than one cluster (e.g. Struyf et al., 1997). It is similar to the "fuzzy c-means" algorithm of Bezdek et al. (1984). Fuzzy clustering is similar to probabilistic mixture models (e.g. Fraley and Raftery, 2002, Fraley et al., 2012) except that a formal model is not used; instead, cluster membership weights are incorporated directly into the algorithm without attempts at probability justification. Geoscientific examples of the use of fuzzy $c$-means for cluster analysis are those of Dekkers et al. (1994) and Kruiver et al. (1999).

(v) AGNES (R function "agnes") is an agglomerative hierarchical clustering method.

(vi) DIANA (R function "diana") is a divisive hierarchical clustering method.

(vii)MONA (R function "mona") is a divisive hierarchical method for clustering objects with binary features only (and so it is unlikely to be of much use in clustering analytical data pertaining to tephra samples; it is included here for completeness).

\section{References not cited in main text}

Dekkers, M.J., Langereis, C.G., Vriend, S.P., Van Santvoort, P.J.M., De Lange, G.J., 1994. Fuzzy $c$-means cluster analysis of early diagenetic effects on natural remanent magnetisation acquisition in a $1.1 \mathrm{Myr}$ piston core from the central Mediterranean. Physics of the Earth and Planetary Interiors 85, 155-171.

Fraley, C., Raftery, A.E., Murphy, T.B., Scrucca, L., 2012. MCLUST version 4 for R: Normal mixture modelling for model-based clustering, classification, and density estimation. Technical Report No. 597, Department of Statistics, University of Washington. $57 \mathrm{pp}$.

Jovanovska, E., Cvetkoska, A., Hauffe, T., Wagner, B., Sulpizio, R., Francke, A., Albrecht, C., Wilke, T., 2016. Differential resilience of ancient sister lakes Ohrid and Prespa to environmental disturbances during the Late Pleistocene. Biogeosciences 13, 1149-1161.

Wells, A.F., Frost, G.V., Christopherson, T., Macander, M.J., Trainor, E.R., 2016. Ecological Land Survey and Soil Landscapes Map for Aniakchak National Monument and Preserve, Alaska, 2014. Natural Resource Report NPS/ANIA/NRR-2016/1133, pp. 1-190. 